Gustavo Alberto Giménez Lugo

\title{
Um Modelo de Sistemas Multiagentes para Partilha de Conhecimento Utilizando Redes Sociais Comunitárias
}

Tese apresentada à Escola Politécnica

da Universidade de São Paulo para obtenção do Título de Doutor em Engenharia. 
Gustavo Alberto Giménez Lugo

\section{Um Modelo de Sistemas Multiagentes para Partilha de Conhecimento Utilizando Redes Sociais Comunitárias}

Tese apresentada à Escola Politécnica da Universidade de São Paulo para obtenção do Título de Doutor em Engenharia.

Área de concentração:

Sistemas Digitais

Orientador:

Prof. Dr. Jaime Simão Sichman 


\section{Ficha Catalográfica}

Giménez Lugo, Gustavo Alberto

Um Modelo de Sistemas Multiagentes para Partilha de Conhecimento Utilizando Redes Sociais Comunitárias. São Paulo, 2004. 192 p.

Tese (Doutorado) - Escola Politécnica da Universidade de São Paulo. Departamento de Engenharia de Computação e Sistemas Digitais.

1. Sistemas Multiagentes. 2. Engenharia de Conhecimento 3. Redes Comunitárias. I. Universidade de São Paulo. Escola Politécnica. Departamento de Engenharia de Computação e Sistemas Digitais. II. Título. 
Isso de querer ser exatamente aquilo que a gente é ainda vai nos levar além...

P. Leminski - Distraídos Venceremos 


\section{Agradecimentos}

Aos componentes da rede social (estendida) do LTI: Alexandre, Anna, Bianchi, Carlota, Diana, Fabricio, Johnny, Luis, Nuno, Rafael, Sara ... porque cada um sabe a quanto alcança a minha conta para consigo e porque ainda acredito que a realidade é subjetiva e a objetividade uma ilusão.

Ao meu orientador, Prof. Jaime Sichman, pelos acordos e principalmente por permitir tratar as diferenças, fonte da criatividade e da diversão.

À Professora Analia Amandi pela oportunidade e aos integrantes do grupo de pesquisa do ISISTAN-UNCPBA pelo aprendizado com bom humor.

Ao Ilsonei, pelo bom senso para auxiliar na praxis de sistemas.

Ao Hernan e a D. Nené, muito especialmente, pela cumplicidade para ver "no outro que é o mesmo", pela paciência para ensinar o que é, no dizer de Tzvetan Todorov, conhecer, respeitar e amar.

À Professora Graça Marietto, pelas discussões sobre agentes, simulações e simulacros do real.

Ao Nuno, pelas rodas de conversas sobre a (não) objetividade do trabalho dito científico.

A D. Nice e ao Valdinei pela oportunidade de entender o Adoniran, o Trem das Onze e parte do que acredito ser o acolhedor espírito dos verdadeiros donos de São Paulo.

Ao Jomi(e rede), pelas mil e uma lições sobre (a)-gente-s.

A todos os meus queridos hobbits, vivos ou eternos, de qualquer idade, sexo, raça, nacionalidade, que lutam e sempre lutaram para que o conhecimento, em todas as suas formas, oficiais ou não, pertença à humanidade, pela fraternidade que nos toca.

Às minhas duas famílias, de coração. Para os meus irmãos (e irmãs) que 
carrego sempre comigo. Aos meus avôs e principalmente para os meus pais que me ensinaram muito cedo que o horizonte está feito para andar, na tentativa de chegar a nós mesmos.

Muito especialmente, ao meu amor, Andrea, por mostrar que para abrir os meus olhos bastava abrir o coração.

Esta página estará eternamente em construção ... 


\section{Resumo}

Este trabalho apresenta um modelo para sistemas multiagentes constituídos por agentes de informação destinados a auxiliar comunidades humanas que partilham conhecimento. Tais agentes são cientes do entorno social dos usuários, pois possuem representações do conhecimento dos mesmos e também das redes sociais que os circundam, organizadas subjetivamente. Conceitos pertencentes às suas ontologias são estendidos com informação organizacional para representar de forma explícita as situações nas quais foram aprendidos e utilizados. Discute-se como tais agentes autônomos podem raciocinar sobre o uso e a privacidade de conceitos em termos de construções organizacionais, possibilitando raciocinar sobre papéis sociais em comunidades abertas na Internet. 


\section{Abstract}

This work presents a model for multi-agent systems for information agents supporting information-sharing communities. Such agents are socially aware in the sense that they have representations of the users' knowledge and also of their social networks, which are subjectively organized. Concepts in their ontologies are extended with organizational information to record explicitly the situations in which they were learned and used. It is discussed how such autonomous agents are allowed to reason about concept usage and privacy in terms of organizational constructs, paving the way to reason about social roles in open Internet communities. 


\section{Sumário}

Lista de Figuras

Lista de Tabelas

Lista de Abreviaturas

1 Introdução 1

1.1 Problema abordado . . . . . . . . . . . . . 2

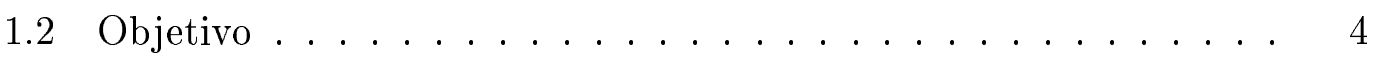

1.3 Motivação .......................... 6

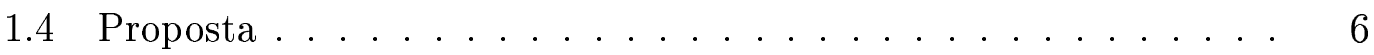

1.5 Contribuições esperadas .................... 9

1.6 Organização do texto . . . . . . . . . . . . . . 10

I Conceitos Envolvidos 11

2 Acesso à informação: enfoques clássicos $\quad 12$

2.1 Recuperação de informação . . . . . . . . . . . . 12

2.1.1 Premissas gerais em RI ............. 16

2.1.2 Modelos de RI . . . . . . . . . . . . 17

2.1.3 Avaliação em RI . . . . . . . . . . . . . 23

2.2 Categorização de textos . . . . . . . . . . . . . 28

2.2.1 Funções de ponderação . . . . . . . . . . . . 29 
2.2.2 Espaço de atributos . . . . . . . . . . . 31

2.2.3 Métodos de categorização ............. 33

2.2.4 Avaliação dos métodos de categorização . . . . . . . . 39

2.3 Comentários . . . . . . . . . . . . . . . 42

3 Acesso à informação: novos caminhos 43

3.1 Agentes de informação . . . . . . . . . . . . . . 47

3.2 Redes comunitárias . . . . . . . . . . . . 53

3.2.1 Redes pessoais ............... 56

3.2.2 Redes e sistemas peer-to-peer ........... 58

3.3 Organização e SMA ........................ 61

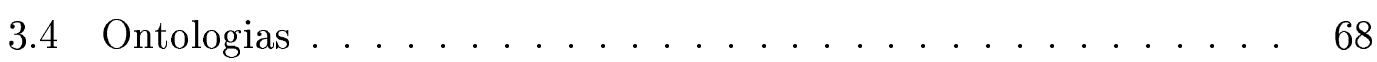

3.4.1 Ontologia formal ................ 70

3.4.2 Representação de ontologias . . . . . . . . . 72

3.4.3 Uso de ontologias por agentes de informação . . . . . . 76

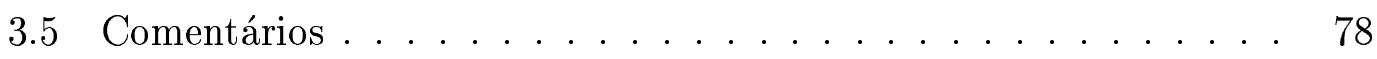

\section{$\begin{array}{lr}\text { II Abordagem Proposta } & 80\end{array}$}

4 Agentes de informação para partilha de conhecimento 81

4.1 Representação de papéis sociais . . . . . . . . . . 85

4.2 Ontologias com anotações organizacionais . . . . . . . . . . . . 91

4.3 Exemplo de raciocínio . . . . . . . . . . . . . 101

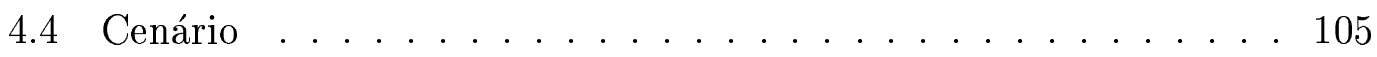

4.5 Arquitetura de agente ................. 110

4.6 Discussão . . . . . . . . . . . . . . . . . . 112 
5.1 Implementação do agente COMMUNET . . . . . . . . . . . . 116

5.1 .1 Ontologia inicial ............... 120

5.1.2 Dinâmica de um agente COMMUNET . . . . . . . . 124

5.1 .3 Interação com o usuário . . . . . . . . . . . . 126

5.1 .4 Implementação das anotações . . . . . . . . . . . . . . 134

5.2 Condições experimentais . . . . . . . . . . . . 137

5.2.1 Testes com usuários reais . . . . . . . . . . 137

5.2 .2 Questionário................... 138

5.3 Resultados e Análise . . . . . . . . . . . . . . 139

5.3.1 Rastreamento temporal .............. 139

5.3.2 Diferenciação de ações e detecção de mudanças nas categorias da busca ................... 142

5.3.3 Tratamento de sociogramas conceituais . . . . . . . 147

5.3.4 Papéis em sociogramas conceituais . . . . . . . 150

5.3.5 Avaliação do questionário ............. 153

5.4 Comentários . . . . . . . . . . . . . . . 154

6 Conclusões $\quad 156$

6.1 Contribuições . . . . . . . . . . . . . 156

6.2 Trabalhos futuros ..................... 160

$\begin{array}{ll}\text { Anexos } & 162\end{array}$

A Associação de ações e categorias a seqüências de busca $\quad 162$

$\begin{array}{lll}\text { B Sociogramas conceituais } & 169\end{array}$ 
C Respostas de um usuário ao questionário

C.1 Usuário X . . . . . . . . . . . . . . . . . . 177

Referências Bibliográficas 


\section{Lista de Figuras}

1.1 Estimativa de páginas indexadas em dezembro de 2001 pelos maiores sítios de busca segundo a Search Engine Watch. . . . . . . . . 3

1.2 Quando procuram informações, os seres humanos consideram as comunidades das quais fazem parte. . . . . . . . 5

1.3 Um agente computacional capaz de interagir com outros agentes numa comunidade, relacionando a sua ontologia e a sua representação organizacional com a sua rede social de contatos. . . . . 8

2.1 Um modelo de sistemas de RI segundo Oard (2000). . . . . . . . 13

2.2 Um modelo do componente de detecção segundo Oard (2000). . 14

2.3 Uma taxonomia da ignorância segundo Mamdani (1997). . . . . . 16

2.4 Exemplo de execução do algoritmo para a seleção de palavras utilizadas para categorizar um conjunto de documentos on-the-fly. $\quad 37$

3.1 A Web Semântica vista em camadas. Adaptado de Koivunen (2001), Berners-Lee (2002) e Costello e Jacobs (2003). . . . . . . . 46

3.2 Habilidades básicas e tecnologias relacionadas aos agentes de informação segundo Klusch (2001). . . . . . . . . . . . 50

3.3 Rede pessoal típica (MÜLLER; WELLMAN; MARIN, 1999). . . . . 57

3.4 Rede pessoal de um aluno de curso a distância, segundo Haythornthwaite (2000). . . . . . . . . . . . 58

3.5 Localização de arquivos nas arquiteturas dos sistemas Napster e Gnutella (SAROIU; GUMMADI; GRIBBLE, 2002). . . . . . . . 60

3.6 Linha temporal da existência de um agente João participando em diversos grupos e desempenhando papéis diferentes. . . . . . . 62

3.7 Tipos de organização segundo (HÜBNER, 2003). . . . . . . . . 63 
3.8 Exemplo de especificação estrutural de organização utilizando o modelo Morse $^{+}$. . . . . . . . . . . . . . . . . . . 64

3.9 Exemplo de especificação funcional utilizando o $\mathcal{M O I S E}^{+}$. . . . 66

3.10 Conceituação do modelo organizacional $\mathcal{M o I S E}^{+}$, expressada utilizando a notação UML. . . . . . . . . . . . . . . 67

3.11 Relacionando ontologia, linguagem e conceituação (GUARINO, 1997).

3.12 Exemplo de agente realizando inferência com o auxílio de uma ontologia. Adaptado de Costello e Jacobs (2003) e Costello (2003). 77

4.1 Exemplo de Especificação Estrutural da visão organizacional subjetiva do agente pretendido, no seu estado inicial. . . . . . . . 89

4.2 Exemplo de Especificação Funcional de um agente dedicado a partilhar conhecimento. . . . . . . . . . . . . 90

4.3 Elementos das facetas KUOS, KAOS e Access. . . . . . . 98

4.4 Linha temporal do agente João com as situações recuperadas através das anotações propostas, atreladas ao conceito NeuronSimulationActivationPotential. . . . . . . . . . . . . . . 99

4.5 Um agente João raciocinando sobre outros agentes num contexto organizacional e relacionando-os a partes da sua ontologia $O_{\text {João }}$. 102

4.6 Arquivos (à esq.) e mensagens de e-mail (à dir.) do usuário fictício

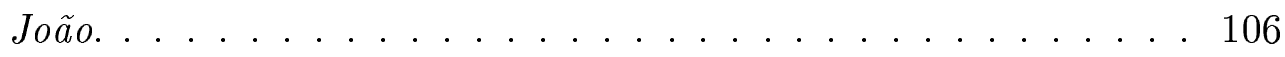

4.7 Ontologia inicial indexando os arquivos e mensagens do usuário fictício Jo ão. . . . . . . . . . . . . . . . . . . . . 107

4.8 Rede pessoal do usuário fictício João. . . . . . . . . . . . . 107

4.9 Identificação de um subconjunto da ontologia situada do usuário, correspondente a um grupo (ou papel social). . . . . . . . . 108

4.10 Conceitos referenciados por dois grupos de contatos da rede social de Joâo. . . . . . . . . . . . . . . . . . . . 109 
4.11 Visão funcional do processamento requerido para implementar a proposta. ........................ 110

4.12 Arquitetura de agente capaz de integrar as representações de conhecimento e de organização subjetiva, aplicada à partilha de conhecimento. ...................... 111

5.1 Fases do levantamento dos dados do Usuário. . . . . . . . . . . . 117

5.2 Pré-processamento de arquivos de documentos. . . . . . . . . . 118

5.3 Pré-processamento de mensagens de e-mail. . . . . . . . . . . 119

5.4 Componentes mais relevantes do agente COMMUNET, diferenciando os pacotes codificados dos pré-existentes. . . . . . . . 121

5.5 Página do projeto ODP para o tópico RDF (KOIVUNEN, 2001). . 122

5.6 Conteúdo de um tópico ODP em RDF(KOIVUNEN, 2001). . . . . 123

5.7 Uma seqüência de utilização do agente COMMUNET. . . . . . . . 125

5.8 Sociograma extraído automaticamente por um agente COMMUNET.127

5.9 Grupos e papéis sociais representados num agente COMMUNET. Para cada um podem ser definidos diversos graus de permissões de acesso............................ 128

5.10 Perfil de um usuário COMMUNET. . . . . . . . . . . 130

5.11 Ferramenta de busca conceitual fornecida por um agente COM-

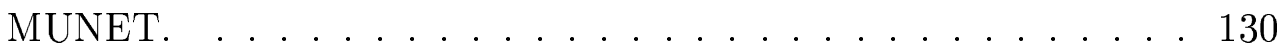

5.12 Ferramenta de busca conceitual de um agente COMMUNET, mostrando respostas de dois contatos. . . . . . . . . . . . 132

5.13 Perfil de um usuário COMMUNET, mostrando traços de interação social nos documentos e links. . . . . . . . . . . 133

5.14 Versão implementada da faceta KAOS. . . . . . . . . . . 134

5.15 Amostras da representação textual de instâncias da anotação KAOS.135

5.16 Versão implementada da faceta KUOS. . . . . . . . . . . 136

5.17 Amostras da representação textual de instâncias da anotação KUOS.136 
5.18 Histograma dos horários de acesso do usuário User1 segundo o agente utilizado como páginas brancas. . . . . . . . . . 140

5.19 Histogramas de horários de acesso individuais e histograma conjunto de um grupo de usuários COMMUNET. . . . . . . . . . . 141

5.20 Seqüência de ações de busca do usuário User1, diferenciando as ações de consulta, os downloads e as leituras de documentos próprios.

5.21 Seqüência de ações de busca do usuário User民, diferenciando as consultas, os downloads, as leituras de documentos próprios e a adoção de contatos recomendados. . . . . . . . . . . . 143

5.22 Seqüência de ações de busca temática concentrada, detectadas pelo agente COMMUNET dedicado ao usuário User3. . . . . . . . . . 144

5.23 Seqüência de ações de busca temática com um eixo central, detectadas pelo agente COMMUNET dedicado ao usuário User1. . . . 145

5.24 Seqüência de ações de busca temática com mudança de foco, detectadas pelo agente COMMUNET dedicado ao usuário User2. . . 145

5.25 Visão tridimensional dos tipos de ações de busca e conceitos na seqüência detectada pelo agente COMMUNET do usuário User1. 146

5.26 Visão tridimensional dos tipos de ações de busca e conceitos na seqüência detectada pelo agente COMMUNET do usuário User2. 146

5.27 Sociograma conceitual inicial, computado pelo agente do usuário User1. Os contatos encontram-se igualmente distantes do usuário. 147

5.28 Sociograma conceitual, considerando apenas a categoria Knowledge Representation, computado pelo agente do usuário User2. . . 149

5.29 Sociograma conceitual, considerando apenas a categoria Agents, computado pelo agente do usuário User2. . . . . . . . . . . 149

5.30 Sociograma conceitual, considerando todas as categorias, computado pelo agente do usuário User民 após múltiplas interações. . . . . . . 150

5.31 Sociograma conceitual inicial, considerando todas as categorias e mostrando quatro papéis, computado pelo agente do usuário User2. 151 
5.32 Sociograma conceitual para a categoria Knowledge Representation, mostrando papéis, computado pelo agente do usuário User2. . . . 152

5.33 Sociograma conceitual para a categoria Agents, mostrando papéis, computado pelo agente do usuário User2. . . . . . . . . . 152

A.1 Amostra de uma seqüência de ações do usuário User1, por tipo de ação (esq.) e considerando os conceitos envolvidos (dir.). . . . 163

A.2 Agente do usuário User1: visão tridimensional da seqüência tratada

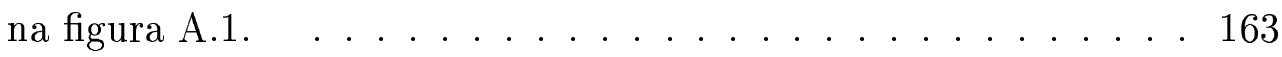

A.3 Segunda amostra de uma seqüência de ações do usuário User1, por tipo de ação (esq.) e mostrando os conceitos envolvidos (dir.). . . 164

A.4 Agente do usuário User1: visão tridimensional da mesma seqüência da figura A.3. . . . . . . . . . . . . . 164

A.5 Amostra de uma seqüência de ações do usuário UserQ, por tipo de ação (esq.) e considerando os conceitos envolvidos (dir.) . . . . . 165

A.6 Agente do usuário User2: visão tridimensional da mesma seqüência referenciada na figura A.5. . . . . . . . . . . 165

A.7 Segunda amostra de uma seqüência de ações do usuário User2, por tipo de ação (esq.) e considerando os conceitos envolvidos(dir.). 166

A.8 Vista tridimensional da seqüência de ações do usuário User民, mostrada na figura A.7. ................... 166

A.9 Amostra de uma seqüência de ações do usuário User3, por tipo de ação (esq.) e segundo os conceitos envolvidos (dir.). . . . . . . 167

A.10 Visão tridimensional da mesma seqüência referenciada na figura A.9, executada pelo usuário User3. . . . . . . . . . . 167

A.11 Segunda amostra de uma seqüência de ações do usuário User3, por tipo de ação (esq.) e considerando os conceitos envolvidos(dir.). 168

A.12 Vista tridimensional da seqüência de ações do usuário User3, mostrada na figura A.11. ........................ 168 
B.1 Sociogramas conceituais simples e incluindo papéis sociais, para o usuário User1. São mostradas as categorias: Neural Networks e Agents. . . . . . . . . . . . . . . 170

B.2 Sociogramas conceituais do usuário User2. São mostradas as categorias: Machine Learning, Knowledge Representation e Agents. . 171

B.3 Sociogramas conceituais do usuário User2. São tratadas isoladamente as categorias: Belief Networks, Philosophy e Fuzzy. . . . . . 172

B.4 Sociogramas do usuário User3. Aparecem as categorias: Artificial Intelligence e Agents. . . . . . . . . . . . . . . . 173

B.5 Sociogramas do usuário User4. São mostradas as categorias: Agents/Toolkits e Agents. . . . . . . . . . . . . . . . . . . 174

B.6 Sociogramas do usuário User5. Aparecem as categorias: Agents e Agents/Publications/Tools. . . . . . . . . . . . . 175 


\section{Lista de Tabelas}

2.1 Formas de ponderação de palavras (AAS; EIKVIL, 1999). . . . . . 30

2.2 Comparação entre métodos de categorização de texto (AAS; EIKVIL, 1999). IM: Informação Mútua; GI: Ganho de Informação; PE: Ponto de equilíbrio; P:Precisão. . . . . . . . . . . . . 41

2.3 Desempenho de métodos de categorização de texto (AAS; EIKVIL, 1999). Os dados da tabela são os valores dos pontos de equilíbrio. “-" denota método não testado; "x" implica método testado, porém, o critério de avaliação não sendo o do ponto de equilíbrio. . . . . 41

3.1 Exemplos de sistemas colaborativos e mistos, baseados em conteúdo e colaboração. Adaptado de (MLADENIC, 1999) . . . . . . . . 52

3.2 Expressividade comparativa de lógicas de descrições segundo Wache

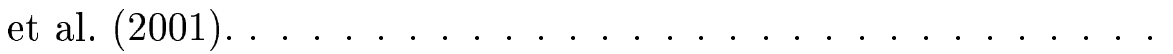




\title{
Lista de Abreviaturas
}

\author{
AM Aprendizado de Máquina \\ DAML DARPA Agent Markup Language \\ DE Descrição Estrutural \\ DF Descrição Funcional \\ DVS Decomposição por Valores Singulares \\ EnO Entidade Organizacional \\ EsO Estrutura Organizacional \\ ES Esquema Social \\ FOAF Friend of a Friend Finder \\ FTP File Transfer Protocol \\ HTML HyperText Markup Language \\ HTTP HyperText Transfer Protocol
}

IA Inteligência Artificial

IAD Inteligência Artificial Distribuída

ISL Indexação por Semântica Latente

KQML Knowledge Query and Manipulation Language

MD Mineração de Dados

MOISE+ Model of Organization for multI-agent SystEms

MSV Máquinas de Suporte Vetorial 
ODP Open Directory Project

OIL Ontology Inference Layer

OKBC Open Knowledge Base Connectivity

OWL Ontology Web Language

P\&D Pesquisa e Desenvolvimento

PLN Processamento de Linguagem Natural

PRP Probabilistic Ranking Principle

P2P Peer-to-Peer

RDF Resource Description Framework

RDFS Resource Description Framework Schema

RDP Resolução Distribuída de Problemas

RI Recuperação de Informação

SACI Simple Agent Communication Infrastructure

SMA Sistemas Multiagentes

TFTP Trivial File Transfer Protocol

URI Universal Resource Indentifier

URL Universal Resource Locator

W3C World Wide Web Consortium

XML Extensible Markup Language 


\section{Introdução}

Faz parte do senso comum a crença de que podemos usufruir das informações disponibilizadas na Internet e em meios similares. No entanto, quando realmente partimos à procura do conhecimento imerso nesse oceano de informação, percebemos que dispomos de pouco mais do que alguns mapas incompletos e técnicas de busca não muito eficientes.

Viabilizar a cooperação entre pessoas, através da partilha de seus conhecimentos de forma a obter melhores resultados nas suas tarefas particulares, tem sido um dos objetivos almejados pela Ciência da Computação há décadas. A Internet deve o seu sucesso à aceitação desta idéia como lugar comum em nossa época. Ao procurar informações, de uma forma ou de outra, acabamos dependendo das heurísticas de quem reputamos bem-sucedido em sucessivas navegações.

Tornar realidade a cooperação no sentido mais amplo do termo, no entanto, tem-se mostrado tarefa árdua. Comunicação apenas não basta. Agrupamentos de pessoas evidenciam a existência de comunidades de sentido ${ }^{1}$ (CASTORIADIS, 1991; BACZKO, 1985; GIBSON; KLEINBERG; RAGHAVAN, 1998) que não podem ser reduzidas a visões únicas e totalizantes: viver no "Oriente" ou no "Ocidente" pouco ou nada diz sobre os gostos dos grupos sociais aos quais um indivíduo pertence e com os quais se identifica. O esforço dispendido para tornar as técnicas computacionais capazes de servir à interação entre seres humanos mostra que estes significados devem ser apreendidos.

Sistemas Multiagentes (SMA) têm sido alvo de intensas pesquisas na última década por fornecerem ao usuário um nível de abstração que facilita a explicitação das suas requisições. Estes consideram a atribuição de intencionalidade a componentes de um sistema computacional denominados agentes (NEWELL,

\footnotetext{
${ }^{1}$ Cada coletividade produz um sistema simbólico que permite designar sua identidade, distinguindo papéis e posições sociais, exprimindo e impondo crenças e códigos comuns.
} 
1982; SEARLE, 1983; CASTELFRANCHI, 1998).

Agentes computacionais podem ser auxiliares mais eficientes na medida em que disponham de uma representação que torne explícitas as comunidades de sentido, tanto em relação à sua semiótica quanto aos seus integrantes.

Dado este enfoque inicial, o problema a ser tratado nesta tese é descrito a seguir. Sucessivamente são apresentados o objetivo, a motivação e a proposta da tese. Na seqüência, aparecem ainda as contribuições esperadas e a organização do restante do texto.

\subsection{Problema abordado}

A denominada $W e b$ (teia) é formada pelo conjunto de sítios que disponibilizam recursos utilizando o protocolo HyperText Transfer Protocol (HTTP). Cada sítio é, basicamente, um servidor HTTP. A Web utiliza como infra-estrutura a rede Internet. Os recursos são publicados através de páginas no formato HyperText Markup Language (HTML), interconectadas por links (ligações). Um link é um apontador para o endereço HTTP de um recurso alvo.

A natureza dinâmica e distribuída da $W e b$ parece sobrepujar qualquer esforço individual de mapeá-la. Os repositórios indexam apenas uma fração instantânea dela. Segundo Lawrence e Gilles (1999), como citado por Kobayashi e Takeda (2000), dados de 1999 indicavam que as máquinas de busca mais importantes ${ }^{2}$ não cobriam, cada uma, mais do que $16 \%$ da Web. A figura 1.1 mostra a situação em dezembro de $2001^{3}$. Nela, a franja superior do Google indica os links que podem ser indiretamente atingidos através do seu uso, mas que não estão efetivamente indexados, e a faixa inferior do Inktomi indica sítios nela classificados como sendo os "melhores da Web".

Em relação ao tamanho, apenas considerando a Web com mais de 8 milhões de sítios únicos ${ }^{4}$, devem ser considerados dois tipos de conteúdo (LYMAN;

\footnotetext{
${ }^{2}$ Foram consideradas HotBot, Altavista, Northern Light, Excite, Infoseek, Lycos, Snap, Microsoft, Google, Yahoo e Euroseek.

${ }^{3}$ http://searchenginewatch.org, acessado em maio de 2002.

${ }^{4}$ No sentido de estarem associados a servidores específicos, segundo o Online Computer Library Center (OCLC, www.oclc.org) citado em http://www.pandia.com/sw-2001/57websize.html.
} 


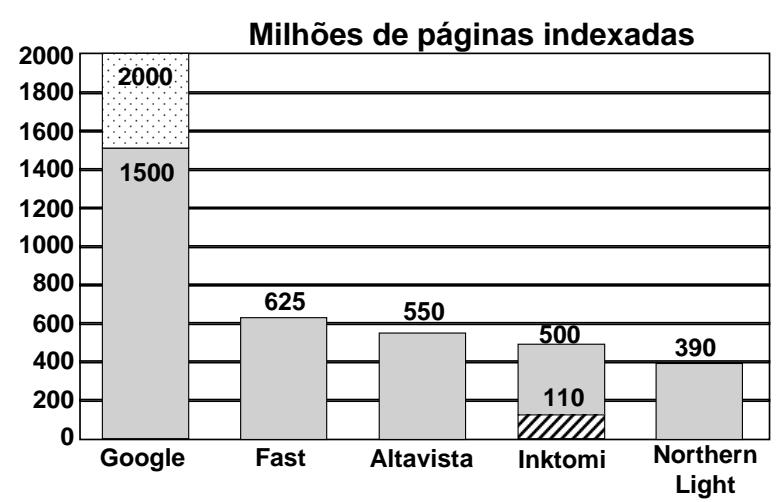

Figura 1.1: Estimativa de páginas indexadas em dezembro de 2001 pelos maiores sítios de busca segundo a Search Engine Watch.

VARIAN, 2000): os disponibilizados como páginas estáticas (chamada de Web superficial) e os que fazem parte de bases de dados especializadas e sítios dinâmicos (chamada de Web profunda). A Web superficial teria constado, no ano 2000, de aproxidamente 2.500 milhões de documentos ${ }^{5}$ (6.000 milhões em 2001(RAVIA, 2001)) e a $W e b$ profunda conteria 550.000 milhões de documentos ${ }^{6}$, sendo $95 \%$ acessíveis publicamente (LYMAN; VARIAN, 2000). Segundo Ravia (2001), a taxa de crescimento da Web superficial teria começado a diminuir a partir de 2001.

Adicionalmente a esses dados, a visibilidade de uma página ou sítio, destinada pelos seus criadores a ser pública, pode ser diretamente afetada por motivos comerciais (LIVINGSTON, 2000), políticos (INTRONA; NISSENBAUM, 2000) ou militares (LABOVITZ; AHUJA; BAILEY, 2001) ${ }^{7}$. No entanto, formas de busca alternativas (RAVIA, 2001) podem ajudar a trazer à luz essas porções de conhecimento que, sendo originalmente públicas, são desfocadas pelo exercício dessas diversas formas de preconceito.

Dada a vastidão e a diversidade do conteúdo presente na Internet, o problema enfrentado é a busca de uma forma eficiente de recuperar informações desse corpus, a partir da requisição de um usuário. Para tanto, não basta dispor so-

${ }^{5}$ Como a média de cada documento seria entre 10 e 20 kbytes, o tamanho atingiria entre 25 a 50 terabytes, dos quais $40 \%$ apenas seriam conteúdo textual, i.e. entre 10 e 20 terabytes (LYMAN; VARIAN, 2000).

${ }^{6}$ Com tamanho médio de 14 kbytes para cada documento, sendo necessários aproximadamente 7.500 terabytes, dos quais $56 \%$ seriam de conteúdo, i.e 4.200 terabytes. Dois sítios (o Centro de Dados de Clima dos EUA e a NASA) concentrariam 7,8\% da rede profunda e os 60 sítios maiores conteriam $10 \%$ do conteúdo total (LYMAN; VARIAN, 2000).

${ }^{7}$ Em torno de $5 \%$ da $W e b$ não seria de fato sequer mapeável (LABOVITZ; AHUJA; BAILEY, 2001). 
mente de máquinas de busca convencionais. É duvidoso que um usuário exponha publicamente, por vontade própria, de forma irrestrita, o seu conhecimento, na forma de documentos, mensagens etc. Um caminho a ser explorado, então, é a construção de agentes computacionais capazes de partilhar informação em sistemas abertos (como nas arquiteturas Peer-to-Peer (P2P)) de forma a preservar melhor a privacidade de certos conhecimentos e facilitar a transmissão de outros. Estes agentes devem ser capazes de representar tanto o conhecimento quanto os contatos sociais (e o seu grau de proximidade) dos usuários aos quais estão dedicados.

\subsection{Objetivo}

Na vida real, indivíduos pertencem a comunidades e, dentro das mesmas, são filiados a grupos. Portanto, é corriqueira a situação em que a busca de informações ocorra não somente na Internet, mas também no seu círculo de conhecidos. Já a disposição que uma pessoa manifesta em compartilhar os seus recursos de informação (por exemplo, na forma de documentos) com outra depende não somente do seu conhecimento, mas também do tipo de relação interpessoal que mantém com o respectivo interlocutor.

A figura 1.2 mostra esquematicamente alguns dos fatores que podem ser considerados para abordar o problema. Um indivíduo possui, além dos seus recursos de informação, uma estruturação do seu conhecimento, a sua ontologia ${ }^{8}$. Ele também é ciente da sua rede de contatos interpessoais, denominada Rede Social Pessoal. Porém, os contatos da sua Rede Pessoal não são tratados igualmente, dependendo do grupo e do papel $^{9}$ que tal contato desempenha em relação a si. Assim sendo, um indivíduo também leva em conta a sua visão organizacional subjetiva do seu entorno comunitário ao decidir compartilhar/buscar informações.

O objetivo geral deste trabalho é o de contribuir na formação/estruturação de comunidades virtuais, tendo como base redes sociais de conhecimento. Concretamente, a tese pretende modelar um agente computacional capaz de auxiliar na

\footnotetext{
${ }^{8}$ Uma ontologia pode ser entendida como a forma em que um indivíduo organiza o que percebe como sendo a realidade. Em Inteligência Artificial, denota um artefato que compreende um vocabulário específico e um conjunto de suposições sobre o significado das palavras de tal vocabulário (TAMMA, 2002).

${ }^{9}$ No sentido sociológico, por exemplo amigo, chefe, etc.
} 


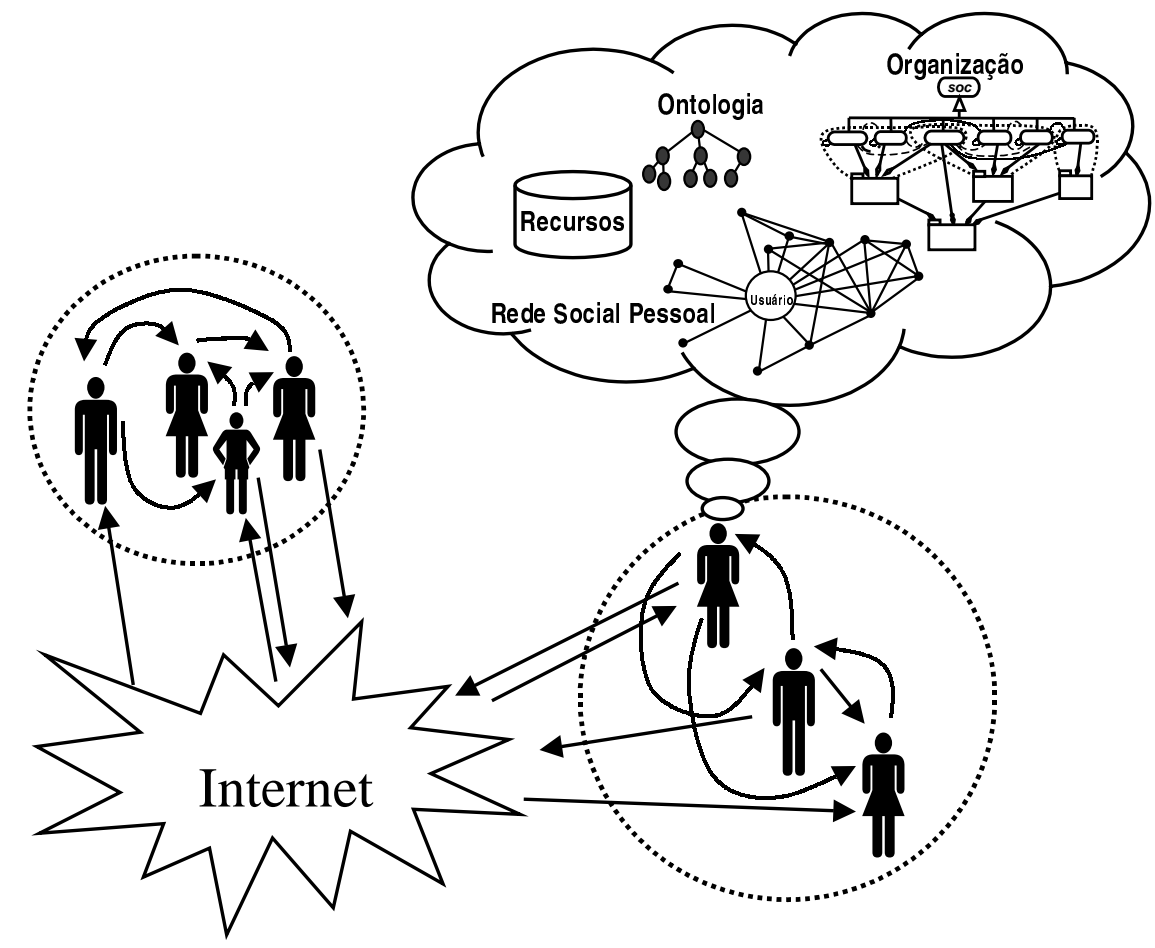

Figura 1.2: Quando procuram informações, os seres humanos consideram as comunidades das quais fazem parte.

troca de conhecimentos entre pares num ambiente comunitário, possibilitando:

- Localização de pessoas que possuam os conhecimentos procurados e que poderiam ser descobertas (e eventualmente reputadas) através de Redes Sociais (cadeia de recomendações);

- Acesso a conhecimentos (palavras-chaves, documentos, etc.), de posse de contatos sociais, que não estejam necessariamente disponíveis em páginas da $W e b$.

Tal agente deve ser capaz de tratar os diversos aspectos que aparecem na figura 1.2, e que são considerados pelos seres humanos quando da procura e partilha de informações. Os agentes dedicados aos usuários são concebidos como componentes de um SMA aberto, capaz de fornecer uma infra-estrutura de mediação computacional para comunidades. 


\subsection{Motivação}

A exploração de alternativas que facilitem o acesso ao conhecimento imerso na Internet é um problema em aberto em Ciência da Computação. Oyama, Hiramatsu e Ishida (2001) ressaltam que as técnicas de agentes de informação cooperativos precisam ser estendidas de forma a fornecer suporte não somente a equipes mas também a comunidades (vide seção 3.2). A opção por SMA decorre da sua adequação para tratar a cooperação social decentralizada (particularmente em sistemas $\mathrm{P} 2 \mathrm{P}$ ), fornecendo a abstração necessária para possibilitar tanto o projeto do sistema quanto o próprio raciocínio das entidades de software que interagem diretamente com o usuário. Considerando este fato, a motivação deste trabalho se encontra em:

- Procurar alternativas para a partilha de conhecimento, utilizando a Internet como infra-estrutura para a interação peer-to-peer;

- Alavancar a criação e a consolidação de comunidades de usuários mediados computacionalmente.

\subsection{Proposta}

O tratamento dos componentes descritos na figura 1.2 requer a elaboração de um agente capaz de aplicar técnicas oriundas de diversas areas da Ciência da Computação. Elas aparecem nas diversas fases que viabilizam o seu funcionamento:

- Inicialmente o agente deve processar e indexar os recursos disponibilizados pelo usuário (e.g. documentos e mensagens de correio eletrônico), de forma a tornar os seus conteúdos manipuláveis computacionalmente. Para tanto, são aplicadas técnicas de Recuperação de Informações (RI);

- Numa segunda fase, a estruturação do conhecimento do usuário, i.e. a sua ontologia, deve ser representada através de estruturas computacionais, utilizando técnicas de engenharia de conhecimento;

- As mensagens de correio eletrônico, uma vez processadas, fornecem uma base para a extração automática da rede de contatos pessoais do usuário; 
- A visão organizacional subjetiva do usuário, designando grupos e papéis sociais aos contatos da rede social pessoal, pode ser tratada computacionalmente, formalizando-a pela adoção de um modelo de organização para sociedades multiagentes.

No cenário vislumbrado, os agentes computacionais propostos fazem parte de um SMA aberto, numa arquitetura P2P, onde cada agente está associado a um usuário humano. Esta concepção decentralizada é mostrada na figura 1.3.

A figura ilustra parte de um cenário onde:

- Cada agente possui uma estruturação de seu conhecimento do usuário, na forma de uma instância de uma ontologia particular, derivada de uma ontologia inicial;

- Cada agente possui uma representação organizacional subjetiva dos seus contatos, que formam sua rede pessoal. Propõe-se que o usuário construa, usando a sua rede pessoal de contatos como referência, a sua visão subjetiva de organização e que esta representação utilize o modelo de especificação organizacional ${ }^{10} \mathcal{M O I S E}^{+}$(HÜBNER, 2003);

- Uma mesma ontologia geral é fornecida inicialmente para cada agente, onde a cada conceito estão atreladas palavras, consideradas como atributos associados ao conceito;

- Propõe-se que durante a dinâmica existencial do agente os conceitos da ontologia particular sejam anotados com informações que referenciem tanto o uso destes conceitos, quanto a representação organizacional subjetiva do usuário. Estas anotações servem para rastrear as mudanças conceituais e o seu uso organizacional, facilitando a localização de especialistas mesmo no decurso de mudanças.

Em tal cenário, ao receber uma requisição de outro agente em relação a um conceito, um agente verificaria quais são os recursos e contatos relacionados a este conceito. Esta informação está armazenada nas anotações. A seguir, disponibilizaria as informações, levando em conta o seu grau de privacidade em relação ao

\footnotetext{
${ }^{10}$ Uma especificação organizacional é a explicitação formal de uma organização natural ou artificial.
} 


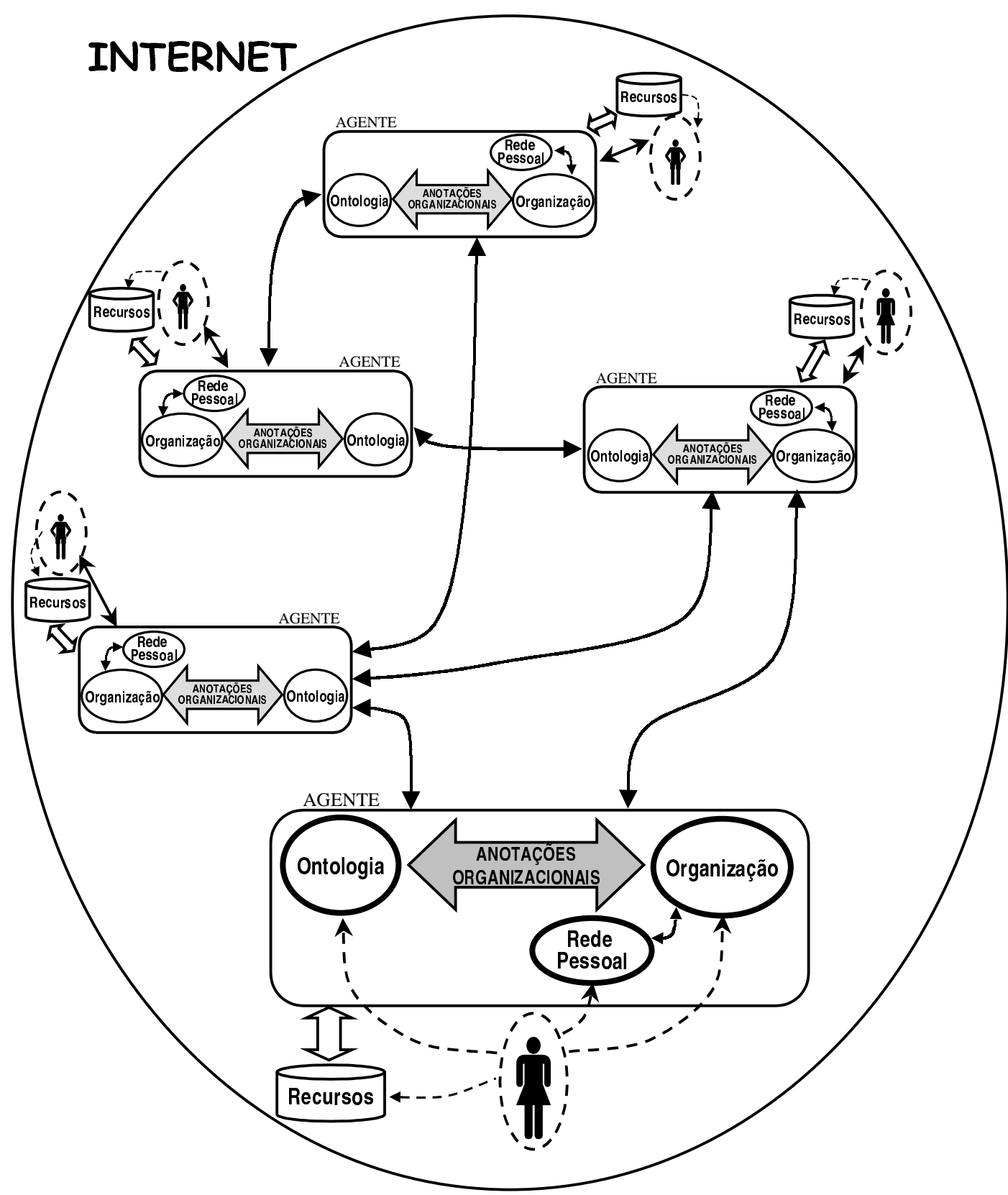

Figura 1.3: Um agente computacional capaz de interagir com outros agentes numa comunidade, relacionando a sua ontologia e a sua representação organizacional com a sua rede social de contatos. 
papel que o agente solicitante desempenha na visão organizacional subjetiva do usuário. Um SMA com tais características pode ser utilizado para auxiliar uma comunidade de usuários na manipulação e gestão dos seus conhecimentos numa forma mais próxima à maneira pela qual os seres humanos realizam esta tarefa.

\subsection{Contribuições esperadas}

Como parte das contribuições desta tese, o modelo a ser elaborado deve responder a diversas perguntas que permitam projetar um SMA colaborativo, dedicado à recuperação de informações na Internet usando redes sociais:

- Como construir uma representação da rede social da(s) comunidade(s) à(s) qual(is) pertence um usuário de forma a se aproximar da visão do usuário?

- Como podem ser relacionadas a estruturação do conhecimento e a rede social de um usuário?

- Como utilizar a estruturação do conhecimento e a rede social do usuário para localizar pessoas que possuam conhecimentos num certo domínio?

- Como pode o usuário ter maior controle sobre diferentes recursos (documentos, contatos, ontologias, etc.), preservando a sua privacidade sem inviabilizar a partilha de informação P2P?

- Quais são as inovações deste método?

Uma hipótese deste trabalho é que a utilização da ferramenta experimental a ser elaborada será maior ao minimizar a necessidade de intervenção do usuário nas etapas anteriores ao uso efetivo. Assim, outra pergunta decorre das anteriores:

- Como construir a ontologia de um usuário com o mínimo de intervenção da sua parte?

De forma geral, a inclusão destas capacidades em agentes de informação pode ajudar na concepção de agentes que ampliem a noção de mediadores entre os usuários e as fontes de informação (WIEDERHOLD, 1992). 


\subsection{Organização do texto}

O texto está distribuído em duas partes. Na primeira, composta de dois capítulos, são apresentados os conceitos que guiam a discussão do objeto da tese. Na segunda parte, são detalhadas a proposta e o encaminhamento teórico-metodológico adotado.

A primeira parte inclui os capítulos 2 e 3. No capítulo 2, são abordadas algumas das técnicas clássicas empregadas no acesso à informação. Já no capítulo 3, são comentados alguns tópicos relacionados à exploração dos caminhos abertos com o advento da Internet e a sua associação com o paradigma de agentes computacionais e comunidades de usuários. Os agentes computacionais tratados no texto são concebidos de forma a incluir entre as suas habilidades as técnicas mostradas tanto no capítulo 2 quanto no capítulo 3 .

A segunda parte inclui os capítulos 4 e 5. No capítulo 4, é apresentado o modelo da proposta, detalhando seus aspectos principais, que são embasados nos conceitos expostos na primeira parte. A seguir, no capítulo 5 são explicitadas as particularidades de uma implementação onde agentes computacionais foram dotados com algumas das propriedades advocadas pela proposta, de forma a demonstrar as possibilidades abertas. Ao final deste capítulo são apresentados os resultados experimentais, bem como uma análise dos mesmos.

Finalmente, o capítulo 6 apresenta as principais contribuições do trabalho, face aos resultados esperados descritos no capítulo 1, bem como alguns possíveis trabalhos futuros decorrentes da pesquisa realizada. Adicionalmente, são incluídos em anexos dados suplementares que dizem respeito ao experimento efetuado: gráficos correlacionando ações e conceitos a seqüências de busca, sociogramas conceituais e um questionário respondido por um dos usuários do sistema implementado. 


\section{Parte I}

\section{Conceitos Envolvidos}




\title{
2 Acesso à informação: enfoques clássicos
}

\author{
as coisas não começam com um conto \\ nem acabam com um • \\ P. Leminski - La vie en close
}

Este capítulo tem o objetivo de descrever os principais conceitos envolvidos no processo de elaboração de sistemas computacionais clássicos dedicados a facilitar o acesso de um usuário a informações por ele solicitadas.

\subsection{Recuperação de informação}

A conceituação de Recuperação de Informação (RI), devida inicialmente a Mooers (1951), como citado por Saracevic (1995), é feita, em geral, de uma forma predominantemente funcional e não descritiva. A seguir, são apresentadas algumas definições de RI encontradas na literatura:

"RI é o nome do processo ou método onde um possível usuário de informação pode converter a sua necessidade de informação numa lista real de citações de documentos armazenados que contenham informações que lhe sejam úteis . . . RI abarca os aspectos intelectuais da descrição da informação e a sua especificação para busca, assim como também quaisquer sistemas, técnicas ou máquinas que sejam empregadas para efetuar a operação", segundo Mooers (1951), apud (SARACEVIC, 1995).

"A tarefa de RI consiste na identificação dos documentos relevantes, 
numa dada coleção, que um dado usuário que necessite de informação julgará útil ou relevante" (TURTLE; CROFT, 1997).

"Escolha, a partir de um conjunto de documentos, daqueles que são relevantes para uma determinada consulta (query)"(RUSSELL; NORVIG, 1995).

"Um sistema de RI relaciona consultas de um usuário - expressões formais de necessidades de informação - a documentos armazenados em um banco de dados" (FRAKES; BAEZA-YATES, 1992).

"É a parte da Ciência da Computação que estuda a recuperação de informações (não de dados) de uma coleção de documentos escritos. Os documentos recuperados estão destinados a satisfazer a necessidade de informação de um usuário geralmente expressada em linguagem natural" (BAEZA-YATES; RIBEIRO-NETO, 1999).

De qualquer modo, uma vez de posse dos dados da consulta, são selecionados os documentos que se apresentam como mais relevantes comparando a consulta com representações dos documentos previamente armazenadas. Opcionalmente, é revisada a representação da consulta para tratar consultas posteriores.

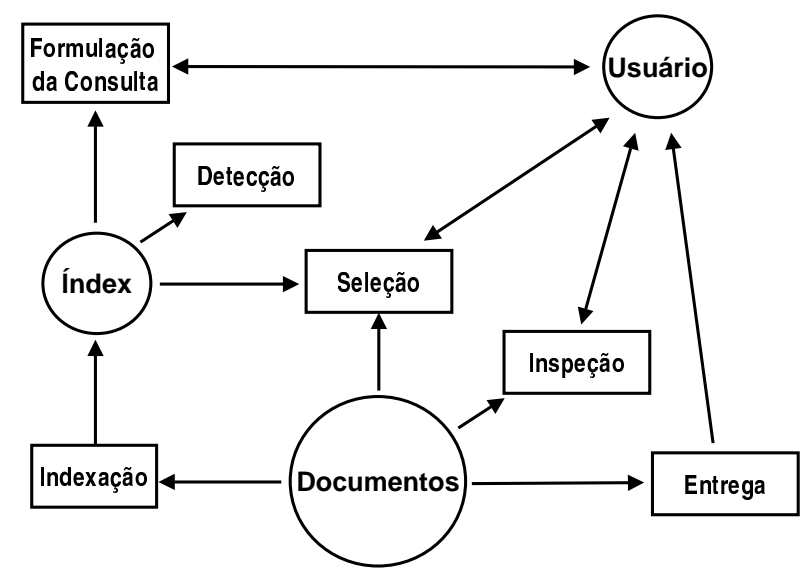

Figura 2.1: Um modelo de sistemas de RI segundo Oard (2000).

O processo é iniciado com a aquisição da consulta, a qual é comparada com o conteúdo do índex para detectar as palavras empregadas pelo usuário. De posse de um conjunto de palavras, elas são utilizadas para selecionar os documentos 
considerados relevantes, apresentando-os para serem inspecionados, o que pode provocar uma revisão da consulta (vide figuras $2.1,2.2$ ).

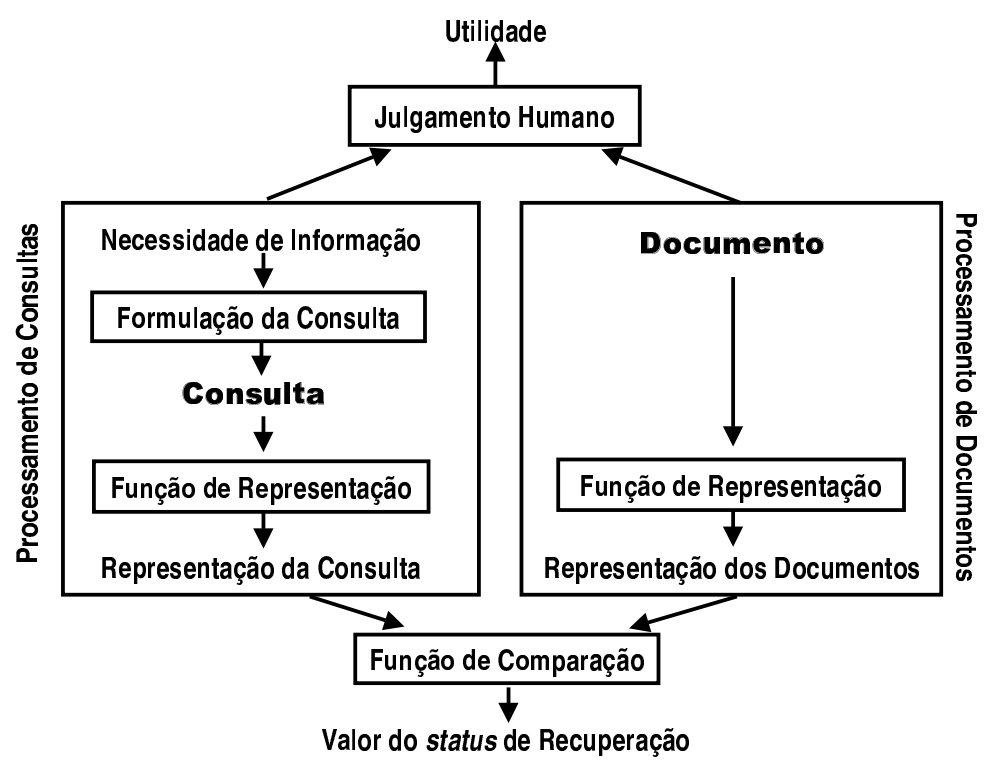

Figura 2.2: Um modelo do componente de detecção segundo Oard (2000).

Uma coleção de documentos pode incluir documentos textuais e não textuais tais como fotografias, som, vídeo, módulos de software, etc. RI é aplicada, dentre outras formas, na busca e navegação através da Internet e constitui o coração da P\&D nas bibliotecas digitais.

Qualquer sistema de RI inclui três componentes básicos: identificação e representação do conteúdo do documento, aquisição e representação da necessidade de informação e a especificação da função de comparação que seleciona os documentos relevantes baseada nas representações. Os principais problemas associados a estes componentes são os seguintes:

- Representação dos documentos: dado um determinado texto, mesmo os seres humanos dificilmente irão coincidir quanto ao conjunto de conceitos a serem usados para melhor representar o seu conteúdo. O uso de técnicas automatizadas para gerar descrições introduz incertezas adicionais. A complexidade é ainda maior se tentarmos representar o grau de adequação de cada conceito ao conteúdo de um dado documento;

- Representação das necessidades de informação: os mesmos problemas de representação já citados existem. Entretanto, uma incerteza adicional é in- 
troduzida pois usualmente a necessidade de informação não é claramente articulada. Isto é agravado pelo fato desta necessidade mudar freqüentemente durante o proceso de busca na medida em que o usuário vai verificando quais os tipos de documentos disponíveis;

- Função de comparação (matching): o processo de comparação deve tratar a incerteza inerente às representações dos documentos e das necessidades de informação. Porém, mesmo que tivéssemos representações precisas, o processo de comparação seria incerto, pois o mesmo conceito pode ser representado de formas diferentes, a mesma representação pode ser usada para conceitos diferentes e os conceitos que aparecem em uma representação não são independentes.

Além destes três componentes, a maioria dos sistemas de RI incluem um quarto elemento:

- Realimentação da relevância: pode-se pedir ao usuário para selecionar documentos, ou frações de documentos, considerados relevantes a partir de um conjunto recuperado. Este conjunto de documentos relevantes pode ser usado para modificar as representações da necessidade de informação ou a função de comparação para melhorar as respostas a consultas posteriores. Em alguns casos, o histórico dos juízos de relevância pode ser usado para alterar a representação dos documentos.

Os diversos problemas associados à imperfeição, que existem em cada um dos componentes citados, aparecem na figura 2.3, representados numa taxonomia da ignorância, segundo Mamdani (1997). As diversas técnicas de RI atacam com maior sucesso apenas os problemas decorrentes dos conceitos que aparecem dentro da área pontilhada. Nada há de definitivo nesta classificação, sendo bom salientar que o termo ausência é usado para o tipo de incerteza modelada usando lógicas não-monotônicas. Aqui cabe também citar a existência de sistemas lógicos que tratam com razoável desenvoltura a inconsistência (COSTA, 1964).

Partindo para uma visão mais abrangente da RI, aparece o conceito de acesso à informação (HEARST, 1997) como forma de aquisição de conhecimentos de fontes diversas. Estas fontes podem estar na forma textual tradicional, ou então na 


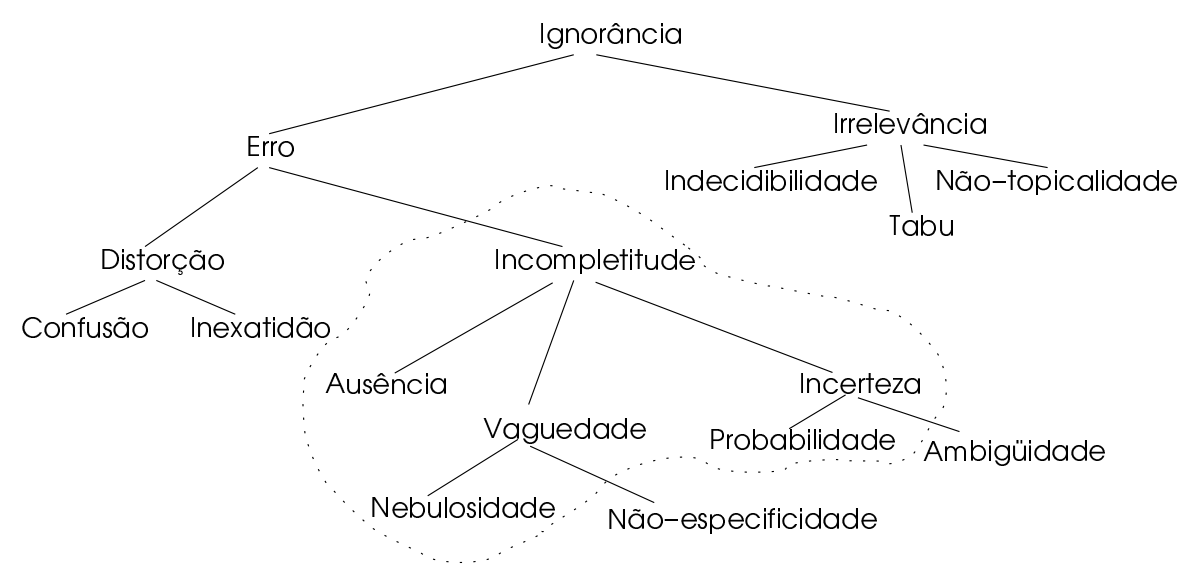

Figura 2.3: Uma taxonomia da ignorância segundo Mamdani (1997).

forma de um som, imagens ou vídeo. No limite, a noção de realidade é trabalhada como senso comum construído, que pode vir a ser sistematizado e formalizado. A concepção de representação como filtro da realidade pode ser enfocada através da lente mais abrangente de percepções (atingíveis) de realidades (possíveis), através de cortes sócio-culturais (INTRONA; NISSENBAUM, 2000). Em última análise, RI existe como atividade social que interliga e permite a interação entre os produtores/autores de informação e os seus usuários/leitores (SARACEVIC, 1995).

A seguir serão apresentadas as premissas que norteiam a teoria de RI, os modelos e as formas de avaliação, bem como os questionamentos metodológicos que idealmente devem guiar um trabalho em RI.

\title{
2.1.1 Premissas gerais em RI
}

\author{
TEXTOS TEXTOS TEXTOS \\ malditas placas fenícias \\ cobertas de riscos rabiscos \\ como me deixastes os olhos piscos \\ a mente torta de malícias ... \\ P. Leminski - La vie en close
}

Os modelos de RI têm uma teoria de acesso à informação e um conjunto de premissas que orientam a teoria. O termo teoria é usado aqui no sentido matemático ou lógico, no qual a teoria referencia um conjunto de axiomas e regras de inferência que permitem derivar teoremas. Um modelo é uma instância concreta da teoria, onde é definido um conjunto de objetos sobre os quais afirmações 
podem ser feitas, restringindo as formas de interação entre classes de objetos. No caso de RI, o modelo de recuperação especifica as representações usadas para os documentos e para as necessidades de informação, junto com a forma de compará-las.

Algumas premissas comuns aos modelos de RI são (TURTLE; CROFT, 1997):

- Os objetos sendo recuperados são textuais;

- A compreensão que o usuário tem da sua necessidade de informação será refinada durante o processo de busca;

- A recuperação é baseada em representações do conteúdo textual e das necessidades de informação;

- As representações tanto do texto, quanto das necessidades de informação, são incertas.

A aplicação destas premissas deu origem a técnicas de recuperação que enfatizam a recuperação baseada em escalas ou pontuação, formulação iterativa de consultas, realimentação de relevância e análise de consultas simples em linguagem natural.

Outros tipos de sistemas de informação possuem teorias e premissas diferentes. Sistemas típicos de bancos de dados representam maior número de tipos de objetos que um sistema típico de RI. Estes objetos, porém, possuem um conteúdo muito bem definido. Mesmo que estas fronteiras estejam se esvaindo, tópicos envolvendo incerteza na especificação da consulta ou representação dos objetos não aparecem com freqüência nas pesquisas relacionadas a bancos de dados.

\title{
2.1.2 Modelos de RI
}

\author{
lá vai um homem sozinho \\ o que ele pensa da noite \\ eu não sei \\ apenas adivinho \\ P. Leminski - La vie en close
}

Segundo Turtle e Croft (1997), os três tipos de modelos para RI de uso mais difundido são os seguintes: 
- Modelos de correspondência exata de palavras (e.g., consultas booleanas usando palavras-chave);

- Modelos usando espaços vetoriais, com os documentos e consultas sendo vistos como vetores num espaço vetorial n-dimensional, onde a distância vetorial é usada como medida de similaridade;

- Modelos probabilísticos, onde a recuperação é vista como um problema de estimação da probabilidade de que a representação de um documento corresponda ou satisfaça uma consulta.

Tanto o modelo de correspondência exata quanto o modelo de espaços vetoriais podem ser elaborados como modelos probabilísticos que usam um conjunto particular de estimativas para as probabilidades dos seus componentes.

Um quarto tipo de modelo, baseado em lógica, tem atraído renovado interesse a partir de meados da década de 90 . Neste modelo, os documentos e as consultas são tratados como conjuntos de proposições. A similaridade é baseada no grau em que uma consulta pode ser inferida de um documento, possivelmente usando conhecimentos adicionais sobre o domínio (TURTLE; CROFT, 1997).

No modelo de correspondência exata, a forma mais comum de requerer informação tem sido a consulta que combina, de forma booleana, diversas palavraschave. Por exemplo, a consulta "(linguagem E natural) OU (lingüística E computacional)" será atendida pela recuperação dos documentos que apresentam ocorrência exata da combinação de palavras que aparecem na consulta. O usuário, em geral, tende a achar difícil atingir bons resultados usando consultas booleanas. Isto fica explícito, por exemplo, no caso da consulta não retornar documento algum, pois não é claro como a consulta poderia ser reelaborada para achar algum documento relevante. Como citado por Russell e Norvig (1995), é possível mudar um E por um OU, mas os usuários acabam achando que são muitas as possibilidades e escassa a ajuda acessível.

Num modelo baseado em espaços vetoriais, cada lista de palavras (seja uma consulta ou um documento) é tratada como um vetor n-dimensional, onde $n$ é o número de tokens relevantes na coleção de documentos. Neste modelo, a consulta seria do tipo "lingüística computacional de linguagem natural", a qual seria tratada como um vetor com o valor 1 para estes quatro termos (não levando 
a preposição "de" em conta ) e com o valor 0 para todos os outros. Achar um documento será, então, uma tarefa de comparar este vetor com a coleção de vetores representando os documentos, retornando aqueles que estejam mais próximos. O modelo baseado em espaços vetoriais é mais flexível que o modelo booleano, pois os documentos podem ser classificados usando a distância ao vetor de consulta, apresentando primeiro os mais próximos.

Existem muitas variações deste modelo, sendo alguns sistemas equipados com analisadores morfológicos que fariam corresponder "computação lingüística" a "lingüística computacional". Também podem permitir estabelecer na consulta que dois termos devem aparecer perto um do outro para contar como correspondentes e ainda há os que usam thesauri (léxicos) para aumentar automaticamente as palavras na consulta com os seus sinônimos.

Somente os sistemas mais ingênuos contabilizam igualmente todos os termos no vetor. A maioria dos sistemas ignoram palavras comuns como "a" e "uma". Uma boa forma de contabilizar os termos, de forma diferenciada, é designar um peso maior a um termo se ele é um bom discriminante: se aparece numa quantidade pequena de documentos e não em muitos deles. Este modelo de RI está, quase por inteiro, no nível de palavras. Admite um tratamento de sintaxe muito restrito, quando requer que as palavras estejam próximas umas das outras para serem contabilizadas. Um espaço igualmente pequeno é permitido para classes semânticas na forma de listas de sinônimos.

Como conseqüência, diversas pesquisas tentaram responder à seguinte pergunta: a RI não melhoraria se fossem usadas técnicas mais sofisticadas, por exemplo de processamento de linguagem natural? Muitos têm trilhado esta via, porém segundo Russell e Norvig (1995): "surpreendentemente (ou quem sabe nem tanto) nenhuma das tentativas apresentou uma melhora significativa numa faixa ampla de tarefas relacionadas a RI". A frase de Russell e Norvig (1995) deve ser olhada com atenção pois ela não afirma de modo algum a impossibilidade/inutilidade do uso de técnicas de Processamento de Linguagem Natural (PLN). Pelo contrário, ela aponta para a necessidade de focalizar a pesquisa no problema de representar e tratar os contextos (possivelmente diferentes) onde os documentos, o processo da sua produção e o processo de recuperação estão imersos. É possível sintonizar técnicas de PLN para domínios particulares do conhecimento, porém é bem mais 
difícil aplicar as técnicas a uma coleção irrestrita de textos.

A conclusão, segundo Russell e Norvig (1995), é que a maior parte da informação pertencente a um texto está contida nas palavras. Em RI, diversas técnicas estatísticas podem ser aplicadas. Isto equivale a extrair todas as palavras contidas num documento, ordená-las alfabeticamente e, então, comparar cuidadosamente esta lista com outra lista ordenada de forma semelhante. Embora muita informação seja perdida em relação ao documento original, é mantida informação suficiente para decidir se duas listas ordenadas referem-se a tópicos similares. Em contraposição, as técnicas de PLN podem, eventualmente, extrair informações adicionais para retirar a ambigüidade dos termos e para determinar relações entre frases. A classificação de textos por tópicos é uma tarefa onde as técnicas de PLN atingiram sucesso considerável, devido ao fato das categorias serem fixas (RUSSELL; NORVIG, 1995).

Quanto aos modelos probabilísticos de RI, eles partem do assim chamado Probabilistic Ranking Principle (PRP)(COOPER, 1994), que afirma que o desempenho ótimo de recuperação é atingido quando documentos são classificados de acordo com a probabilidade de que sejam julgados relevantes para uma determinada consulta. Dada uma representação de consulta $q_{j}$ e uma representação de documento $d_{k}$, e se $R$ denota o evento de que o documento $d_{k}$ é julgado relevante para $q_{j}$, então desejamos arranjar os documentos segundo o valor da probabilidade $P$ dada por $P\left(R \mid q_{j}, d_{k}\right)$ ou por $P\left(R \mid q_{j}, d_{k}, K\right)$, onde $K$ é algum corpo de conhecimento de domínio sobre o qual recai nossa decisão em relação à relevância. No entanto, a aplicação do PRP geralmente envolve algumas premissas questionáveis (COOPER, 1994):

- Decisões quanto à relevância de um documento para uma consulta específica são consideradas independentes de outros documentos na coleção, i.e., documentos podem ser considerados de forma isolada. Na prática, a ordem na qual os documentos são apresentados a um usuário pode influenciar o seu julgamento de relevância, porém a dependência entre documentos é geralmente ignorada;

- É problemático supor que os documentos apresentados são ordenados de forma próxima àquela em que o usuário o faria. Esta afirmação é agravada 
pelo fato de ser feita, freqüentemente, na ausência de qualquer exemplo de documento relevante.

Apesar destes problemas, os modelos baseados no PRP oferecem as teorias mais rigorosamente desenvolvidas em RI. Estes modelos são a base dos sistemas que atualmente oferecem os mais altos níveis de desempenho em RI.

Dados os conjuntos de consultas possíveis $Q$ e dos documentos possíveis $D$, a maioria dos modelos probabilísticos possuem, como o seu espaço de eventos ${ }^{1}$, o conjunto $Q \mathrm{x} D$. Os modelos diferem na estrutura da consulta e nas formas de representação dos documentos. Nos modelos mais simples, as consultas e os documentos são representados como vetores de valores binários, nos quais cada elemento corresponde a um atributo (e.g., termo) que pode ser designado a um documento ou consulta. Num sistema simples no qual $n$ documentos contém $m$ termos únicos, existem $2^{m}$ possíveis representações de documentos, das quais no máximo $n$ são definidas. Os termos da consulta que não ocorrem na coleção de documentos são geralmente ignorados, existindo $2^{m}$ possíveis representações da consulta.

Modelos mais complexos modificam o conjunto de documentos e de representações da consulta de várias formas (TURTLE; CROFT, 1997):

- A maioria permite utilizar vetores de números reais para representar i) o grau em que o atributo está associado ao documento ou à consulta, ou ii) a probabilidade de que o atributo seja um descritor correto de um documento ou consulta;

- O conjunto de atributos originais pode ser substituído por um conjunto menor. Alguma forma de análise de fatores ${ }^{2}$ é utilizada para reduzir conjuntos

\footnotetext{
${ }^{1}$ Este espaço é o conjunto de todos os possíveis resultados de uma experiência. Neste caso, quais os resultados possíveis (documentos recuperados) no caso de ser realizada a experiência de fazer consultas.

${ }^{2}$ É um nome genérico dado a uma classe de métodos de estatística multivariada, cujo principal propósito é definir a estrutura subjacente a uma matriz de dados. De forma geral, focaliza o problema de analisar a estrutura das interrelações (correlação) entre um grande número de variáveis definindo um conjunto de dimensões comuns subjacentes, denominados de fatores. O pesquisador pode primeiramente identificar as diferentes dimensões da estrutura e depois determinar o grau no qual cada variável é explicada por cada dimensão. Determinadas as dimensões e as explicações de cada variável, pode-se chegar à sumarização e redução de dados (SHIN-YUAN, 2001).
} 
de atributos com discriminação pobre ${ }^{3}$;

- Separar conjuntos de atributos (vocabulários) para documentos ou consultas distintas;

- Consultas estruturadas (e.g. usando operadores booleanos) podem ser utilizadas ao invés de vetores de consulta planos;

- A estrutura interna dos documentos pode ser representada de forma a permitir que, por exemplo, a recuperação possa priorizar o fato de que um atributo ocorre no resumo ou no título ao invés de ocorrer na indicação de autor ou no rodapé;

- Os relacionamentos entre documentos podem ser representados de forma que a recuperação possa usar as relações semânticas entre documentos (e.g., citações, estrutura de co-citação, ligações de hipertexto etc.)(GILES; BOLLACKER; LAWRENCE, 1998) (MCCALLUM et al., 2000);

- Conjuntos mais complexos de atributos podem ser utilizados para permitir a representação de atributos que podem ou não estar presentes no conjunto indexador subjacente ${ }^{4}$ (e.g., frases ou classes de sinônimos) (DEERWESTER et al., 1990).

A noção de relevância é de difícil definição e tem provocado fartos debates. Idealmente, relevância é relação de mapeamento $Q \mathrm{x} D$ num conjunto de categorias de relevância. Assim, numa classificação binária a relevância dos documentos pode assumir dois valores: relevantes ou não. Alguns modelos permitem vários graus de relevância, de forma que a faixa da relação de relevância é expandida. Estas escalas de relevância múltipla não têm se mostrado úteis, sendo aplicadas usualmente apenas escalas binárias.

Conceitualmente, a relação de relevância é especificada pelo usuário e é definida para todos os pares consulta/documento. Na prática, esta relação é definida

\footnotetext{
${ }^{3}$ No sentido de descartar termos que não são úteis para diferenciar a qual grupo (e.g., domínio do conhecimento, grupo de interesse) um documento pertence.

${ }^{4}$ Por exemplo, expressões que são sinônimos deveriam fazer com que documentos passem a ser considerados como sendo relevantes para a mesma consulta, mesmo que o fato de serem sinônimos não apareça de forma explícita, i.e. fique subjacente.
} 
somente para uma pequena porção da coleção de documentos para cada consulta, porque o usuário somente pode avaliar um número relativamente pequeno de documentos.

Como a relação de relevância é desconhecida antes da recuperação, cada modelo de recuperação contém uma definição implícita de relevância. Em modelos de correspondência exata, a relevância é geralmente definida de forma a satisfazer uma expressão lógica de primeira ordem. Em modelos probabilísticos, a relevância é definida em termos da probabilidade de relevância, condicionada por um conjunto de evidências que incluem as representações de documentos e consultas. Para modelos de espaço vetorial, a relevância é definida em termos de distância entre o documento e a consulta.

\title{
2.1.3 Avaliação em RI
}

\author{
celeuma luas \\ onde se lê uma \\ leiam-se duas \\ P. Leminski - La vie en close
}

Avaliar implica verificar o desempenho de um sistema. A questão da avaliação em RI pode ser colocada em função da problemática de explosão da informação já apontada na década de 40 por Bush (1945) como citado por Saracevic (1995), e por outros bem antes dele como demonstram os milenares catálogos sumérios. No dizer de Saracevic (1995):

"Quão satisfatório foi e é RI na resolução do problema de explosão da informação nas áreas em que foi aplicada?"

Isto leva a outras questões correlatas, como:

Quão satisfatoriamente RI auxilia às pessoas nas situações em que elas se defrontam com problemas de pesquisa, uso e interação com informação advinda da massa de informações existentes e a miríade de escolhas possíveis? 
A explosão de informação é um problema social complexo, que envolve aspectos cognitivos, culturais e de comunicação e não simplesmente um problema técnico.

Por tudo isto, as preocupações com avaliações em RI apareceram já pouco depois das primeiras propostas e protótipos. Kent et al. (1955), apud (SARACEVIC, 1995), foram os primeiros a propor o critério de relevância e as medidas de precisão e relevância (mais tarde renomeado recall - cobertura de recuperação).

Avaliações são conduzidas em contextos diversos (e.g., avaliação de um sistema de RI operacional, um protótipo de laboratório ou um modelo no papel) com os mais diferentes objetivos (e.g., quantificar a efetividade da recuperação, efetividade em relação ao custo, qualidade da coleção, satisfação do usuário). Ainda hoje, as medidas mais populares para medir o desempenho ou efetividade de recuperação de informação são o já citado par precisão e recall.

Precisão é a proporção dos documentos recuperados que são relevantes para uma dada consulta em relação ao total de documentos recuperados. Recall é a razão entre o número de documentos recuperados que são relevantes para uma consulta e o total dos documentos na coleção que são relevantes para a consulta. Supondo que o conjunto de documentos relevantes para uma consulta (relevantes) e o conjunto de documentos recuperados por uma consulta (recuperados) são conhecidos, podem-se definir estas medidas como:

$$
\text { Precisão }=\frac{\mid \text { relevantes } \cap \text { recuperados } \mid}{\mid \text { recuperados } \mid}=P(\text { relevantes } \mid \text { recuperados })^{5}
$$

$$
\text { Recall }=\frac{\mid \text { recuperados } \cap \text { relevantes } \mid}{\mid \text { relevantes } \mid}=P(\text { recuperados } \mid \text { relevantes })^{6}
$$

Para comparar a efetividade de dois modelos de RI, são usadas coleções de teste padronizadas. Uma coleção deste tipo consiste dos seguintes elementos (TURTLE; CROFT, 1997):

- Um conjunto de documentos, que pode conter somente alguns dados como

\footnotetext{
${ }^{5}$ Probabilidade de um documento ser relevante dado que ele foi recuperado.

${ }^{6}$ Probabilidade de um documento ser recuperado dado que ele é relevante.
} 
título, autor, data e abstract (resumo) ou então o texto completo. Podem ser utilizadas informações adicionais, tais como um conjunto de termos usado como vocabulário de controle, descritores designados por autor e informação sobre citações;

- Um conjunto de consultas, constituídas por consultas reais submetidas por usuários, seja usando linguagem natural ou alguma linguagem formal de consulta. Ocasionalmente consultas artificialmente construídas são utilizadas (e.g., consultas construídas para recuperar documentos conhecidos ou o texto de um documento usado como amostra);

- Um conjunto de julgamentos de relevância, sendo que para cada consulta o conjunto de documentos relevantes é identificado. Para coleções pequenas, isto pode ser obtido revisando todos os documentos. Para coleções grandes, geralmente são combinados os resultados de diferentes representações da consulta construída por diferentes usuários. O julgamento de relevância pode ser feito pelo usuário que submete a consulta ou por especialistas no respectivo domínio do conhecimento. De qualquer modo, os julgamentos são inerentemente subjetivos. Via de regra, são preferidas as consultas e julgamentos obtidos diretamente dos usuários.

Coleções de teste são caras pois requerem julgamentos de relevância para sua criação. Tais julgamentos consomem muita mão-de-obra para um número significativo de consultas. Estudos deste tipo começaram em meados da década de 50 (Cranfield) continuaram nos anos 70 com SMART e na década de 90 com a coleção TREC $^{7}$ (de Text Retrieval Conference, cuja primeira versão é de 1993, onde técnicas novas de RI são testadas contra um corpus) (SARACEVIC, 1995).

Uma divisão dos objetivos das avaliações em vários níveis foi estabelecida por Saracevic (1995):

- Engenharia/processamento: visa verificar falhas, erros, velocidade, etc. Para RI, se deseja obter uma métrica da efetividade e eficiência de um dado método ou algoritmo;

\footnotetext{
${ }^{7}$ Este rótulo designa tanto a conferência quanto a sistemática adotada na mesma, onde os autores de trabalhos em RI avaliam as técnicas desenvolvidas por eles utilizando um corpus padronizado. Estão associados aos documentos de tal corpus julgamentos de relevância estabelecidos por especialistas.
} 
- Entrada: deseja-se obter dados sobre o grau de cobertura no domínio focalizado;

- Saída: o interesse reside na observação das interações, busca, realimentação e saídas fornecidas;

- Usuário e Uso: avalia-se as possíveis aplicações a certos problemas e tarefas, a facilidade de uso, o segmento de mercado;

- Social: o interesse é o de avaliar o impacto no(s) ambiente(s), pesquisa, produtividade, tomada de decisões, etc. num determinado domínio.

Questões de eficiência e economia podem ser contrastadas em cada nível. Destes níveis, os três primeiros corresponderiam, aproximadamente, a uma avaliação centrada no sistema e os três últimos a uma avaliação centrada no usuário. Até agora, a maioria dos esforços tem sido no nível de processamento, de saída e de usuário e uso. São escassos os estudos no nível social (e.g., avaliação do impacto de MEDLINE na tomada de decisões clínicas empreendida por Lindberg et al. (1993), como citado por Saracevic (1995)).

Estabelecidos os possíveis objetivos, é mister considerar os requisitos para realizar uma avaliação de sistemas em geral. Novamente, Saracevic (1995) apresenta uma proposta coerente daqueles que seriam necessários:

- Um sistema, ou a sua representação prototipada, junto com um processo (algoritmo, simulação);

- Critério(s), explicitando os objetivos da avaliação, tal como o critério de relevância em $\mathrm{RI}$;

- Medida(s), baseada(s) no(s) critério(s), tais como precisão e recall;

- Instrumentos de medição, tais como os julgamentos de relevância fornecidos por analistas no esquema TREC;

- Metodologia, para obter as medidas e conduzir a avaliação, e.g., os passos de inicialização e procedimentos a serem seguidos no esquema TREC. 
Como citado por Saracevic (1995), Tague-Sutcliffe (1992) comenta os requisitos numa forma mais detalhada. Mesmo assim, partindo dos requisitos citados, já aparecem diversos questionamentos discutidos em Saracevic (1995): De que forma a composição incomum de tipos e assuntos dos documentos no TREC afetam os enfoques testados e os resultados? Quais os pontos fracos na utilização do TREC como veículo praticamente único de avaliação? Um último aspecto tem uma grande importância: Qual será a avaliação de RI interativa, dado que TREC, assim como os seus antecessores, trabalha em modo de lotes?

Além destes pontos, surge o questionamento de se considerar apenas o critério de relevância como o único na maioria dos estudos. Mesmo tendo sido propostos critérios adicionais como utilidade e comprimento da busca ou caminho da busca (relacionado ao uso de RI na Internet), estes não têm sido suficientemente explorados, pois os esquemas antecessores do TREC, assim como ele próprio, consideram apenas a relevância.

Para finalizar, Saracevic (1995) mostra o seguinte conjunto de categorias onde se encaixam os tópicos, críticas e questões metodológicas relacionadas à validade e confiabilidade da avaliação:

- Coleção (de dados): Como são selecionados os ítens (e.g., documentos) a serem usados na avaliação? Quão apropriados eles são (homogêneos, representativos, etc.)? Qual o tamanho da coleção? Como são tratados os ítens da coleção?

- Consultas: Como são geradas? Quão apropriadas, representativas elas são? Como são tratadas?

- Busca: Como ela é conduzida? Quais os procedimentos usados? Quão realista ela o é?

- Resultados: Como são obtidos? Quem são os juízes? Como é conduzido o julgamento? Quão realista ele o é? Como é tratada a realimentação (se ela existir)?

- Análise: Como é realizada? Que ferramentas estatísticas ou de outro tipo são usadas? Quais e como são feitas as comparações? 
- Interpretação e generalização: Quais as conclusões? Como são garantidas com base nos resultados? Quão generalizáveis são as descobertas?

\title{
2.2 Categorização de textos
}

\author{
$X X$ anos de xis, \\ $X X$ anos de xerox, \\ $X X$ anos de xadrez, \\ não busquei o sucesso, \\ não busquei o fracasso, \\ busquei o acaso, \\ esse deus que eu desfaço. \\ P. Leminski - La vie en close
}

Considerando a RI um conjunto geral de tarefas dedicadas ao gerenciamento de documentos, Sebastiani (2002) destaca entre tais tarefas a categorização de textos como sendo uma das que ganharam maior relevância nos anos 90 .

A idéia básica para implementar a categorização de textos é a chamada hipótese de agrupamento (cluster hypothesis), relativa à noção de que documentos fortemente associados tendem a ser relevantes para as mesmas consultas (FALOUTSOS; OARD, 1995). Note-se que a hipótese de agrupamento pode ser aplicada também a termos ao invés de documentos. Termos que co-ocorrem são usualmente relevantes uns aos outros, o que é muito útil na construção automática de dicionários de sinônimos (léxicos ou thesaurus).

No caso da forma de representação ser vetorial, por exemplo, cada documento está representado como um ponto num espaço t-dimensional. Os agrupamentos são formados particionando estes pontos. Segundo Van-Rijsbergen (1979), como citado por Faloutsos e Oard (1995), o procedimento de particionamento deve ser teoricamente bem fundado (sound) e eficiente, sendo os critérios para ser um procedimento ser bem fundado os seguintes:

- Deve ser estável sob crescimento, i.e., o particionamento não deve mudar drasticamente com a inserção de novos documentos;

- Pequenos erros na descrição dos documentos devem levar a pequenas mudanças no particionamento;

- O método deve ser independente da ordem inicial dos documentos. 
Para analisar a eficiência, o principal critério utilizado é o tempo requerido para realizar o processo de agrupamento.

Nenhum método preenche ambos os critérios ("bem fundado" e eficiente), podendo os existentes ser classificados em dois grupos (FALOUTSOS; OARD, 1995):

- Métodos "bem fundados", baseados na matriz de similaridade documentodocumento;

- Métodos iterativos, mais eficientes, que partem diretamente dos vetores dos documentos.

Usualmente, um método de categorização compreende diversas etapas, explicadas resumidamente nas subseções seguintes do texto:

- Pré-processamento;

- Ponderação das palavras;

- Redução do espaço de atributos;

- Categorização propriamente dita.

Inicialmente, os documentos que são submetidos a um processo de classificação são previamente tratados. Tal fase, denominada pré-processamento do texto, consiste na remoção de palavras comuns, redução às raízes, etc. As palavras remanescentes após tal processo devem ser ponderadas quanto ao seu poder de discriminação.

\title{
2.2.1 Funções de ponderação
}

\author{
... ai do acaso, \\ se não ficar do meu lado. \\ P. Leminski - La vie en close
}

Após o pré-processamento segue a fase de indexação das palavras. Existem várias formas de determinar o peso $a_{i k}$ de uma palavra $i$ no documento $k$, mas a maioria dos enfoques são baseados em duas observações empíricas em relação a documentos textuais (AAS; EIKVIL, 1999): 


\begin{tabular}{lc}
\hline Esquema & Função de ponderação \\
\hline Booleana & $a_{i k}= \begin{cases}1 & \text { se } f_{i k}>0 \\
0 & \text { em outro caso. }\end{cases}$
\end{tabular}

Por freqüência do termo

$$
a_{i k}=f_{i k}
$$

O peso é igual ao número de vezes que o termo $i$ aparece no documento $k$.

Ponderação tf-idf (term frequency/inverse document frequency - freqüência do termo/ freqüência inversa do documento ). (SALTON; $M C G I L L, 1983)$

$$
a_{i k}=f_{i k} * \log \left(\frac{N}{n_{i}}\right)
$$

O peso é proporcional ao número de ocorrências num documento e inversamente proporcional ao número de documentos onde o termo aparece.

Ponderação tfc (SALTON; BUCKLEY, 1988)

$$
a_{i k}=\frac{f_{i k} * \log \left(\frac{N}{n_{i}}\right)}{\sqrt{\sum_{j=1}^{M}\left[f_{j k} * \log \left(\frac{N}{n_{j}}\right)\right]^{2}}}
$$

Similar ao esquema $t f-i d f$. Leva em conta a diferença de comprimento dos textos (comprimento é normalizado).

Ponderação ltc (BUCKLEY et al., 1994)

$$
a_{i k}=\frac{\log \left(f_{i k}+1\right) * \log \left(\frac{N}{n_{i}}\right)}{\sqrt{\sum_{j=1}^{M}\left[\log \left(f_{j k}+1\right) * \log \left(\frac{N}{n_{j}}\right)\right]^{2}}}
$$

Usa o logaritmo da freqüência do termo para reduzir os efeitos de diferenças grandes entre as freqüências.

Ponderação por entropia (DUMAIS, 1991)

$$
a_{i k}=\log \left(f_{j k}+1\right) *\left(1+\frac{1}{\log N} \sum_{j=1}^{N}\left[\frac{f_{i j}}{n_{i}} \log \left(\frac{f_{i j}}{n_{i}}\right)\right]\right)
$$

Baseado em teoria da informação. A equação $\frac{1}{\log N} \sum_{j=1}^{N}\left[\frac{f_{i j}}{n_{i}} \log \left(\frac{f_{i j}}{n_{i}}\right)\right]$ indica a incerteza média (valor da entropia para) a palavra $i$. Tem valor -1 se o termo é igualmente distribuído sobre todos os documentos e 0 se o termo aparece num único documento.

Tabela 2.1: Formas de ponderação de palavras (AAS; EIKVIL, 1999). 
- Quanto maior é o número de vezes que um termo aparece em um documento, mais relevante ele é para o tópico ao qual o documento se refere;

- Quanto maior é o número de vezes que um termo aparece em documentos diferentes da mesma coleção, menor é o poder deste termo para ser usado como discriminador entre documentos.

Na tabela 2.1 são mostradas seis formas diferentes de ponderação baseados nestes valores. Na tabela, $f_{i k}$ indica a freqüência do termo $i$ no documento $k, N$ o número de documentos da coleção, $\operatorname{com} n_{i}$ sendo o número total de vezes que o termo $i$ ocorre na coleção completa de documentos. Já M é o número de palavras na coleção após a remoção das palavras comuns e a redução das restantes às suas raízes.

Dentre as diversas formas de ponderação, a mais popular é a ponderação $t f$ $i d f$. Na mesma, o peso de uma palavra é proporcional ao número de ocorrências num documento e inversamente proporcional ao número de documentos onde o termo aparece. Segundo Dumais (1991), a melhor técnica é a ponderação por entropia.

\subsubsection{Espaço de atributos}

... la masa de adjetivos

corresponde a un objeto real;

el hecho es puramente fortuito.

J. L. Borges - Tlön, Uqbar, Orbis Tertius

O passo seguinte consiste em resolver o problema da alta dimensionalidade do espaço de atributos. Cada termo corresponde a uma dimensão, o que pode provocar que o número de dimensões atinja centenas de milhares numa coleção de documentos. A maioria dos enfoques para redução de dimensionalidade pode ser classificado em duas categorias (AAS; EIKVIL, 1999): seleção de atributos e re-parametrização.

No primeiro grupo, as técnicas tentam retirar termos não-informativos. Entre elas estão: i) limiar de freqüência de documento; ii) ganho de informação (GI); iii) estatística $\chi^{2}$; iv) informação mútua (IM) e v) força do termo. As três técnicas 
mais eficientes segundo Yang e Pedersen (1997), como citado por Aas e Eikvil (1999), são as seguintes:

- Por limiar de freqüência de documento (document frequency thresholding): A freqüência de documento de um termo é o número de documentos onde ela ocorre. Esta técnica remove os termos cuja freqüência de documento esteja abaixo de algum limiar pré-determinado. A suposição é que palavras raras não influenciam no desempenho global ou não são informativas para predizer categorias;

- Ganho de informação: Mede a quantidade de informação ${ }^{8}$ (em bits) obtida e utiliza tal valor para a predição de categorias sabendo da presença ou ausência de um termo em um documento. O ganho de informação é computado para cada termo do conjunto de treinamento e os termos cujo ganho esteja abaixo de algum limiar pré-determinado são retirados;

- Estatística $\chi^{2}$ : A decisão está baseada no grau de dependência existente entre um termo $t$ e uma classe $c_{j}$ dada pela função $\chi^{2}\left(t, c_{j}\right)$.

Na segunda categoria, denominada re-parametrização, tentam-se construir novos atributos como combinações ou transformações dos atributos originais. Um dos enfoques mais populares é a Indexação por Semântica Latente (ISL) (Latent Semantic Indexing)((DEERWESTER et al., 1990) apud (FALOUTSOS; OARD, 1995)). A idéia básica é que existe alguma estrutura subjacente ou latente no padrão de uso de termos ao longo de vários documentos e que técnicas estatísticas podem ser usadas para estimar esta estrutura. Os vetores de termos podem revelar dependência entre termos. Assim, a coleção passa a ser vista como uma matriz de palavrasXdocumentos onde a similaridade entre termos pode ser computada usando a medida do cosseno. Termos similares são designados a uma composição única (OARD, 2000). A ISL tenta atacar os problemas de sinonímia (formas diferentes de referir-se ao mesmo objeto) e polissemia (termos com mais

\footnotetext{
${ }^{8} \mathrm{~A}$ partir da obra de Claude Shannon e Warren Weaver, Andrei Kolmogorov formulou nos
} anos 60 a teoria da informação algorítmica. Nela, a complexidade de um sistema é definida como a descrição mais curta do mesmo, i.e. o mínimo número de bits de informação necessários, o que equivale ao programa mais curto que efetue a sua computação. A teoria da informação algorítmica procura a mensagem mais curta que codifique tudo o que é possível saber sobre um sistema. Assim, Kolmogorov define aleatoriedade como um sistema que não pode ser comprimido (SCARUFFI, 1998). 
de um significado). Termos que não aparecem em um documento podem estar próximos (no espaço vetorial) ao documento, caso seja consistente com os padrões mais importantes de associação nos dados. A recuperação é efetuada usando os termos numa consulta para identificar um ponto no espaço semântico estabelecido e retornando os documentos na vizinhança deste espaço.

\subsubsection{Métodos de categorização}

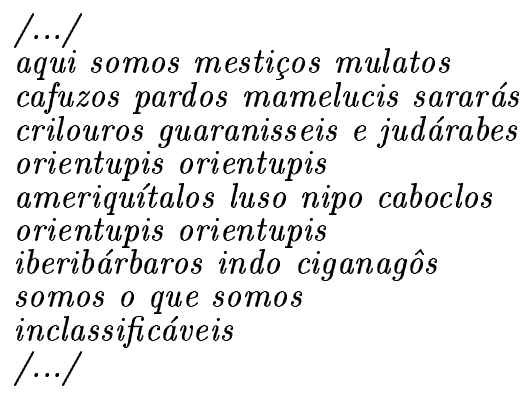

\section{A. Antunes - Inclassificáveis}

Após a fase de redução do espaço de atributos, pode-se partir para categorizar os documentos de uma coleção. O problema da categorização de textos é a tarefa de designar uma ou mais categorias pré-definidas a documentos contendo texto livre. Muitas fontes de dados textuais presentes na Internet (notícias, correio eletrônico) e em bibliotecas digitais são compostas de tópicos diferentes (problema de categorização multi-classe).

Em problemas de classificação multi-classe, é frequente que os documentos sejam relevantes para mais de um tópico. Alguns métodos têm sido desenvolvidos para categorização textual multi-classe, porém o problema de multi-etiquetagem onde um documento pertence a mais de uma classe, tem recebido pouca atenção (AAS; EIKVIL, 1999).

O enfoque comum para a categorização multi-classe, ou de multi-etiquetagem, é decompor a tarefa em problemas de categorização binária ${ }^{9}$ disjuntos, um para cada classe existente. Para classificar um novo documento devem ser aplicados todos os classificadores binários e, posteriormente, devem ser combinadas as suas predições numa única decisão. O resultado final é um ranking de tópicos possíveis.

\footnotetext{
${ }^{9} \mathrm{O}$ documento é simplesmente considerado relevante ou não em relação a um tópico em particular.
} 
O fato de ignorar qualquer correlação entre classes diferentes é a principal desvantagem neste enfoque.

Alguns dos métodos mais usados para categorização são (AAS; EIKVIL, 1999):

- Algoritmo de Rocchio. É o método clássico para filtragem em RI. Um vetor protótipo é construído para cada classe e um vetor de documento é classificado calculando a sua distância a cada um dos vetores protótipo. O vetor protótipo para uma classe é computado como o vetor das médias, considerando todos os vetores documento que pertencem à dada classe. $\mathrm{O}$ aprendizado é, por isso, muito rápido;

- Algoritmo de Bayes ingênuo (naive). É construído usando os dados de treinamento para estimar a probabilidade de cada classe, dados os valores dos atributos em uma nova instância de documento. Para estimar as probabilidades, é usado o teorema de Bayes ${ }^{10}$. A "ingenuidade" de tal modelo está na suposição de independência entre termos, i.e., supõe-se que os atributos são condicionalmente independentes dada a (variável de) classe. Mesmo que esta suposição não seja geralmente verdadeira quanto à aparição de termos em documentos, esse classificador é bastante efetivo;

- $K$ Vizinhança. O algoritmo kNN (k-nearest neighbour) ((DUDA; HART, 1973) apud (AAS; EIKVIL, 1999)) efetiva um ranking dos vizinhos de um documento considerando os vetores de documentos. As classes destes vizinhos são ponderadas usando a similaridade de cada vizinho em relação ao documento sendo considerado. A similaridade pode ser medida usando, por exemplo, a distância euclidiana ou o cosseno entre os dois vetores.

O método kNN é do tipo aprendizado baseado em instâncias, sem uma fase de treinamento off-line. A computação principal é feita nos valores dos documentos de treinamento, utilizando um documento de teste, de forma a achar os $k$ vizinhos mais próximos;

- Árvore de decisão. Neste caso, o vetor do documento é comparado com uma árvore de decisão para determinar se é relevante ou não para o usuário. A

\footnotetext{
${ }^{10} \mathrm{~A}$ regra $P(H \mid e)=\frac{P(e \mid H) \cdot P(H)}{P(e)}$, onde $H$ é uma hipótese e $e$ um evento, passa a ser $P\left(c_{j} \mid d\right)=$ $\frac{P\left(d \mid c_{j}\right) \cdot P\left(c_{j}\right)}{P(d)}$ onde $c_{j}$ é uma classe e $d$ um documento.
} 
árvore é construída a partir de exemplos, sendo uma das técnicas mais populares o algoritmo CART ((BREIMAN et al., 1984) apud (AAS; EIKVIL, 1999)). O CART constrói uma árvore de decisão binária particionando o conjunto de vetores de treinamento através de cada nó, levando em conta uma função que considera um único elemento do vetor. Outro algoritmo para árvore de decisão é o C4.5, de Quinlan (1993) apud (AAS; EIKVIL, 1999);

- Máquinas de Suporte Vetorial (MSV). Este método mostra bom desempenho para generalização. Ele integra as fases de redução de dimensionalidade e classificação. Somente pode-se aplicar a tarefas de classificação binária, ou seja, usando este método a categorização deve ser tratada como uma série de problemas de classificação dicotômicos. O treinamento de uma MSV consiste na determinação de um valor que maximize a distância entre exemplos de treinamento que pertençam a classes diferentes;

- Classificação por votação. Muitos pesquisadores têm investigado a técnica de combinar as predições de múltiplos classificadores para produzir um classificador único. O processo é denominado de votação. Estes algoritmos utilizam como entradas um classificador e um conjunto de treinamento e treinam o classificador diversas vezes usando versões diferentes do conjunto de treinamento. Os classificadores gerados são, então, combinados para criar um classificador final que é usado para classificar o conjunto de teste. Os algoritmos de votação podem ser divididos em dois tipos: de bagging (aniagem) e de boosting. A principal diferença entre os dois tipos está na forma em que as diferentes versões do conjunto de treinamento são criadas. Segundo Breiman (1996), como citado por Aas e Eikvil (1999), o algoritmo de bagging toma como entrada um algoritmo de classificação $f$ e um conjunto de treinamento $T$ e retorna um conjunto $f^{*}$ de classificadores. Cada classificador $f_{r}$ no conjunto $f^{*}$ é aprendido a partir de uma amostra $T_{r}$ do conjunto $T$. A amostra é formada usando seleção aleatória (com distribuição de probabilidades uniformemente distribuída), com $N$ substituições ( $N$ é o tamanho do conjunto de treinamento). Isto cria um conjunto de treinamento com o mesmo número de amostras que o original, porém alguns casos podem ser representados mais de uma vez, enquanto outros podem não estar representados. A freqüência esperada com a qual os casos do 
conjunto $T$ são representados numa amostra $T_{r}$ é descrita pela distribuição de Poisson discreta. Para classificar uma nova amostra (documento), cada um dos classificadores $f_{r}$ é aplicado. O resultado do classificador final é a classe que obtém o maior número de votos.

Segundo Freund e Shapire (1996), como citado por Aas e Eikvil (1999), no caso de boosting, os métodos também escolhem um conjunto de treinamento de tamanho $N$ para o classificador $f_{r}$ selecionando aleatoriamente, com substituições, exemplos do conjunto $T$ original. Porém, a distribuição de probabilidade para a seleção não é uniforme. Ela depende da freqüência com que a amostra foi classificada erroneamente pelos $k-1$ classificadores prévios. Assim, tenta-se produzir novos classificadores que são mais capazes de classificar corretamente exemplos para os quais o desempenho dos classificadores correntes é ruim. Diferentes formas de boosting geram as probabilidades para seleção das amostras de formas diferentes.

Além destas técnicas gerais, existem outras, destinadas a usos mais específicos. Quando os textos a serem categorizados encontram-se na $W e b$, pode ser muito útil processar on-the-fly (de forma quase instantânea) um conjunto de páginas HTML, resultantes de uma requisição a uma máquina de busca de propósito geral, de forma a categorizá-las utilizando apenas um conjunto de termos nelas presentes. Particularmente, um algoritmo que pode ser aplicado a este tipo de tarefa é o denominado DSP (Dominating Set Problem, ou Problema do Conjunto Dominante $^{11}$ ), apresentado no trabalho de Lawrie, Croft e Rosenberg $(2001)^{12}$.

O algoritmo DSP trata o problema de seleção dos termos mais relevantes que permitem criar uma hierarquia de termos a ser utilizada para classificar on-thefly um conjunto de documentos. O algoritmo considera o problema de seleção de termos mais importantes como sendo um problema similar ao de cobertura em grafos. Como o objetivo dos autores foi o de construir hierarquias de termos para sumarização automática, a hierarquia produzida a partir de um conjunto de documentos pode ser vista também como um sumário.

\footnotetext{
${ }^{11}$ Neste caso, o problema consiste em achar um conjunto mínimo de termos que apareça próximo do maior número de palavras diferentes existentes nos documentos. Próximo implica que uma palavra esteja a $x$ palavras de distância (antes ou depois) de outra num texto.

${ }^{12}$ Este algoritmo revelou-se o mais promissor e aquele cujos parâmetros foram apresentados pelos autores com maior clareza, em relação a outros, como o que aparece em (POIBEAU, 2001).
} 
a) Corpo do documento

aa bb cc dd ee ff gg hh ii jj aa bb cc dd ee ff gg hh ii jj

b) Modelo do vocabulário contido no texto( $x=1)$

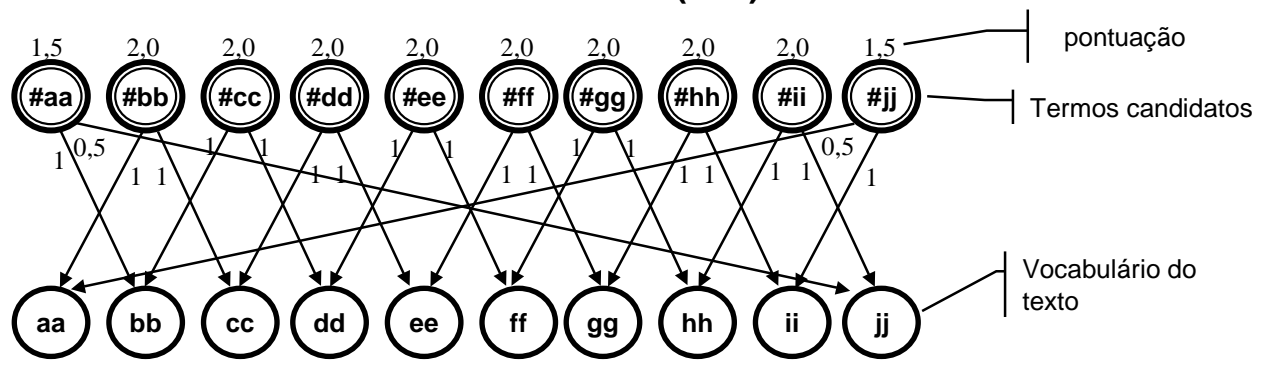

c) Progressão do algoritmo

i) Escolha de \#cc, com pontuação 2,0

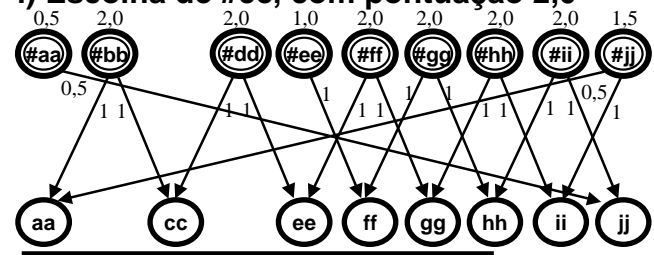

TE(Termos Escolhidos): \#cc

VC(Vocabulário Coberto): bb,dd

iv) Escolha de \#bb, com pontuação 2,0

ii) Escolha de \#ff, com pontuação 2,0
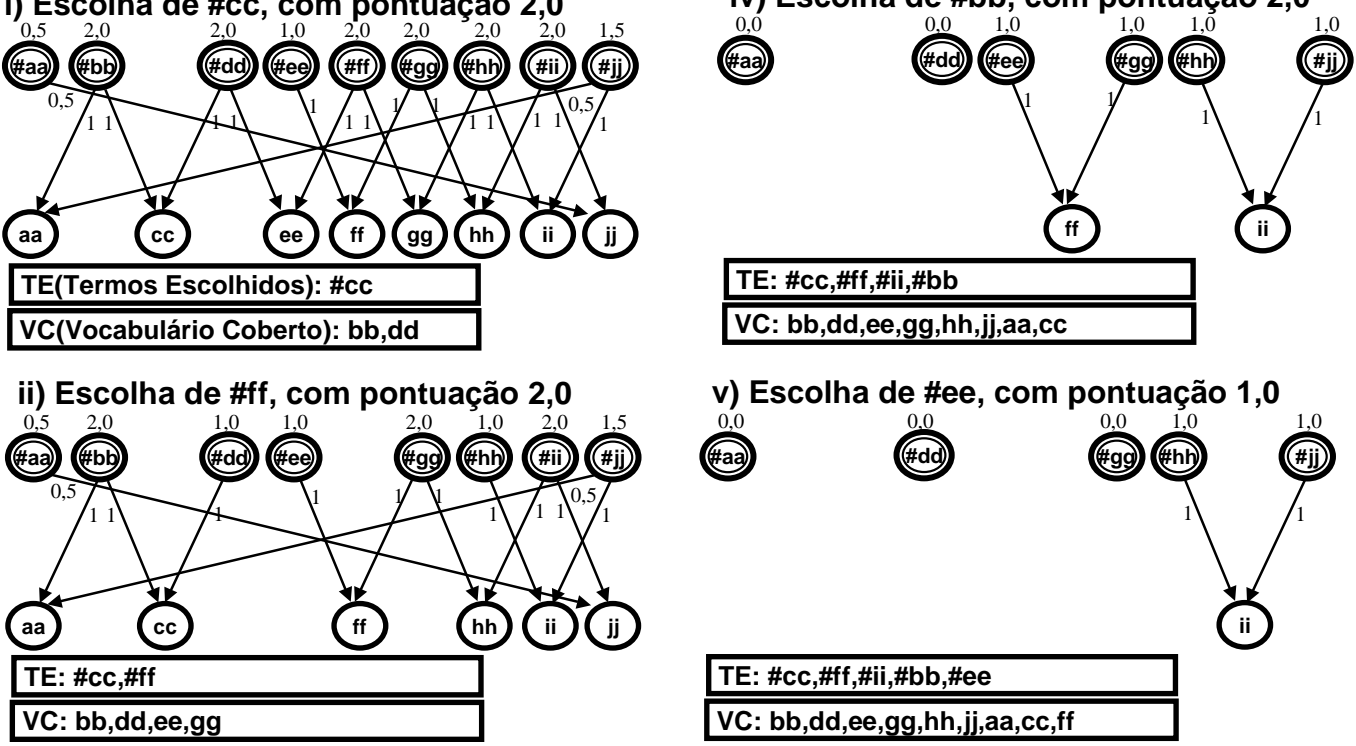

v) Escolha de \#ee, com pontuação 1,0

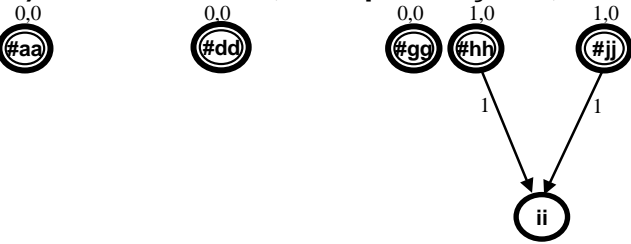

TE: \#cc,\#ff,\#ii,\#bb,\#ee

VC: bb,dd,ee,gg,hh,jj,aa,cc,ff

iii) Escolha de \#ii, com pontuação 2,0

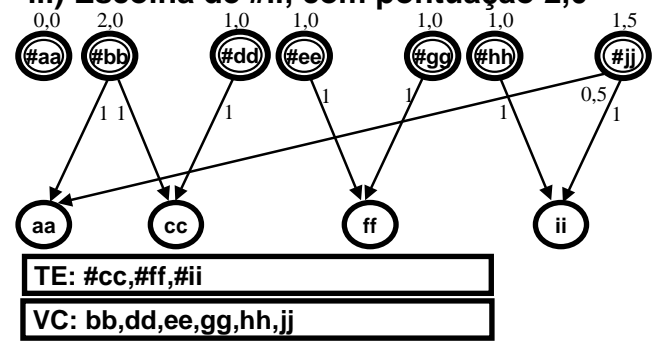

vi) Escolha de \#hh, com pontuação 1,0

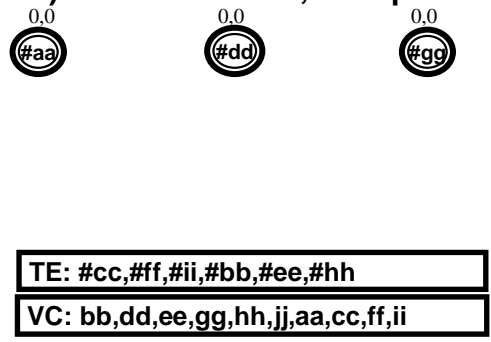

Figura 2.4: Exemplo de execução do algoritmo para a seleção de palavras utilizadas para categorizar um conjunto de documentos on-the-fly. 
O funcionamento do algoritmo é representado didaticamente na figura 2.4. Basicamente, o algoritmo inicia utilizando um conjunto de termos candidatos e o conjunto de termos que aparecem nos documentos (de fato eles contém os mesmos termos). Os termos que aparecem nos documentos são denominados de vocabulário. A partir destes termos, pode ser computado um modelo probabilístico de linguagem. Tal modelo é composto de todas as probabilidades condicionais $\mathbf{P}\left(A \mid \mathrm{B}_{x}\right)$, onde $A$ é o termo candidato e $B$ é um termo do vocabulário. A probabilidade $\mathbf{P}\left(A \mid \mathrm{B}_{x}\right)$ é computada como sendo o número de vezes nas quais o termo $A$ aparece a (no máximo) $x$ palavras de distância de $B$, dividido pelo número de vezes que $B$ aparece. O valor de $x$ indica o tamanho da janela (bilateral) utilizada para calcular a probabilidade. A probabilidade condicional é computada diretamente ao invés de usar a regra de Bayes, pois os termos são, de fato, variáveis dependentes. O peso do arco existente entre um termo candidato e um termo do vocabulário é denominado afinidade. No cálculo para resolver o problema DSP, são utilizados os pesos de vértices e não os dos arcos. Assim, o peso de um vértice é considerado como sendo o somatório do peso dos arcos a ele conectados.

É gerado, assim, um grafo bipartido que é utilizado efetivamente para escolher os termos dentre os termos candidatos. A cada iteração, é escolhido o termo candidato cujo vértice apresenta o maior peso, sendo subtraídos dos outros termos candidatos (vértices) o peso dos arcos (caso existam) que os conectavam a termos do vocabulário que foram cobertos pelo termo candidato que foi escolhido (i.e. estavam conectados a este termo).

Lawrie, Croft e Rosenberg (2001) experimentaram valores de $x$ iguais a 1 , 2 e 5 , obtendo os melhores resultados quando da utilização de uma janela $x$ de valor igual a 1. Ao final da execução do algoritmo, é obtida uma lista de termos. Como a ordem de extração dos termos é relevante (o primeiro termo escolhido é aquele com maior peso etc.), este dado é armazenado. Os autores mostram experimentalmente que, para a execução da tarefa de categorização on-the-fly, os resultados obtidos utilizando esta técnica são superiores àqueles obtidos utilizando as técnicas de subsunção de termos, hierarquias lexicais e aos valores mais altos atrelados à medida $t f / i d f$. 


\title{
2.2.4 Avaliação dos métodos de categorização
}

\author{
O círculo achou esquisita a proposta \\ mas consintiu e foi andando devagar \\ balançando a rotunda cabeça... \\ para a casa que sempre fora do quadrado \\ M. Ernesto - Transmorfações
}

Ao avaliar o desempenho dos classificadores, considere-se o caso de classificação binária múltipla ${ }^{13}$. Segundo Aas e Eikvil (1999) quatro valores são interessantes para cada categoria:

- $a$ : número de documentos corretamente designados para uma categoria;

- $b$ : número de documentos incorretamente designados para uma categoria;

- $c$ : número de documentos incorretamente rejeitados para uma categoria;

- $d$ : número de documentos corretamente rejeitados para uma categoria.

A partir delas são definidas, entre outras, as seguintes medidas de desempenho (AAS; EIKVIL, 1999):

$$
\begin{gathered}
\text { recall }=\frac{a}{a+c} \\
\text { precis } \tilde{a} o=\frac{a}{a+b} \\
\text { fallout }=\frac{b}{b+d} \\
\text { acuidade }=\frac{a+d}{a+b+c+d} \\
\text { erro }=\frac{b+c}{a+b+c+d}
\end{gathered}
$$

\footnotetext{
${ }^{13}$ Considerando a categorização multi-classe como problemas de classificação binária disjuntos.
} 
Ponto de equilíbrio (break even): Se a precisão e o recall são ajustados para ter valores iguais, este valor é chamado de ponto de equilíbrio do sistema.

Medida F (F-measure): Este critério combina precisão e recall ((LEWIS; GALE, 1994) apud (AAS; EIKVIL, 1999)):

$$
F_{\beta}=\frac{\left(\beta^{2}+1\right) * \text { precisão } * \text { recall }}{\beta^{2} * \text { precisão }+ \text { recall }}
$$

onde $\beta$ é um parâmetro que permite ponderações diferentes de precisão e recall.

Já no caso de avaliação de desempenho de classificadores que produzam um ranking de categorias para cada documento, com um escore de confiança para cada categoria candidata, é indicado o enfoque chamado "precisão média interpolada de 11 pontos" ((YANG, 1997) apud (AAS; EIKVIL, 1999)). Nele o valor de recall para cada documento específico é dado por:

$$
\text { recall }=\frac{\text { Número de categorias corretas encontradas }}{\text { Total de categorias verdadeiras }}
$$

Para cada um dentre 11 valores $0.0, \ldots, 1.0$ desta fração, o sistema decide quanto tem que se descer na lista do ranking (i.e., o tamanho do numerador) para atingir o valor de recall especificado. Depois, a precisão é computada para este número de categorias segundo:

$$
\text { precis ão }=\frac{\text { Número de categorias corretas encontradas }}{\text { Total de categorias encontradas }}
$$

É computada então a média dos 11 valores de precisão resultantes para obter um só valor de desempenho para o documento.

As tabelas 2.2 e 2.3 mostram uma comparação de métodos de categorização segundo (AAS; EIKVIL, 1999). Esses métodos trabalharam sobre a coleção de teste Reuters-21578 ${ }^{14}$. Detalhes complementares sobre estes métodos são comentados em (SEBASTIANI, 2002), onde a discussão é essencialmente a mesma, sendo mais aprofundada em alguns aspectos algorítmicos.

\footnotetext{
${ }^{14}$ www.research.com/ lewis/reuters $21578 . h t m l$. Esta coleção foi levantada a partir de noticias da Reuters de 1987.
} 


\begin{tabular}{|c|c|c|c|c|c|c|c|}
\hline Autor & Treino & Teste & Tópicos & Indexaç. & Redução & Classif. & Medida \\
\hline $\begin{array}{l}\text { (DUMAIS } \\
\text { et al. } \\
1998)\end{array}$ & 9603 & 3299 & 118 & bool. & IM & binária & $\mathrm{PE}$ \\
\hline $\begin{array}{l}\text { (JOACHIMS, } \\
1997)\end{array}$ & 9603 & 3299 & 90 & $\mathrm{tfc}$ & GI & binária & $\mathrm{PE}$ \\
\hline $\begin{array}{l}\text { (SHAPIRE; } \\
\text { SIN- } \\
\text { GER, } \\
1998)\end{array}$ & 9603 & 3299 & $?$ & tf-idf & Nenhum & $\begin{array}{l}\text { multi- } \\
\text { classe }\end{array}$ & $\mathrm{P}$ \\
\hline $\begin{array}{l}\text { (WEISS; } \\
A P T E ; \\
D A M E- \\
\text { RAU, } \\
1999 \text { ) }\end{array}$ & 9603 & 3299 & 95 & freq. & $?$ & binária & $\mathrm{PE}$ \\
\hline $\begin{array}{l}\text { (YANG, } \\
1997)\end{array}$ & 7789 & 3309 & 93 & ltc & $\chi^{2}$ & binária & $\mathrm{PE}$ \\
\hline
\end{tabular}

Tabela 2.2: Comparação entre métodos de categorização de texto (AAS; EIKVIL, 1999). IM: Informação Mútua; GI: Ganho de Informação; PE: Ponto de equilíbrio; P:Precisão.

\begin{tabular}{|c|c|c|c|c|c|c|}
\hline Autor & Rocchio & Bayes & $k-N N$ & Árvore & $M S V$ & Votação \\
\hline $\begin{array}{l}\text { (DUMAIS } \\
\text { et al., } \\
1998 \text { ) }\end{array}$ & 61.7 & 75.2 & - & - & 87.0 & - \\
\hline $\begin{array}{l}\text { (JOACHIMS, } \\
\text { 1997) }\end{array}$ & 79.9 & 72.0 & 82.3 & 79.4 & 86.0 & - \\
\hline $\begin{array}{l}\text { (SHAPIRE; } \\
\text { SINGER, } \\
\text { 1998) }\end{array}$ & $\mathrm{x}$ & $\mathrm{x}$ & - & - & - & $\mathrm{x}$ \\
\hline $\begin{array}{l}\text { (WEISS; } \\
A P T E ; \\
D A M E- \\
R A U, \\
1999)\end{array}$ & 78.7 & 73.4 & 86.3 & 78.9 & 86.3 & 87.8 \\
\hline $\begin{array}{l}\text { (YANG, } \\
1997)\end{array}$ & 75.0 & 71.0 & 85.0 & 79.0 & - & - \\
\hline
\end{tabular}

Tabela 2.3: Desempenho de métodos de categorização de texto (AAS; EIKVIL, 1999). Os dados da tabela são os valores dos pontos de equilíbrio. "-" denota método não testado; "x" implica método testado, porém, o critério de avaliação não sendo o do ponto de equilíbrio. 


\subsection{Comentários}

As técnicas clássicas de recuperação de informação, apresentadas neste capítulo, são utilizadas em dois momentos por agentes que seguem o modelo de agente proposto, como citado na seção 1.4: i) inicialmente são aplicadas no processamento e indexação dos recursos de informação disponibilizados pelo usuário, na forma de documentos e mensagens de correio eletrônico; ii) o agente recorre a elas para identificar os documentos relevantes para uma requisição.

Adicionalmente, estas técnicas são aplicadas à extração de termos relacionados a um conceito, a partir de conjuntos de documentos HTML considerados como exemplos positivos para o conceito. Dentre estes termos, devem ser escolhidos os mais representativos, o que implica na redução de dimensionalidade. $\mathrm{O}$ algoritmo selecionado para ser implementado foi o algoritmo $D S P$, detalhado na seção 2.2.3. Esta escolha está fundamentada em três fatos: i) ele fornece uma forma de sumarização automática; ii) o cenário para o qual o algoritmo foi projetado foi inspirado na $W e b$; iii) o seu desempenho experimental, segundo a literatura, é satisfatório.

O modelo de agente proposto, embora incorpore técnicas de RI, é destinado a um ambiente comunitário. Nesse contexto, outras habilidades, relacionadas aos conceitos de agência, ontologias e redes sociais, são de fundamental importância. Tais conceitos serão abordados no capítulo seguinte. 


\title{
3 Acesso à informação: novos caminhos
}

\author{
Eles ergueram a Torre de Babel, \\ para escalar o Céu, \\ Mas Deus não estava lá! \\ Estava ali mesmo, entre eles, \\ Ajudando a construir a torre
}

M. Quintana - Nova Antologia Poética

A popularização do uso da Internet nos anos 80 levou ao incremento na freqüência e no tipo de comunicações mediadas computacionalmente. Exemplos típicos de troca de informações nesta época eram simples mensagens de correio eletrônico (e-mail) e troca de documentos usando protocolos específicos como o File Transfer Protocol (FTP) e o Trivial File Transfer Protocol (TFTP). Com estas ferramentas, comunidades de usuários apareceram e se desenvolveram como verdadeiros foros de opinião e cooperação.

Num segundo momento, no início dos anos 90, uma novidade trouxe grandes mudanças, quando as idéias de Tim Berners-Lee ${ }^{1}$ foram concretizadas através do protocolo HTTP e do formato HTML (BERNERS-LEE, 1989). A troca de informação comunitária atingiu uma nova dimensão.

Porém, a repentina abundância veio acompanhada de um problema: Como filtrar o enorme volume de documentos disponibilizados? Neste contexto, perdeuse a noção de comunidade (existente no interior do $\mathrm{CERN}^{2}$ ) da qual BernersLee tinha retirado a sua inspiração. E com ela também a noção de contexto

\footnotetext{
${ }^{1} E$ E digno de nota que Berners-Lee não tinha no domínio da computação o foco dos seus trabalhos. Longe de ser demérito, isto mostra a importância de ter visões mais abrangentes, transdisciplinares e com uma certa aderência com o real, em qualquer domínio do conhecimento que queira ampliar os seus horizontes.

${ }^{2}$ European Organization for Nuclear Research, à qual Berners-Lee estava filiado na época da sua proposta original.
} 
temático inerente a uma comunidade. A nova situação era a de um sistema aberto, onde cada usuário tinha suas próprias preferências e necessidades e muito poucas indicações para achar o que procurava.

Neste vácuo, nasceram as grandes máquinas de busca centralizadas, exemplos de uma aplicação direta das técnicas de RI. Embora as máquinas de busca de propósito geral apresentem bons resultados, elas trabalham mormente na superfície (páginas HTML, grupos de notícias etc.) desse oceano de informação. O resultado obtido com as máquinas de busca deve ser analisado e filtrado de forma a corresponder a um certo contexto que depende fortemente das necessidades particulares de cada usuário. Aparecem então as primeiras tentativas de elaboração de sistemas que forneçam informação personalizada. O eixo central nesses casos tem sido o uso de técnicas clássicas de RI associadas ao paradigma de agentes computacionais (NEWELL, 1982; SEARLE, 1983; CASTELFRANCHI, 1998).

Porém, mesmo com avanços na personalização, o problema do contexto continua existindo. O usuário, embora interconectado a outros usuários, ainda não tem acesso ao conhecimento de vizinhos (virtuais, emocionais e/ou físicos) que poderiam fornecer informações que poupariam tempo e esforços. Isto desemboca, a partir do final dos anos 90, no aparecimento dos sistemas P2P de troca de arquivos, aplicados à partilha de músicas (popularmente no formato MP3). Os exemplos mais conhecidos destes sistemas são o Napster e Gnutella (SAROIU; GUMMADI; GRIBBLE, 2002) e, mais recentemente, Freenet (CLARKE et al., 2001), sendo este último dedicado à partilha de arquivos. Embora não possuam contexto organizacional nem memória temática, o seu sucesso é tamanho que vários trabalhos estão dedicados a levantar as redes por eles formadas e a explorar algoritmos e protocolos de localização e configuração de recursos (SCHLOSSER; CONDIE; KAMVAR, 2003).

Ao mesmo tempo, Berners-Lee lidera um grupo da World Wide Web Consortium (W3C $)^{3}$ que focaliza o problema de contexto e advoga o uso de anotações nas páginas disponíveis na rede, de forma a nelas inserir meta-informações. A proposta utiliza a linguagem Extensible Markup Language (XML) ${ }^{4}$ para aprimorar

\footnotetext{
${ }^{3} \mathrm{http}: / /$ www.w3.org.

${ }^{4} \mathrm{XML}$ permite inventar tags que podem conter dados ou outras tags. A linguagem diferencia entre tipos de elementos e elementos, de forma análoga à diferenciação entre propriedades
} 
um arcabouço baseado na linguagem Resource Description Framework (RDF) ${ }^{5}$, que é o coração da chamada Web Semântica (BRAY, 2001).

Dois exemplos de descrições em RDF são:

〈rdf:Description about='http://www.textuality.com/RDF/Why-RDF.html'> $<$ Author>Tim Bray</Author>

$<$ Home-Page rdf:resource='http://www.textuality.com' />

$</$ rdf : Description $>$

<Camera rdf:ID= 'Canon-Sure-Shot-Z155' '>

$<$ cost $>318$ USD $</$ cost $>$

$</$ Camera $>$

A segunda descrição indica que a Canon Sure Shot Z155 é uma instância (ou recurso) da classe Camera. A classe Camera possui uma propriedade denominada cost (custo). Particularmente, a instância descrita possui como valor desta propriedade 318 dólares. Assim, representa-se que a Canon Sure Shot Z155 é uma Camera e custa 318 dólares (COSTELLO, 2003).

Algumas especificações particulares para a $W e b$ Semântica tentam levar em conta aspectos relativos a comunidades, como no caso do Friend of a Friend Finder (FOAF) (BRICKLEY; MILLER; LISTMEMBERS, 2003), que tenta anotar como meta-dados, por exemplo, os conhecidos de uma pessoa, telefones, tópico de um documento, apelidos etc.

A Web Semântica pode ser vista como uma estrutura em camadas sobrepostas, mostrada na figura 3.1. Dentre elas, a mais recente definição em relação a uma camada foi a adoção em fevereiro de 2004 da linguagem Ontology Web Language (OWL) pelo W3C, recomendando-a para expressar ontologias. $\mathrm{OWL}^{6}$

e instâncias (statements). Embora seja ótima como padrão básico de intercâmbio, a ordem em que os elementos aparecem é relevante e a manipulação das estruturas de dados que podem ser geradas é difícil. Tais fatos a tornam inviável, quando usada isoladamente, como padrão para intercâmbio de meta-dados (BRAY, 2001).

${ }^{5} \mathrm{RDF}$ propriamente é um arcabouço para descrição e intercâmbio de meta-dados. Está baseado em recursos (algo que possua uma Universal Resource Indentifier (URI), i.e. um nome único, como uma página HTML), propriedades (um recurso que tem um nome e possa ser usado como propriedade, por exemplo "autor") e instâncias (combinação de um recurso, uma propriedade e um valor, conhecidos como "sujeito", "predicado"e "objeto" de uma instância) (BRAY, 2001).

${ }^{6}$ OWL deriva da linguagem DAML+OIL e esta por sua vez deriva de DARPA Agent Markup Language (DAML) e Ontology Inference Layer (OIL). Todas elas estão baseadas no uso de 
fornece uma sintaxe XML para expressar afirmações sobre propriedades e classes (COSTELLO; JACOBS, 2003).

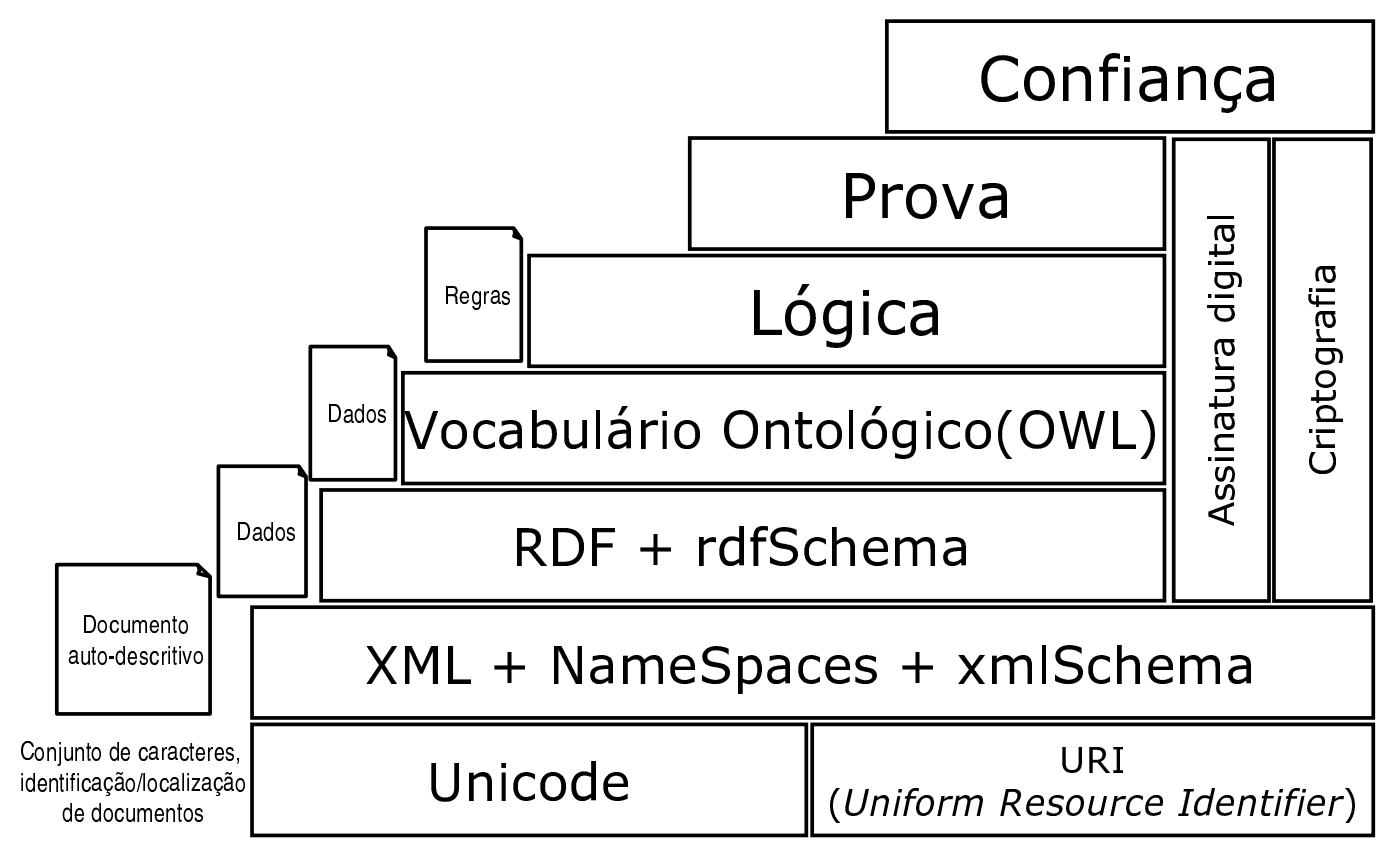

Figura 3.1: A Web Semântica vista em camadas. Adaptado de Koivunen (2001), Berners-Lee (2002) e Costello e Jacobs (2003).

Embora a $W e b$ Semântica possa ser muito útil, críticas têm sido levantadas quanto às possíveis formas de interpretação do sentido social de um conteúdo qualquer. $^{7}$ (CLARK, 2003).

Após esta breve descrição de um cenário em mudança constante, as seções seguintes esboçam com maiores detalhes os tópicos, dentre os apresentados, pertinentes ao enfoque a ser proposto neste trabalho: agentes, redes comunitárias, organizações e ontologias.

O primeiro conceito a ser abordado é o de agentes, pois os esforços de representação e contextualização como os citados estão destinados a explicitar conhecimentos de uma forma que seja manipulável por agentes computacionais inteligentes.

$\overline{\mathrm{RDF}}$ (atrelado ao Resource Description Framework Schema (RDFS)). De fato, é aproveitada a extensibilidade de RDFS para definir construções e restrições que implementem características de frames e de lógica de descrições (FREITAS, 2003).

${ }^{7} \mathrm{O}$ fato de ser explicitado na Especificação de Conceitos e Sintaxe Abstrata de RDF que: "um grafo RDF ... possui dois tipos de sentido: um formal e outro social", tem sido o eixo central das discussões e questionamentos. Este problema obviamente é espalhado para outras camadas. 


\title{
3.1 Agentes de informação
}

\author{
Minha vida é uma colcha de retalhos, \\ todos da mesma cor ... \\ M. Quintana - Nova Antologia Poética
}

$\mathrm{Na}$ década de 90 , a popularização do uso da Internet e a maior visibilidade do paradigma de agentes levou as aplicações dedicadas a manipular documentos a utilizar um novo tipo de enfoque. Foram acrescidas às técnicas clássicas funcionalidades decorrentes de requisitos ligados a visões de agência, surgindo os chamados agentes de informação.

A despeito de sua difusão, o termo agente não possui uma definição clara e consensual. De todo modo, o conceito pode ser visto como uma abstração útil, usada em Ciência da Computação para referenciar artefatos que possuem algumas características em comum. Agentes são usualmente processos que estão em execução de forma contínua, que sabem o que fazer e quando fazê-lo. Agentes comunicam-se com outros agentes, fazendo requisições e executando as tarefas requisitadas. De acordo com Jennings e Wooldrigde (1998), um agente possui uma longa lista de propriedades, dentre as quais podem ser destacadas as seguintes:

- Autonomia: operam sem intervenção humana direta e possuem controle sobre as suas ações;

- Habilidade social: comunicam-se através de uma linguagem comum com outros agentes e inclusive com seres humanos;

- Reatividade: percebem o seu ambiente e reagem a mudanças;

- Pró-atividade: são capazes de exibir comportamento dirigido a um objetivo, tomando a iniciativa de atingí-lo.

Uma distinção importante é feita por Crow (2000), referente à diferenciação entre atribuição e descrição de agência. Tal autora estabelece que agentes devem apresentar "funções cognitivas", no sentido preconizado por Minsky (1986) e por Minsky e Riecken (1994), para serem vistos pelos usuários como manifestando intencionalidade, ou então até apresentar-se a eles como personagens credíveis, 
como no trabalho de Hayes-Roth, Brownston e Gent (1995). A possessão de tais qualidades, entretanto, é uma questão de atribuição. Neste sentido a distinção entre os modelos usados pelos "usuários" e pelos "projetistas" é relevante (CROW, 2000).

A noção de intencionalidade, segundo Dennett (1987), como citado em (CROW, 2000), é dada pela seguinte definição (o grifado não é do original):

"INTENTIONALITY is the possession of the attribute of aboutness - to show intentionality, entities must have things in them that are about other things in the sense that there is information about these other things not just present but usable by the entity in its modulation of behaviour."

$\mathrm{ou}$

“ INTENCIONALIDADE consiste em possuir o atributo de aboutness $^{8}$ (poder-ter-algo-em-relação-a) - para apresentar intencionalidade, entidades devem possuir algo que diga respeito a outra(s) coisa(s). O sentido é o de expressar que informações sobre essa(s) outra(s) coisa(s) não apenas existem mas que são utilizáveis pela entidade para ajustar o seu comportamento."

Dada esta definição, o enfoque atributivo de agência focaliza o modelo que o usuário referencia e o enfoque descritivo remete ao modelo usado pelo projetista. Como citado por Crow (2000), Wiederhold (1992) sustenta que um motivo forte para encorajar a atribuição de agência a um sistema por parte do usuário é que os programas podem servir de mediadores ${ }^{9}$ entre pessoas e recursos de informação.

A construção da organização coletiva nesta abordagem, denominada SMA, é feita a partir de agentes. As pesquisas em SMA têm as suas origens em trabalhos

\footnotetext{
${ }^{8}$ Isto poderia ser interpretado como uma forma de capacidade para vir-a-manifestar alteridade, i.e. uma pré-condição para poder relacionar-se com o outro como sujeito (LÉVINAS, 1997).

${ }^{9} \mathrm{~A}$ noção de mediador proposta por Wiederhold é fortemente orientada à interação com bancos de dados. Ao considerar a noção de agência, o conceito de mediação atinge um novo patamar.
} 
diversos na área de Inteligência Artificial Distribuída (IAD) (BOND; GASSER, 1988).

Para além de aspectos como coordenação e comunicação, já pré-existentes na IAD, uma característica cada vez mais relevante é a capacidade de representação e raciocínio social (SICHMAN et al., 1994; SICHMAN, 1998; CASTELFRANCHI, 1998; SICHMAN, 2001). De fato, ao mesmo tempo em que agentes devem interagir com outros agentes e inclusive com seres humanos, tomar decisões e executar ações em representação dos usuários (MAES, 1994), eles devem fazê-lo a partir da sua própria representação parcial do ambiente (e.g. os usuários) e dos outros agentes sem assumir que estes últimos sejam benevolentes e sem poder recorrer a um sistema de controle centralizado ou a uma representação global desse ambiente.

Devido à enorme quantidade de informação disponível, na Internet e em outros repositórios, e ao escasso tempo de que o usuário em geral dispõe para achar informação relevante, um tipo de agente que tem sido alvo de intensas pesquisas é o chamado Agente de Informação Inteligente (KLUSCH, 2001; LEVY; WELD, 2000; KOBAYASHI; TAKEDA, 2000; MLADENIC, 1999; FININ; NICHOLAS; MAYFIELD, 1998).

Agentes de informação são definidos por Klusch (2001) como sendo entidades computacionais de software que:

- Podem acessar uma ou múltiplas fontes de informação, distribuídas e heterogêneas;

- Adquirem, mediam e mantêm pró-ativamente informação relevante em representação do usuário ou de outros agentes, preferivelmente numa forma just-in-time.

De uma forma geral podem ser:

- Cooperativos: quando os agentes colaboram na execução de tarefas;

- Não-cooperativos: se os agentes não colaboram para executar tarefas.

Ambos os tipos de agentes mencionados, por sua vez, podem ser:

- Racionais: se o agente pode decidir racionalmente quando e como executar tarefas, comprar e negociar para aumentar o seu benefício; 
- Adaptativos: quando o agente é capaz de adaptação a um meio dinâmico (usuário, rede, informação);

- Móveis: se o agente pode transportar-se de forma autônoma pela Internet para executar tarefas em servidores diferentes.

Agentes deste tipo, ao ajudar o usuário a filtrar informações, fazem uso de técnicas diversas. As habilidades e tecnologias básicas relacionadas com agentes de informação aparecem na figura 3.2. Como pode-se perceber, as habilidades relacionadas às tarefas refletem as noções apresentadas no capítulo 2 , já as outras capacidades refletem aspectos cognitivos e sociais mais propriamente ligados ao paradigma de agentes.

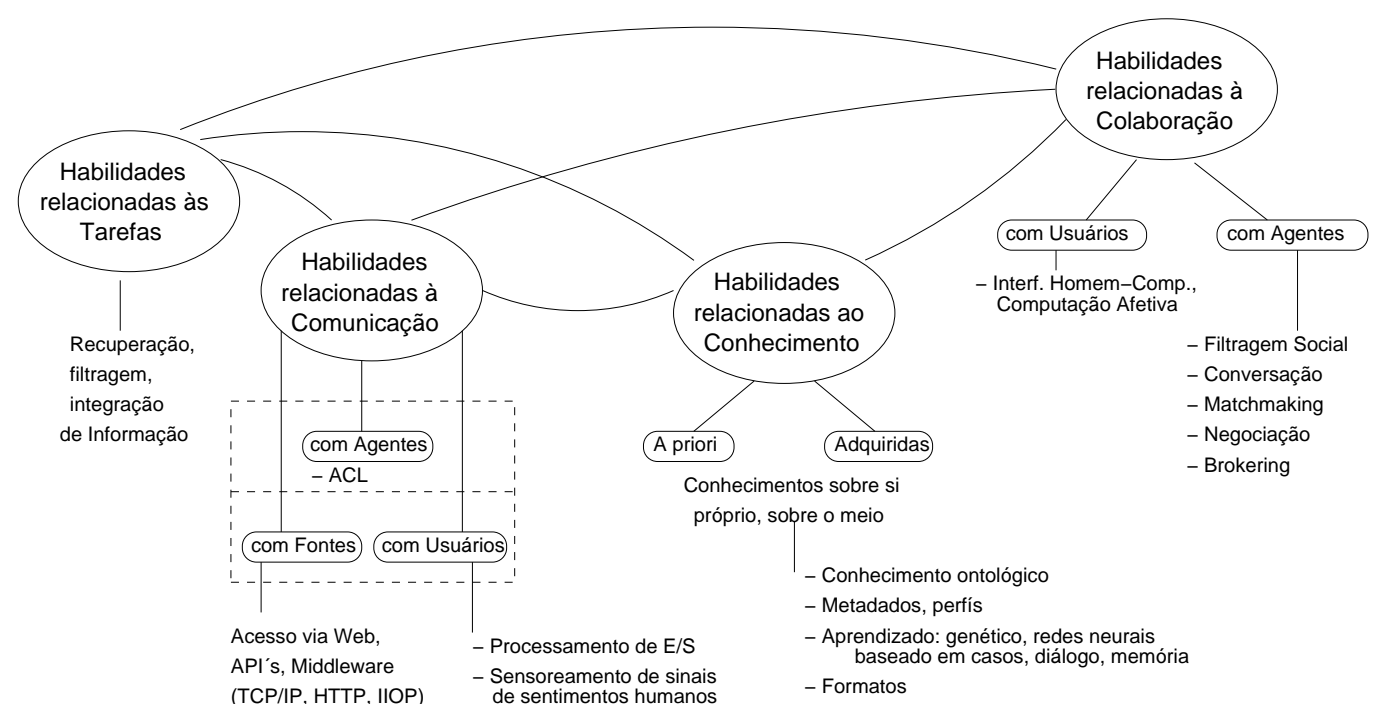

Figura 3.2: Habilidades básicas e tecnologias relacionadas aos agentes de informação segundo Klusch (2001).

As habilidades referenciadas por Klusch podem ser combinadas de formas diversas. A intersecção de RI com Aprendizado de Máquina (AM), denominada aprendizado de texto, tem fornecido soluções inovadoras. Mladenic (1999) focaliza sistemas que empregam agentes de informação que usam técnicas de AM ou Mineração de Dados (MD) para fornecer assistência ao usuário na busca de informação na Internet ou representando-o em tarefas mais simples. Dois tipos de métodos usados com freqüência no desenvolvimento de SMA aplicados à recuperação de informação baseados em AM são os seguintes (MLADENIC, 1999), (FININ; NICHOLAS; MAYFIELD, 1998): 
- Enfoques Baseados em Conteúdo: quando os agentes procuram itens similares àqueles preferidos pelo usuário baseados na comparação do conteúdo. As suas raízes estão na RI, sendo populares quando o alvo do sistema desenvolvido está constituído por dados textuais como documentos HTML ou news (boletins de novidades). Podem ser aplicados com sucesso a usuários isolados;

- Enfoques Colaborativos: também chamados de aprendizado social (MAES, 1994), partem da suposição de que existe um conjunto de usuários usando o sistema. Recomendações ao usuário são baseadas na reação de outros usuários. Ao invés de computar similaridade entre itens o sistema computa a similaridade entre os usuários, recomendando os itens que usuários similares acharam interessantes. Como não há análise do conteúdo de cada item, podem ser manipulados itens com qualquer conteúdo.

Ambos os enfoques apresentam deficiências. O enfoque baseado em conteúdo, além de ter dificuldades em capturar formatos diversos do conteúdo (música, imagens), tende a recomendar apenas itens similares aos já vistos. No enfoque colaborativo ou social, um número reduzido de usuários em relação ao número de itens, usualmente, provoca uma cobertura esparsa das preferências. Além disso, os usuários similares somente passam a ser considerados dessa forma quando emitiram juízos em relação a um número suficiente de itens similares. Já para usuários com preferências não usuais, o sistema apresentará um desempenho ruim, pois os dados a serem comparados serão escassos.

A tabela 3.1 mostra alguns sistemas baseados no enfoque colaborativo ou numa mistura de ambos. As recomendações feitas referem-se a pessoas (ReferralWeb), produtos (Firefly) ou leituras (Phoaks, Fab).

O desempenho destes tipos de sistemas reside crucialmente na modelagem que fazem dos seus usuários. Muito embora a pesquisa dedicada à modelagem para interação de agentes de sofware com o usuário tenha avançado visivelmente nos últimos anos (RODHES; MAES, 2000; MAGLIO et al., 2000), os dados por eles adquiridos não são ainda compartilhados e sim dedicados a um único usuário. A prova da importância de contar com dados sobre comunidades de agentes é que a pesquisa aplicando AM a redes de usuários para obter recomendações vai melhorando os seus resultados, e.g., no aprendizado de filtros colaborativos (BILLSUS; 
SISTEMAS COLABORATIVOS

\begin{tabular}{|c|c|c|}
\hline & Objetivo & Descrição \\
\hline Ringo & $\begin{array}{l}\text { Procura de } \\
\text { músicas }\end{array}$ & $\begin{array}{l}\text { Recomendação de músicas preferidas } \\
\text { por usuários com preferências } \\
\text { semelhantes. Cobertura esparsa é } \\
\text { enfocada construindo modelos de } \\
\text { usuários interessados em tipos } \\
\text { específicos de música (MAES, 1994). }\end{array}$ \\
\hline Firefly & $\begin{array}{l}\text { Procura de } \\
\text { músicas, } \\
\text { filmes e } \\
\text { livros }\end{array}$ & $\begin{array}{l}\text { Usuários iniciam dando nota a itens } \\
\text { pré-determinados de forma a ter perfil } \\
\text { inicial (MAES, 1994). }\end{array}$ \\
\hline GroupLense & $\begin{array}{l}\text { Filtragem de } \\
\text { mensagens } \\
\text { Usenet }\end{array}$ & $\begin{array}{l}\text { Notas dadas por usuários a mensagens } \\
\text { e correlações entre pares de usuários } \\
\text { baseadas nas notas. A escassez de } \\
\text { notas, devido ao grande número de } \\
\text { mensagens, é tratada particionando as } \\
\text { mensagens em grupos contendo aquelas } \\
\text { que são lidas geralmente juntas } \\
\text { (KONSTAN et al., 1997). }\end{array}$ \\
\hline Phoaks & $\begin{array}{l}\text { Percorrer a } \\
\text { web }\end{array}$ & $\begin{array}{l}\text { Redistribuição de recomendações } \\
\text { recolhidas de mensagens Usenet. A } \\
\text { busca é orientada por tópicos } \\
\text { (TERVEEN et al., 1997). }\end{array}$ \\
\hline Referral Web & $\begin{array}{l}\text { Procura de } \\
\text { especialistas }\end{array}$ & $\begin{array}{l}\text { Recontrução incremental das redes } \\
\text { sociais presentes na Internet usando } \\
\text { co-ocorrência de nomes em documentos } \\
\text { web (KAUTZ; SELMAN; SHAH, 1997). }\end{array}$ \\
\hline Siteseer & $\begin{array}{l}\text { Percorrer a } \\
\text { web }\end{array}$ & $\begin{array}{l}\text { Usuários agrupados por similaridade de } \\
\text { endereços favoritos (bookmarks). São } \\
\text { recomendadas páginas web priorizando } \\
\text { as que foram obtidas de pastas } \\
\text { similares ou que aparecem como } \\
\text { favoritas de usuários similares. } \\
\text { (RUCKER; POLANCO, 1997). }\end{array}$ \\
\hline \multicolumn{3}{|c|}{ SISTEMAS MISTOS - Baseados em conteúdo e colaboração } \\
\hline & Objetivo & Descrição \\
\hline$F a b$ & $\begin{array}{l}\text { Percorrer a } \\
\text { web }\end{array}$ & $\begin{array}{l}\text { Perfís dos interesses de cada usuário são } \\
\text { baseados em conteúdo. É usada a } \\
\text { colaboração para identificar usuários } \\
\text { similares, sendo recomendadas páginas } \\
\text { semelhantes ao perfil de um usuário } \\
\text { além daquelas preferidas por usuários } \\
\text { similares. Os agentes encarregados da } \\
\text { coleta dos itens recomendados evoluem } \\
\text { usando algoritmos genéticos, } \\
\text { especializando-se em tópicos } \\
\text { (BALABANOVÍC; SHOHAM, 1997). }\end{array}$ \\
\hline Lifestyle Finder & $\begin{array}{l}\text { Percorrer a } \\
\text { web }\end{array}$ & $\begin{array}{l}\text { As características de um perfil de } \\
\text { usuário são extraídas através de um } \\
\text { questionário, agrupando-se os usuários } \\
\text { similares em função de dados } \\
\text { demográficos (KRULWICH, 1997). }\end{array}$ \\
\hline WebCobra & $\begin{array}{l}\text { Percorrer a } \\
\text { web }\end{array}$ & $\begin{array}{l}\text { Gera perfil de cada usuário a partir de } \\
\text { documentos relevantes usando um } \\
\text { etiquetador (tagger). Usuários } \\
\text { distribuídos por semelhança de perfís } \\
\text { em agrupamentos colaborativos(VEL; } \\
\text { NESBITT, 1998). }\end{array}$ \\
\hline
\end{tabular}

Tabela 3.1: Exemplos de sistemas colaborativos e mistos, baseados em conteúdo e colaboração. Adaptado de (MLADENIC, 1999) . 
PAZZANI, 1998); no tratamento da recomendação como um problema de classificação (BASU; HIRSH; COHEN, 1998) e no tratamento de recomendações para grupos (QUEIROZ et al., 2002). A cooperação em um SMA dedicado a RI poderia ser melhorada sensivelmente partilhando estes dados, mas para isso é necessário um modelo adequado de partilha de conhecimento dos usuários.

\title{
3.2 Redes comunitárias
}

\author{
Os compradores das ceramistas de Ocumicho querem que \\ elas assinem os seus trabalhos. Elas usam sinete para \\ gravar o nome ao pé de seus diabinhos. Mas muitas vezes \\ esquecem de assinar, ou aplicam o sinete da vizinha... \\ Elas não entendem esse assunto de glória solitária. \\ Dentro de sua comunidade de índios tarascos, uma é todas. \\ Fora da comunidade, uma é nenhuma, como acontece ao dente \\ que se solta da boca. \\ E. Galeano - Mulheres
}

A existência e funcionamento de redes sociais, mediadas computacionalmente, tem como exemplo proeminente a denominada The Well ${ }^{10}$, criada em 1986 em Sausalito, CA, USA. A intensidade e a riqueza das trocas propiciadas por ela têm inspirado pesquisas e, principalmente, parecem sustentar de forma viva a hipótese de que a cooperação, entre membros de uma comunidade aberta $^{11}$, formada por membros responsáveis e dispostos a participar efetivamente deste tipo de interação, traz enormes benefícios. Outro exemplo é o projeto GNU ${ }^{12}$, no qual diversos grupos estão dedicados à elaboração de plataformas e aplicações computacionais distribuídas livremente e que têm gerado um profundo impacto na concepção do software como ferramenta de inclusão social.

Quando uma pessoa requer o conselho de um especialista confiável, ela não aceita, de maneira geral, opiniões de desconhecidos. Ela requer que o especialista seja reputado como tal por uma série de amigos e colegas, eles próprios confiáveis. Isto é denominado cadeia de referências (KAUTZ; SELMAN, 1998; KAUTZ; SELMAN; SHAH, 1997). Segundo Travers e Milgram (1969), Wasserman e Galaskiewicz (1994) apud (KAUTZ; SELMAN, 1998), o conjunto de todas as

\footnotetext{
${ }^{10} \mathrm{http} / / /$ www.well.com.

${ }^{11}$ No sentido de entrada e saída constante de participantes.

${ }^{12}$ http://www.gnu.org.
} 
possíveis cadeias de referência numa comunidade passa a ser denominado rede social.

A deteç̧ão destas redes na Internet remonta ao trabalho seminal de Schwartz e Wood (1993), com a aplicação de análise de grafos ao tráfego de correio eletrônico. Schwartz e Wood exploraram o fenômeno denominado mundo pequeno (TRAVERS; MILGRAM, 1969), que indica que o diâmetro de uma grande rede social humana é tipicamente muito pequeno.

Um exemplo deste fenômeno do mundo pequeno, fornecido pelo matemático Paul Erdös, está dado pela seguinte relação de co-autoria com um certo autor "João": o número de Erdös de uma pessoa é definido como sendo um se a pessoa escreveu um artigo com João, dois se escreveu um artigo com alguém que escreveu um artigo com João etc. Com base nesta definição, o maior número de Erdös conhecido para uma pessoa é 7 , sendo provavelmente o diâmetro do mundo inteiro tão pequeno quanto 6 ou 7 (SCHWARTZ; WOOD, 1993).

Schwartz e Wood atingiram resultados empíricos que reafirmavam estas suposições, isolando agrupamentos com as características de mundo pequeno, e chegando a especializá-los para o caso de interesses particulares. Trabalhos posteriores aplicaram técnicas semelhantes ao correio eletrônico (KAUTZ; SELMAN; MILEWSKI, 1996; KANFER; SWEET; SCHLOSSER, 1997) e à co-ocorrência de nomes em páginas web (KAUTZ; SELMAN, 1998; OGATA; FUKUI; YANO, 1999) para a localização de especialistas e recomendação de serviços (YU; SINGH, 1999; SINGH; YU; VENKATRAMAN, 2001).

Garton, Haythornthwaite e Wellman (1997) apontam que para Wasserman e Faust (1994) a análise de redes sociais focaliza os padrões de relacionamentos entre pessoas, organizações, estados, etc. Delgado (2001) destaca que a noção de rede desempenha, ela própria, um papel predominante na Teoria de Organizações como visto no trabalho de Carley (2002).

Uma rede social pode ser particionada considerando noções como grupo e posição (GARTON; HAYTHORNTHWAITE; WELLMAN, 1997; SCOTT, 1992). Um grupo, para a análise de redes sociais, é uma estrutura descoberta empiricamente. A noção de posição tenta agrupar membros de uma rede considerando as similaridades que aparecem no conjunto de relações que eles mantêm ${ }^{13}$.

\footnotetext{
${ }^{13}$ Os integrantes de uma rede podem ser divididos em dois conjuntos, um contendo os in-
} 
Ao particionar os membros segundo a posição, podem ser obtidas indicações de que os mesmos partilham acessos similares a recursos de informação (GARTON; HAYTHORNTHWAITE; WELLMAN, 1997).

Adicionalmente, em (SCHLICHTER; KOCH; XU, 1998) são diferenciadas as noções de comunidade, grupo e equipe:

- Comunidade: é um conjunto de pessoas que partilham algo (e.g. uma linguagem, acesso a uma rede, etc.) mas não necessariamente conhecem umas às outras ou interagem pessoalmente entre si;

- Grupo: é uma comunidade cujos membros conhecem uns aos outros. Não existe necessariamente cooperação num grupo. A interação é frouxa pois não existem tarefas conjuntas ou um objetivo comum. São exemplos de grupo, um grupo de amigos ou os membros de um instituto de pesquisa;

- Equipe: os membros conhecem uns aos outros e cooperam para atingir um objetivo comum, partilhando algum artefato no qual estão trabalhando (e.g. um documento editado de forma conjunta).

A principal diferença entre estes três tipos de agrupamentos está no nível de interação entre os membros e na existência de objetivos e artefatos compartilhados. Deve ser notado, no entanto, o fato de que não existe uma clara separação, sendo possível tanto a ocorrência de transições entre eles, quanto a existência de grupos e equipes dentro de comunidades (SCHLICHTER; KOCH; XU, 1998).

O principal aspecto no suporte a comunidades é o de facilitar a identificação e a seleção de potenciais parceiros para colaborar. Já no suporte a equipes, o ponto focalizado passa a ser o processo de cooperação (SCHLICHTER; KOCH; $\mathrm{XU}, 1998)$.

As relações pessoais são particularmente importantes quando se requer um ambiente seguro, para criar um clima apropriado para uma comunidade dedicada, e.g. ao aprendizado, usando a partilha peer-to-peer de experiências individuais (HAYTHORNTHWAITE, 2000). Uma visão mais próxima das ligações interpessoais requer um detalhamento maior do componente básico das redes sociais, as redes pessoais, que são comentadas a seguir.

divíduos que "comandam" e outro com aqueles que "obedecem". Os indivíduos que fazem parte de um mesmo conjunto não possuem necessariamente ligações entre eles. 


\title{
3.2.1 Redes pessoais
}

\author{
...El Ser es semejante a la masa de una esfera \\ bien redondeada, cuya fuerza es constante desde \\ el centro en cualquier dirección... \\ Parménides apud J. L. Borges - La esfera de Pascal
}

Para explorar as formas pelas quais as relações são mantidas e as estruturas sociais formadas através das ligações existentes, podem ser usados dados coletados das ligações interpessoais mantidas online. Estes dados fornecem informações sobre as redes pessoais ou egocêntricas de cada pessoa envolvida.

Um exemplo é apresentado por Haythornthwaite (2000), onde foram descobertos, através de questionários, os tipos de relações entre alunos de cursos à distância. Os dados coletados ilustram com quem se comunicam, qual a freqüência e qual o assunto.

Segundo Campbell e Lee (1991) apud (MÜLLER; WELLMAN; MARIN, 1999), são diversas as informações que uma análise pode/deve levar em conta:

- Características do indivíduo focalizado (e.g., o seu gênero);

- Características das ligações (ties) entre o indivíduo focalizado e os membros da rede. Estas podem ser características relacionais (e.g. a freqüência de contato com cada membro), conteúdo relacional (e.g. o grau no qual um membro fornece apoio emocional), ou ainda o tipo relacional (e.g. se um membro é amigo, vizinho, colega de trabalho ou parente);

- Características dos membros da rede com os quais o indivíduo focalizado mantém ligações (e.g. gênero);

- Composição da rede, as características agregadas dos membros da rede e das ligações em cada rede pessoal (e.g., a freqüência média de contato com o indivíduo focalizado, a proporção dos membros que fornecem apoio emocional);

- Características estruturais da rede, por exemplo a densidade de ligações numa rede, ou o número de grupos. 
Um indivíduo mantém ligações fortes e ligações fracas. As primeiras são mais íntimas, as outras, mais instrumentais. As ligações fortes são mantidas através de uma freqüência de contato maior e baseadas num maior número de tipos de intercâmbio (e.g. e-mail, telefone, encontros pessoais), fornecendo informações mais oportunas, pois pessoas próximas estão mais motivadas a partilhar o que sabem (HAYTHORNTHWAITE, 2000). A figura 3.3 mostra uma rede pessoal típica.

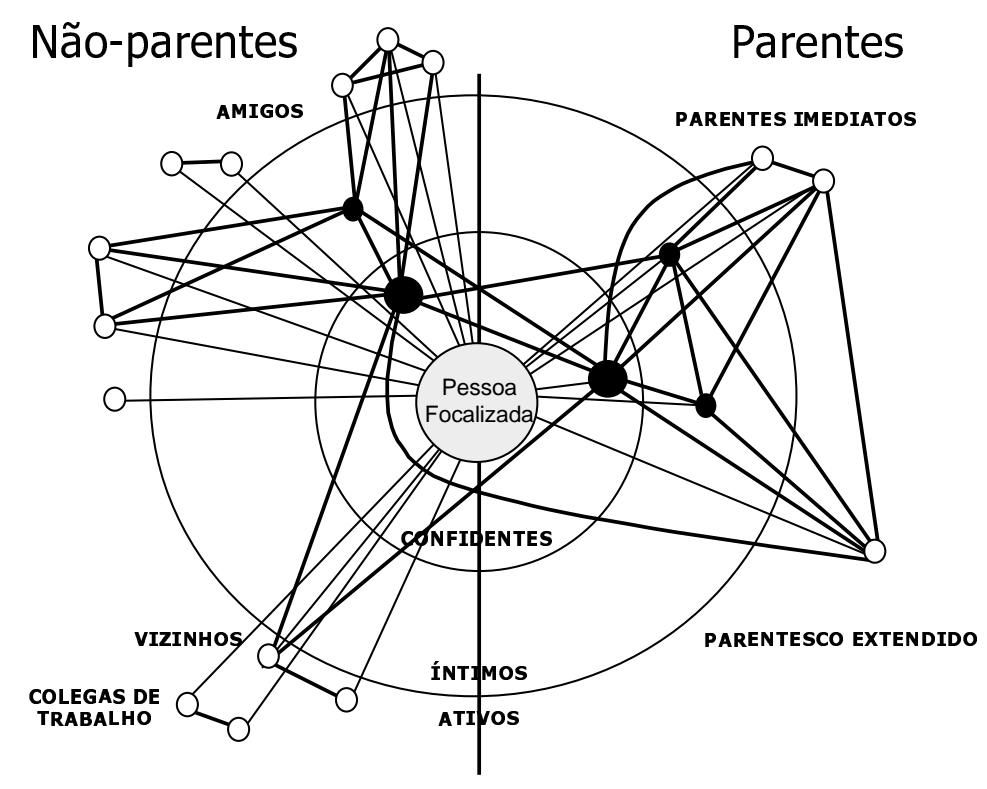

Figura 3.3: Rede pessoal típica (MÜLLER; WELLMAN; MARIN, 1999).

Na rede pessoal típica da figura 3.3 (MÜLLER; WELLMAN; MARIN, 1999), as distâncias entre os contatos e a pessoa focal indicam a força de cada ligação. Como expressado por Granovetter (1973) apud (HAYTHORNTHWAITE, 2000), as ligações fracas são mantidas através de contatos menos freqüentes, utilizando um número menor de meios diferentes, porém, fornecem acesso a informações de fontes mais remotas. A figura 3.4 exemplifica dados de um levantamento empírico. Na mesma aparecem dados obtidos com alunos de cursos a distância, integrantes de turmas com tamanhos entre 14 e 23 indivíduos.

Como enunciado por Haythornthwaite (2000), a freqüência da comunicação não está correlacionada necessariamente com a força, ou o caráter pessoal, de uma ligação (e.g. pode ser mantida uma comunicação muito frequente com colegas de trabalho num projeto). Porém, a mesma autora sustenta que, para o grupo de alunos cujos dados foram analisados em (HAYTHORNTHWAITE, 2000), a asso- 


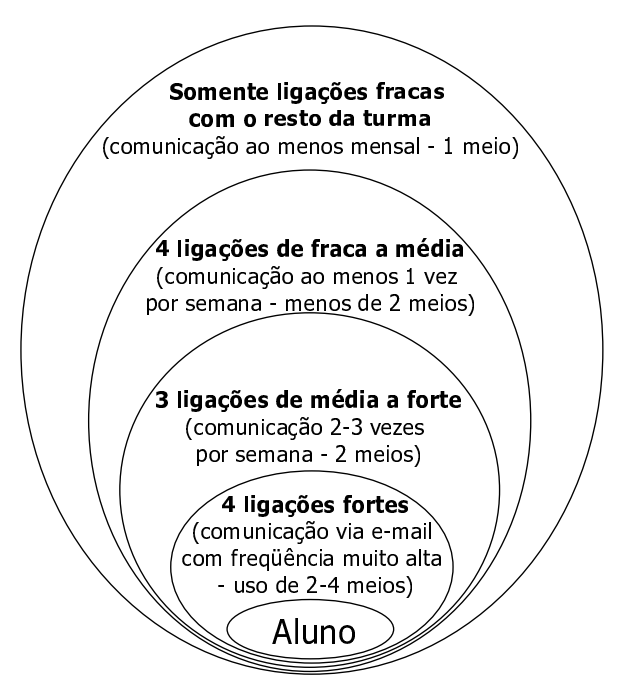

Figura 3.4: Rede pessoal de um aluno de curso a distância, segundo Haythornthwaite (2000).

ciação de freqüência à força das ligações era uma suposição razoável. A figura 3.4 ilustra a rede pessoal de um aluno típico, correlacionando a força das ligações com o número de meios diferentes usados na manutenção dos laços correspondentes. É explicitado o número de contatos com os quais o aluno mantém cada tipo de ligação, e.g. pode-se perceber que o aluno mantém ligações fortes com apenas quatro contatos. No mesmo trabalho foi citado outro resultado interessante, indicando que um grande número de ligações fracas é associado a um número pequeno de ligações fortes e vice-versa ${ }^{14}$.

\subsubsection{Redes e sistemas peer-to-peer}

... Orlando Rojas ... conta que uns policiais surgiram em sua casa e levaram os livros. Todos ... Um oficial desafiou Orlando:

- Vocês gritam muito, mas são uma meia dúzia. -Somos meia dúzia. Por enquanto somos meia dúzia ... Mas quando formos sete...

E. Galeano - Dias e Noites de Amor e de Guerra

As redes pessoais podem ser exploradas de formas diversas. Dependendo da sua constituição e finalidade, elas podem ser vistas como um sistema de repu-

\footnotetext{
${ }^{14}$ Ainda, a distribuição de ligações fortes e fracas mantidas pelos alunos tinha uma clara tendência no sentido da manutenção de ligações fortes - 73 a 92\% com 3-5 ligações fortes e apenas entre 38 e $50 \%$ dos alunos mencionando entre 9-12 ligações fracas.
} 
tação ${ }^{15}$ e/ou como sistemas de fluxo de informação ou autoridade. Por exemplo, os hyperlinks contidos em páginas web podem ser vistos como recomendações, implicitamente reputando outras fontes de informação. De fato, eles constituem a base implícita para o funcionamento do algoritmo denominado PageRank, empregado pelo Google ${ }^{16}$ e que considera um sistema de pontuação baseado no número de páginas (de fato, as ligações ou links que elas contém) que apontam para uma determinada página em particular, estabelecendo um sistema de reputação implícita ${ }^{17}$.

Um estudo particularmente interessante é o empreendido por Flake et al. (2002). Nele, os autores tentam identificar comunidades através de um algoritmo baseado em maximização de fluxo em grafos. O conceito de comunidade por eles empregado define que "uma comunidade é uma coleção de páginas tais que cada página membro possui mais ligações para dentro da comunidade do que para fora dela". O grafo alvo é um subconjunto de páginas web interligadas. Como o problema é NP completo para o caso geral, o algoritmo requer um conjunto inicial de páginas (denominadas sementes) utilizadas como extensões de um nó fonte artificialmente incluído. Num exemplo de utilização do algoritmo, foi fornecida como semente a página de Stephen Hawking, incluída num grafo contendo dezenas de milhares de páginas interconectadas, sendo obtida uma comunidade de aproximadamente 200 páginas (fortemente relacionadas).

Estes resultados não somente confirmam a existência de comunidades de sentido mas evidenciam a sua força e extensão. Com tais indícios, não é de estranhar o sucesso dos sistemas peer-to-peer (P2P) que, fundamentalmente, permitem uma forma ativa de conexão entre usuários, sendo potencialmente capazes de servir como bases para o desenvolvimento de infra-estruturas para o chamado Software Social. Os softwares sociais são sistemas computacionais (com propriedades relacionadas a diversos atributos de agência) capazes de representar e manipular construções cognitivas e organizacionais que os aproximem das representações que os seres humanos usam como ferramentas no seu convívio social. Softwares

\footnotetext{
${ }^{15}$ No sentido sociológico do termo, ou seja, como medida de concordância do comportamento observado de um agente (num determinado contexto social) em relação a determinado papel social/comportamento prototípico esperado.

${ }^{16} \mathrm{http}: / / \mathrm{www}$.google.com.

${ }^{17} \mathrm{O}$ algoritmo, porém, não é de forma alguma imune a outras influências, existindo intervenção humana direta (centralizada e transparente ao usuário) para estabelecer o maior ou menor peso de certos links dependendo do sítio ao qual a página pertence.
} 
sociais podem viabilizar a integração e a manipulação de conhecimento ligado a estruturas sociais mais profundas, das quais as páginas web são apenas a superfície.

Os sistemas P2P dedicados a partilhar arquivos, como o Gnutella e o Napster, cujas arquiteturas podem ser observadas na figura 3.5, também tentam tirar proveito de uma estrutura de redes de contatos, porém, num contexto diverso. Em tais sistemas, arquivos são armazenados nos computadores dos usuários individuais ou pares, sendo trocados diretamente entre o par que solicita e o que possui o arquivo, através de um protocolo semelhante ao HTTP. Todos os pares são simétricos, podendo funcionar como clientes e servidores, o que os diferencia de arquiteturas distribuídas convencionais. A principal diferença nas suas arquiteturas está na forma de localizar pares que possuam o arquivo procurado.

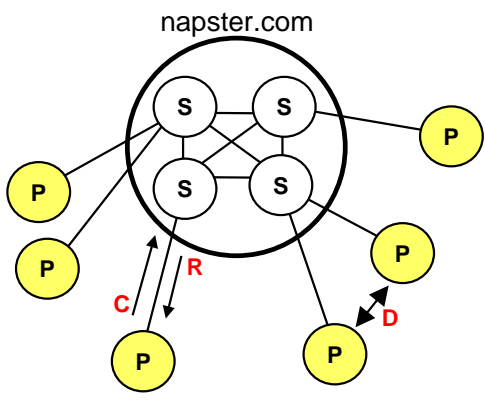

Napster

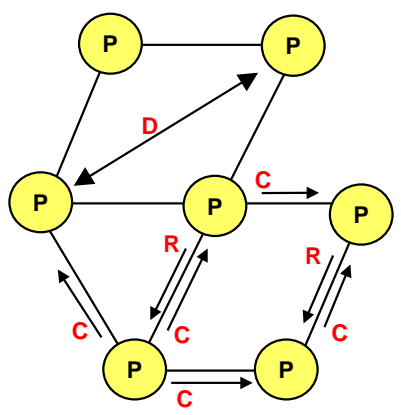

Gnutella
(S) Servidor

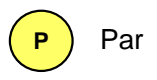

C Consulta

R Resposta

D Download

Figura 3.5: Localização de arquivos nas arquiteturas dos sistemas Napster e Gnutella (SAROIU; GUMMADI; GRIBBLE, 2002).

Como visto na figura 3.5, no Napster um grande conjunto de servidores centrais dedicados mantém um índice de arquivos sendo partilhados pelos pares ativos (que sempre estão conectados ao grupo de servidores). Já no caso do Gnutella, os pares formam uma rede baseada em circuitos virtuais, forjando conexões ponto-a-ponto com um conjunto de vizinhos. Para localizar um arquivo, um par inicia um fluxo controlado de requisições na rede enviando pacotes para todos os seus vizinhos. Cada par receptor verifica se possui o arquivo solicitado e, em caso afirmativo, responde ao par que originou a requisição. De todo modo, o par receptor passa adiante a requisição com algumas restrições ${ }^{18}$.

\footnotetext{
${ }^{18} \mathrm{O}$ recorte do espaço de espalhamento de requisições é feito através da implementação de protocolos específicos, utilizando heurísticas como: número de contatos que já espalharam
} 
Entretanto, nas redes estabelecidas através dos sistemas P2P correntes, a proximidade dos contatos numa vizinhança não é estabelecida com base na força de ligações interpessoais. No caso do Gnutella, por exemplo, o levantamento dos vizinhos é feito usando mensagens de ping (ICMP). Como não existem conhecimentos que guiem o acesso de outros usuários aos documentos locais de um determinado par (seja por reputação, forma da ligação, obediência a uma estrutura organizacional qualquer, ou ainda alguma outra métrica), o usuário pode decidir apenas o que compartilhar ou não com qualquer outro usuário. Além disso, a distribuição de carga (respostas a requisições de transmissão de arquivo) leva em conta apenas parâmetros como a largura de banda disponibilizada pelos pares e não o seu nível de colaboração ou o seu conhecimento temático.

O acesso ao conhecimento de um par poderia ser facilitado através da representação explícita de categorias conceituais com atributos que seriam utilizados como indexadores (e.g. termos) para classificar os documentos compartilhados, i.e. na forma de ontologias, conceito este que será discutido mais adiante. Para ser melhor explorados, tais sistemas podem ainda comportar uma visão organizacional centrada no par (e associando ao mesmo a noção de agência), que respeite a sua autonomia e o torne capaz de aprender a partir das suas interações com outros pares (que passariam a ser considerados também como agentes). Ambos os tópicos, organização e ontologias, são discutidos a seguir.

\subsection{Organização e SMA}

... porque é desorganizando que eu posso me organizar Porque eu me organizando posso desorganizar ...

Chico Science - Da Lama ao Caos

As redes sociais apresentadas são modeladas, na literatura, como sociedades planas do ponto de vista organizacional. Isto decorre da posição do observador em relação ao fenômeno modelado (as redes são vistas desde uma posição exterior a elas). Embora este posicionamento seja útil para estabelecer diversas caracuma requisição num caminho determinado (i.e. no mesmo sentido de hops usado em sistemas distribuídos); parar quando é atingida circularidade (i.e. ao receber de volta uma mensagem já repassada) etc. 
terísticas estruturais e dinâmicas (SINGH; YU; VENKATRAMAN, 2001) (PUJOL; SANGUESA; DELGADO, 2002), ele não reflete o posicionamento subjetivo dos agentes integrantes. Como visto na seção 3.2.1, os seres humanos transitam, no seu dia a dia, por diversos grupos sociais, mantendo com alguns deles laços identitários, profissionais, de entretenimento ou afetivos. Isto pode ser representado, como no exemplo didático da figura 3.6, pela trajetória temporal de um agente João, associando a sua participação em determinados grupos (e desempenhando papéis neles) a pontos específicos no tempo.

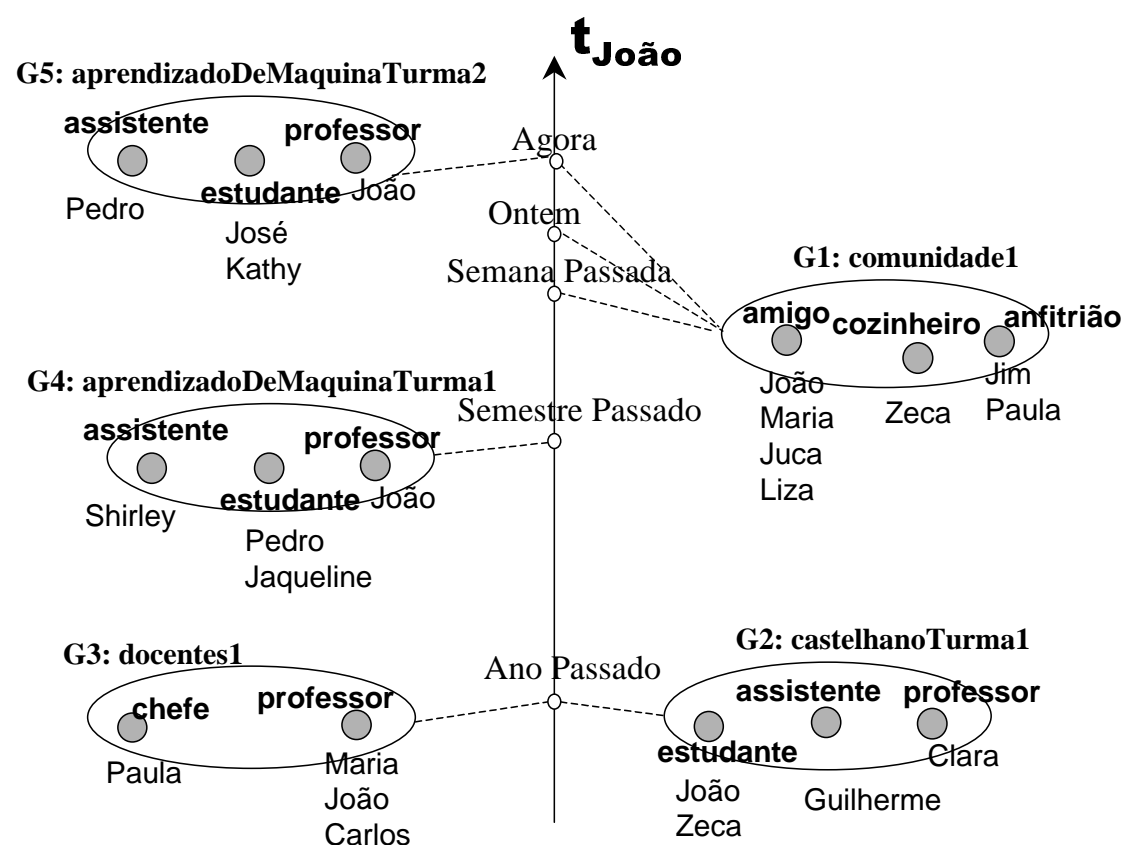

Figura 3.6: Linha temporal da existência de um agente João participando em diversos grupos e desempenhando papéis diferentes.

Agrupamentos de agentes como os exemplificados na figura 3.6 podem ser tratados computacionalmente. Para tanto devem existir formas de representação explícita. Isto leva a verificar a existência de diversas formas de conceber uma organização para sociedades multiagentes, como mostrado na figura 3.7. Na mesma podem ser observadas quatro formas gerais (HÜBNER, 2003):

- Quando não existe organização dentro do SMA, apenas um observador pode modelar o comportamento do sistema como sendo organizado, representado na figura pelo símbolo AR;

- Quando a organização que existe no SMA é construída pelos próprios agen- 
tes a partir da observação do sistema. Por serem construções subjetivas, cada um dos agentes pode construir uma representação organizacional distinta. Na figura este caso é representado pelo símbolo AC;

- O sistema possui uma organização, mas os agentes não têm capacidade para conhecer tal organização, sendo representado pelo símbolo OR na figura. Tal política é adotada nos sistemas de resolução distribuída de problemas e em sistemas distribuídos clássicos, quando a organização do sistema se encontra na mente do projetista e é codificada "em duro" nos agentes;

- Quando os agentes podem tanto conhecer a organização institucionalizada, quanto a organização observada (simbolizado por OC na figura). Novamente, os agentes podem ter representações distintas devido ao seu processo de percepção.

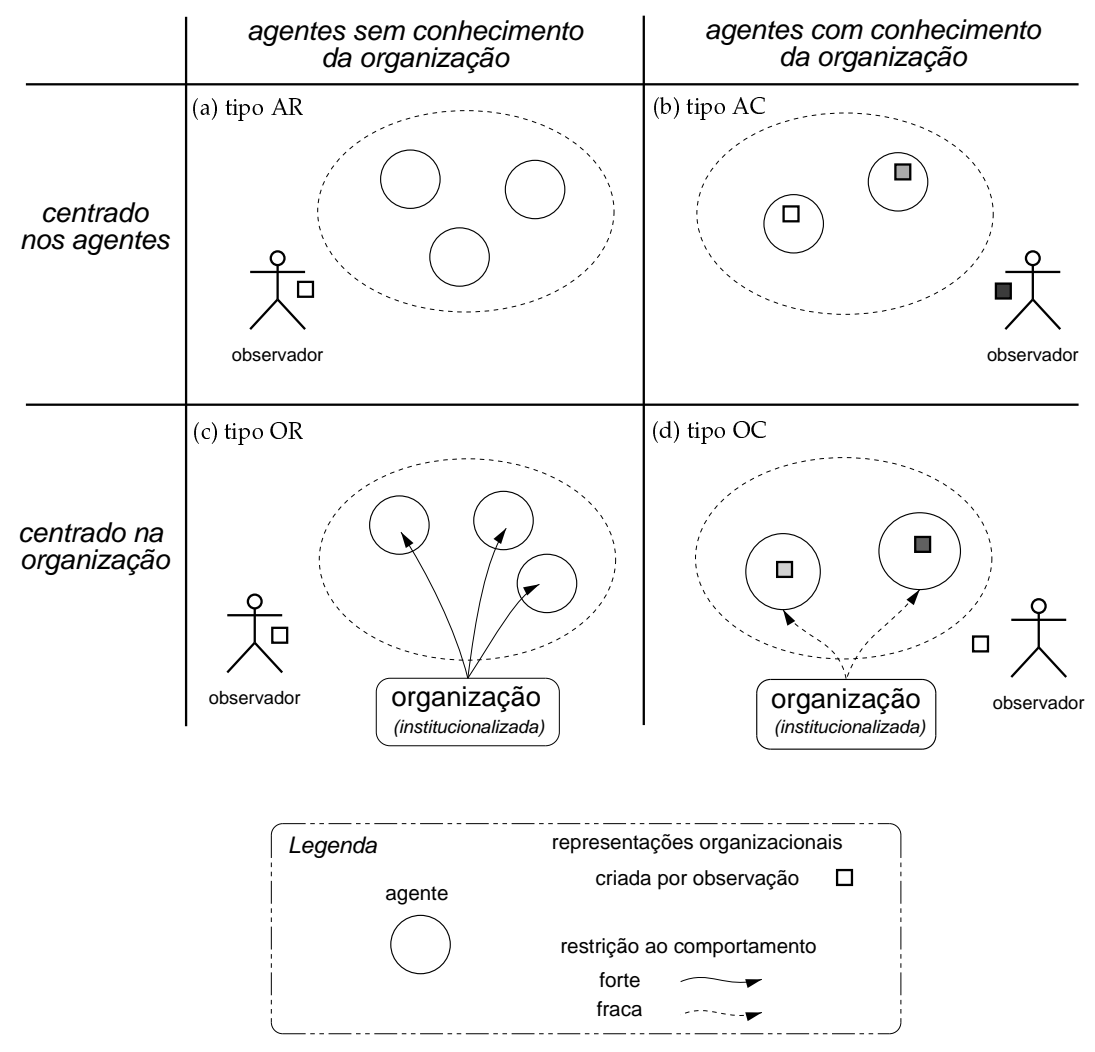

Figura 3.7: Tipos de organização segundo (HÜBNER, 2003).

Dentre os modelos existentes para especificação de organizações em SMA, se destaca o modelo $\mathcal{M O I S E}^{+}$(HÜBNER, 2003) (HÜBNER; SICHMAN; BOISSIER, 2002), pois fornece uma base para a reorganização e ainda divide claramente 
os aspectos estruturais, funcionais e deônticos de uma organização ${ }^{19}$. O modelo MoIsE $^{+}$(Model of Organization for multI-agent SystEms) é uma tentativa de associar papéis e planos numa especificação organizacional coerente. Enquanto os papéis configuram a estrutura de uma organização, os planos definem o seu funcionamento.

Adotando o modelo $\mathcal{M O I S E}^{+}$e partindo da experiência existencial do agente Jo $\tilde{o} o$ (vide a figura 3.6 ), a mesma pode ser representada estruturalmente como na figura 3.8 .

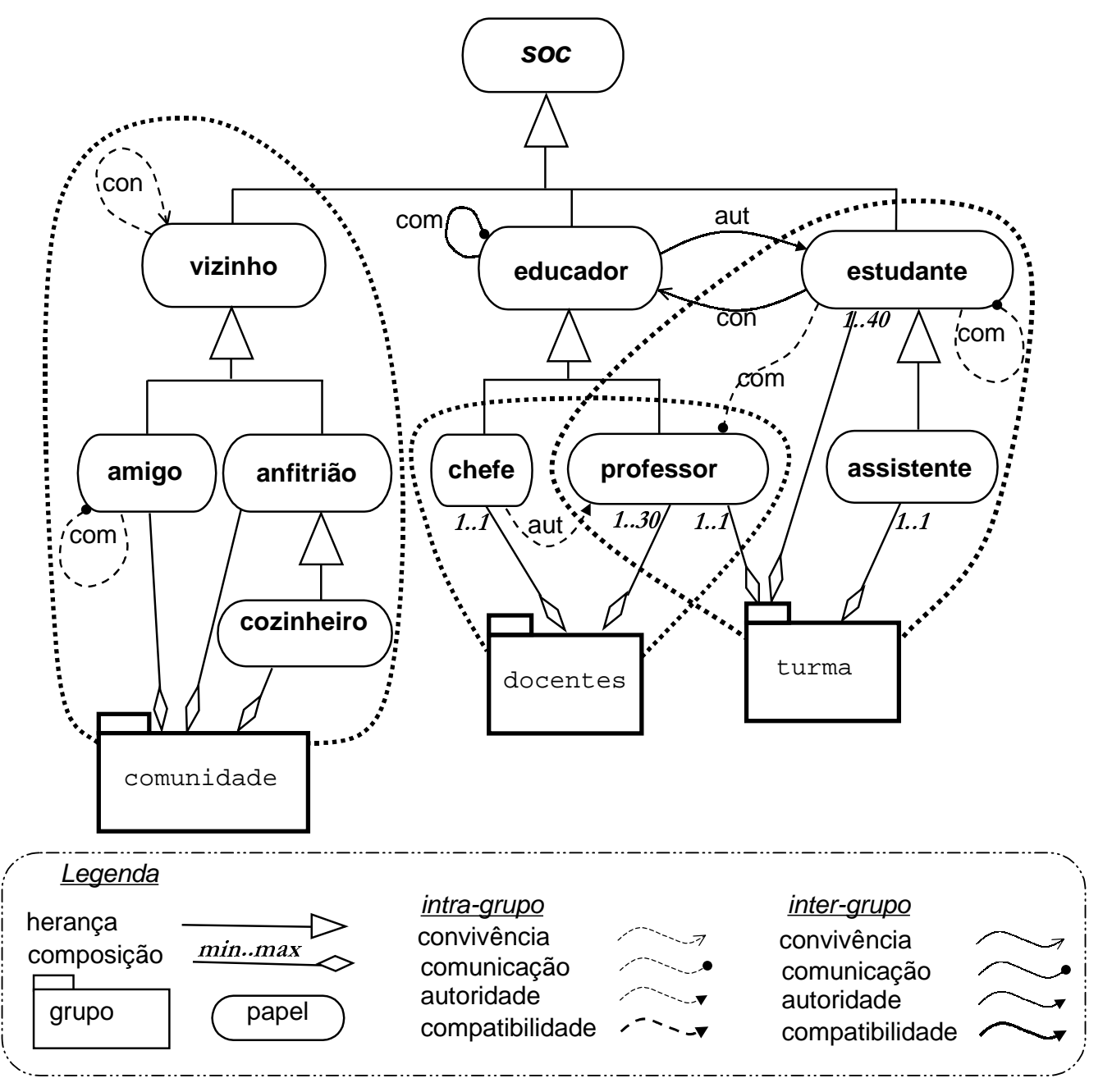

Figura 3.8: Exemplo de especificação estrutural de organização utilizando o modelo $\mathcal{M O I S E}^{+}$.

A especificação estrutural no modelo $\mathcal{M}$ oISE $^{+}$é elaborada em três níveis:

\footnotetext{
${ }^{19}$ Para os fins desta tese, a dimensão deôntica, que associa explicitamente obrigações/comportamentos a papéis específicos, não será aprofundada.
} 
- Individual: define os comportamentos pelos quais um agente é responsável quando desempenha um papel;

- Social: fornece a estrutura e interconexão dos papéis entre si;

- Coletivo: permite a agregação dos papéis em estruturas maiores, denominadas grupos.

No nível individual, os papéis são definidos e estruturados por uma relação de herança. Um papel é um conjunto de restrições que um agente deve seguir, quando aceita entrar num grupo e passar a desempenhar tal papel. Os papéis são limitados no nível social por ligações (de convivência, comunicação, autoridade e compatibilidade). As ligações limitam as interações de um agente em relação a outro. Por exemplo, um agente somente pode se comunicar com outro se existe uma ligação de comunicação entre os papéis que desempenham.

Os papéis somente podem ser desempenhados no nível coletivo, ou seja, num grupo já criado a partir de uma especificação de grupo. No modelo $\mathcal{M o I s E}^{+}$, uma especificação de grupo, i.e. um novo tipo de grupo, é definida por:

- Um conjunto de papéis;

- Um conjunto de ligações ${ }^{20}$;

- Um conjunto de compatibilidades ${ }^{21}$ entre papéis;

- O número de agentes que devem desempenhar os papéis no tipo de grupo definido.

Por exemplo, na figura 3.8, o grupo turma deve ter um agente desempenhando o papel de professor, um agente desempenhando o papel de assistente e, no máximo, 40 agentes desempenhando o papel de estudante. Como numa organização podem existir vários grupos, a especificação estrutural pode ser vista como uma coleção de grupos e papéis.

\footnotetext{
${ }^{20} \mathrm{Um}$ agente desempenhando um papel $X$ pode manter uma representação de agentes que desempenhem um papel $Y$ se existir uma ligação de convivência entre eles. Uma ligação de autoridade implica numa ligação de comunicação que, por sua vez, implica numa ligação de convivência (HÜBNER, 2003).

${ }^{21}$ Por exemplo, uma especificação poderia definir que numa mesma turma um agente que desempenha o papel de professor não poderia desempenhar também o papel de aluno.
} 
Já o aspecto funcional de uma especificação no modelo $\mathcal{M O I S E}^{+}$descreve a forma usual de atingir determinados objetivos pelos agentes. No modelo $\mathrm{MoIsE}^{+}$, a representação funcional está baseada nos denominados Esquemas Sociais (LUGO; HÜBNER; SICHMAN, 2001), que consistem da decomposição de um objetivo social em um conjunto de sub-objetivos, sendo os mesmos distribuídos entre os agentes participantes. Por exemplo, a figura 3.9 mostra um Esquema Social que representa uma determinada estratégia para ensinar e aprender uma disciplina. Num Esquema Social, as responsabilidades pela consecução de sub-objetivos são distribuídas através de missões. Uma missão é um conjunto de sub-objetivos com os quais um agente se compromete ao assumir um papel.

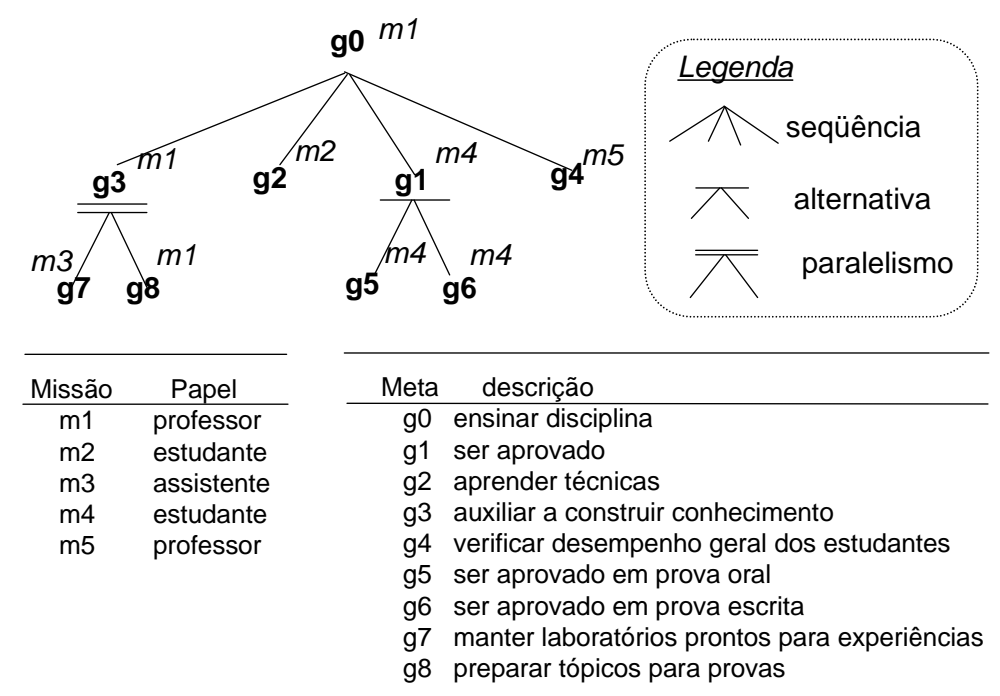

Figura 3.9: Exemplo de especificação funcional utilizando o $\mathcal{M O I S E}^{+}$.

Para levar em conta o contexto subjetivo dos agentes, é necessário que os mesmos possuam uma forma de explicitar a sua representação. Em um sistema aberto como o existente nas redes sociais, é necessário ainda que o sistema de representação comporte a reorganização. No caso da classificação referenciada na figura 3.7, este tipo de visão organizacional, centrada no agente, corresponderia ao simbolizado por AC.

A noção formal de organização utilizada pelo modelo $\mathcal{M o I s E}^{+}$é mostrada conceitualmente da figura 3.10 . 


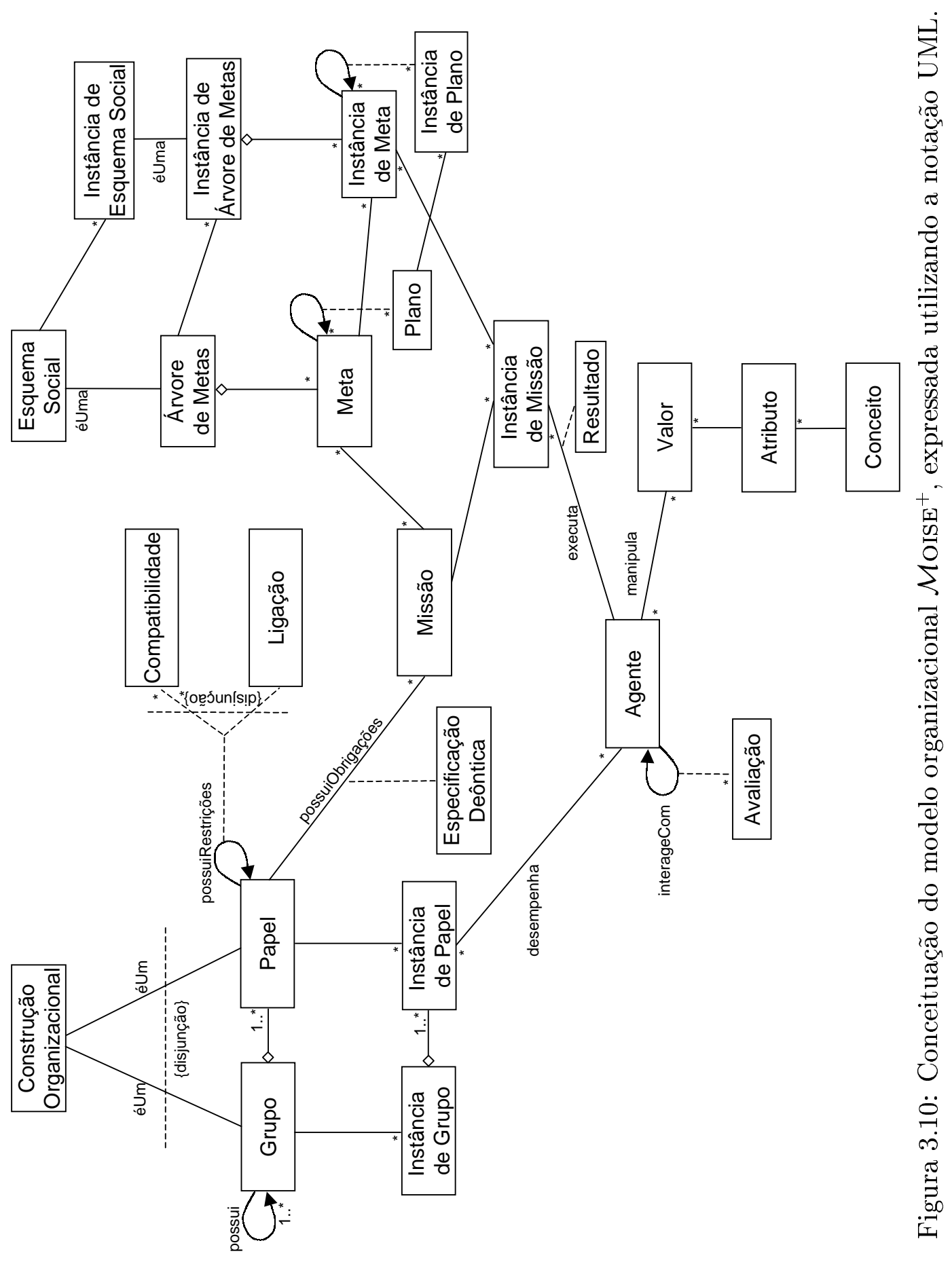




\subsection{Ontologias}

... Dividió el universo en 40 categorías o géneros, subdivisibles luego en diferencias ... ambigüedades, redundancias y diferencias recuerdan las que el Dr. Franz Kuhn atribuye a cierta enciclopedia china que se titula Emporio celestial de conocimientos benévolos. En sus remotas páginas está escrito que los animales se dividen en a)pertenecientes al Emperador, b)embalsamados, c) amaestrados...

J.L. Borges - El idioma analítico de John Wilkins

Este trabalho pretende aplicar conceitos de SMA no contexto de comunidades de usuários na Internet. Cada usuário numa rede (quando a mesma é vista como um SMA) possui uma visão particular do ambiente. Esta visão particular do ambiente pode ser interpretada como uma forma particular de organizar o mundo ${ }^{22}$, decorrente de uma certa posição epistemológica. A visão pode ser explicitada através de uma ontologi ${ }^{23}$. Uma ontologia é definida, em termos computacionais, segundo Guarino (1997), como correspondendo a uma teoria lógica projetada para dar conta do significado pretendido para certo vocabulário. Guarino e Giaretta (1995) sugerem que uma conceituação é:

“...an intensional semantic structure which encodes the implicit rules constraining the structure of a piece of reality."

“...uma estrutura semântica intencional que codifica as regras implícitas que delimitam a estrutura de uma fração da realidade."

Uma ontologia é então o comprometimento com uma conceituação particular do mundo, como representado na figura 3.11. Esta definição é um refinamento de outra que estabelece que uma ontologia é uma especificação explícita de uma conceituação, apresentada por Gruber (1995). Muito embora os trabalhos em Inteligência Artificial enfatizem o fato de uma ontologia ser compartilhada, visão

\footnotetext{
${ }^{22}$ Tipicamente construída, no Ocidente, na forma de uma classificação platônico-aristotélica.

${ }^{23}$ Atualmente, no dizer de Emmanuel Lévinas, "implica a possibilidade de conceber a contingência e a facticidade como ato da intelecção- possibilidade descoberta por Husserl mas ligada por Heidegger à intelecção do ser em geral... Pensar não é mais contemplar, mas engajar-se, estar englobado no que se pensa... É assim que somos responsáveis para além de nossas intenções"(LÉVINAS, 1997).
} 
esta decorrente da ênfase dada (principalmente nos anos 90) à interoperabilidade e à comunicação entre agentes, o compartilhamento pode ser dado (para um agente) num espaço social cujos integrantes não co-existem física e temporalmente, e.g. um vocabulário conceitual utilizado num núcleo familiar que já não existe pode ser a base para um agente organizar a realidade que o cerca ${ }^{24}$.

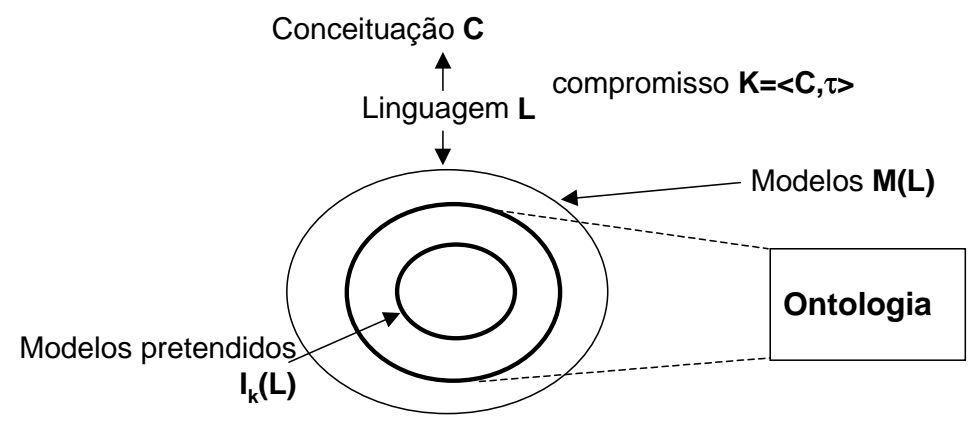

Figura 3.11: Relacionando ontologia, linguagem e conceituação (GUARINO, 1997).

Na concepção de Tamma (2002), o termo ontologia denota, em Inteligência Artificial, um "artefato de engenharia" que é composto de um vocabulário específico e de um conjunto de asserções referentes ao significado pretendido para as palavras de tal vocabulário. Como o foco estaria, assim, no vocabulário utilizado para descrever uma realidade em particular, esta noção de ontologia é dependente da linguagem, em contraposição ao significado filosófico do termo ${ }^{25}$. Guarino e Giaretta (1995) identificaram as interpretações mais comuns do termo ontologia:

i) Ontologia como disciplina filosófica;

ii) Ontologia como um sistema conceitual informal;

iii) Ontologia como levantamento semântico formal;

iv) Ontologia como uma especificação de uma conceituação;

\footnotetext{
${ }^{24}$ Ontologias estão relacionadas a (formas de) memórias coletivas.

${ }^{25}$ Ao enveredar por este caminho devem ser consideradas as noções semióticas de Peirce, diferenciando claramente o rótulo utilizado para descrever um conceito do conceito propriamente, e.g. o conceito "copo", comum a muitas culturas, recebe rótulos diferentes em outras tantas línguas.
} 
v) Ontologia como representação de um sistema conceitual através de teoria lógica:

a)caracterizada através de propriedades formais específicas;

b)caracterizada somente através dos seus propósitos específicos;

vi) Ontologia como o vocabulário utilizado por uma teoria lógica;

vii) Ontologia como uma especificação (num meta-nível) de uma teoria lógica.

Dentre estas definições, a segunda e a terceira são definidas no nível semântico, enquanto outras referenciam um artefato concreto no nível sintático, para ser utilizado com algum propósito específico. Já a primeira difere das outras pela sua natureza (GUARINO; GIARETTA, 1995). Tamma (2002) destaca que estas definições seguem uma espécie de trajetória contínua onde, num dos lados, o foco principal é a semântica do conhecimento descrito ${ }^{26}$, enquanto do outro lado a atenção é mais voltada a noções que envolvem sintaxe, como teorias lógicas ou bases de conhecimento.

\subsubsection{Ontologia formal}

Um ramo particular do trabalho com ontologias é o estudo da chamada ontologia formal (HUSSERL, 1986). Influenciado pelo trabalho de Kant, Husserl introduziu esta noção, criticando a visão da lógica como simples cálculo que não leva em consideração o significado dos símbolos utilizados. Husserl (1986) propôs (na sua publicação em 1913) uma lógica do conteúdo ideal na qual ele identificou seis tópicos de interesse:

- significado e expressão;

- gênero e espécie;

- partes e todos;

- o papel da gramática na combinação de significados;

\footnotetext{
${ }^{26}$ Neste caso, podem ser referenciadas através da noção de conceituação.
} 
- experiências intencionais e os seus conteúdos;

- conhecimento em termos do significado pretendido e da satisfação/cumprimento do significado.

Husserl enfatizou o papel da intencionalidade no ato de dirigir a atenção a um objeto (alvo) de percepção e denominou de fenomenologia esta forma de pesquisa. Nela são diferenciados os conceitos de ontologia material ${ }^{27}$ e ontologia formal ${ }^{28}$. No dizer de Tamma (2002), a ontologia formal é a teoria das distinções, que pode ser aplicada independentemente do estado do mundo, i.e.:

- Distinção entre entidades do mundo (objetos físicos, eventos, regiões etc.);

- Distinção entre as categorias (no meta-nível) utilizadas para modelar o mundo (conceito, propriedade, estado etc.).

A utilidade da noção de ontologia formal transparece quando são necessárias ferramentas capazes de avaliar as ontologias desenvolvidas para fins práticos. Por exemplo, Welty e Guarino (2001) desenvolveram uma metodologia de análise ontológica formal denominada OntoClean. OntoClean é uma metodologia para a avaliação das decisões ontológicas e fornece meios para avaliar ontologias elaboradas utilizando metodologias de engenharia de conhecimento, tais como a apresentada por Uschold e Gruninger (1996) e no método Methontology (GÓMEZPÉREZ, 1998). As noções filosóficas nas quais está fundada OntoClean são quatro (TAMMA, 2002):

- identidade: aquilo que ajuda a reconhecer (de fato re-conhecer, conhecer novamente) as características que permitem distinguir uma instância de outras, e.g. o número da carteira de identidade de uma pessoa que possibilite identificá-la univocamente;

- essência: a noção de uma propriedade ser essencial implica que ela é verdadeira em todos os mundos possíveis. Na verdade, Welty e Guarino (2001)

\footnotetext{
${ }^{27}$ Que corresponderia de certa forma à noção de ontologia num tópico específico, no sentido utilizado em Inteligência Artificial, i.e. biologia, direito.

${ }^{28}$ Correspondente à ontologia de Aristóteles. Para Tamma (2002) esta noção é muito próxima da noção de ontologia de topo, utilizada por Guarino.
} 
utilizam a noção de rigidez (derivada de essência) para representar uma propriedade que é necessária para todas as instâncias. Por exemplo, ao modelar a entidade do mundo denominada estudante deve-se escolher entre considerá-la um conceito ou um papel (no sentido utilizado em representação de conhecimento), porém, ao aplicar a noção de rigidez pode verificar-se que ser um estudante não é uma propriedade rígida, considerando que podem existir mundos onde uma pessoa não é um estudante;

- unidade: permite diferenciar as partes de uma instância do restante do mundo através de uma relação unificadora que as agrupa. Por exemplo, a pergunta é este o meu carro? remete a um problema de identidade, já a pergunta a buzina faz parte do meu carro? é um problema de unidade;

- dependência: quando considerada como relativa às propriedades, permite diferenciar o intrínseco do extrínseco. Propriedades intrínsecas são aquelas que caracterizam inerentemente um objeto, não dependendo de nenhum outro objeto. Em geral, são boas candidatas para tornar-se condições de identidade.

\subsubsection{Representação de ontologias}

Para além destas breves considerações formais, existem diversas formas de representação do conhecimento utilizadas para expressar ontologias ${ }^{29}$, sendo uma das mais populares aquela baseada em frames (MINSKY, 1974). Esta é baseada fundamentalmente nas noções de classe, slot e faceta. As classes (conceitos), representam coleções de objetos que partilham as mesmas propriedades, descritas por slots (atributos) que por sua vez possuem facetas (restrições adicionais). Outra forma de representação de conhecimento são as lógicas de descrições, que focalizam a expressividade. A tabela 3.2 mostra um exemplo de comparação de lógicas deste tipo, ressaltando características específicas. Dentre as lógicas comparadas, deve ser destacada a que fundamenta OIL, pois é a mesma que serve como uma das bases para a linguagem OWL, usada na Web Semântica, citada no início deste capítulo.

\footnotetext{
${ }^{29}$ Freitas (2003) apresenta com maiores detalhes os conceitos que perpassam a representação de conhecimento com ênfase nas implicações para a $W e b$ Semântica.
} 


\begin{tabular}{|c|c|c|c|}
\hline & CLASSIC & OIL & LOOM \\
\hline \multicolumn{4}{|l|}{ Operadores Lógicos } \\
\hline conjunção & $\mathrm{x}$ & $\mathrm{x}$ & $\mathrm{x}$ \\
\hline disjunção & & $\mathrm{x}$ & $\mathrm{x}$ \\
\hline negação & & $\mathrm{x}$ & $\mathrm{x}$ \\
\hline \multicolumn{4}{|l|}{ Restrições nos slots } \\
\hline valores de slot & $\mathrm{x}$ & & $\mathrm{x}$ \\
\hline restrições de tipo & $\mathrm{x}$ & $\mathrm{x}$ & $\mathrm{x}$ \\
\hline restrições de faixa & $\mathrm{x}$ & $\mathrm{x}$ & $\mathrm{x}$ \\
\hline restrições existenciais & $\mathrm{x}$ & $\mathrm{x}$ & $\mathrm{x}$ \\
\hline cardinalidades & $\mathrm{x}$ & $\mathrm{x}$ & $\mathrm{x}$ \\
\hline \multicolumn{4}{|l|}{ Definições dos slots } \\
\hline atributos funcionais & $\mathrm{x}$ & $\mathrm{x}$ & $\mathrm{x}$ \\
\hline conjunções de slots & & & $\mathrm{x}$ \\
\hline slots transitivos & & $\mathrm{x}$ & \\
\hline slots inversos & & $\mathrm{x}$ & $\mathrm{x}$ \\
\hline \multicolumn{4}{|l|}{ Axiomas } \\
\hline igualdade & $\mathrm{x}$ & $\mathrm{x}$ & $\mathrm{x}$ \\
\hline implicação & $\mathrm{x}$ & & \\
\hline disjuntos & $\mathrm{x}$ & $\mathrm{x}$ & $\mathrm{x}$ \\
\hline cobertura & & $\mathrm{x}$ & \\
\hline \multicolumn{4}{|l|}{ Asserções } \\
\hline entidades & $\mathrm{x}$ & $\mathrm{x}($ parcial $)$ & $\mathrm{x}$ \\
\hline instâncias de relações & $\mathrm{x}$ & $\mathrm{x}($ parcial $)$ & $\mathrm{x}$ \\
\hline
\end{tabular}

Tabela 3.2: Expressividade comparativa de lógicas de descrições segundo Wache et al. (2001). 
Uma representação de uso muito estendido, cujo modelo de conhecimento está baseado em frames, é a denominada Open Knowledge Base Connectivity (OKBC) (CHAUDHRI et al., 1998). OKBC possui um modelo cujo foco é uma API (Application Programming Interface) para acessar bases de conhecimento visando a interoperabilidade. As classes são organizadas numa hierarquia de herança múltipla $(I S-A)$.

No seguinte exemplo didático, é representado em OKBC o conceito Machine Learning, representado pela classe (c) MachineLearning; um dos atributos ou slots (s) do conceito é o limiar de disparo para a simulação de um neurônio, expressado pelo par (valorMin, valorMax); as facetas (f) expressam o domínio do valor de limiar, considerado como variando entre zero e um, com o valor usual pertencendo à faixa entre 0.4 e 0.6 .

\section{c:MachineLearning;}

s: NeuronSimulationActivationPotential

f: Domain: $[0.0,1.0]$;

f: Value: $[0.4,0.6]$;

OKBC não fornece uma linguagem para descrever axiomas. No entanto, como expressado por Crow (2000), autores como Fridman-Noy e Haffner (1997) fornecem indícios à idéia de que existe uma linha muito tênue separando os axiomas da estruturação de conceitos, i.e., uma categoria pode ser representada usando o formalismo de frames ou, alternativamente, os mesmos fatos podem ser representados utilizando axiomas. Adicionalmente, a facilidade de manipulação tem contribuído para a popularidade de representações baseadas em frames.

Contudo, o trabalho de Tamma (TAMMA; BENCH-CAPON, 2001; TAMMA, 2002) mostrou que o conjunto de meta-propriedades ${ }^{30}$ tais como as escolhidas pelo trabalho de Welty e Guarino (2001) poderia ser complementado. Especificamente, o meta-modelo conceitual, nem formal nem diretamente executável, poderia ser estendido para contemplar outras características além de identidade, rigidez (essência), unidade e dependência. No meta-modelo conceitual estendido, além das características anteriores são adicionadas o comportamento das propri-

\footnotetext{
${ }^{30} \mathrm{O}$ conjunto de categorias utilizadas para modelar o mundo.
} 
edades de conceitos no decorrer do tempo, a modalidade, a diferenciação entre protótipos e exceções assim como o tratamento de herança e distinção. O objetivo de Tamma (2002) foi o de prover uma semântica mais rica para os conceitos e, ao mesmo tempo, fornecer um guia que possa ser utilizado por engenheiros de conhecimento para determinar, por exemplo, as condições de identidade e rigidez ${ }^{31}$. Estas características tornam-se ainda mais úteis quando devem ser enfrentados problemas como o alinhamento de ontologias diferentes.

Tamma (2002) aplicou o meta-modelo conceitual estendido ao modelo OKBC apenas como suporte para prova de conceitos. O meta-modelo estendido foi implementado no OKBC adicionando facetas específicas. Assim, o exemplo inicial poderia apresentar-se do seguinte modo:

c:MachineLearning;

a: NeuronSimulationActivationPotential

f: Domain: $[0.00,1.00]$;

f: Value: $[0.40,0.60]$;

f: Typeofvalue: prototypical;

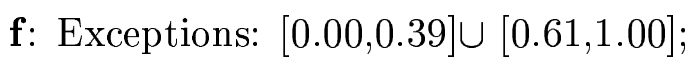

f: Ranking: 3 ;

f: Changefrequency: Volatile;

f: Event: (stimulated, [0.20,0.60], after, R);

f: Event: (damaged, [0.90-1.00], after, I);

No exemplo que utiliza o modelo estendido de Tamma e Bench-Capon (2001), a representação disponibilizada mostra que o limiar usual está entre 0.40 e 0.60 e fora dessa faixa os valores seriam "exceções" (exceptions). O "tipo de valor" (Typeofvalue) indica que o valor (value) do atributo é válido para qualquer instância típica (prototypical) do conceito. Tal faceta pode assumir ainda os valores "herdado"(inherited) ou "diferenciador" (distinguishing) entre subconceitos de um mesmo nível. As exceções são permitidas num grau dado pelo ranking. O ranking com valor 3 indica que o grau de confiança na observação do valor usual é

\footnotetext{
${ }^{31}$ Esta visão privilegia a noção de que as ontologias devem fornecer ao engenheiro informação suficiente para entender os conceitos de um domínio (no mundo real) e também devem permitir uma análise ontológica formal. Nesta perspectiva as fronteiras entre aquilo que deve ser considerado conhecimento ontológico e conhecimento epistémico se esvaem (TAMMA, 2002).
} 
para a "maioria" (most) dos casos (a escala vai de 1 a 7 , sendo 1 o maior). A "freqüência de mudança" (Changefrequency) "volátil" indica que o valor de limiar pode mudar mais de uma vez (outros valores podem ser regular(regularmente), once only (uma só vez) e never(nunca)). São descritos "eventos" (Events) que podem mudar o limiar junto com os novos valores, e.g. se um neurônio é simulado como sendo estimulado por um neurotransmissor, o limiar pode vir a ser tão baixo quanto 0.20 "depois" (after) do evento; finalmente, a mudança no valor do limiar é reversível $(R)$, provavelmente após o fim do efeito dessa substância. Já se um neurônio é danificado (damaged), o limiar muda irreversivelmente $(I)$.

\subsubsection{Uso de ontologias por agentes de informação}

Em qualquer caso, o uso de ontologias para explicitar conhecimentos implícitos é um enfoque viável para superar o problema de heterogeneidade semântica. A figura 3.12 apresenta um exemplo que ilustra como um agente inteligente pode valer-se de uma ontologia (circunstancialmente expressada utilizando OWL) para realizar uma inferência e responder de maneira adequada a uma requisição, apesar de ter de processar uma terminologia inesperada (não conhecida de antemão). Um agente com esta habilidade certamente reúne as características previstas por Wiederhold (1992).

A interoperabilidade entre agentes pode ser atingida reconciliando as diferentes visões de mundo através do compromisso com uma ontologia comum (WACHE et al., 2001; FALASCONI; LANZOLA; STEFANELLI, 1996). Esta visão predomina nos SMA que aplicaram ontologias. Por exemplo, em DOOGGIE (WILLIAMS; REN, 2001), os agentes aprendem significados uns dos outros através da passagem de objetos (e.g. documentos) numa forma puramente distribuída. Já Steels (1998) mostra um SMA que converge para uma ontologia comum usando um jogo lingüístico onde prima a interação social. Em InfoSleuth (NODINE; PERRY; UNRUH, 1998), a colaboração entre agentes de informação é viabilizada através de ontologias, representando serviços de agentes, usadas na distribuição de tarefas. No sistema RETSINA (SYCARA, 1999), os agentes de informação usam ontologias como ferramentas de mediação entre as requisições de agentes e as fontes de informação externas ao sistema.

Embora existam agentes de informação que usam ontologias para representar 


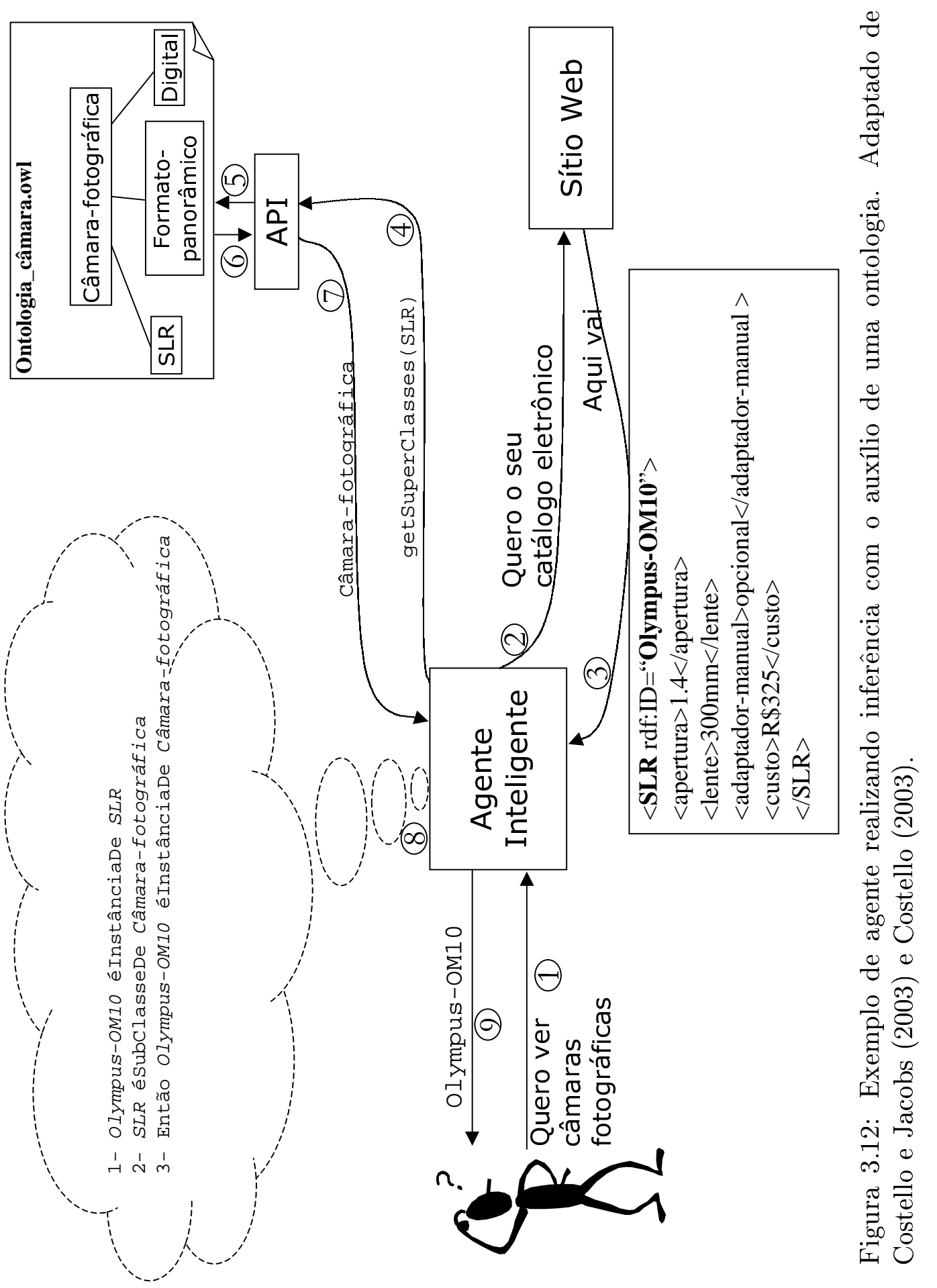


perfís de usuários isolados (PRETSCHNER, 1999; CHAFFEE; GAUCH, 2000), é escassa a pesquisa na aplicação de mapeamentos de ontologias destinados a sistemas que auxiliem a comunidades de usuários (LACHER; GROH, 2001). Quando tal mapeamento é mencionado (GANDON, 2001), ele é restrito a estruturas organizacionais relativamente estáveis e bem conhecidas, notadamente estruturas de empresas. Em (GANDON, 2001), por exemplo, o levantamento da ontologia básica foi efetuada com considerável esforço manual.

O comprometimento com uma conceituação particular, no entanto, não implica a correspondência total da ontologia de um agente com a de um grupo em particular. De forma geral, esta correspondência é apenas parcial sendo influenciada pelas experiências particulares de cada agente.

Um dos poucos trabalhos que tentaram, efetivamente, usar ontologias particulares e coletivas, comparando-as, é o sistema CAIMAN (LACHER; GROH, 2001). Em fase de protótipo, seu objetivo é a partilha de uma coleção de documentos. Seu ponto de partida, porém, é o uso exclusivo de técnicas clássicas de RI para agrupar documentos, que produzem categorias não comparáveis a uma classificação humana.

\subsection{Comentários}

Os conceitos abordados neste capítulo podem ser aplicados na proposta apresentada na seção 1.4, que contempla a representação e manipulação do conhecimento e do entorno social do usuário. O agente pretendido reúne as características de um agente de informação, integrando habilidades relacionadas à recuperação de informação com outras diretamente ligadas à noção de agência:

- De posse de uma representação dos recursos de informação disponibilizados pelo usuário, o agente deve ser capaz de elaborar a rede de contatos pessoais do usuário;

- A rede de contatos pessoais pode ser formalizada de forma a refletir a visão organizacional subjetiva do usuário utilizando o modelo $\mathcal{M O I S E}^{+}$;

- O meta-modelo de representação de conhecimento utilizado deve ser capaz de suportar traços de interação social; 
- O conhecimento do usuário pode ser representado, para fins práticos, por uma ontologia que seja compatível com o modelo de representação que fundamenta o OKBC.

O modelo de agente a ser proposto deve permitir o tratamento do conhecimento como possuindo uma componente social, integrando as noções de rede social, de ontologia e de representação organizacional para facilitar a manipulação e partilha de conhecimentos e recursos atrelados aos mesmos. No capítulo seguinte, é desenvolvida a proposta que incorpora estas habilidades de forma a integrar e a manipular ambas as representações, a organizacional e a do conhecimento do usuário, relacionando-as com os recursos que o usuário disponibiliza para a partilha de conhecimento numa comunidade. 


\section{Parte II}

Abordagem Proposta 


\title{
4 Agentes de informação para partilha de conhecimento
}

\author{
entendo \\ mas não entendo \\ o que estou entendendo \\ P. Leminski - La vie en close
}

A hipótese central deste trabalho é que a representação que os agentes computacionais fazem dos usuários deve levar em conta as comunidades das quais os seres humanos fazem parte, explicitando os grupos ${ }^{1}$ a que os mesmos pertencem no seu dia-a-dia e associando-os a conceitos ${ }^{2}$. Tal conhecimento, que remete às estruturas organizacionais que conformam o tecido social nas comunidades humanas, possibilitaria realçar a relação de um conhecimento específico com a forma de inserção do usuário numa comunidade. Este enfoque é aplicado à partilha de conhecimento efetuada por agentes de informação destinados a interagir formando um SMA cooperativo.

A perspectiva apresentada é uma alternativa para a construção de aplicações caracterizadas como sendo Software Social. O Software Social é descrito em (BOYD, 2003) como sendo um software "cujo funcionamento é construído de baixo para cima (bottom-up), com pessoas aderindo ao sistema (por exemplo, baixando uma aplicação e registrando um identificador) e filiando-se através de escolhas e ações pessoais (por exemplo, agregando/retirando e sendo agregado/retirado de listas de conhecidos)". Boyd também sublinha que, diferentemente do Software de Suporte a Grupos (groupware), "o Software Social pretende dar suporte aos desejos de indivíduos de filiarem-se, aos seus desejos de pertencer a grupos para

\footnotetext{
${ }^{1} \mathrm{E}$ eventualmente até os papéis, no sentido sociológico do mesmo, como pai, filho, amigo, colega de trabalho, chefe, etc.

${ }^{2}$ Por exemplo, os conceitos "agente" e "organização" podem ser associados a ontologias de integrantes de um grupo de pesquisa em Inteligência Artificial (IA).
} 
atingir seus objetivos pessoais". Na perspectiva do Software de Suporte a Grupos, as pessoas são designadas a grupos definidos em organizações formais, divididas em geral segundo funcionalidades. Não pode ser esquecido o fato de que os modelos clássicos de organização usados em Ciência da Computação decorrem de visões funcionalistas interpretadas, mormente, através das Ciências Administrativas. Estas, por sua vez, tiveram origem na Biologia, que por sua vez, as gerou espelhando-se na Física ${ }^{3}$. A visão do Software Social não descarta, absolutamente, a visão funcionalista, mas reposiciona-a apenas como parte de um contexto maior onde as interações sociais são causa e efeito ${ }^{4}$, não apenas contingências decorrentes de necessidades (biológicas e/ou computacionais).

O fato de permitir a um agente, imerso numa rede social, representar, quando e se necessário, o seu entorno social como sendo orgânico e atrelado a uma ontologia, lhe permite melhor gerenciar o seu conhecimento e os seus contatos. O uso de um formalismo como o modelo $\mathcal{M O I S E}^{+}$permite partir de um quadro como o que aparece na figura 3.6 e explicitá-lo estruturalmente como, por exemplo, aparece na figura 3.8. Desde o ponto de vista científico, o compromisso com uma representação formal de organização cuja semântica é conhecida e claramente explicitada já justificaria o uso de um modelo como o $\mathcal{M O I S E}^{+}$. Adicionalmente, isto permitiria ao agente saber o que ele pode (ou deve) tornar conhecido a outro(s) agente(s) com o(s) qual(is) ele interage cooperando (ou quem sabe competindo), por exemplo, durante a negociação de uma coalizão.

Para partilhar conhecimento entre agentes representando comunidades de usuários, pretende-se o desenvolvimento de um modelo que utiliza SMA e RI. Tal modelo deve levar em conta os níveis de privacidade estabelecidos por cada usuário, considerando os diversos grupos aos quais ele pertence. Neste ponto, devem ser diferenciadas, no modelo, noções como grupo e comunidade, descritas na seção 3.2 verificando a adequação a caracterizações existentes (OYAMA; HIRAMATSU; ISHIDA, 2001; SCHLICHTER; KOCH; XU, 1998). Assim, o objetivo

\footnotetext{
${ }^{3}$ Uma discussão introdutória a respeito é apresentada em (LANSING, 2002), inclusive abrangendo as críticas de Marx, retomadas pela Escola de Frankfurt e posteriormente por R. Lewontin, das simplificações em que incorre o modelo evolutivo darwinista. Complementarmente, em (CASTELFRANCHI, 2001) são exploradas as possibilidades autopoiéticas de sistemas modelados desde o ponto de vista social.

${ }^{4}$ Possivelmente como restrições particulares a serem consideradas num certo ambiente físico, fortemente entrelaçadas com as circunstâncias sociais. Inclusive, uma alternativa que coloca em xeque o darwinismo é apresentada no "Mundo das Margaridas" em (LOVELOCK, 1992).
} 
central é modelar um agente computacional capaz de interagir com outros numa rede social.

O perfil de um usuário será definido a partir de sua ontologia ${ }^{5}$. As ontologias individuais poderiam referenciar usuários que pertencessem aos grupos presentes na rede social, da qual o usuário faz parte, formada por exemplo através do uso de $e$-mail. No caso de serem utilizadas as mensagens de e-mail para o levantamento de redes pessoais, autores como Yu e Singh (1999) chamam a atenção para o fato de que as mensagens podem ser mais indicadoras de experiência e interesse do que de conhecimento especializado.

É possível, com o auxílio do usuário, estruturar as redes de contatos, agregando estes últimos em grupos e papéis. O usuário faz tais agrupamentos no seu dia-a-dia e o agente pode auxiliá-lo na explicitação. Em decorrência, o agente passaria a ter acesso à representação da visão organizacional subjetiva do usuário. Por exemplo, um usuário poderia criar os papéis "orientador", "colegas" e "amigos" num grupo chamado "trabalho". Isto permite registrar as situações de troca de informações atreladas a tais construções organizacionais.

Como os agentes passam a ser mediadores dos contatos entre usuários, permitindo, por exemplo, trocas de certos arquivos, cada agente deveria deter também uma representação do conhecimento do usuário a que serve. Eles poderiam, assim, tentar identificar os conceitos envolvidos nas trocas de informações. Com isso, poderiam buscar relacionar os conceitos ligados às experiências e interesses àqueles usados localmente pelo usuário. Este conhecimento pode ser tratado de forma mais apropriada explicitando-o para os usuários (e eventualmente para grupos) nas suas ontologias. Para tanto, o modelo conceitual para tais ontologias deve ser capaz de comportar meta-propriedades (vide seção 3.4) ligadas à interação social entre agentes.

Os agentes pretendidos passariam a estar conectados numa rede P2P. Agentes deste tipo teriam a habilidade de se situar numa rede social. Dado que uma das formas de interação em redes sociais é a cooperação, esta cooperação pode efetivar-se, por exemplo, com a troca de conhecimentos. É através da infra-estrutura fornecida pela rede social que o conhecimento especializado pode

\footnotetext{
${ }^{5} \mathrm{Tal}$ ontologia pode ser uma ontologia formalmente expressa, ou uma ontologia shallow, ou seja, aquela onde os atributos dos conceitos são baseados em extração automática. Lassila e McGuinness (2001) apresentam uma classificação de ontologias segundo a sua expressividade.
} 
efetivamente ser compartilhado. As formas de cooperação podem ser:

- Partilha de vocabulário (sinônimos considerando um mesmo conceito);

- Partilha de subconjuntos da ontologia do usuário (em relação a um papel desempenhado pelo usuário);

- Partilha de arquivos (atrelados a conceitos);

- Partilha de uma seqüência de busca de um determinado tópico (palavras chaves usadas e links seguidos numa seqüência de exploração, denominada trial ou tentativa (PIKRAKIS et al., 1998)).

Estas formas de colaboração implicam, por um lado, a obtenção de conhecimento em graus cada vez mais refinados, e por outro, a gradativa disposição de partilhar os mesmos, dependendo da força da relação com outros agentes e do engajamento em determinados grupos. Os agentes de informação considerados devem ser capazes de representar e raciocinar sobre os agentes de outros usuários, situando e gerenciando socialmente o conhecimento explícito contido na ontologia do usuário ao qual cada um está dedicado. Os agentes conectados formariam um SMA, onde cada agente teria a capacidade de mapear a rede social da qual o usuário faz parte e de manipular a sua ontologia.

A seguir, passa a ser detalhada a proposta de modelo de representação a ser utilizada pelo agente. Na próxima seção, uma breve discussão sobre o uso de papéis sociais e a representação pretendida para eles é apresentada. Na seqüência, a proposta de representação de conhecimento do agente é detalhada, baseada num meta-modelo conceitual que estende com meta-propriedades organizacionais o conjunto de categorias utilizadas para modelar o mundo (vide seção 3.4). Tal meta-modelo conceitual estendido é desenvolvido, como prova de conceito, adicionando facetas específicas ao OKBC. Entretanto, não se pretende alterar o padrão OKBC ou estabelecer uma nova forma de representação de conhecimento. O objetivo é apresentar uma nova forma de olhar para o conhecimento, reconhecendo componentes sociais no mesmo. As novas meta-propriedades dos atributos fornecem uma descrição semântica mais rica em relação às interações sociais ${ }^{6}$. O objetivo é permitir que um agente relacione o seu conhecimento com a sua representação organizacional subjetiva.

\footnotetext{
${ }^{6}$ Implementadas através de anotações nos atributos dos conceitos.
} 


\subsection{Representação de papéis sociais}

..Uma gata o que é que é?
ESPERTA!
E um jumento o que é?
PACIENTE!
Não é grande coisa realmente
prum bichinho se assanhar...
E o cachorro o que é que é?
LEAL!
E a galinha o que é que é?
TEIMOSA!
Nẫo parece mesmo grande coisa
Vamos ver o que que dá

Esperteza!, Paciência!, Lealdade!, Teimosia!, e mais dia menos dia a lei da selva vai mudar... Todos juntos somos fortes!, Somos ágeis, Somos algo!, Todos nós no mesmo barco Não há nada pra temer! Ao meu lado há um amigo que preciso proteger...

Todos Unidos(Tutti Uniti)- Os Saltimbancos

Seres humanos são gregários, a necessidade de filiação parece imanente. Nas palavras de E. Durkheim, "em cada sociedade de grandes dimensões existem sempre interesses particulares, locais e profissionais, que tendem a reunir as pessoas de acordo com esses interesses" (BOBBIO; MATTEUCCI; PASQUINO, 1998).

Porém, no interior de um mesmo grupo, são tecidas relações de cumplicidade, pautadas na igualdade e também relações de desarmonia, ou de diversas formas de autoridade $^{7}$. Não tratamos da mesma maneira a todos os integrantes dos grupos a que pertencemos. Em diversos modelos elaborados para estudar as sociedades humanas, um dos conceitos recorrentes é o de papel social. A principal concepção está relacionada à noção weberiana de adequação dos tipos-ideais a uma certa "realidade objetiva" (e.g. o capitalista, o sacerdote, o profeta, o cientista, o político etc.) (ORTIZ, 1983) ${ }^{8} 9$. A noção de "papel social" tem se mostrado não somente conveniente, mas útil. Neste trabalho a referência ao conceito de "papel social" carrega a seguinte conotação:

"padrão de comportamento individual que é reconhecido socialmente, permitindo assim um meio de identificação e de inserção de um

\footnotetext{
${ }^{7}$ Evidenciado pelos diversos tratamentos dados às trocas do capital simbólico (BOURDIEU, 1998).

${ }^{8} \mathrm{~A}$ idéia já transparece na leitura de A Ética Protestante e o Espírito do Capitalismo (WEBER, 2001).

${ }^{9}$ De fato, A. Schutz, demonstra que a sociologia weberiana, que estuda a ação subjetiva e o seu significado, se assenta sobre uma perspectiva fenomenológica. O "mundo objetivo" aparece como uma rede de intersubjetividade, resultado de ações dirigidas para o "outro" e que adquirem significado na medida em que o "outro" compartilha (comigo) o mesmo mundo social no qual tais ações se desenrolam (SCHUTZ, 1972).
} 
indivíduo numa sociedade" - Talcott Parsons ${ }^{10}$ (SILVA, 2003).

A partir desta definição, o papel representa a expectativa de um certo comportamento. Papéis sociais incluem ações e/ou qualidades. Por exemplo, o papel social do "professor" pode exigir que ele "dê boas aulas", "distribua trabalhos" etc. (i.e. ações); e, ao mesmo tempo, aquele que desempenha este papel deve ser "dedicado", "honesto" e "responsável" (i.e. qualidades). Ainda, papéis sociais podem, ou não, ser compatíveis entre sí (e.g. ser "pai" e "filho" da mesma pessoa). Por estes motivos, é muito mais fácil pedir a uma pessoa um juízo de valor sobre outra quando explicitado o grupo e o papel social com o qual o comportamento do "outro" deve ser comparado. Por exemplo, se Zeca convive com João na sua vizinhança e João e Zeca são amigos, digamos que ocasionalmente um e outro cumprem o papel de cozinheiro, mas Zeca vive queimando os pratos que prepara. Ao perguntar a João se Zeca "é confiável?", a pergunta fica muito mais clara com o adendo "como amigo", ou ainda "como cozinheiro?", vê-se que a resposta pode perfeitamente ser afirmativa para a primeira e comportar uma rotunda negativa, no segundo caso ${ }^{11}$.

Em outras palavras, uma rede social pode ser vista através da sua conformação orgânica, não bastando um valor qualquer de "proximidade" ou "excelência no desempenho" associada a cada contato, pois o filtro através do qual se processa este cálculo social é o papel desempenhado pela contraparte no contexto de um grupo determinado. Isto é tanto mais crucial se for considerado que o agente deve interagir com o usuário para explicitar as suas expectativas. Ao aproximar a representação que o agente faz daquela do usuário, as chances de sucesso são maiores no processo de interpretação de um determinado perfil. Embora este trabalho não tencione aprofundar quanto à identificação de tarefas e qualidades associáveis a um papel social, nem às métricas que as mensurem, já existem trabalhos, como o detalhado por Carter, Bitting e Ghorbani (2002), que tentam uma formalização de reputação enquanto atrelada a modelos de papéis prototípicos em SMA aplicados à partilha de informação.

O tratamento dado a grupos e a papéis no modelo $\mathcal{M o I S E}^{+}$se ajusta con-

\footnotetext{
${ }^{10}$ Parsons procurou desenvolver, nos anos 50, uma análise dos sistemas sociais, numa perspectiva estrutural-funcionalista.

${ }^{11}$ A qualidade de ser "confiável" pode ser decomposta, por sua vez, em diversos parâmetros, dependendo do grupo/papel ("constância", "honestidade" etc.). Porém, o mais interessante é que tende a ser um valor recíproco, i.e. geralmente confio em quem confia em mim.
} 
venientemente ao conceito de papel social, tal como adotado neste trabalho. Considerando uma rede pessoal, os agrupamentos associados à noção de grupo, tal como citado na seção 3.2 , junto com os papéis sociais identificados pela visão subjetiva do usuário, podem ser especificados usando o modelo organizacional MoISE $^{+}$(HÜBNER; SICHMAN; BOISSIER, 2002). Um grupo, no modelo $\mathcal{M o I S E}^{+}$, deve ser especificado como tendo um objetivo último. Isto é tratado considerando que o objetivo de um grupo é a troca de informações (tal objetivo poderia ser a sua simples sobrevivência) ${ }^{12}$.

Ao utilizar o modelo $\mathcal{M o I s E}^{+}$(vide a seção 3.3) no contexto do modelo de representação proposto, as dimensões organizacionais (estrutural, funcional e deôntica) são consideradas como segue:

- Dimensão Estrutural: os grupos e papéis sociais, na visão do usuário, passam a ser descritos por uma especificação estrutural;

- Dimensão Funcional: cada agente pode estabelecer a sua visão das ações esperadas em relação à obtenção de metas específicas dentro de cada grupo. O modelo comporta, dependendo da arquitetura adotada, uma situação em que exista um conjunto de objetivos que o usuário poderia associar a um papel (representando assim as ações esperadas em relação a um papel) ${ }^{13}$. Como caso particular, na abordagem deste trabalho, o modelo é orientado para o domínio de acesso à informação e cada agente possui apenas a descrição de uma estratégia para requisitar ou ceder informação;

- Dimensão Deôntica: caso sejam especificados os conjuntos de ações para domínios específicos, passaria também a ser tratada a "obrigatoriedade" de executar uma ação esperada, ou atingir um objetivo, em relação a um agente desempenhando um papel. Da mesma maneira, ao papel podem ser atreladas "qualidades" (que devem ser parametrizáveis, por exemplo, um papel pode ter associados um "tempo de execução máximo de atividades", ou a "obrigatoriedade de responder a uma requisição" ou, ainda, "tempo

\footnotetext{
${ }^{12} \mathrm{~A}$ noção de equipe, apresentada na seção 3.2 , pode ser considerada num estágio posterior, usando este mesmo modelo e identificando-a com os agrupamentos de agentes que estão envolvidos na execução de um Esquema Social (ES) como citado na seção 3.3.

${ }^{13}$ Por exemplo, num domínio de trabalho cooperativo semi-estruturado, os agentes poderiam ser dotados de capacidades como "preencher planilha", "copiar arquivo", "calcular valores" etc. que podem ser atrelados a papéis específicos.
} 
de permanência num grupo" etc.). Neste trabalho em particular, não será abordada esta dimensão no tratamento experimental.

A adoção do modelo $\mathcal{M}$ oISE $^{+}$traz consigo vantagens, tais como:

- O compromisso com uma representação formal de organização cuja semântica é conhecida e claramente explicitada. No caso de abrir mão da utilização do modelo $\mathcal{M o I S E}^{+}$, o agente não somente teria de adotar uma representação ad-hoc de organização (ou ainda alguma métrica de "proximidade" ou "confiança") mas, deveria ter uma forma de garantir a semântica das representações dos outros agentes. Isto não é um problema trivial em SMA abertos, pois, embora a abordagem proposta não aborde a coalizão de agentes onde dados organizacionais podem ser trocados, o modelo proposto comporta perfeitamente tal situação;

- A aplicação de uma especificação formal de organização para o caso de SMA onde a representação organizacional é centrada no agente, avança no sentido de explorar a noção de autonomia (enquanto relacionada aos efeitos da explicitação e uso da visão organizacional subjetiva do agente) ${ }^{14}$.

Segue um exemplo do uso do modelo $\mathcal{M O I S E}^{+}$no agente pretendido. A Especificação Estrutural, mostrada na figura 4.1, mostra a visão organizacional subjetiva de um agente no seu estado inicial. Cada papel possui associado o seu próprio nível de acesso ao conhecimento do usuário focalizado. O papel "desafeto" representa o espaço organizacional reservado a agentes que, por um motivo ou outro, não são dignos da confiança do usuário. Por este motivo é o papel que terá, eventualmente, o maior grau de restrições de acesso ao conhecimento.

Como era de se esperar, a Especificação Estrutural mostra um menor grau de restrições em relação, por exemplo, à especificação da figura 3.8. Especificamente no que diz respeito à compatibilidade e à comunicação, pois:

- Agentes com papéis diferentes do papel usuário podem comunicar-se com agentes que desempenhem o mesmo papel;

\footnotetext{
${ }^{14}$ Com base nesta proposta, trabalhos futuros podem tirar proveito das visões organizacionais subjetivas ligadas a ontologias, empregando-as como ponto de partida em diversas estratégias de trocas de conhecimento que podem ser estudadas e comparadas quantitativamente.
} 


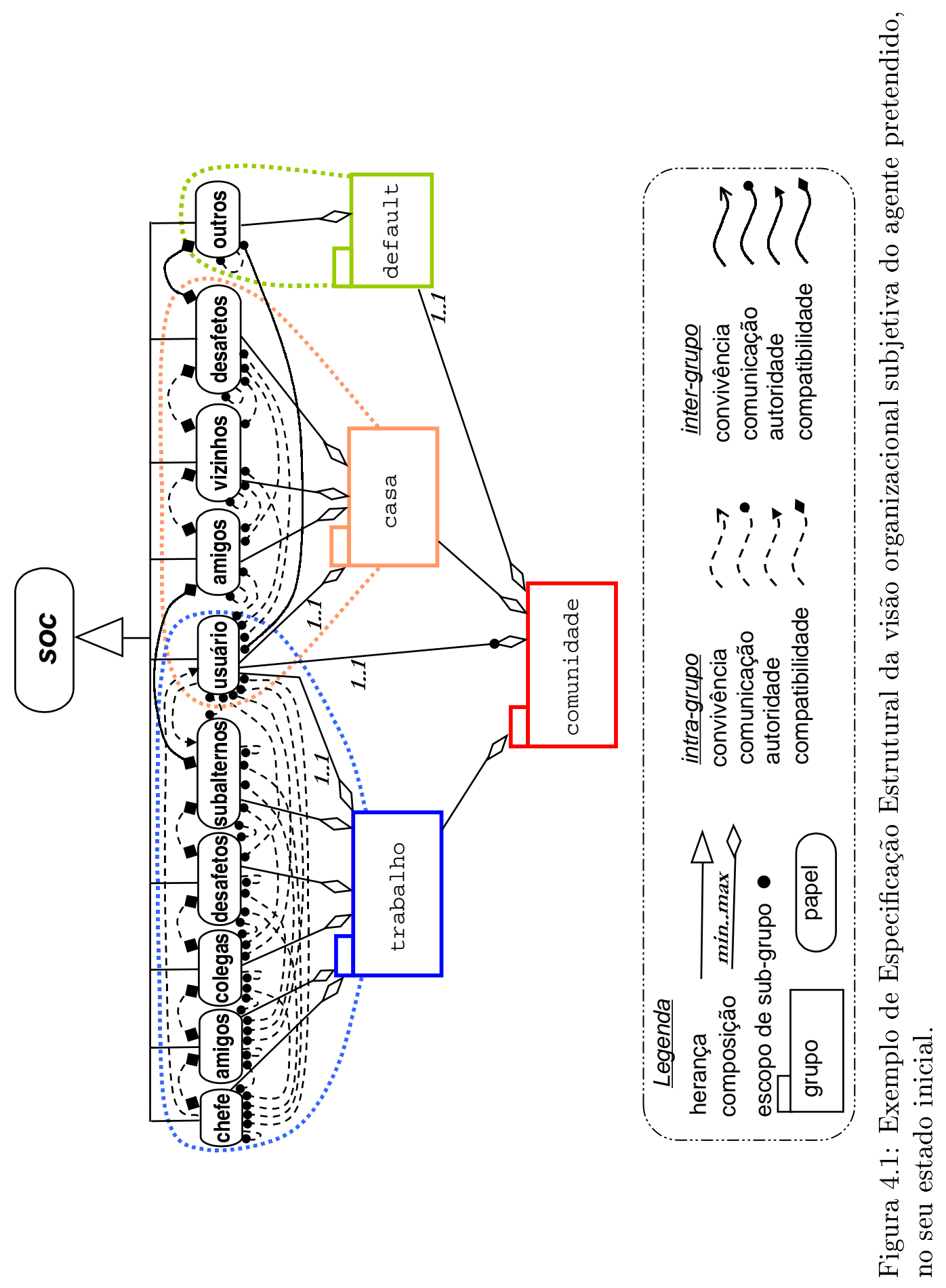


- Como hipótese inicial, agentes que desempenhem qualquer papel podem comunicar-se com qualquer outro agente, desempenhando papéis no mesmo grupo;

- O grupo raiz é o grupo comunidade;

- Existe apenas um agente desempenhando o papel de usuário, considerando todos os sub-grupos (trabalho, casa e default) do grupo comunidade (graficamente isto é dado pelo escopo de sub-grupo no grupo raiz);

- A transitividade da ligação de compatibilidade é utilizada de forma a permitir ao usuário humano a liberdade de designar agentes a papéis os mais diversos, com exceção do papel usuário, reservado ao agente do correspondente usuário focal (i.e. o usuário dono do agente).

A figura 4.2 mostra a Especificação Funcional típica do agente proposto. A mesma é um esquema social simples para troca de conhecimento, que é de fato a finalidade do SMA.

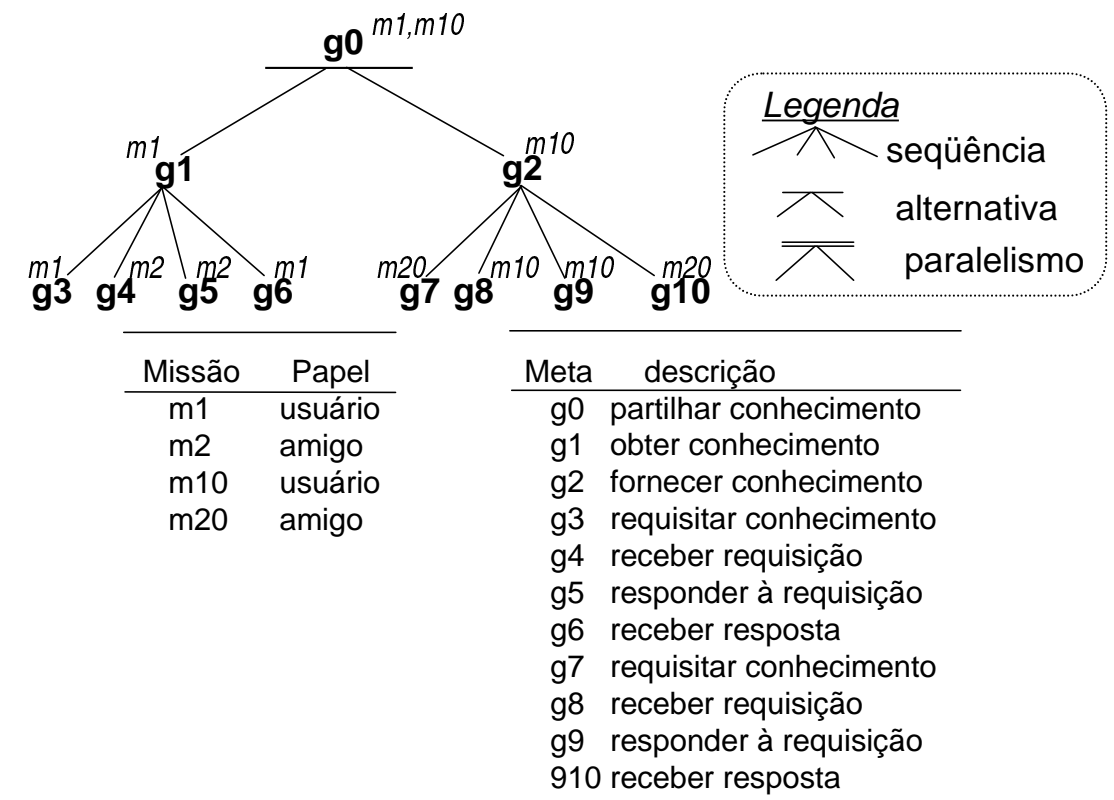

Figura 4.2: Exemplo de Especificação Funcional de um agente dedicado a partilhar conhecimento.

Já em relação à especificação deôntica, a mesma estabelece apenas que é dada a permissão para que qualquer agente, desempenhando qualquer um dos papéis, possa comprometer-se com qualquer uma das missões. 
Na seção seguinte é detalhada a proposta que permite a construção de ontologias que comportem a associação de papéis organizacionais a atributos de conceitos. Esta proposta é aplicada, como prova de conceito, a um modelo de representação baseado em frames.

\subsection{Ontologias com anotações organizacionais}

... Tendria que haber en nuestro lenguaje palabras que tengan voz. Espacio libre. Su propia memoria. Palabras que subsistan solas, que lleven el lugar consigo. Un lugar. Su lugar. Su propia materia. Un espacio donde esa palabra suceda igual que un hecho. Como en el lenguaje de ciertos animales, de ciertas aves, de algunos insectos muy antiguos. ¿Pero existe lo que no hay?...

\section{A. Roa Bastos - Yo el Supremo}

O objetivo de incluir novas meta-propriedades num meta-modelo conceitual (vide seção 3.4) utilizado na construção de ontologias é o de fornecer a um agente a oportunidade de poder manipular explicitamente informações organizacionais relacionadas a um conceito. Não se pretende construir um novo modelo de conhecimento para ontologias ${ }^{15}$, mas apenas fornecer a capacidade de representar descrições de atributos enriquecidas com semântica associada a interações sociais, quando da definição de conceitos em ontologias.

Será considerado que uma sociedade é a entidade organizacional de mais alto nível. Assim, uma ontologia mais geral pode estar atrelada à mesma. Igualmente, grupos, papéis e agentes podem ter ontologias específicas associadas. Os traços que as interconectam são desenhados através das ligações (e.g., temporais, autoridade etc.) organizacionais.

O conhecimento de um agente não deve ser considerado como coincidindo completamente com a ontologia de algum papel, pois a especificação de um papel pode mudar no percurso do tempo. Um papel indica o que se deve esperar de um agente, o que ele deveria saber, e não o que ele de fato conhece. O conhecimento de fato depende das experiências acumuladas pelo agente. Como discutido por Sichman e Conte (1998), um papel pode ser enriquecido pelas experiências de agentes que o desempenharam e vice-versa.

\footnotetext{
${ }^{15}$ Da mesma maneira que no trabalho de Tamma (2002).
} 
O alvo deste trabalho é a utilização de SMA para auxiliar comunidades humanas já existentes. Um ser humano geralmente mantém as suas ligações organizacionais através de índices para conceitos. Desta forma, não necessariamente diferencia ontologias distintas, mas acessa partes (não necessariamente disjuntas) do seu conhecimento, na medida em que são socialmente necessárias (e.g. dependendo do grupo), como sugerido por Maurice Halbwachs (HALBWACHS, 1990; LAVABRE, 2000) ${ }^{16}$. Um agente atuando para representar seu usuário pode tirar vantagem da mesma estratégia, caso utilize o contexto onde o conhecimento é necessário. Assim, uma informação importante que pode ser armazenada, dado um modelo de organização como o $\mathcal{M o I S E}^{+}$, está relacionada ao grupo onde o conhecimento foi utilizado e, mais especificamente, o Esquema Social, o papel e o plano que dele necessitaram. A representação específica de uma instância é a visão subjetiva de um agente que lembra a sua participação numa versão de um Esquema Social. Para recuperar uma fração particular de uma representação de conhecimento, um agente pode usar as ligações temporais desenvolvidas através da memória dos grupos (i.e. agentes especializados, ligações de comunicação) aos quais pertenceu. Para tanto, um mecanismo conveniente deve ser adicionado aos modelos existentes para elaborar ontologias.

O enfoque a seguir é complementar ao de Tamma e Bench-Capon (2001), porém, focalizando um aspecto diferente da manipulação de ontologias, qual seja a noção de situar conceitos sociais/individuais num contexto organizacional. Como apontado por Halbwachs (HALBWACHS, 1990; LAVABRE, 2000), a memória possui um caráter eminentemente social. O agente, nesta visão, passa de ser considerado apenas um "ser no mundo" para ser um "ser com os outros"17. Assim, adicionalmente às meta-propriedades descritas por Welty e Guarino (2001) (identidade, rigidez, unidade e dependência), são agregadas três meta-propriedades relacionadas a características sociais do conhecimento:

- Situação de aquisição e atualização: esta propriedade permite descrever as situações socio/organizacionais, i.e. um estado-do-social-no-mundo,

\footnotetext{
${ }^{16}$ Os trabalhos de Maurice Halbwachs propõem uma visão sociológica coletiva da memória, como contraposição à tese, de cunho mais psicologicista, que concebe a memória apenas como experiência individual egocêntrica. Tais idéias foram desenvolvidas na década de 30, sendo popularizadas a partir da década de 50.

${ }^{17}$ No dizer de Simone de Beauvoir, "não há uma polegada do meu caminho que não passe pelo caminho do outro".
} 
quando da aprendizagem de um atributo como sendo descritor de um conceito. Por exemplo, um agente pode aprender que o atributo aprendizadoDeMáquina está relacionado ao conceito inteligênciaArtificial. O contexto no qual este aprendizado (no espaço conceitual) tomou lugar pode ter sido o de uma sala de aula (o espaço físico) onde um experimento estava sendo conduzido, no qual diversos agentes desempenhavam papéis como aluno ou professor (o espaço organizacional). Esta experiência poderia ser marcada com a data do acontecimento, o resultado do esquema social executado para realizar o experimento sendo conduzido (grau de sucesso ou insucesso), a importância da experiência para o agente (por exemplo associável ao seu grau de interesse) e a visão organizacional subjetiva do agente que aprendeu (quais outros agentes eram alunos, quem era o professor etc.). Como um mesmo conceito pode ser re-atualizado em diversas ocasiões, esta propriedade permitiria rastrear o seu percurso de aprendizagem ${ }^{18}$.

- Situação de uso: esta propriedade permite descrever as situações sócioorganizacionais de utilização de um atributo que descreve um conceito que já tenha sido aprendido. Existem dois tipos de situações:

- i) Quando o agente utiliza um atributo pertencente a um conceito e decide armazenar o fato. Por exemplo, um agente pode registrar a utilização do atributo representaçãoDeConhecimento para referenciar o conceito engenhariaDeConhecimento ao especificar o objetivo de um projeto a ser desenvolvido por um grupo de pesquisa;

- ii) Quando o agente observa a utilização de um atributo por um outro agente e decide registrar a experiência. Este caso pode ser considerado um caso especial de aprendizado, quando um agente lembra um fato mas não necessariamente adota o conceito ${ }^{19}$. Por exemplo, um agente Tião pode registrar o fato de observar numa reunião que um outro agente João utilizou o atributo métodosNuméricos para referenciar o conceito inteligênciaArtificial. Digamos que para João a associação feita por Tião entre o atributo e o conceito seja considerada incorreta. Mesmo assim, João pode decidir registrar a situação, pois pode vir a

\footnotetext{
${ }^{18}$ Uma espécie de manifestação da sua adaptação cognitiva/organizacional a novos meios.

${ }^{19}$ Caso um agente observe outro e depois decida pela incorporação, tal situação seria registrada duas vezes, a primeira indicando o uso observado e a segunda indicando o aprendizado.
} 
ser de utilidade numa outra situação (João pode decidir referenciar esta experiência como contra-exemplo) ou, quem sabe, pode ser o ponto de partida para iniciar uma negociação entre ambos de forma a definir melhor o conceito inteligênciaArtificial e/ou seus atributos.

Este tipo de experiência poderia ser marcada com a data do acontecimento, a avaliação que o agente observador faz da adequação do uso do atributo pelo agente observado, a importância da experiência para o agente observador (por exemplo associável ao seu grau de interesse) e a visão organizacional subjetiva do agente observador (quais eram os papéis desempenhados pelos diversos agentes que participaram da experiência). Como um mesmo conceito tende a ser re-utilizado em diversas ocasiões, esta propriedade permitiria rastrear, por exemplo, o grau de confiança de um agente na sua crença sobre a contribuição de um atributo na descrição correta de um conceito ${ }^{20}$.

- Acessibilidade social: permite a um agente discriminar explicitamente os atributos e os conceitos que devem ser considerados privados, diferenciandoos dos que podem ser partilhados (e.g. publicamente num grupo). Por exemplo, um agente Enrico pode perfeitamente interagir com outro agente George considerando o conceito reaçãoNuclearEmCadeia num certo grupo "discussão", mas não necessariamente elicitará alguma informação sobre o valor do atributo seqüênciaDeAtivação sobre o qual ele desenvolve trabalhos e partilha informações num outro grupo "pesquisa". A necessidade de diferenciar (situando socialmente) o conhecimento "público" do "privado" é especialmente crítico quando são considerados agentes autônomos colaborativos num SMA aberto, dado que os mesmos devem ser capazes de contar uns com os outros, considerando as metas de outros agentes e possuindo atitudes em relação àquelas metas (SICHMAN et al., 1994; CASTELFRANCHI, 1998).

Estas meta-propriedades precisam referenciar um modelo formal de organização para SMA de forma a descrever explicitamente um estado organizacional. Para tanto é adotado o modelo $\mathcal{M O I S E}^{+}$.

Como prova de conceito, estas meta-propriedades devem ser aplicáveis a uma forma específica de representação do conhecimento. Da mesma maneira que no

\footnotetext{
${ }^{20}$ Uma manifestação de reforço cognitivo e/ou organizacional.
} 
trabalho de Tamma (2002), a representação escolhida foi OKBC por ser muito conhecida pela comunidade que estuda ontologias e por fornecer facilidades para ser estendida de forma a comportar novas características.

Para cada uma das meta-propriedades sugeridas é definida uma faceta correspondente, a ser implementada como extensão do modelo OKBC para armazenar o contexto organizacional ao qual (atributos de) conceitos estão atrelados:

\section{a)Situação Organizacional de Aquisição de Conhecimento (KAOS}

- Knowledge Acquisition Organizational Situation): permite evocar o estado organizacional onde o conhecimento foi aprendido. Como podem existir múltiplas anotações deste tipo (um conceito pode ser modificado muitas vezes), ela é definida como um conjunto $\left\{\left(l v_{k}, t i d_{k}, g i_{k}, s s i_{k}, r_{k}, m_{k}, d_{k}, o_{k}, i_{k}\right) \mid\right.$ $k=1, \ldots, m\}$, onde:

- $l v_{k}$ guarda o valor aprendido, ou seja, o estado de um par atributo-valor (ou slot-valor) associado ao slot (ou conceito);

- $t i d_{k}$ é o identificador da construção organizacional (por exemplo, agente, instância de grupo) que de fato ensinou o atributo (ou slot);

- $g i_{k}$ é o identificador da instância de grupo $(g i)$ que o agente agt quer registrar;

- $s s i_{k}$ é o identificador da instância de um esquema social (ssi) que o agente agt quer registrar;

- $r_{k}$ registra o papel de $t i d_{k}$, ou pode ser vazio;

- $m_{k}$ é a missão particular que estava sendo executada quando o atributo foi aprendido;

- $d_{k}$ armazena o rótulo temporal utilizado para indicar quando o atributo foi aprendido;

- $o_{k}$, registra a crença do agente em relação ao resultado da execução do esquema social dentro do qual o valor foi aprendido. Pode ir de 0.0 (falha total), até 1.0 (sucesso absoluto). 
- $i_{k}$ é um valor real associado à crença do agente agt quanto ao grau de importância da experiência que envolveu o aprendizado do conhecimento. A faixa de valores vai de 1.0 (experiência muito importante) a 0.0 (sem importância alguma). Este valor é diferente de $o_{k}$ podendo ser associado à utilidade de certo conhecimento aprendido. Por exemplo, se uma ligação de autoridade foi estabelecida ao aprender certo conhecimento, então o valor pode depender de qual é o papel sobre qual a autoridade foi criada, ou ainda do número de agentes que estava desempenhando tal papel.

Esta faceta é aplicável ao caso em que um agente adquiriu uma parte do seu conhecimento através de boato ou alguma forma mais normativa, i.e. através de regras de interação que fazem parte de uma organização formalmente estabelecida. Ela pode armazenar a identidade da entidade organizacional que a ensinou, o que pode ser usado num grupo para determinar qual o indivíduo cujo conhecimento foi socialmente adotado, i.e., quando foi aprendido algo e com quem.

\section{b)Situação Organizacional de Uso de Conhecimento (KUOS - Kno-} wledge Usage Organizational Situation): permite evocar o estado organizacional onde o conhecimento foi usado por um agente agt. Como podem existir múltiplas (digamos $n$ ) anotações deste tipo, ela é definida como um conjunto $\left\{\left(a g_{k}, d s_{k}, g i_{k}, s s i_{k}, r_{k}, m_{k}, d_{k}, a_{k}, i_{k}\right) \mid k=1, \ldots, n\right\}$ onde:

- $a g_{k}$ é o identificador do agente que utilizou o atributo: seja ele o próprio agente agt ou algum outro agente $a g_{\text {alter }}$ que foi observado;

- $d s_{k}$ é uma descrição textual opcional;

- $g i_{k}, s s i_{k}, r_{k}, m_{k}$ e $i_{k}$ usam a mesma definição estabelecida para a faceta KAOS. $r_{k}$ é o papel específico que o agente $a g_{k}$ estava desempenhando quando da utilização do atributo;

- $d_{k}$ registra o rótulo temporal indicando quando o valor foi utilizado;

- $a_{k}$ é um valor real relacionado à crença do agente sobre o grau de propriedade no uso do atributo. A faixa vai de 1.0 (absolutamente apropriado) até -1.0 (absolutamente inadequado). Este valor pode ser retirado, por exemplo, do grau de sucesso (ou insucesso) na execução de uma determinada 
missão (sob a responsabilidade do agente $a g_{k}$ ), que pode ser bem sucedida mesmo que o esquema no qual está incluído falhe;

c)Acessibilidade (Access): esta faceta indica se e quando uma entidade (e.g. agente, grupo) pode ter acesso ao atributo. Podem existir múltiplas instâncias desta faceta, pois um conceito pode ter permissões diferentes para papéis de um mesmo grupo. É definido como um conjunto $\left\{g t_{k}, g i_{k}, r_{k}, a g_{k}\right.$, $\left.s p v_{k}, \mid k=1, \ldots, p\right\}$, onde:

- $g t_{k}$ é o tipo de grupo ao qual é permitido o acesso a certo conhecimento. Este campo pode ser vazio de forma a permitir casos em que uma instância de grupo ou um agente específico possui permissão (se é especificada a instância de um tipo de grupo, que é considerada como sendo única, não há necessidade de especificar também o tipo de grupo);

- $g i_{k}$ é a instância de grupo que pode acessar o conhecimento. Este campo pode estar vazio, permitindo que todas as instâncias de um tipo de grupo possam ter acesso ao conhecimento;

- $r_{k}$ é o papel ao qual é permitido acesso ao conhecimento. Como um papel deve ser considerado no contexto de um tipo de grupo, o valor deste campo deve ser considerado apenas quando $g t_{k}$ ou $g i_{k}$ possuem valores associados;

- $a g_{k}$ é um agente específico que tem permissão de acesso ao conhecimento. Este valor pode estar vazio;

- $s p v_{k}$ é o valor do grau de acesso permitido para o conhecimento. O valor inicial é sempre privado.

Na figura 4.3 aparecem elementos das três facetas definidas, mostrando os seus respectivos parâmetros.

A título de ilustração, será considerada a ontologia própria do agente $J o \tilde{a} o$, cuja linha de existência temporal aparece parcialmente representada na figura 3.6. Na figura 4.4 aparecem as situações recuperadas através das anotações KAOS e KUOS.

João teria adquirido e utilizado o conceito apresentado na seção 3.4. A expressão agora, neste exemplo, corresponderá ao dia primeiro de dezembro de 2010 . 

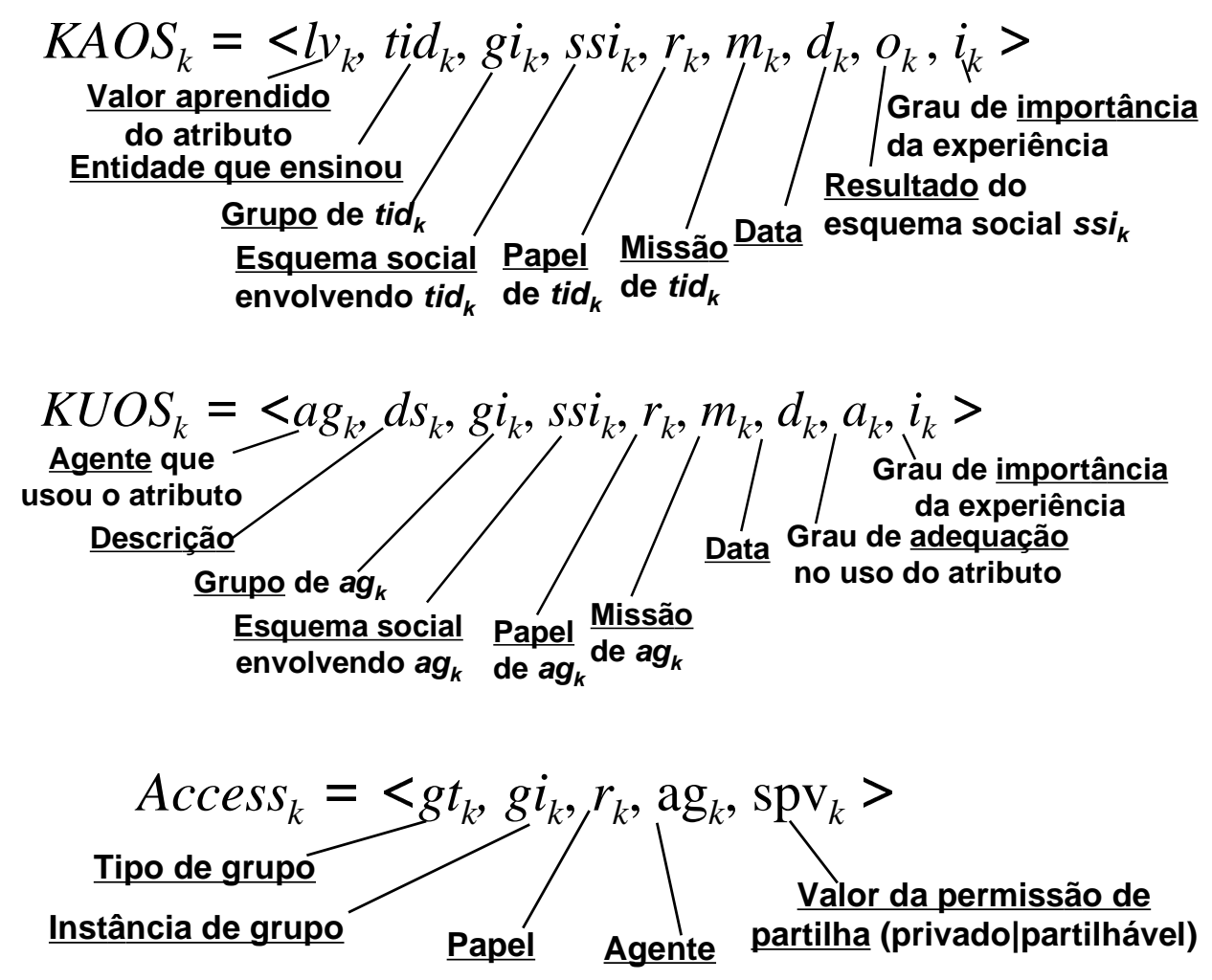

Figura 4.3: Elementos das facetas $K U O S, K A O S$ e Access.

Assim, através do uso das facetas recém definidas o conceito poderia apresentar-se anotado como segue:

c:MachineLearning;

a: NeuronSimulationActivationPotential

f: Domain:[0.0,1.0];

f: Value: $[0.4,0.6]$;

f: KUOS:[Myself,-,G5,81,professor,m5,1Dez2010,0.9,0.8];

f: KUOS:[Myself,-,G4,70,professor,m3,4Jun2010,0.9,0.6];

f: KUOS:[Pedro,-,G4,71,estudante,m5,3Mai2010,0.6,1.0];

f: KAOS:[[0.4,0.6],Dina,G7,w,colega,m6,12Ago2003,0.9,1.0];

f: KAOS:[[0.5,1.0],Ale,G73,v1,professor,m2,23Nov2000,0.8,0.3];

f: Access:[docentes,-,-,-,partilhável];

f: Access:[-,G5,assistente,Pedro,partilhável];

Com as anotações, o exemplo agora expressa que o atributo foi usado 3 ve- 

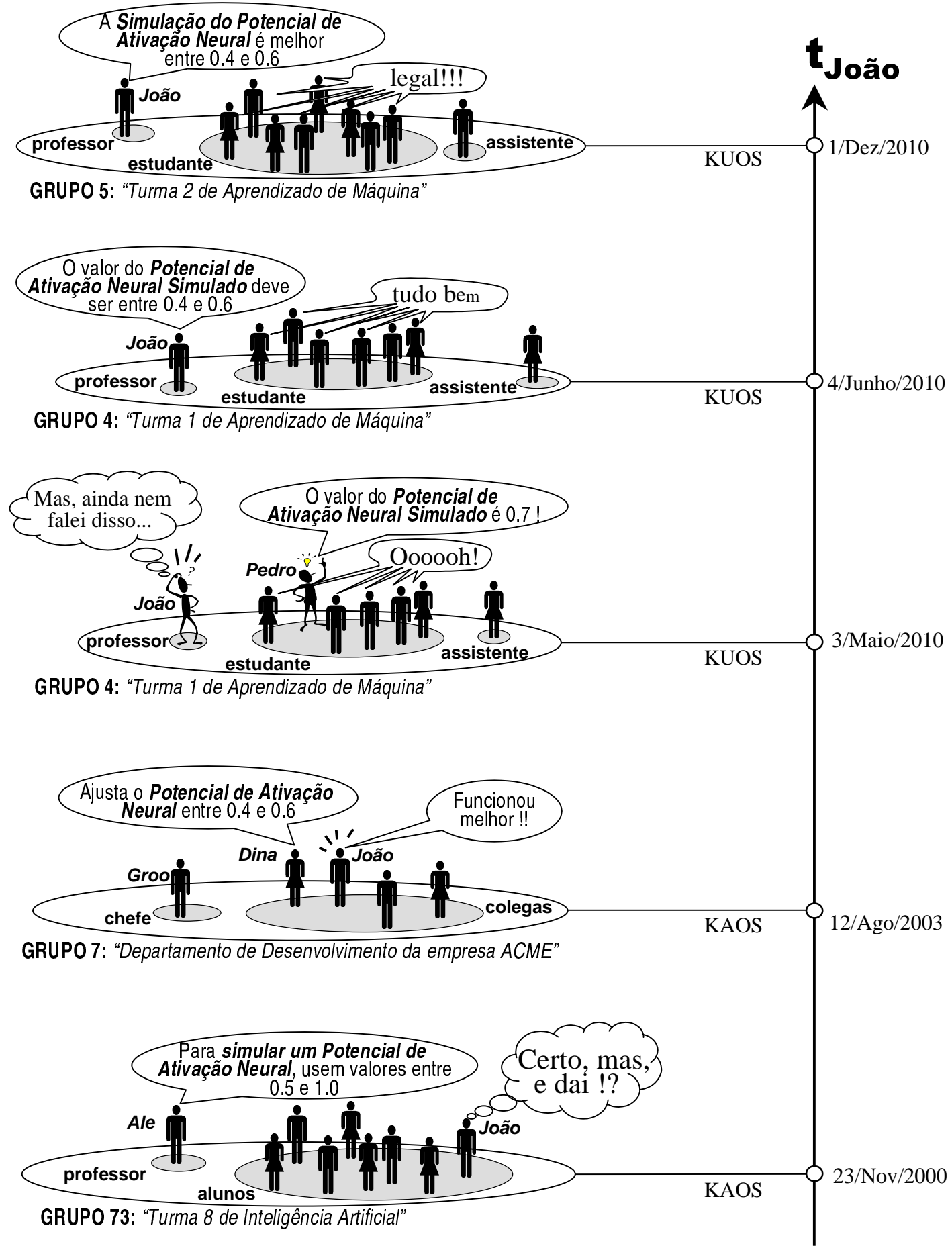

Figura 4.4: Linha temporal do agente João com as situações recuperadas através das anotações propostas, atreladas ao conceito NeuronSimulationActivationPotential. 
zes $(K U O S)$, que existiram duas situações de aquisição $(K A O S)$ e que há duas entidades organizacionais com permissão de acesso(Access).

A terceira linha KUOS indica que João observou que Pedro da instância de grupo G4 (uma instância do tipo de grupo turma, da especificação estrutural da figura 3.8) executou a instância 71 de um esquema social como estudante. Pedro usou o conceito em certa missão $m 5$ no dia 3 de maio de 2010, sendo que João julgou que o grau de adequação foi 0.6 , o que ele considerou muito importante, como mostra o valor de importância 1.0. Podemos supor que João escolheu esse valor, pois embora Pedro não estivesse realmente certo (segundo João), ele observou que Pedro desenvolveu uma ligação de autoridade sobre os seus colegas (estudantes) após usar o conceito. Pela segunda linha KUOS, João parece ter "ensinado" o valor "correto" somente um mês depois de Pedro tê-lo usado. Outro enfoque para obter o valor da importância pode levar em conta a combinação dos índices de João com os de Pedro, como nas redes de crenças.

A segunda linha $K A O S$ indica que [0.5,1.0] foi a faixa aprendida para o valor e quem ensinou foi Ale, numa instância de grupo G73, executando uma instância de esquema $v 1$; ainda, Ale desempenhava o papel de professor e estava executando uma missão m2. A situação teve lugar "dez anos atrás" (no ano 2000) e o resultado de esquema $v 1$ foi considerado muito satisfatório por João (vide o valor 0.8) embora João não a considerou realmente importante (somente 0.3). Como este é o primeiro valor de $K A O S$, considerando a data, este foi o primeiro valor aprendido por João para este atributo, no qual ele continuou acreditando por três anos, até que Dina o "ensinou" corretamente (algo muito importante para João, como o valor de importância de 1.0 indica na segunda linha $K A O S$ ).

A primeira linha Access indica que qualquer agente desempenhando qualquer papel de qualquer instância do tipo de grupo docentes terá acesso ao valor do atributo. O mesmo vale para Pedro, desde que ele seja assistente na instância de grupo G5 (outra instância do tipo de grupo turma) como indica a segunda linha Access.

Do ponto de vista de uma implementação computacional, o valor de $o_{k}$ depende diretamente do resultado de ações estruturadas através de esquemas sociais seguindo o modelo $\mathcal{M o I S E}^{+}$. Por outro lado, diversas métricas e/ou heurísticas podem ser adotadas para fornecer valores quantitativos para os parâmetros $i_{k} \mathrm{e}$ 
$a_{k}$, dependendo do domínio de aplicação. Por exemplo, considerando uma aplicação em RI, para dar valores a $i_{k}$ pode-se:

- Verificar se um determinado termo (atributo) é utilizado (situação de uso) toda vez que é realizada uma consulta em relação a um conceito;

- Verificar se a freqüência de uso um termo (atributo) em particular, considerando uma janela temporal (semana, mês etc.) atinge um valor predeterminado.

No caso de $a_{k}$, pode-se:

- Verificar se os documentos recuperados através da utilização de um determinado termo (atributo associado a um conceito) são efetivamente lidos (verificação do tempo de leitura), impressos ou desconsiderados;

- Verificar se um agente $a g_{A}$ que recebe uma requisição de um outro agente $a g_{B}$ empregando um determinado termo (atributo), utiliza como valoração o valor que ele próprio $\left(a g_{A}\right)$ designou ao termo como descritor correto do conceito abordado;

- Verificar se um novo atributo, recebido de um agente como resposta a uma requisição sobre um conceito (feita quem sabe utilizando um outro conjunto de termos, i.e. atributos), é utilizado com assiduidade por outros agentes do mesmo grupo ao qual pertence o agente que respondeu.

\title{
4.3 Exemplo de raciocínio
}

\author{
saber é pouco \\ como é que a água do mar \\ entra dentro do coco? \\ P. Leminski - La vie en close
}

Embora necessário, o mecanismo apresentado é inútil sem um mecanismo de raciocínio interno ao agente. Uma ontologia à qual este tipo de informação foi adicionada é organizacionalmente situada. Na verdade, as facetas definidas 
permitem processar informação num nível de detalhe que pode ir além da granularidade de uma especificação organizacional no $\mathcal{M o I S E}^{+}$. Isto é feito de forma a permitir a manipulação de situações que podem aparecer no nível de agentes, i.e., de instâncias.

Na figura 4.5 é mostrado um exemplo, ilustrando uma possível construção mental do agente João.

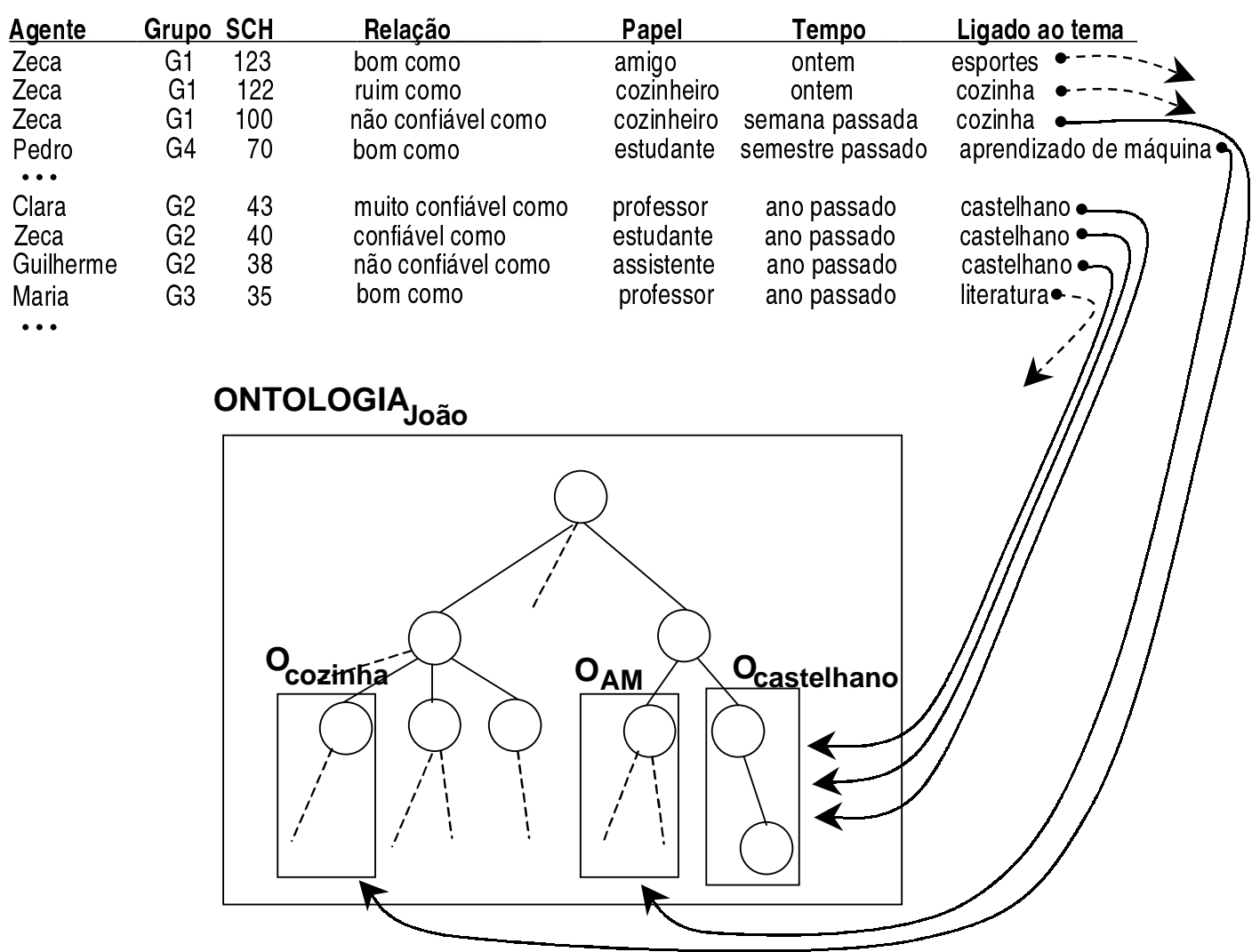

Figura 4.5: Um agente João raciocinando sobre outros agentes num contexto organizacional e relacionando-os a partes da sua ontologia $O_{\text {João}}$.

A tabela da figura 4.5 representa parte das informações concernentes às suas representações das situações organizacionais nas quais participou (com as suas impressões sobre os agentes Zeca, Pedro, Clara, Guilherme e Maria). OJoão é a ontologia completa de João, a sua representação do seu próprio conhecimento. Usando as facetas definidas, João tem agora diversas formas de aceder à sua (de outra forma "monolítica") ontologia $O_{\text {João }}$. Caso alguém pergunte a ele sobre "castelhano", e ele pense que o seu conhecimento de castelhano (indicado por $O_{\text {castelhano }}$ e fazendo parte de $\left.O_{J o a ̃ o}\right)$ não é suficiente para uma situação, ele poderá procurar agora entre os seus conhecidos aqueles que se mostraram 
capacitados (digamos acessando os $i_{k}, o_{k}$ ou $a_{k}$ ) quando do uso $(K U O S)$ e/ou da aquisição $(K A O S)$ de conhecimento sobre castelhano ${ }^{21}$. Por exemplo, João poderia executar o seguinte raciocínio:

i) João precisa traduzir um documento que está escrito em castelhano;

ii) O documento contém um grande número de palavras desconhecidas em castelhano;

iii) João decide que precisa de ajuda para traduzir o documento;

iv) João verifica as anotações (KAOS e KUOS) que aparecem nos atributos dos conceitos de $O_{\text {castelhano }}$ para tentar localizar agentes associados ao tema;

v) João encontra que os agentes Zeca, Guilherme e Clara aparecem nas anotações (a fig.3.6 mostra os grupos nos quais esses agentes aparecem):

- Clara é muito confiável como professora da turma de castelhano (e aparece muitas vezes ensinando, i.e. via $K A O S$, novos termos);

- Guilherme é não confiável como assistente da turma de castelhano (várias vezes empregou termos de forma errada, digamos via $K U O S)$;

- Zeca é confiável como estudante (empregou termos corretamente em muitas ocasiões, i.e. $K U O S$ ) e ainda ensinou ao João vários termos (i.e. aparece também via $K A O S$ );

vi) João verifica se os três agentes aparecem em outros papéis, mesmo não relacionados a $O_{\text {castelhano. }} Z$ eca é o único que também aparece (como amigo ${ }^{22}$ e como cozinheiro ${ }^{23}$ );

vii) De acordo com a representação organizacional, João verifica que através do papel amigo, Zeca, dentre os três, é aquele com o qual terá maior facilidade para estabelecer uma negociação, pois:

\footnotetext{
${ }^{21} \mathrm{Na}$ verdade, a coluna "relação" da figura 4.5 pode ser substituida pelos parâmetros das facetas definidas $\left(e . g ., i_{k}, o_{k}\right.$ ou $\left.a_{k}\right)$.

${ }^{22} \mathrm{Na}$ primeira linha da tabela da figura 4.5.

${ }^{23} \mathrm{Na}$ segunda e terceira linhas da tabela 4.5.
} 
- Temporalmente, Zeca pertence ao seu círculo de amizades desde o ano passado até agora;

- O papel desempenhado por Clara estabelecia uma relação de autoridade sobre o papel que João desempenhava;

- Não houve outras interações com Guilherme e Clara desde o ano passado.

viii) João decide então pedir ajuda ao Zeca para a tradução.

Numa outra perspectiva, poderia ser contemplada uma aplicação no domínio de Educação à Distância (EAD). Seja uma turma $T_{E A D}$, onde os papéis considerando a visão organizacional subjetiva de um aluno Paulo podem ser professor, especialista, amigo e colega. O papel de especialista estaria reservado àqueles alunos que possuem maiores conhecimentos sobre os assuntos do curso. Seja o $a g t_{P e d r o}$ o agente dedicado a Pedro. Provavelmente, numa situação inicial $a g t_{P e d r o}$ terá acesso mais amplo apenas aos recursos dos seus amigos.

No caso de cursos de EAD, é freqüente a distribuição geográfica e ocupacional (e.g. empresas diferentes) dos alunos, o que tende a provocar um nível (inicial) de coesão social muito baixo entre os mesmos. Com isso, os alunos iniciam o curso sabendo muito pouco uns sobre os outros (e.g. com poucos amigos). Um agente computacional que siga os moldes da proposta pode auxiliar na identificação de possíveis parceiros (considerando o conhecimento nos tópicos do curso). Ao observar o resultado dos trabalhos em equipe, disponibilizados publicamente (e.g. numa página acessível a todos os alunos), o agente pode avaliar continuamente (utilizando $K U O S / K A O S$ ) os colegas, e.g. escolhendo os que apresentaram mais inovações corretas $(K A O S)$ ou usos mais consistentes (KUOS).

Um exemplo de regra para avaliar atributos poderia ser simplesmente o fato de aparecerem em trabalhos que obtiveram "boas notas" (e/ou contiveram um maior número de referências bibliográficas novas, mais recentes etc.), outra poderia ser a apresentação do maior número de atributos novos nesses trabalhos. De todo modo, o agt $t_{\text {Pedro }}$ observando o desempenho dos outros alunos, poderia promover a mudança automática de papéis para alguns deles. Por exemplo, alguns dos colegas podem passar a ser considerados especialistas e vice-versa. A manipulação da visão organizacional subjetiva pode ser viabilizada através de regras que podem 
ser explicitadas ao aluno (e.g. Pedro) e apresentadas ao mesmo para que ele determine os seus próprios patamares de (in)satisfação.

Na seção seguinte é descrito um cenário que ilustra uma situação onde são dadas as condições necessárias para implementar o mecanismo apresentado.

\subsection{Cenário}

"Mas eu não quero me encontrar com gente louca", observou Alice.

"Você não pode evitar isso", replicou o gato.

"Todos nós aqui somos loucos. Eu sou louco. Você é louca".

"Como você sabe que eu sou louca?", indagou Alice.

"Deve ser", disse o gato, "ou não teria vindo aqui".

L. Carrol - Alice no País das Maravilhas

Para atingir computacionalmente um raciocínio semelhante ao ilustrado na seção 4.3, é necessário um processamento computacional anterior. O quadro pode ser representado através de um cenário onde deve ser executada uma seqüência de passos, tendo como entradas as mensagens de e-mail e os documentos do usuário, assim como uma ontologia inicial:

i) Os arquivos e mensagens devem ser processados e indexados segundo os atributos dos conceitos pertencentes à ontologia inicial que passa a ser anotada;

ii) Adicionalmente, o processamento das mensagens de e-mail fornece os dados para a construção da rede pessoal;

iii) Os contatos da rede pessoal devem ser estruturados em grupos e papéis pelo usuário, seguindo o modelo $\mathcal{M O I S E}^{+}$;

iv) A partir da ontologia anotada, o agente pode localizar os contatos relacionados a um mesmo conceito e vice-versa, i.e. a partir do modelo organizacional e das anotações na ontologia, o agente possui informação explícita para identificar os conceitos referenciados por contatos que pertencem a um mesmo grupo ou papel. 
Desta forma, seja o mesmo usuário fictício João, com arquivos e mensagens de e-mail como na figura 4.6. As mensagens mostram o destinatário, o assunto, a data de envio e eventuais arquivos em anexo.
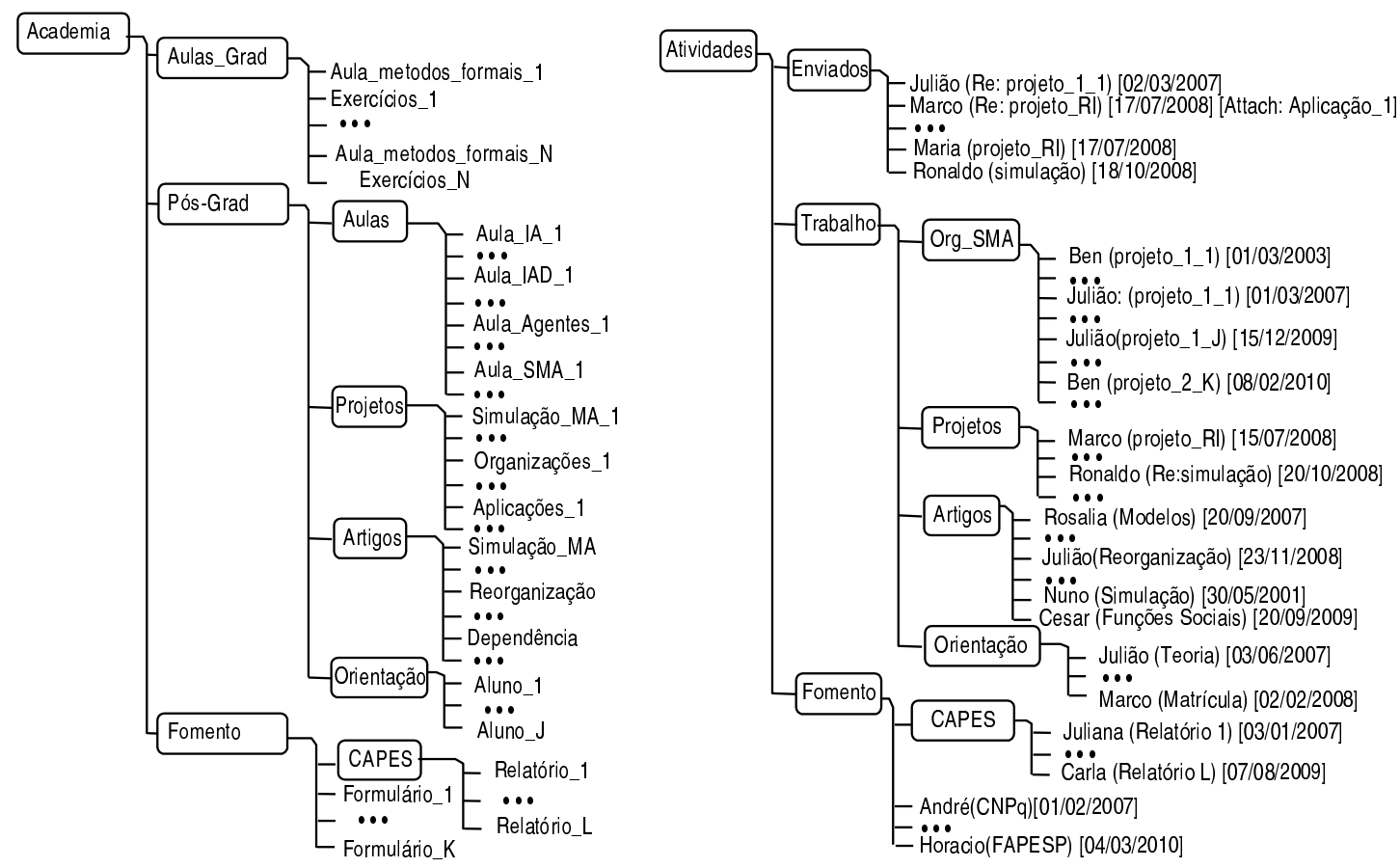

Figura 4.6: Arquivos (à esq.) e mensagens de e-mail (à dir.) do usuário fictício João.

O agente do usuário João possui também com uma certa ontologia inicial, que passará a ser anotada. Cada conceito dessa ontologia possui termos associados que são considerados como os seus atributos. O resultado do processamento dos arquivos, poderia ser apresentado como mostrado na figura 4.7, onde os termos foram utilizados para identificar os conceitos nos documentos e nas mensagens. Os documentos podem estar indexados sob mais de um conceito. Isto corresponde à primeira das fases enunciadas.

Num segundo instante, o agente dedicado ao João pode construir a sua rede pessoal, analisando as mensagens de $e$-mail. O resultado poderia apresentar-se tal como está ilustrado na figura 4.8. Quanto maior a freqüência das comunicações com João, mais próximo dele um contato é representado nesta figura.

Num terceiro momento o agente, através de interações com o usuário, deve estruturar os contatos da rede social segundo a visão dos grupos e papéis do usuário, respeitando o modelo $\mathcal{M} \mathrm{oISE}^{+}$. 


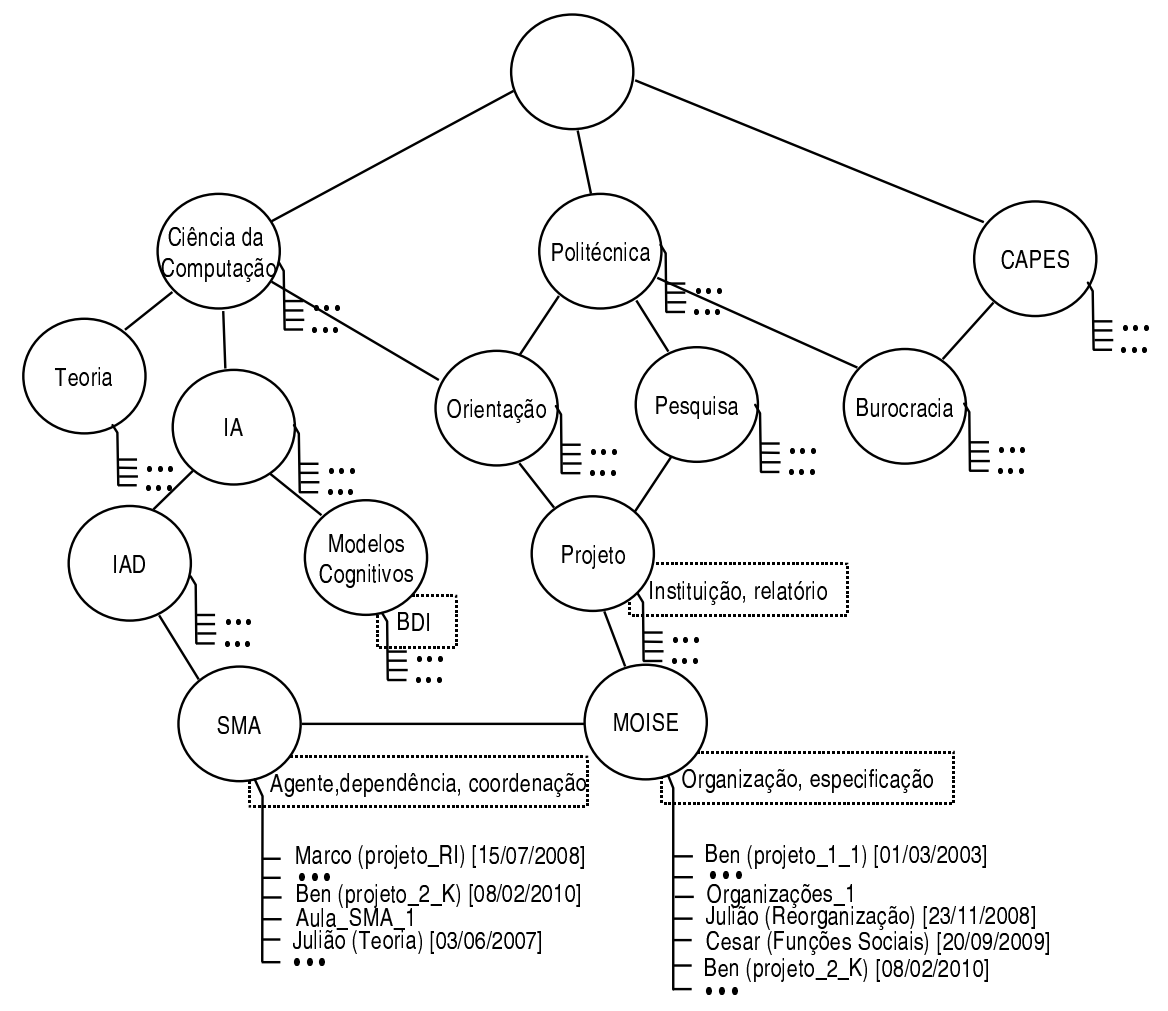

Figura 4.7: Ontologia inicial indexando os arquivos e mensagens do usuário fictício João.

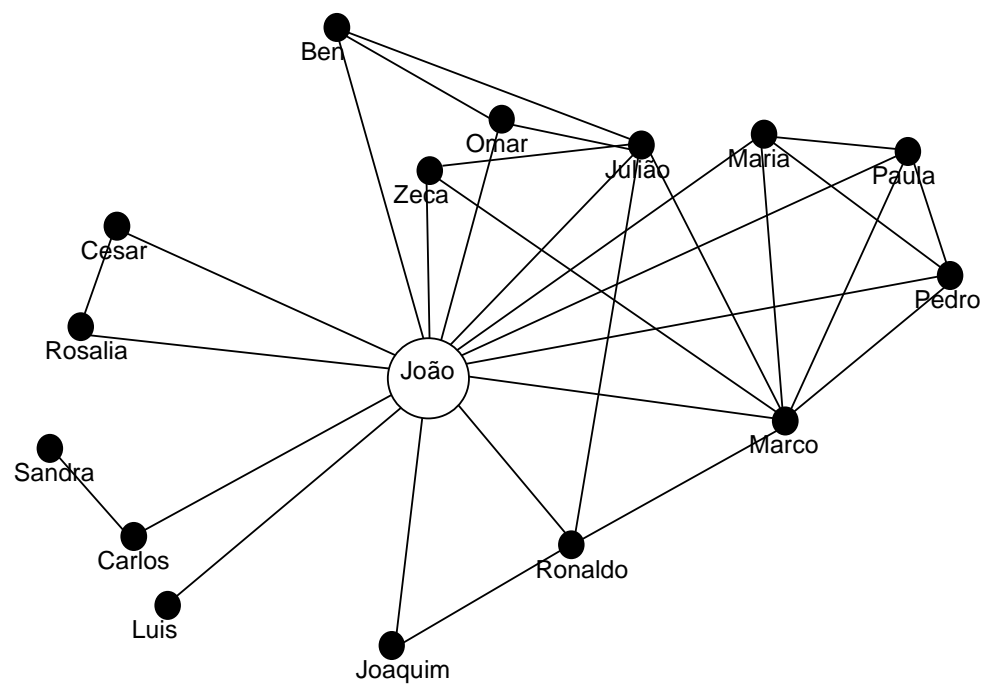

Figura 4.8: Rede pessoal do usuário fictício João. 
Cumpridas as três primeiras fases, a ontologia pode ser combinada com os dados das mensagens, o que permite mapear quais os conceitos aparecem relacionados a cada contato e vice-versa. Esta situação está representada na figura 4.9. Este passo considera os contatos da rede social do usuário fictício João, identificados pelo usuário como formando um grupo (ou papel social).

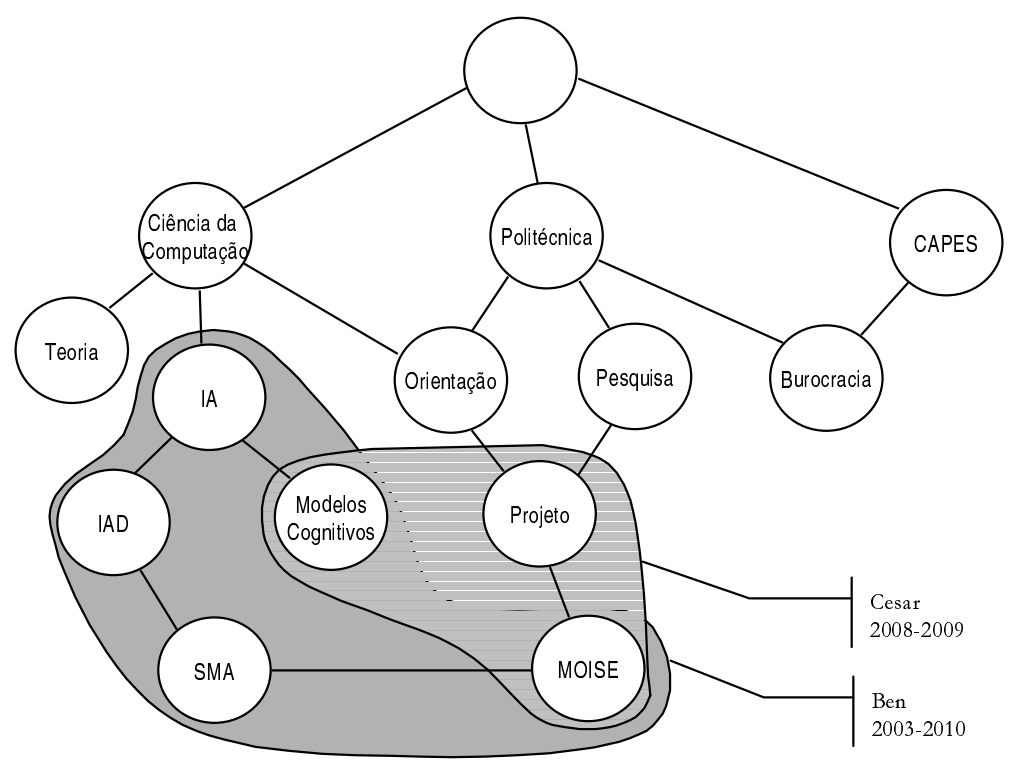

Figura 4.9: Identificação de um subconjunto da ontologia situada do usuário, correspondente a um grupo (ou papel social).

Quando o agente dedicado ao João atinge este ponto, ele está pronto para começar a mediar as interações de João com outros usuários. Assim, quando ocorre a interação entre o agente do usuário João com outros agentes do mesmo tipo, o agente dedicado ao João possui também a capacidade de atualizar os conceitos através das anotações propostas, alterando de forma dinâmica a associação entre conceitos e contatos pessoais. Ao se dispor de tal processamento, o resultado é a capacidade de representar de forma simultânea, o conhecimento anotado do usuário, atrelado a uma visão orgânica da sua rede social. Isto é representado na figura 4.10, onde são apresentados dois grupos de contatos, apontando para períodos de tempo distintos, de forma simultânea como subconjuntos da ontologia situada do usuário fictício João e como contatos na sua rede social.

Na seção seguinte é apresentada uma arquitetura de agente baseada na proposta. Esta arquitetura específica é dedicada à partilha de conhecimento entre agentes que pertencem a uma comunidade. 


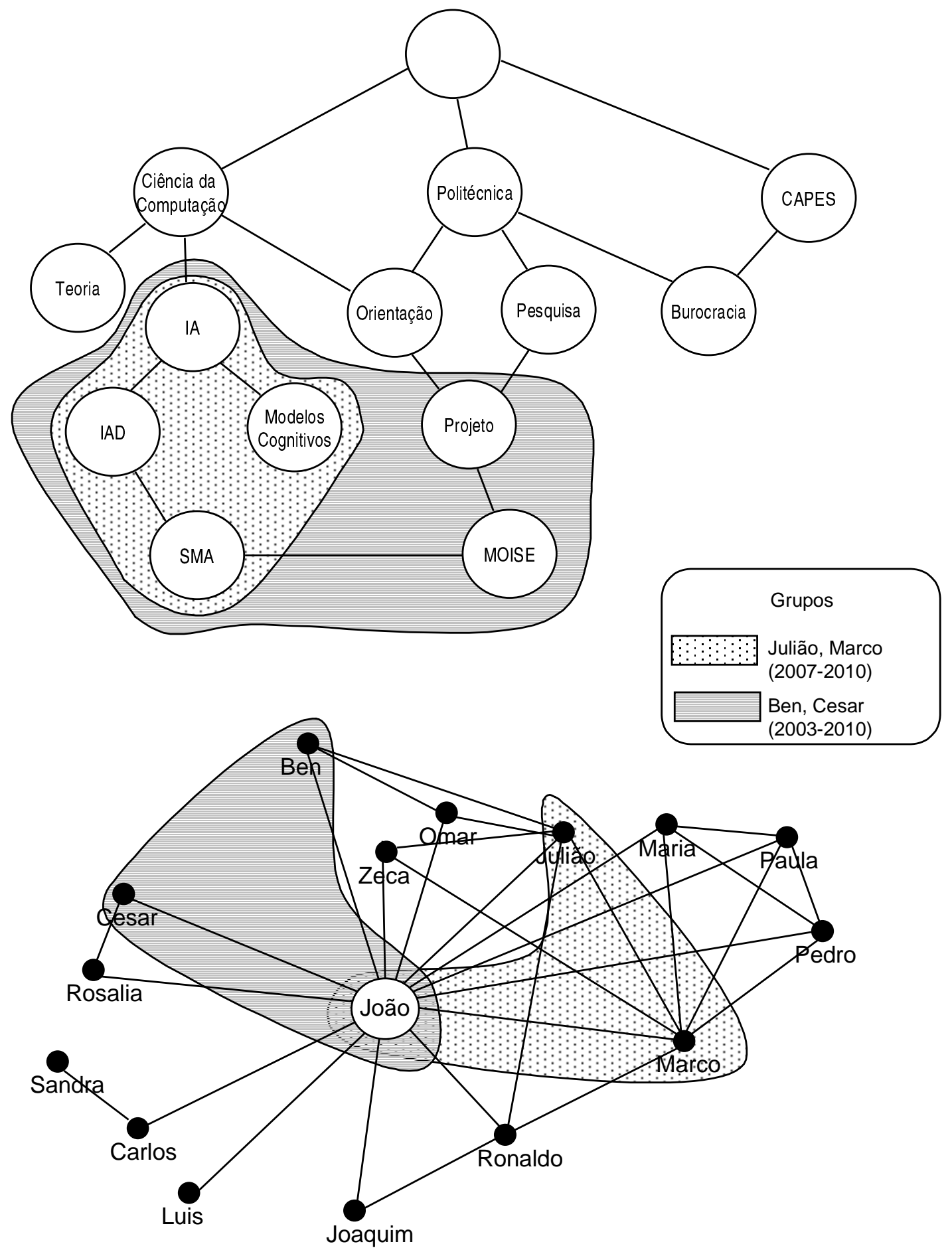

Figura 4.10: Conceitos referenciados por dois grupos de contatos da rede social de João. 


\subsection{Arquitetura de agente}

A cocada é redonda
ele é marrom
O coco em cima é branco

Ma. A. da Silva - Sítios Novos (Caminhos e Parcerias)

São diversas as possibilidades de arquitetura de agentes que tirem proveito do modelo apresentado, de forma a integrar as suas representações de conhecimento e de organização subjetiva. Uma arquitetura que possibilite utilizar o mecanismo de raciocínio apresentado deve comportar também as funcionalidades atreladas a um conjunto de competências como as ilustradas na seção anterior. A figura 4.11 apresenta uma visão funcional do processamento requerido para uma arquitetura que incorpore tais capacidades. A noção de intencionalidade em tais agentes não será implementada, apenas atribuída (vide seção 3.1).

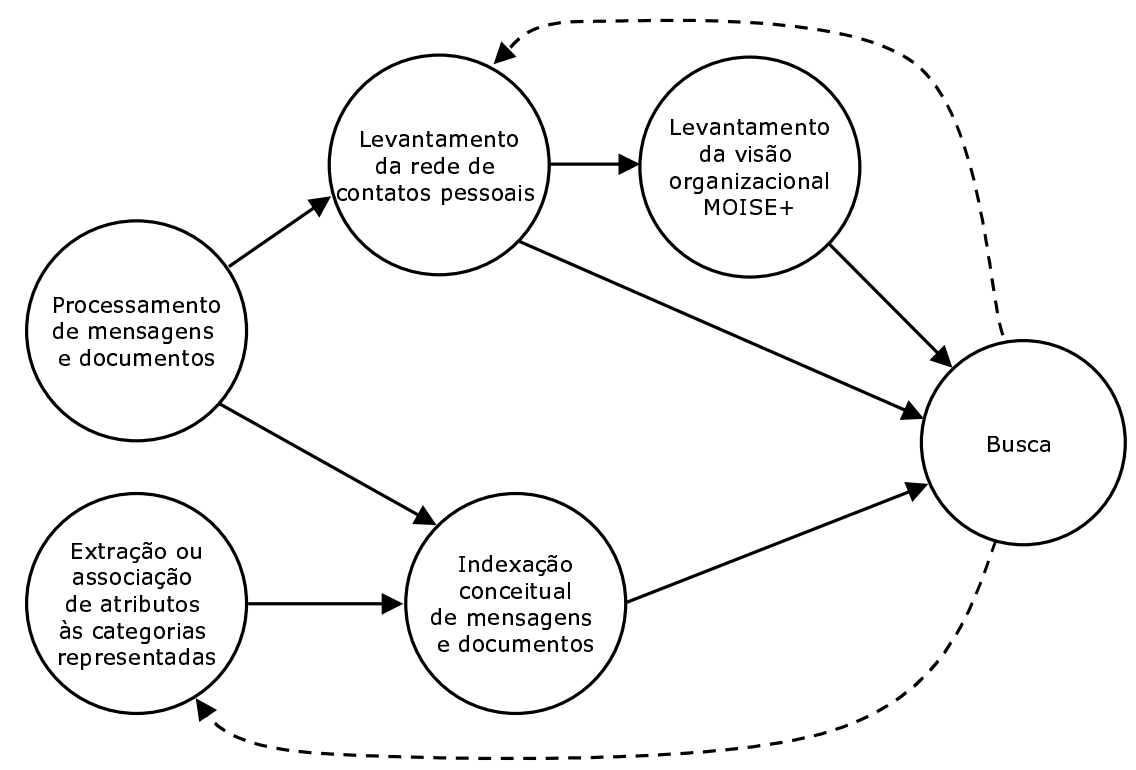

Figura 4.11: Visão funcional do processamento requerido para implementar a proposta.

Considerando como alvo de aplicação o acesso a informações através da partilha de conhecimento, uma arquitetura para este domínio é mostrada na figura 4.12. Na mesma, a ontologia possui conjuntos de termos como atributos dos conceitos (podendo os mesmos ser extraídos de forma automática ou não). Já a representação organizacional segue o modelo $\mathcal{M o I S E}^{+}$. 


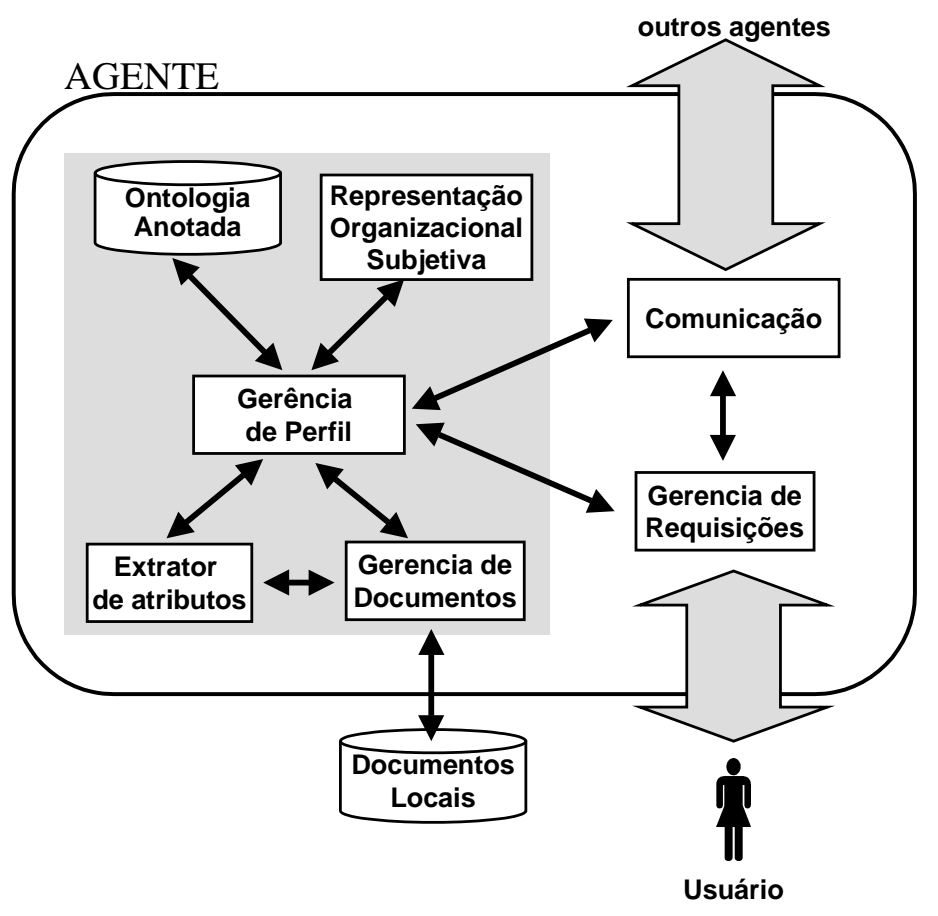

Figura 4.12: Arquitetura de agente capaz de integrar as representações de conhecimento e de organização subjetiva, aplicada à partilha de conhecimento.

Esta arquitetura segue as linhas de arquiteturas para agentes de informação, cujas características mais relevantes aparecem na figura 3.2. Entretanto, são nítidas as influências do modelo proposto. A visão estrutural, apresentada na figura 4.12, reflete os diversos aspectos funcionais da figura 4.11. O processamento de mensagens e documentos é executado pela gerência de documentos. Já a construção da rede de contatos pessoais e a visão organizacional são administrados pelo componente encarregado da representação organizacional subjetiva. A extração/associação de atributos a categorias é executada pelo componente extrator de atributos. A indexação conceitual de mensagens e documentos (que implica no tratamento das anotações propostas) é efetivada através do componente que gerencia o perfil do usuário.

O motor que fornece a dinâmica processual necessária para um aprendizado contínuo é, como era de se esperar, a busca. A partir das conseqüências de uma busca, na forma de novos atributos de conceitos, adoção de documentos recomendados por contatos e inclusive novos contatos, a gerência de perfil efetua as modificações na ontologia anotada.

As habilidades relacionadas às tarefas de RI, como processamento de docu- 
mentos, indexação e identificação, são fornecidas pelos componentes de extração de atributos (termos) relacionados a um conceito e de gerência de documentos. As habilidades relacionadas ao conhecimento e à colaboração são fornecidas pelos componentes que tratam da representação da ontologia anotada e da visão organizacional subjetiva. O componente de comunicação deve tratar dos protocolos e detalhes de comunicação inter-agentes.

Esta arquitetura está destinada a agentes que conformem um SMA integrado na forma de um sistema P2P. Um aspecto que poderia ser tratado por esta arquitetura diz respeito aos algoritmos e protocolos específicos utilizados para localização, troca e distribuição de carga entre agentes-pares. O modelo de representação proposto fornece diversas possibilidades para explorar tais algoritmos, por exemplo através da exploração e explotação de coalizões para distribuição de tarefas entre agentes-pares fortemente relacionados ${ }^{24}$. Este ponto, porém, não diz respeito ao foco central desta tese, portanto não serão abordados detalhes sobre o mesmo, podendo vir a fazer parte de trabalhos futuros.

\title{
4.6 Discussão
}

\author{
... I have seen that in any great \\ undertaking it is not enough for a \\ man to depend simply upon himself. \\ Isna la-wica (Lone Man) - Teton Sioux
}

A proposta apresentada neste capítulo visa retomar, com fins práticos, a noção de representar as experiências intencionais e os seus conteúdos proposta por Husserl (vide seção 3.4) como parte da visão de ontologia formal. O contexto pragmático desta retomada é a representação de conhecimento para agentes computacionais inteligentes e autônomos. Como nestas entidades computacionais a visão social não é preterida, a representação do conhecimento à qual as mesmas tem acesso deve comportar a manipulação simultânea de ambas as noções, i.e. as construções cognitivas possuem uma componente social que deve ser representada explicitamente. Aqui foi detalhada uma forma de concretizar uma resposta

\footnotetext{
${ }^{24}$ Por exemplo, algoritmos podem tirar proveito ao realizar uma busca orientada por tópicos a grupos ou papéis, ou variações, pois isto recorta o espaço de busca e com isto pode-se poupar banda. Ou ainda, ao formar coalizões, os agentes podem intercambiar informações reputando os integrantes de grupos ou papéis.
} 
para tal necessidade em termos computacionais.

No levantamento bibliográfico, aparecem trabalhos com propostas que tratam parcialmente alguns dos conceitos envolvidos. No entanto nenhum deles os trata de forma simultânea.

Em relação ao uso de redes sociais podem ser citados os trabalhos de Kautz e Selman (1998) (ReferralWeb), Yu e Singh (1999), Singh, Yu e Venkatraman (2001)(MARS) e Pujol, Sanguesa e Delgado (2002). Neles são tratadas somente sociedades planas (flat).

No aspecto do tratamento de ontologias, os sistemas YENTA (FONER, 1999) e CAIMAN (LACHER; GROH, 2001) apresentam tentativas de estabelecer agrupamentos conceituais de documentos (eventualmente pertencentes a usuários diferentes) porém utilizando apenas técnicas clássicas de classificação de textos. $\mathrm{O}$ sistema CAIMAN pressupõe que os agrupamentos conceituais de um usuário equivalem a sua ontologia (interpretada como sendo o perfil), mostrando uma tentativa de mapeamento a ontologias de grupos. O sistema MASTER-Web (FREITAS; BITTENCOURT; CALMET, 2001) considera partes da web como um conjunto de agrupamentos conceituais interconectados (artigos sobre ciência, arte, literatura etc.) onde cada agente, num SMA cooperativo, é capaz de processar uma classe e enviar sugestões de páginas possivelmente relacionadas às classes tratadas pelos outros agentes. O sistema OBIWAN (PRETSCHNER, 1999) (CHAFFEE; GAUCH, 2000) mostra outra tentativa, baseada na adoção de uma estrutura de referência, no caso o diretório temático da Magellan (depois absorvida pela Lycos), construindo vetores de termos, na forma de super-documentos para cada diretório e considerando o mesmo um conceito, passando a classificar as páginas visitadas pelo usuário ${ }^{25}$.

Um belo trabalho, explorando as relações entre agentes e ontologias, é apresentado por Steels (1998), sendo estendido logo em Steels e Kaplan (1999) e Steels e Kaplan (2001), partindo das chamadas talking heads (cabeças falantes) e posteriormente usando os robôs AIBO. O autor demonstra que os agentes podem convergir para uma ontologia comum somente através de sucessivas interações. Este resultado é extremamente importante pois, traduz empiricamente para este domínio uma situação conhecida para outros domínios de aplicação das técnicas

\footnotetext{
${ }^{25}$ Esta é uma trilha aberta por trabalhos como Letizia (LIEBERMAN, 1995).
} 
de AM. Ele mostra a falta de relação existente entre categorias retiradas de diferentes tentativas de classificação automatizadas, aplicando o mesmo algoritmo de classificação (no caso o algoritmo expectation-maximization) a conjuntos de objetos (equivalendo a visões de usuários diferentes) para depois tentar chegar a algum tipo de comparação conceitual mais profunda (STEELS; KAPLAN, 2001).

Dentre os trabalhos que influenciaram diretamente a proposta apresentada (seja pela inspiração, crítica ou complementaridade) destacam-se: Tamma e Bench-Capon (2001), mostrando uma possibilidade de anotar ontologias para rastrear o seu comportamento, como comentado na seção 3.4; Pretschner (1999), pelo uso de diretórios concebidos manualmente; e, Singh, Yu e Venkatraman (2001) pela aplicação de redes sociais para localização de especialistas. No entanto, diversos aspectos aqui abordados não foram encontrados em tais trabalhos:

- De forma geral, os trabalhos que usam redes sociais somente focalizam a localização de especialistas e não a partilha de recursos;

- ReferralWeb não é aplicado à RI nem utiliza ontologias;

- $M A R S$ é usado para localização de serviços e possui um interessante algoritmo para uso de reputação, porém não é baseado no uso de ontologias;

- O trabalho apresentado por Pujol, Sanguesa e Delgado (2002) também enfoca a reputação mas somente usa conhecimento, na forma de nomes de contatos, extraído de páginas da $W e b$, e não usa ontologias;

- As ontologias consideradas em YENTA e CAIMAN são derivadas usando métodos de classificação de texto. Os agrupamentos de documentos gerados possuem agrupação temática mas não são equiparáveis a uma classificação humana. O CAIMAN considera como a ontologia de um grupo o agrupamento de documentos compartilhados (super-documentos vetoriais) aos quais são aplicadas técnicas de RI. Ambos os sistemas não trabalham com a noção de mapeamento de redes sociais. A noção de ontologia utilizada nos mesmos é mais próxima do agrupamento automático de termos (clustering);

- O trabalho de Tamma e Bench-Capon (2001) não enfoca redes sociais ou aspectos organizacionais, estando situado mais diretamente dentro da Engenharia de Conhecimento. Além disso, não é destinado à RI; 
- O sistema MASTER-Web não aborda redes sociais;

- O sistema OBIWAN não trabalha com a noção de redes sociais nem com anotações na ontologia que possam relacionar conceitos sob aspectos sociais e/ou organizacionais. Não considera a possibilidade de autonomia dos sistemas locais (dedicados a cada usuário) quanto à representação de conhecimento, pois são consideradas somente ontologias fixas;

- O trabalho de Steels não é aplicado à RI, nem pretende adentrar em detalhes relativos a redes sociais ou à organização.

Existem diversos trabalhos (FRIDMAN; MUSEN, 1999; GÓMEZ-PÉREZ, 1998) dedicados ao alinhamento e à fusão (merging) de ontologias, porém num contexto de Engenharia de Conhecimento semi-automático. O objetivo nesses casos, dada a complexidade do problema, é mais voltado à construção de ontologias a serem eventualmente utilizadas por agentes e não a dotar os mesmos (pelo menos por enquanto) com habilidades para alinhamento/fusão automáticos.

O seguinte capítulo apresenta uma implementação de agente computacional utilizada como prova de conceito para demonstrar a viabilidade da abordagem proposta sem, no entanto, pretender esgotá-la. O agente foi disponibilizado para um grupo de usuários reais e o SMA resultante forneceu resultados que são analisados à luz dos objetivos da tese. 


\title{
5 Tratamento experimental
}

\author{
À gloria sucede o que sucede à água: \\ por mais água que beba, \\ qual lhe sacia a sede? \\ Diverso o sucesso, \\ basta-lhe um verso \\ para essa desgraça \\ que se chama dar certo \\ P. Leminski - Distraídos Venceremos
}

Este capítulo se inicia com a descrição de detalhes de implementação de um protótipo do modelo apresentado no capítulo anterior, denominado COMMUNET. Após a apresentação do cenário que guiou a concepção do agente, são ressaltados alguns dos aspectos considerados essenciais quanto à sua implementação. Na seqüência, são descritas particularidades do experimento realizado com usuários reais. Finalmente, são expostos os resultados obtidos, seguidos da análise dos mesmos.

\subsection{Implementação do agente COMMUNET}

A materialização da proposta compreende diversos componentes de software, implementados e adaptados para que o agente exiba o comportamento desejado. Para a codificação, foi escolhida a linguagem Java.

A arquitetura escolhida para o SMA segue o modelo peer-to-peer, onde, além dos agentes associados a cada usuário, existe apenas mais um agente que atua como "páginas brancas" ${ }^{1}$ para facilitar a localização de outros agentes. Para este

\footnotetext{
${ }^{1}$ No sentido utilizado numa lista telefônica, i.e. fornece apenas a informação necessária para localizar um agente, de forma a poder estabelecer uma comunicação. Tal agente não fornece dados sobre serviços disponibilizados por cada agente ou qualquer outra informação sobre os mesmos.
} 
fim, foi adotada a plataforma Simple Agent Communication Infrastructure (SACI) (HÜBNER; SICHMAN, 2000), que fornece um arcabouço para comunicação de sociedades multiagentes.

Cada agente dedicado a um usuário, ao ser instalado, contém uma mesma ontologia inicial (que será discutida na seção 5.1.1), inclusive com os termos considerados atributos para cada conceito. Como primeiro passo após a sua instalação, o agente processa os documentos e mensagens como ilustrado na figura 5.1 de forma a poder obter uma representação que mapeie tanto o conhecimento (na forma de documentos e mensagens relacionados a um conceito) quanto a rede pessoal do usuário.

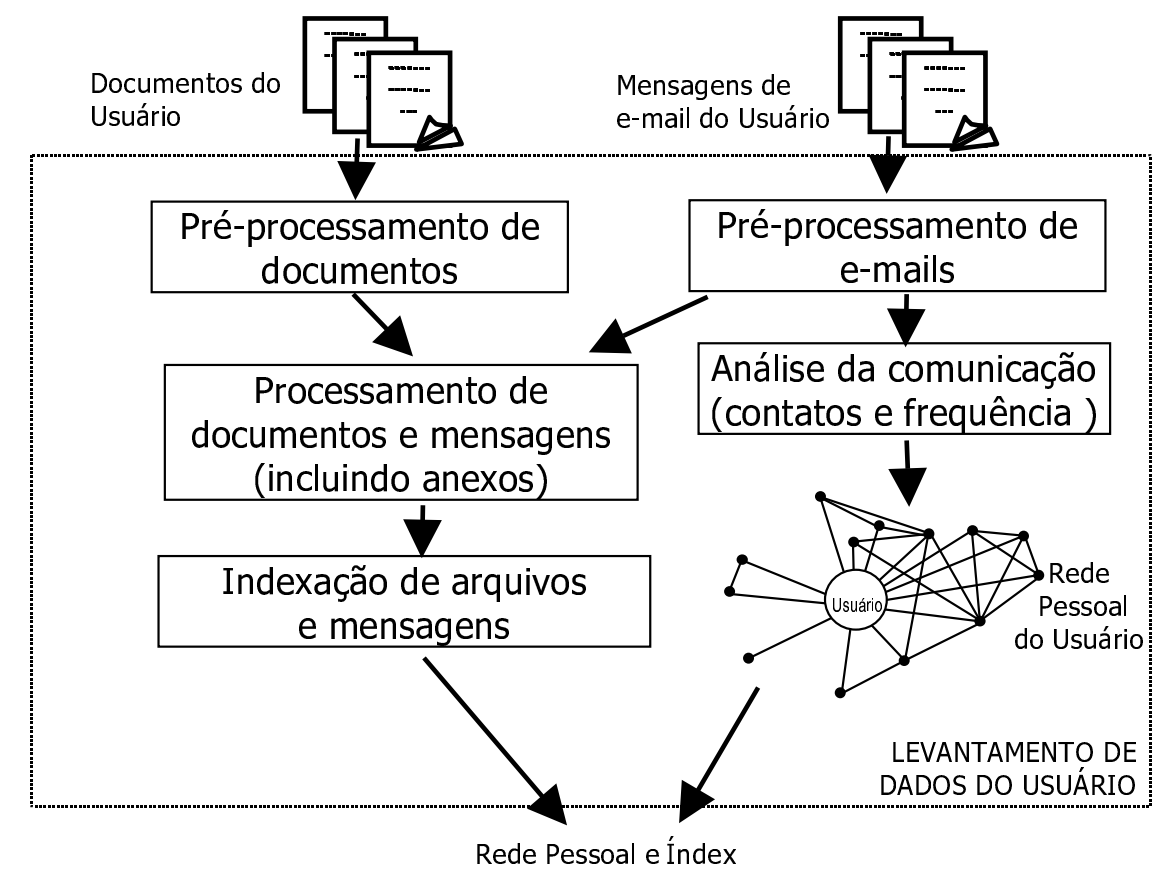

Figura 5.1: Fases do levantamento dos dados do Usuário.

O processamento de documentos é detalhado na figura 5.2. Foram tratados documentos que utilizam três formatos muito populares: o PostScript (i.e. PS), o $P D F$ da Adobe e o DOC produzido pelo $M S$-Word.

Para efetuar a conversão de documentos que se encontrem nos formatos $P S$ e $P D F$ para o formato texto é utilizado um mesmo componente. Tal componente, denominado $p s$ ToText, faz parte da distribuição do aplicativo GhostScript. Já para obter a conversão de documentos disponibilizados no formato utilizado pelo $M S$-Word (i.e. $D O C$ ) é utilizado um aplicativo, originário da comunidade GNU 


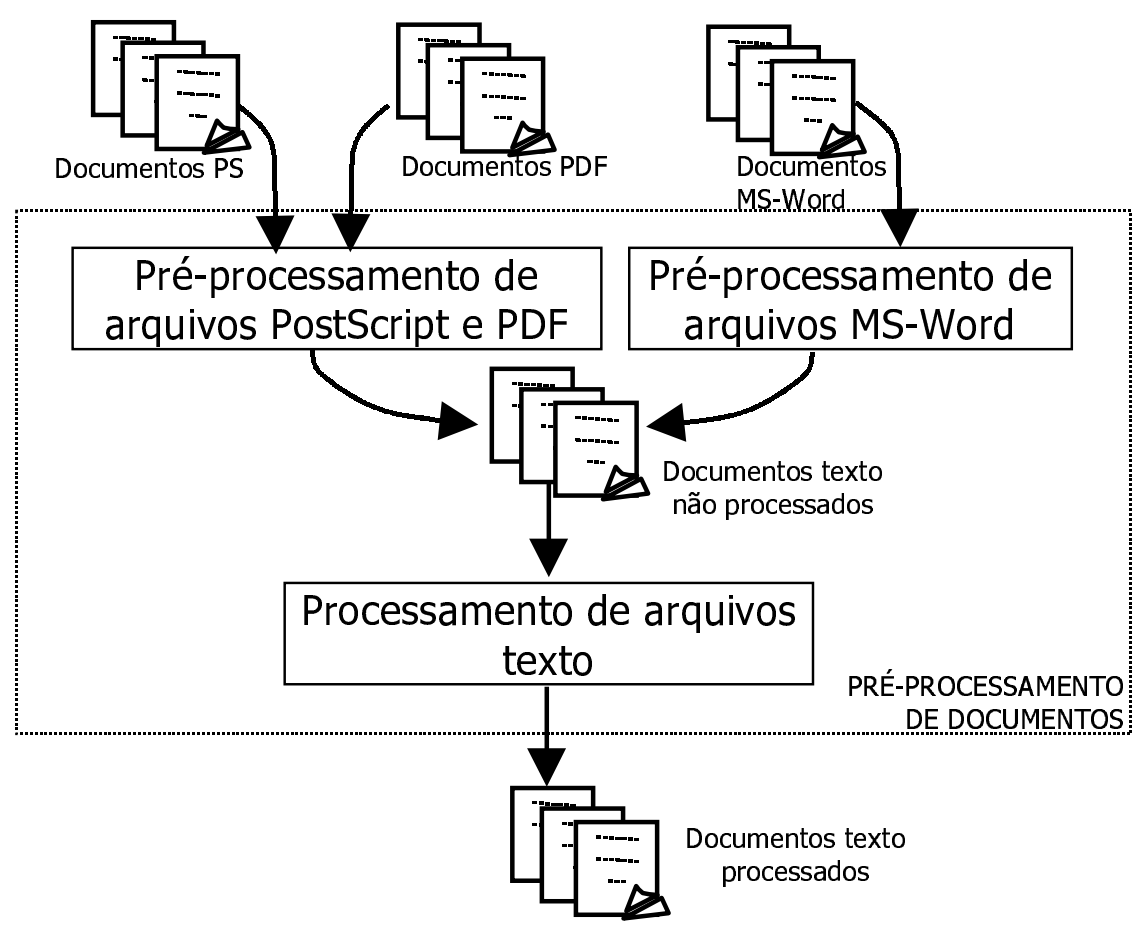

Figura 5.2: Pré-processamento de arquivos de documentos.

e portanto software livre, denominado WvWare. Ambos os componentes citados possuem versões para as plataformas mais populares (i.e. Linux e $M S$-Windows). O resultado destas conversões deve ser novamente processado para obter um texto em condições de ser indexado. Como parte deste pré-processamento é feita a tentativa de preservar, na medida do possível, tanto endereços de e-mail quanto endereços web, além de nomes de pessoas ou instituições. Para tentar manter nomes próprios, é utilizado um algoritmo simples, baseado na heurística de preservar e concatenar palavras que iniciam com maiúsculas e estão interligadas através de certos conectivos, e.g. a palavra "de" que aparece em nomes como Pedro de Souza ou Laboratório de Técnicas Inteligentes.

Para o processamento de mensagens de e-mail (vide figura 5.3) são considerados apenas os conjuntos de mensagens que fazem parte de pastas armazenadas no formato padrão $M B X$. Tal padrão, originário da plataforma Unix, é utilizado pela maioria dos sistemas clientes de correio eletrônico, notadamente com a exceção do $M S$-Outlook Express. No entanto, mesmo os sistemas clientes que não utilizam o padrão $M B X$ para armazenamento, de forma geral, possuem a opção de exportar os seus arquivos utilizando tal padrão. 
O corpo e os cabeçalhos de cada mensagem são processados separadamente. Como uma mensagem pode conter anexos, os mesmos são também decodificados (anexos são transmitidos codificados no padrão base 64) e processados. Quando os anexos são documentos nos formatos PS, PDF e MS-Word, os mesmos são convertidos para o formato texto e processados como já descrito.

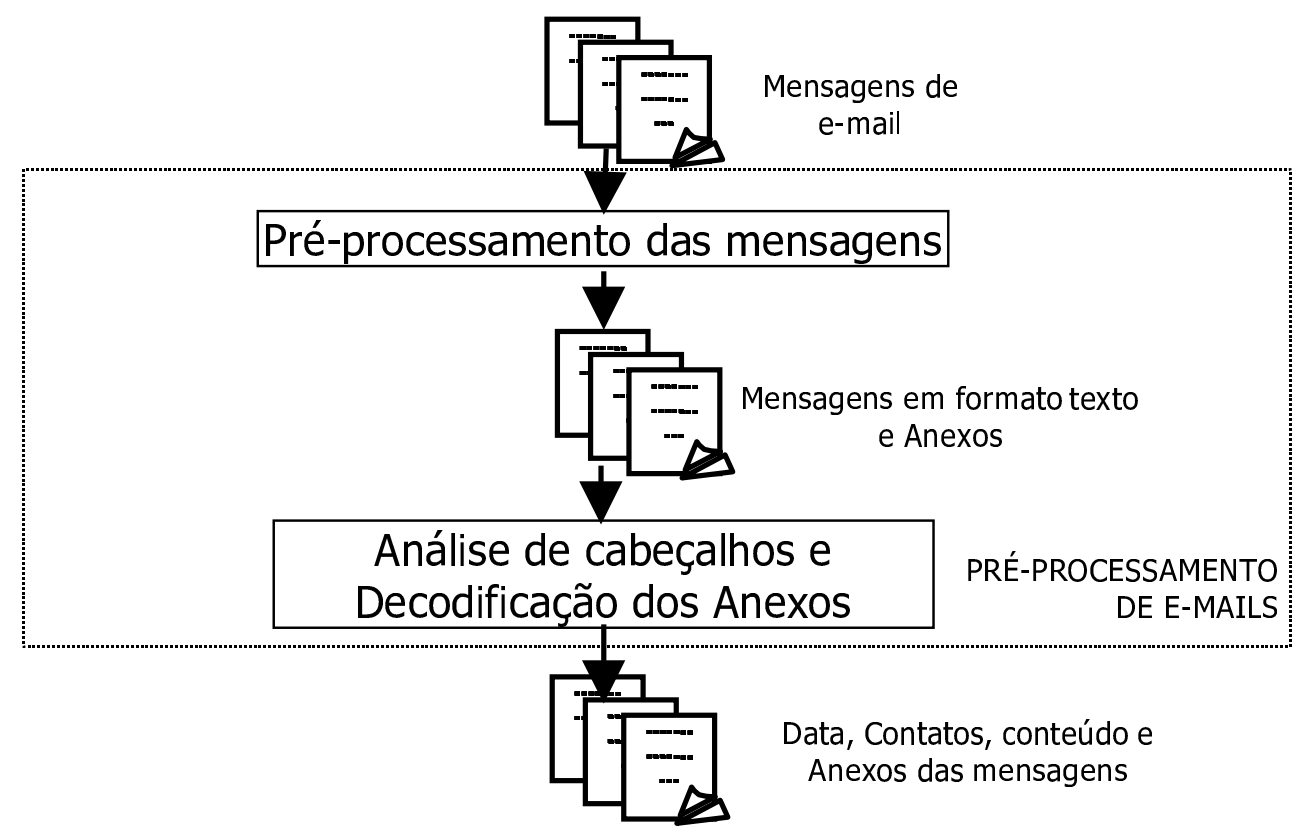

Figura 5.3: Pré-processamento de mensagens de e-mail.

Uma mensagem pode conter outras mensagens encaminhadas. Como os dados contidos em mensagens encaminhadas podem ser muito importantes para montar a rede social, na presente implementação são tratadas as mensagens encaminhadas até a profundidade de encaminhamento 2. Assim, além da mensagem principal $^{2}$ (aquela com profundidade de encaminhamento 0), são tratadas a mensagen encaminhada ${ }^{3}$ (com profundidade de encaminhamento 1 ) e a mensagem contida em uma mensagem encaminhada ${ }^{4}$ (com profundidade de encaminhamento 2).

\footnotetext{
${ }^{2} \mathrm{~A}$ mensagem que possui profundidade de encaminhamento 0 está composta de apenas uma mensagem, i.e. a mensagem principal, que pode ou não conter anexos.

${ }^{3} \mathrm{~A}$ mensagem que possui profundidade de encaminhamento 1 , na verdade está composta de duas mensagens: a mensagem principal e a mensagem que foi encaminhada. A mensagem principal contém aninhada uma outra mensagem, a mensagem encaminhada.

${ }^{4}$ Conceitualmente, a mensagem que possui uma profundidade de encaminhamento 2 , está composta de três mensagens aninhadas: a mensagem principal, que contém aninhada uma mensagem encaminhada, que por sua vez contém uma outra mensagem encaminhada aninhada. Por exemplo, José escreveu uma mensagem para Alberto que a encaminhou para Maria, que por sua vez a encaminhou para João.
} 
Em cada mensagem processada (seja ela de profundidade 0, 1 ou 2), são armazenados não somente os termos encontrados (seja nos corpos das mensagens, seja nos documentos em anexo) mas também a data e ainda quais foram os contatos emissores e os receptores em cada nível de profundidade. Isto equivale a dotar o agente com a capacidade de detectar contatos que não estiveram em comunicação direta com o usuário focalizado (e.g. João), e.g. contatos que não enviaram mensagens para João, mas sim estiveram em comunicação com algum dos contatos de João. Esta habilidade é utilizada para mapear a rede social do usuário focal ao qual o agente está dedicado ${ }^{5}$.

Uma visão dos componentes mais relevantes incluídos no agente implementado é mostrada na figura 5.4, onde são diferenciados os componentes efetivamente codificados daqueles pré-existentes, que foram reutilizados. Ao adotar componentes pré-existentes foi seguida, na medida do possível, a idéia de adotar aqueles cuja divulgação é feita como software livre.

Como citado anteriormente, um aspecto essencial ao colocar em prática a visão de um SMA de agentes inteligentes autônomos e cooperativos é a necessidade (e a escolha) de uma ontologia inicial. Este ponto será abordado a seguir.

\subsubsection{Ontologia inicial}

Como referenciado na seção 4.6, foi provada (computacionalmente) por Steels a necessidade de seqüências de interações para que dois agentes consigam chegar a uma ontologia comum. No caso de usuários humanos, é duvidoso que eles aceitem de bom grado instalar uma aplicação que demoraria meses ou no mínimo semanas para chegar a algum estado estável e que, ainda por cima, requeira uma interação contínua durante o período de aprendizado. Como alternativa, foi escolhida a opção de iniciar com uma ontologia geral, no caso, o diretório temático disponibilizado pelo Open Directory Project (ODP) ${ }^{6}$. O diretório ODP é análogo ao do $Y_{a h o o}{ }^{7}$, porém é livre e aberto, inclusive na sua construção, realizada por voluntários do mundo todo, o que o torna muito mais confiável enquanto

\footnotetext{
${ }^{5}$ Desta forma a rede social cujo centro é o usuário focal é uma estrutura descoberta de forma empírica.

${ }^{6} \mathrm{O}$ projeto DMOZ ODP (Directory.MOZilla.org Open Directory Project) disponibiliza livremente em www.dmoz.org o arquivo completo em formato RDF. O tamanho total da versão utilizada foi de aproximadamente 1,2 GB.

${ }^{7} \mathrm{Http}: / /$ www.yahoo.com.
} 


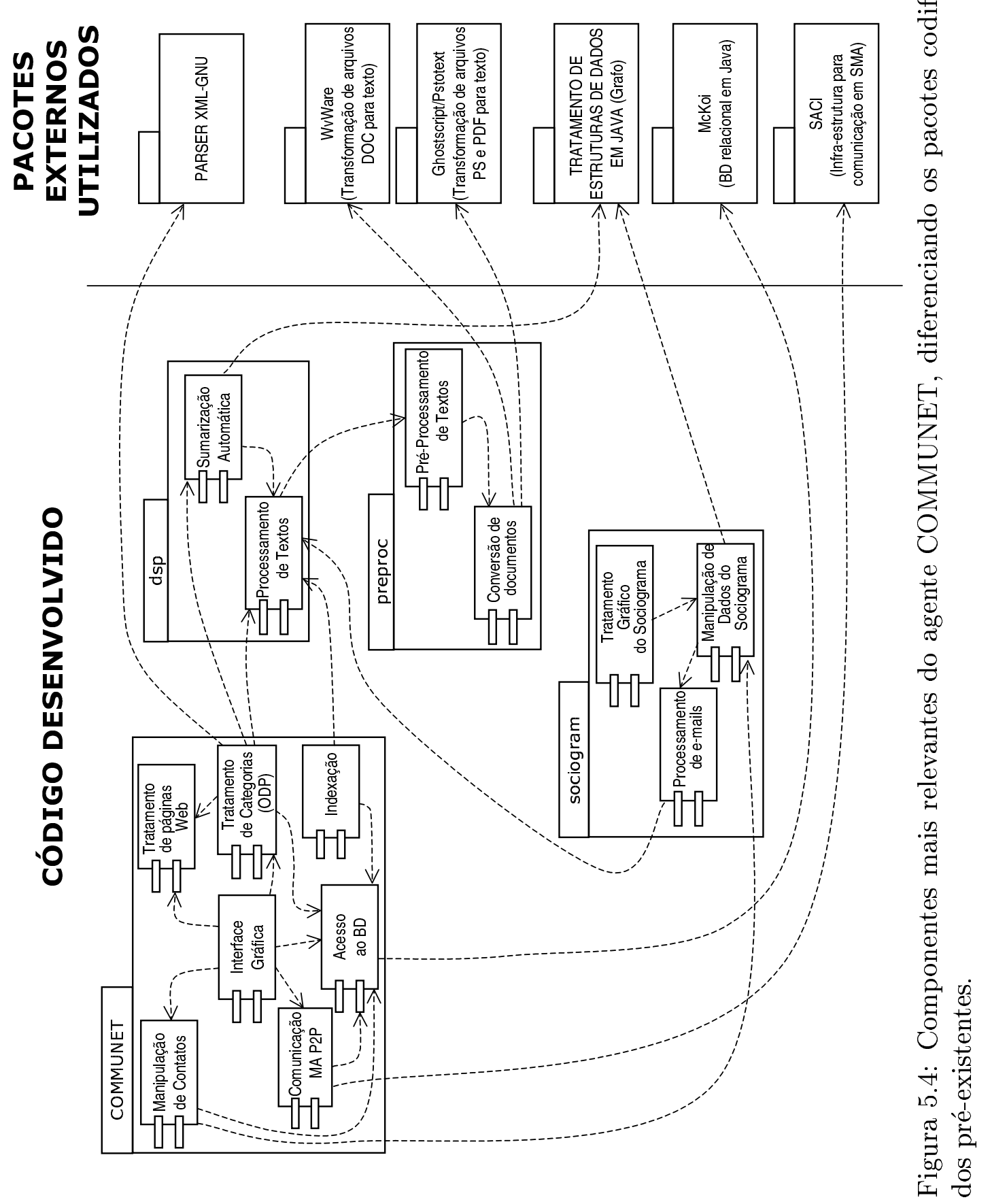


representação geral. Sob cada diretório/tema, estão classificados sítios e páginas relacionadas. Na figura 5.5 aparece um exemplo do conteúdo disponibilizado pelo projeto ODP para um tema, no caso o tema rotulado $R D F$.

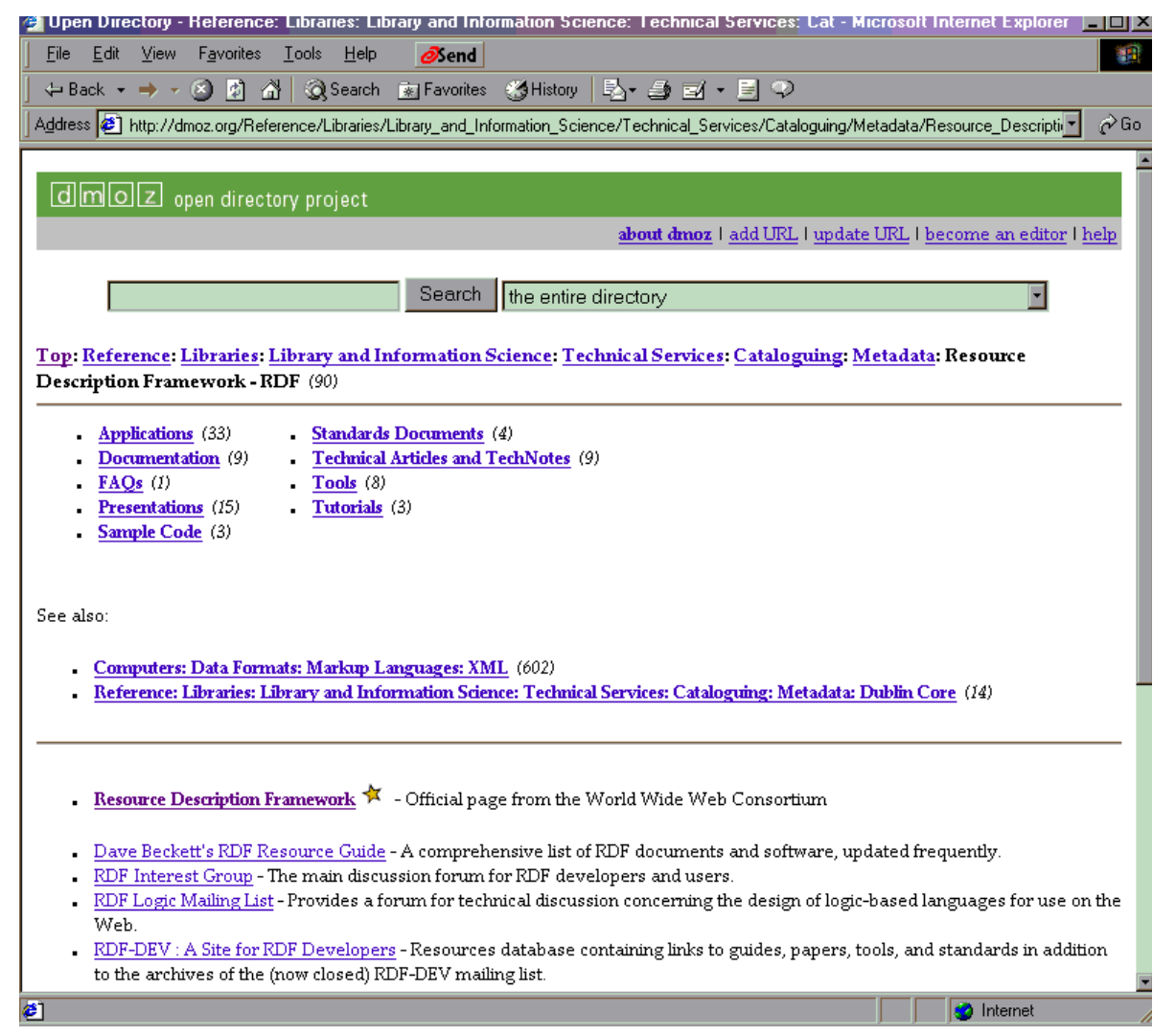

Figura 5.5: Página do projeto ODP para o tópico RDF (KOIVUNEN, 2001).

A figura 5.6 mostra a facilidade com que tal representação pode ser formalizada, no caso utilizando o formato RDF, ao qual alude o próprio tema rotulado. É representado parcialmente o conteúdo mostrado na página referente ao tópico $R D F$ utilizando o formato RDF(KOIVUNEN, 2001).

Na presente implementação, cada diretório/tema é considerado como representando um conceito, e as páginas web referenciadas como sendo exemplos positivos do conceito. Para cada conceito, são considerados como os seus atributos os termos que aparecem nos exemplos positivos. Lassila e McGuinness (2001) apresentam uma classificação de ontologias segundo a sua expressividade. Nessa classificação, uma representação como a descrita é considerada como sendo uma ontologia na forma de hierarquia Is-a informal. Foi escolhido para o experimento o subconjunto ODP que trata de Inteligência Artificial.

Ao invés de considerar todos os termos que aparecem no conjunto de páginas 


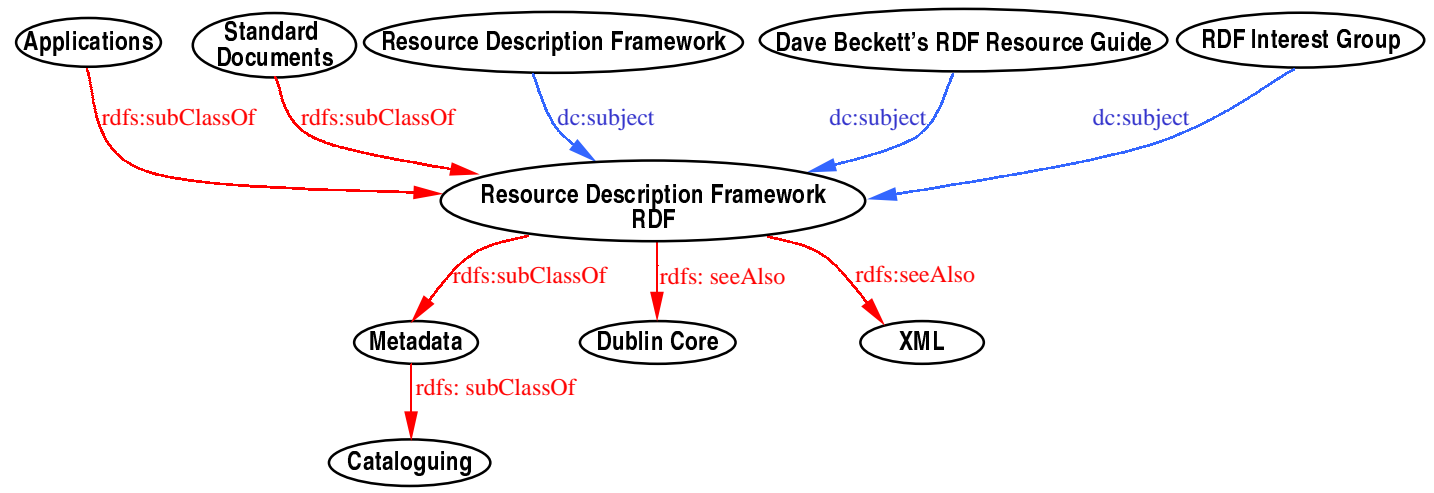

Figura 5.6: Conteúdo de um tópico ODP em RDF(KOIVUNEN, 2001).

HTML associadas a um conceito, na forma de um super-documento (como no caso de Pretschner (1999)), foi adotado e implementado um algoritmo para extração de termos relevantes. Foi verificado que seria necessária a codificação completa de qualquer um dos algoritmos estudados, pois ao tempo da codificação do agente não existiam implementações disponibilizadas dos mesmos. Foi escolhido o algoritmo DSP, retirado do trabalho de Lawrie, Croft e Rosenberg (2001), apresentado na seção 2.2.3. Tal algoritmo revelou-se como sendo o mais promissor. Além disso, os seus parâmetros foram apresentados de maneira clara, o que não aconteceu com outros algoritmos.

O algoritmo DSP considera uma janela de proximidade entre palavras para analisar os termos candidatos. Lawrie, Croft e Rosenberg (2001) experimentaram valores de janela $x$ iguais a 1,2 e 5 , obtendo os melhores resultados quando da utilização de uma janela $x$ de valor igual a 1 , sendo este o valor adotado para o agente implementado. Entretanto, a implementação foi desenhada para suportar janelas com valor 1, 2 ou 5. Para cada conceito é extraída uma lista de termos. Como a ordem de extração dos termos é relevante (o primeiro termo escolhido é aquele com maior peso etc.), este dado é armazenado. Particularmente, o agente desenvolvido trata também as situações em que termos são recebidos de outros agentes ou sugeridos pelo usuário. Neste caso, os termos recebidos passam a ter o maior peso.

Os termos obtidos para cada conceito são utilizados para localizar documentos e mensagens relevantes. Entretanto, não é construído um arquivo inverso para cada conceito, pois, além do problema da maior necessidade de armazenamento, o mesmo teria de ser refeito a cada mudança do conjunto de atributos. Ao invés 
disso, ao acessar um conceito é adotada a opção de recuperar os documentos relacionados, localizando-os através dos atributos (termos chaves) associados ao conceito no momento da consulta.

A seguir é descrita, de forma geral, a dinâmica das ações do agente implementado.

\subsubsection{Dinâmica de um agente COMMUNET}

O funcionamento do sistema COMMUNET como SMA está baseado no uso de um agente que funciona como "páginas brancas" para uma sociedade composta por agentes pessoais designados aos usuários. Os agentes dos usuários poderão entrar e sair da sociedade a qualquer momento. Na figura 5.7 é apresentada uma possível seqüência de utilização de um sistema implementado segundo os conceitos apresentados:

i) O usuário escolhe um conceito e efetua uma requisição em relação ao mesmo;

ii) O agente do usuário procura informação entre os agentes dedicados aos contatos do usuário;

iii) Os agentes dos contatos recebem a requisição em relação ao conceito correspondente;

iv) Os agentes dos contatos respondem à requisição;

v) O agente do usuário consulta uma máquina de busca de propósito geral utilizando os termos que são atributos do conceito;

vi) O agente do usuário recebe a resposta da máquina de busca de propósito geral;

vii) O agente do usuário ordena as respostas recebidas dos contatos consultando as anotações da ontologia e as apresenta junto com a resposta da máquina de busca geral. 


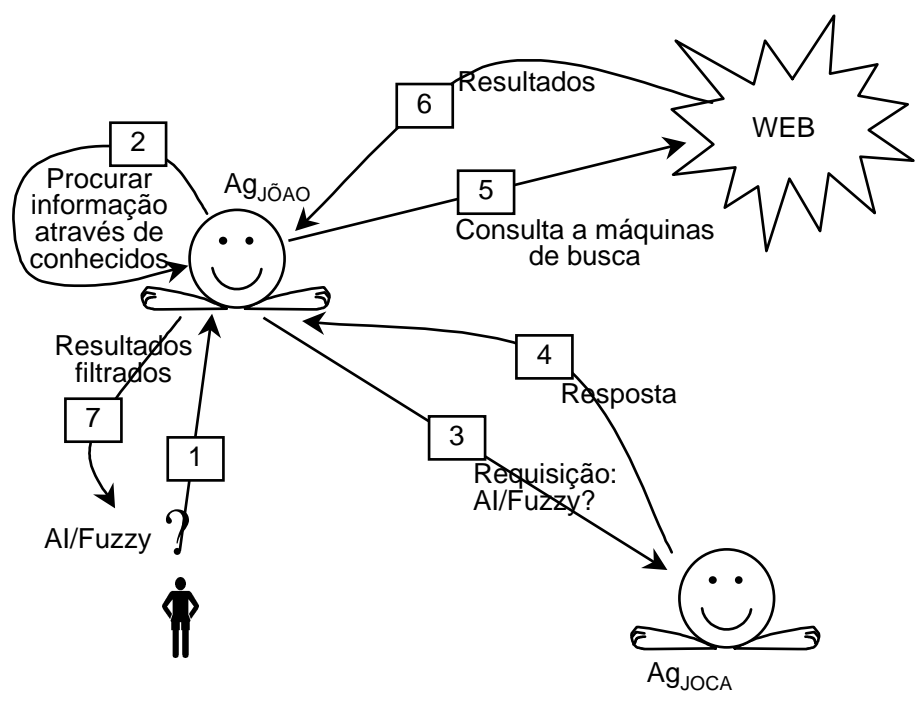

Figura 5.7: Uma seqüência de utilização do agente COMMUNET.

A primeira vez que um agente pessoal COMMUNET faz uma consulta a outros agentes sobre um conceito, o mesmo realiza uma verificação para saber quais os agentes que estão on line dentre os seus contatos e envia mensagens a todos eles. Na medida em que sucessivas consultas são realizadas e respondidas por outros agentes, o agente pessoal vai registrando, através das anotações KAOS e KUOS, quais são os agentes que responderam de maneira mais adequada.

As respostas de outros agentes pessoais a uma consulta são apresentadas ao usuário, que decide se vai recuperar e ler um documento. Caso ele decida ler um documento, o agente requisitará o grau de utilidade que o usuário atribui ao mesmo ${ }^{8}$. Inicialmente, as respostas dos outros agentes são apresentadas ao usuário na ordem de chegada. Porém, gradualmente o agente vai criando um registro de quais foram os outros agentes (e os grupos aos que pertencem) cujas respostas o usuário considerou mais apropriadas, em relação aos conceitos que foram pesquisados. Isto passa a refletir-se na ordem em que os resultados são apresentados aos usuários: as respostas dos agentes que melhor responderam anteriormente são apresentadas primeiro.

Na seqüência é detalhada a interface de interação de um agente COMMUNET com o usuário.

\footnotetext{
${ }^{8}$ Isto poderia ser feito registrando tempos de leitura associados a trechos dos documentos recebidos e/ou indicando se os mesmos foram impressos. Tais opções não foram implementadas pois iriam requerer um esforço considerável para solucionar problemas específicos de captura de eventos em aplicações e/ou sistemas operacionais proprietários.
} 


\subsubsection{Interação com o usuário}

As diversas telas que compõem a interface do agente COMMUNET refletem os diferentes aspectos funcionais, mostrados na figura 4.11, que fundamentam a arquitetura da figura 4.12 .

$\mathrm{O}$ processamento de mensagens e documentos e o levantamento da rede de contatos pessoais, que aparecem na figura 4.11, são as primeiras funcionalidades referenciadas. Após a instalação de um agente COMMUNET, os arquivos de mensagens e documentos do usuário devem lhe ser apresentados. As mensagens devem ser fornecidas na forma de pastas de mensagens no formato $M B X$. Os documentos devem ser inicialmente armazenados em três possíveis diretórios diferentes. Cada um destes diretórios indica, de forma geral (i.e. independentemente de grupos e papéis), qual o grau de visibilidade que o usuário escolhe para um documento: SECRETO, MEDIANO ou PÚBLICO. A seguir, o agente COMMUNET passa a processar e a indexar as pastas de mensagens e/ou as pastas contendo os documentos disponibilizados. O resultado é apresentado sob duas formas diferentes:

- Uma rede pessoal ou sociograma extraído automaticamente;

- Listas de documentos associados a conceitos particulares.

Um sociograma extraído de forma automática por um agente COMMUNET é apresentado na figura 5.8. O usuário aparece no centro do diagrama, representado pelo quadrado vermelho. A distância dos contatos, em relação ao usuário, é menor quanto maior foi número de mensagens trocadas (para contatos que mantiveram comunicação direta com o usuário). Os contatos que não mantiveram comunicação direta (os "amigos dos amigos") aparecem em círculos concêntricos sucessivamente mais distantes. Adicionalmente, a interface apresenta cores diferenciadas para os contatos de primeira, segunda, terceira e quarta ordem:

- Contato de primeira ordem: é aquele que o agente detectou como tendo mantido comunicações diretas com o usuário (aparece na cor laranja);

- Contato de segunda ordem: é aquele que não manteve nenhum contato (detectado) com o usuário, porém, manteve contato direto com pelo menos um usuário de primeira ordem (é representado na cor verde); 


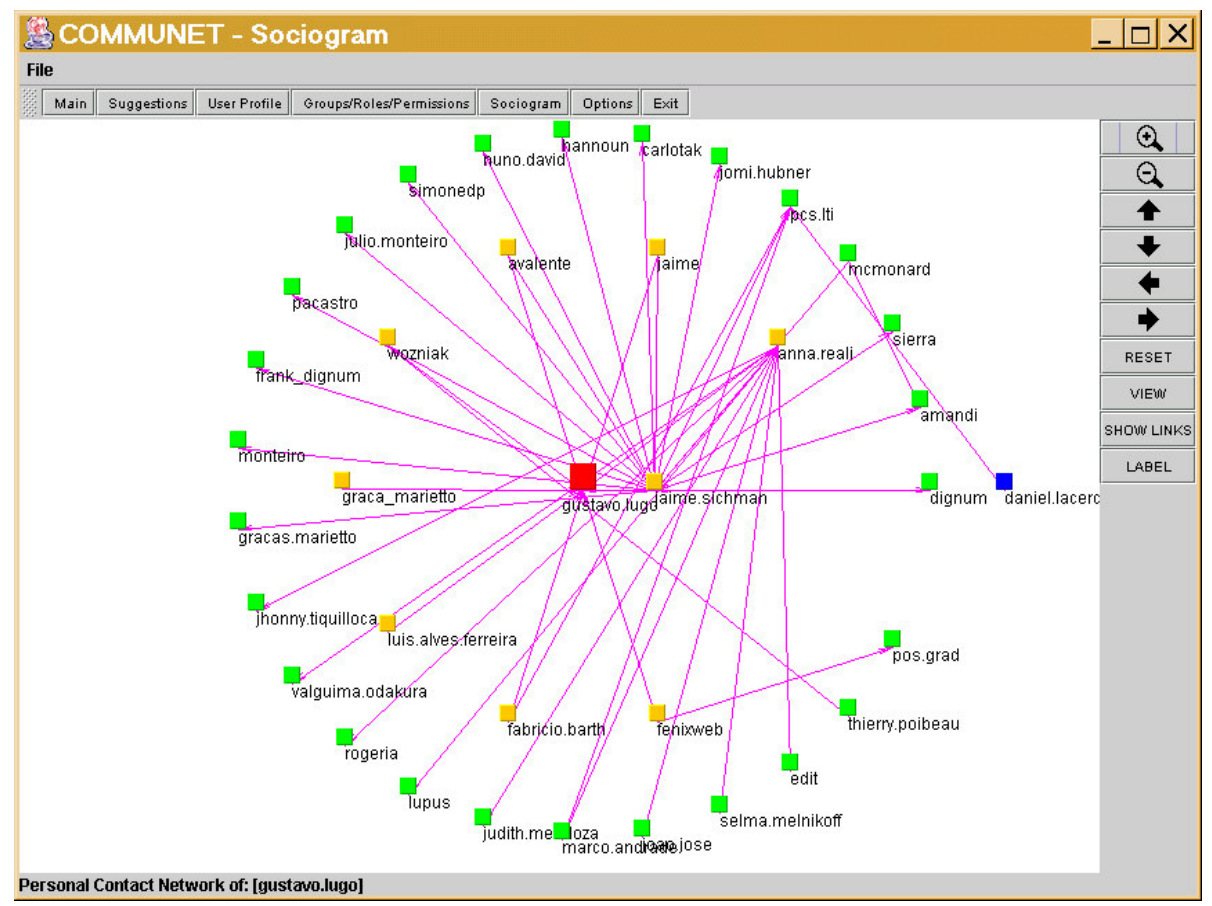

Figura 5.8: Sociograma extraído automaticamente por um agente COMMUNET.

- Contato de terceira ordem: é aquele que não manteve contato nem com o usuário, nem com contatos de primeira ordem, mas manteve contato com pelo menos um usuário de segunda ordem (é representado na cor azul);

- Contato de quarta ordem: é aquele que manteve contato direto apenas com (pelo menos um) contato de terceira ordem (é representado na cor preta ${ }^{9}$ ).

Na seqüência, o usuário deve agrupar os contatos identificados pelo agente (e portanto aparecem no sociograma) segundo os grupos e papéis definidos, como mostra a figura 5.9, onde aparecem os contatos agrupados pelo usuário sob o papel "amigos" do grupo "trabalho". A tela visualizada corresponde ao levantamento da visão organizacional $\mathcal{M o I S E}^{+}$, como mostrado na figura 4.11. Na mesma, são definidos também os níveis de acesso dos contatos associados a cada papel em relação aos recursos do usuário. São definidas as permissões para três tipos de recursos:

- Atributos de conceitos: na forma de palavras-chaves (keywords) utilizadas

\footnotetext{
${ }^{9}$ Particularmente, no caso apresentado na figura 5.8 não existem contatos deste tipo.
} 
para detectar a associação de um documento a um conceito. É possível definir apenas dois níveis de visibilidade: publicável ou nulo;

- Contatos associados a conceitos: na forma de endereços dos contatos. É possível definir quatro níveis de visibilidade: secreto, mediano, público ou nulo. O nível mais elevado é o secreto, sendo que os níveis superiores incluem os inferiores, e.g. ao ter acesso a contatos de privacidade mediana, também estão incluídos os contatos com grau público;

- Documentos associados a conceitos: na forma de arquivos. É possível definir quatro níveis de visibilidade: secreto, mediano, público ou nulo. O nível mais elevado é o secreto, sendo que os níveis superiores incluem os inferiores, e.g. ao ter acesso a documentos secretos, também estão incluídos os documentos com privacidade mediana e os públicos.

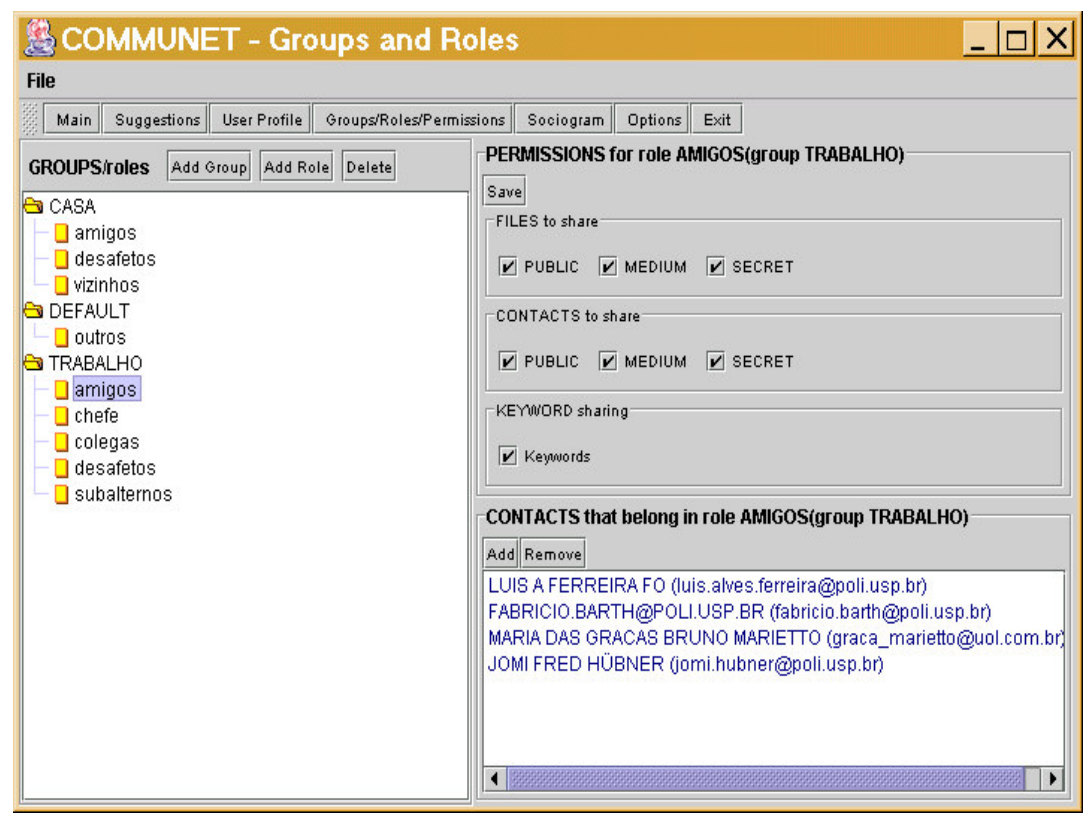

Figura 5.9: Grupos e papéis sociais representados num agente COMMUNET. Para cada um podem ser definidos diversos graus de permissões de acesso.

Também na figura 5.9 pode-se perceber que o usuário forneceu o maior grau de acesso aos seus contatos, documentos e atributos, para os contatos que desempenhem o papel "amigos" no grupo "trabalho". Os agentes agrupados como sendo "desafetos" possuem o maior nível de restrições, i.e. acesso nulo aos atributos, conceitos e documentos. A única ressalva em relação aos "desafetos" é que 
os mesmos tem acesso a endereços web relacionados a um conceito. Isto se deve ao fato das páginas web serem públicas por natureza e sendo o COMMUNET um SMA cooperativo, deve existir um nível mínimo de contribuição entre os contatos que incentive a participação dos mesmos.

Após estas fases preliminares, o agente pode passar a tratar os documentos e os contatos extraídos de forma diferenciada. O perfil de um usuário é apresentado na figura 5.10. São mostrados os atributos, documentos e contatos relacionados ao conceito AI/Agents/Publications acessíveis aos contatos considerados "amigos" do (grupo) "trabalho". Nesta visualização, o subconjunto da ontologia ODP adotado (i.e. aquele que se ocupa de inteligência artificial) é mostrado à esquerda. No centro aparecem os documentos, localizados através dos atributos (palavraschaves), explicitados na parte superior direita da tela. Na parte inferior direita aparecem os contatos que foram localizados como fazendo parte do corpo dos documentos, ou ainda, localizados no corpo das mensagens ou como remetentes, receptores, encaminhadores etc. Todas estas informações, porém, são filtradas de acordo com o papel (e portanto grupo) a ser visualizado, de acordo com o nível das permissões fornecidas pelo usuário. Isto é mostrado na parte superior da tela. As cores dos ícones, que aparecem à esquerda dos contatos e documentos, indicam a classificação dos mesmos quanto à privacidade: secreto (vermelho), mediano (amarelo) e público (verde). Esta visualização corresponde, na figura 4.11, à indexação conceitual de mensagens e documentos influenciada pela visão organizacional $\mathcal{M O I S E}^{+}$.

Uma vez concluída a preparação inicial quanto aos recursos do usuário, o agente COMMUNET está pronto para iniciar interações com outros pares. Posto que um agente COMMUNET está destinado à partilha de conhecimento através do acesso a informações, uma ferramenta de busca conceitual é disponibilizada para o usuário. A visualização desta ferramenta é mostrada na figura 5.11. Esta visualização corresponde à materialização do aspecto funcional da busca e ao tratamento das suas conseqüências, como mostrado na figura 4.11. A ferramenta acessa simultaneamente recursos disponibilizados por outros pares e por uma máquina de busca geral.

Na figura 5.11 a tela aparece dividida em três partes. À esquerda aparece uma interface que permite escolher o conceito alvo da busca. Ao escolher tal 


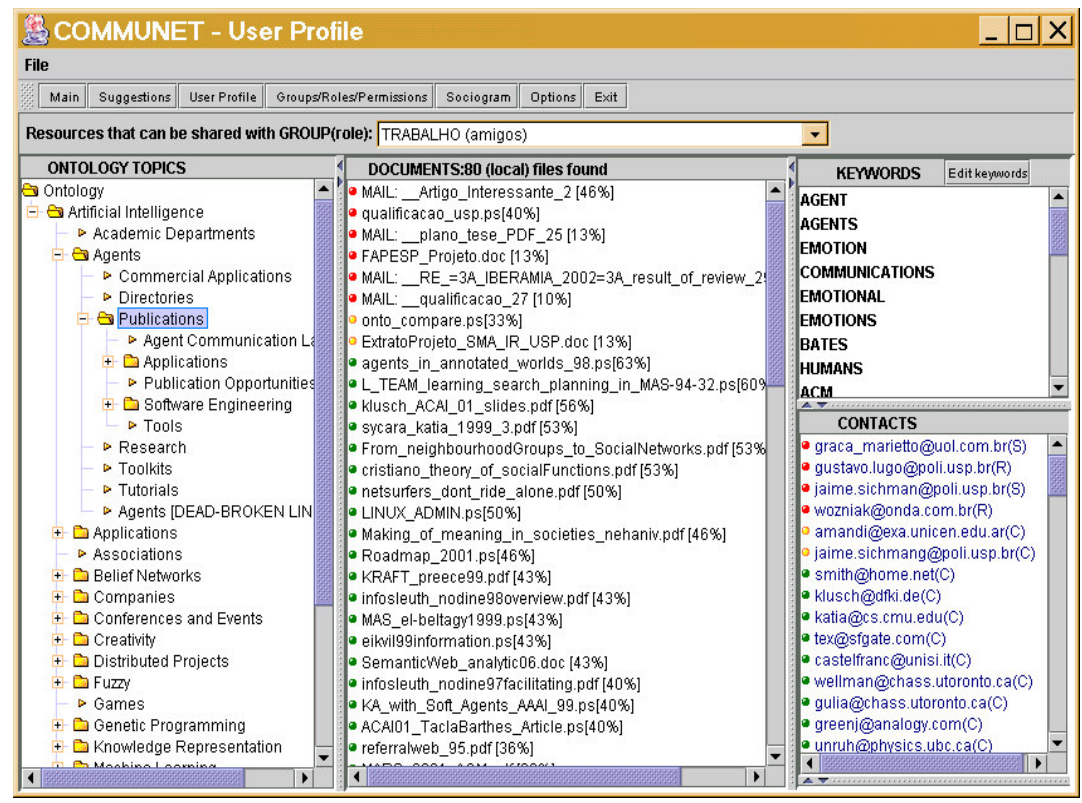

Figura 5.10: Perfil de um usuário COMMUNET.

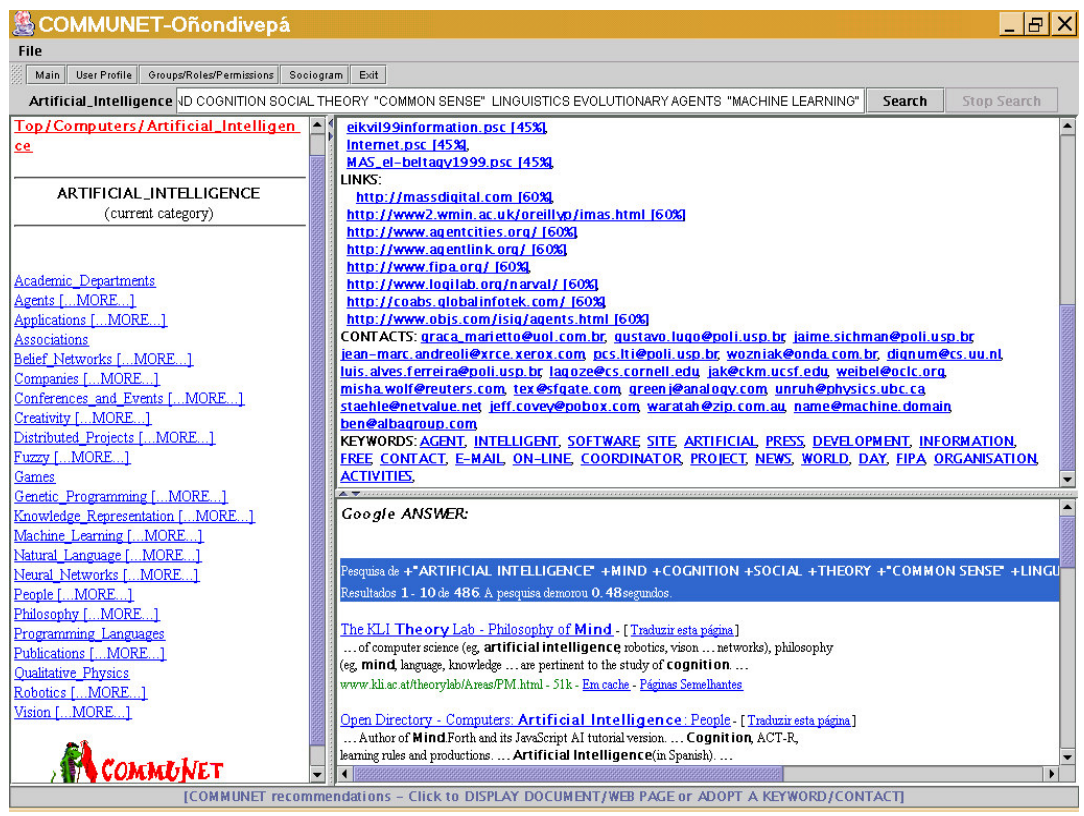

Figura 5.11: Ferramenta de busca conceitual fornecida por um agente COMMUNET. 
conceito (neste caso Top/Computers/AI), os atributos do mesmo aparecem (de acordo à ordem de importância) na parte superior (como palavras-chaves). Ao disparar uma busca, o agente executa requisições em dois espaços distintos:

- Busca P2P: na parte superior direita da tela são mostrados os resultados obtidos ao solicitar aos outros pares conhecimentos relacionados ao conceito Top/Computers/AI/Agents. Podem ser obtidos de cada contato: documentos, links apontando para endereços web, contatos e atributos;

- Requisição a uma máquina de busca geral: na parte inferior direita da tela aparecem os resultados obtidos utilizando as palavras-chaves como requisição para uma máquina de busca geral (no caso o Google ${ }^{10}$ ).

O usuário pode executar diversas ações em relação tanto aos resultados da busca P2P, quanto aos resultados obtidos via máquina de busca geral:

- Escolha de um documento: o agente do usuário solicita o documento ao agente do contato correspondente. Ao finalizar o download o documento é exibido ao usuário, solicitando ao mesmo uma avaliação. A avaliação compreende uma escala com 5 valores: excelente, muito bom, bom, ruim e muito ruim. Esta avaliação é utilizada como julgamento da experiência do agente para as anotações;

- Escolha de um link recomendado por um contato ou pela máquina de busca geral: o agente do usuário abre a página correspondente num browser. A avaliação do usuário é tratada de forma análoga à de um documento;

- Escolha de um contato recomendado, o agente considera que o mesmo passa a ser associado ao conceito alvo da busca;

- Escolha de uma palavra-chave, o agente considera que a mesma passa a ser adotada como atributo do conceito alvo da busca. Neste caso a ontologia do usuário é alterada através da adição de um novo atributo (ou da modificação da importância de um atributo já existente);

\footnotetext{
${ }^{10} \mathrm{http}: / /$ www.google.com.
} 
O usuário pode ainda agregar ou retirar as palavras-chaves apresentadas pelo agente para o conceito alvo. Neste caso, o agente considera que o usuário alterou a sua ontologia pois os atributos do conceito alvo foram modificados.

Na busca P2P, a lista dos resultados obtidos com os contatos é ordenada mostrando primeiro (na parte superior) os recursos disponibilizados por contatos que, nas interações (i.e. utilizando as anotações propostas), tivessem apresentado um maior número de recursos considerados adequados pelo usuário. Um caso particular é mostrado na figura 5.12, onde aparecem as respostas de dois contatos diferentes para a mesma requisição P2P (no caso, Top/Computers/AI/Agents). É possível que o primeiro contato tenha classificado o usuário como "desafeto". Porém, também é possível que este contato simplesmente tenha apagado todos os atributos relacionados ao conceito Top/Computers/AI/Agents sem ter executado busca alguma em relação ao conceito, pois com isso não haveria documentos nem contatos a serem disponibilizados. Já o segundo contato respondeu com diversos valores de atributos, documentos, links e contatos.

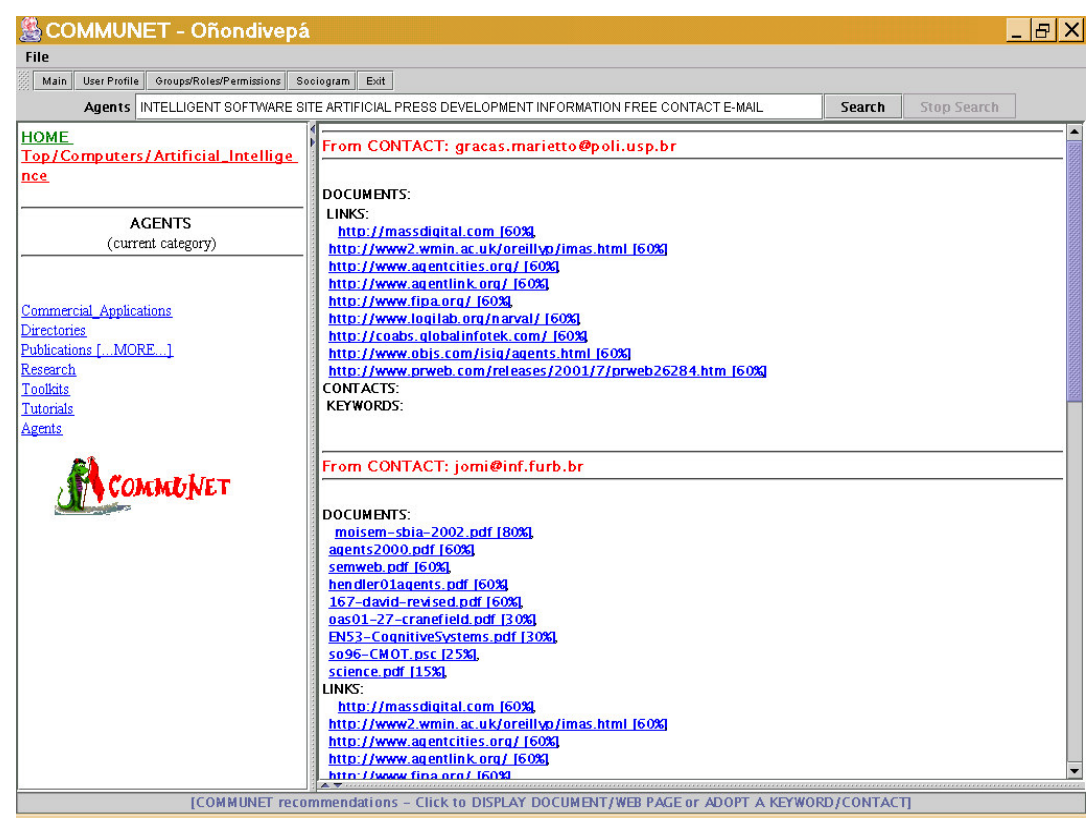

Figura 5.12: Ferramenta de busca conceitual de um agente COMMUNET, mostrando respostas de dois contatos.

As seqüências de interações, decorrentes de sucessivas buscas efetuadas pelo usuário ao qual está designado, são armazenadas pelo agente COMMUNET através das anotações propostas. Na medida em que estas experiências são repre- 


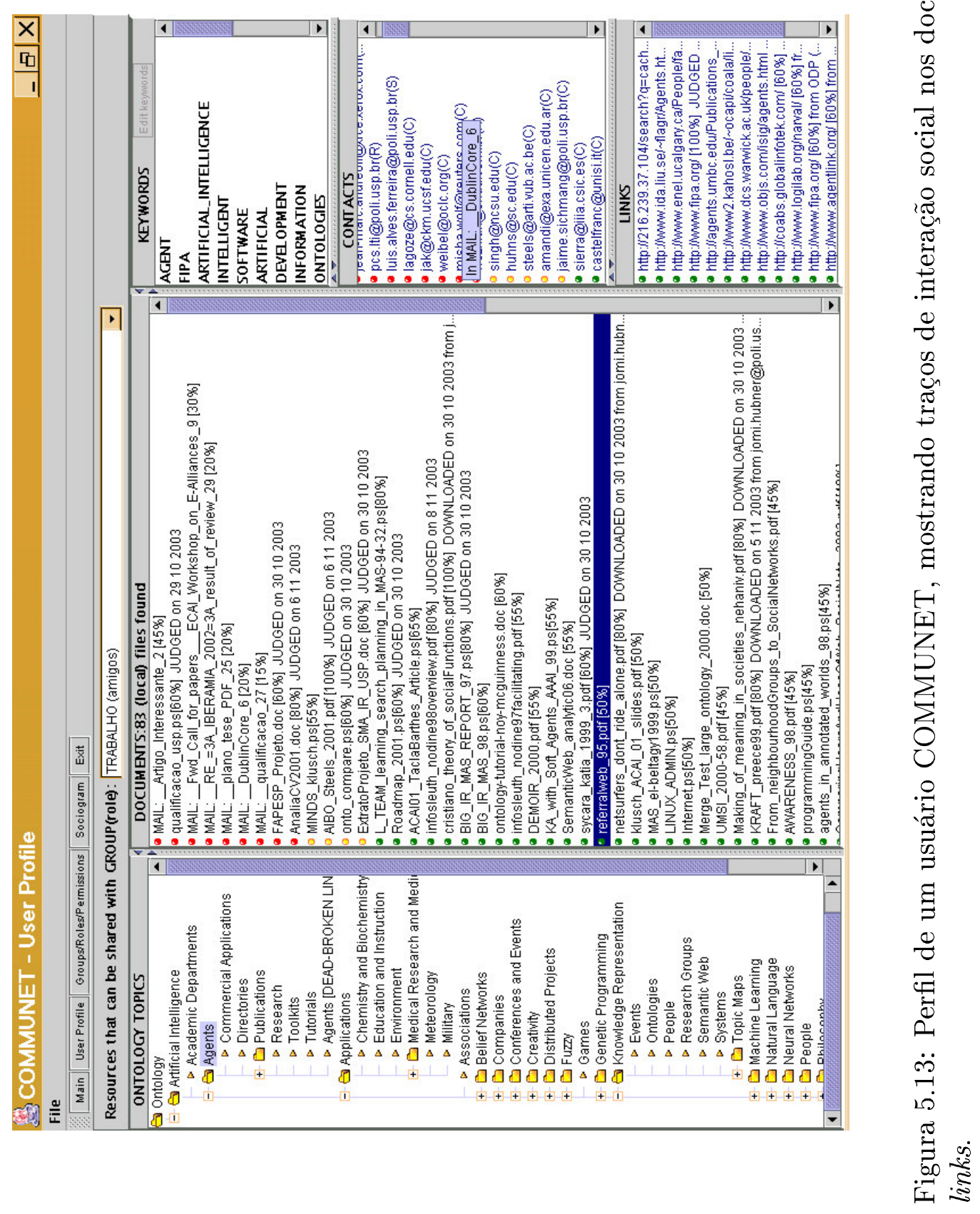


sentadas (de fato, armazenadas como traços de interações sociais), o agente pode explicitá-las para o usuário. Isto pode ser observado na figura 5.13, em relação ao conceito Top/Computers/AI/Agents. Nela, aparecem informações sobre a origem dos documentos recebidos:

- O contato do qual foi obtido;

- A data de obtenção;

- A valoração da experiência (adotada como sendo a adequação do documento em relação ao conceito, segundo o usuário).

No caso dos links, inicialmente os que aparecem são os mesmos que estão classificados sob os conceitos considerados, no arquivo DMOZ ODP utilizado para construir a ontologia inicial. Tais links são os primeiros exemplos positivos dos quais foram extraídos os atributos iniciais de cada conceito.

A seguir, são comentados detalhes referentes ao uso das anotações no agente desenvolvido.

\subsubsection{Implementação das anotações}

O agente implementado utiliza as anotações organizacionais propostas na seção 4.2. Porém, as mesmas foram implementadas apenas parcialmente de forma a poder servir como prova de conceito.

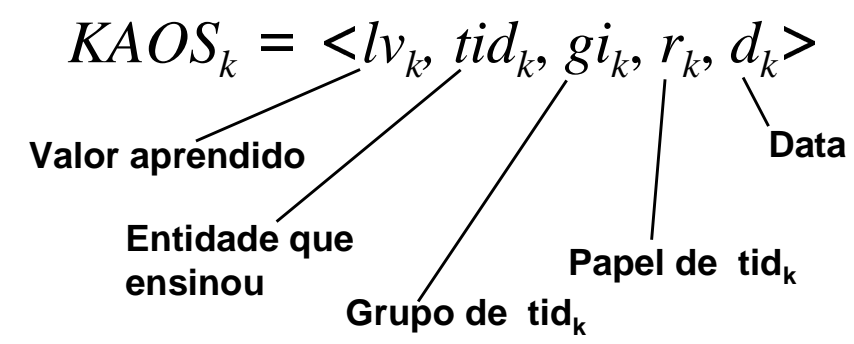

Figura 5.14: Versão implementada da faceta $K A O S$.

A versão da faceta $K A O S$, mostrada na figura 5.14, é utilizada pelo agente para descrever, como parte dos valores, o seguinte conjunto de ações relacionadas ao aprendizado associado a recursos de um conceito: 


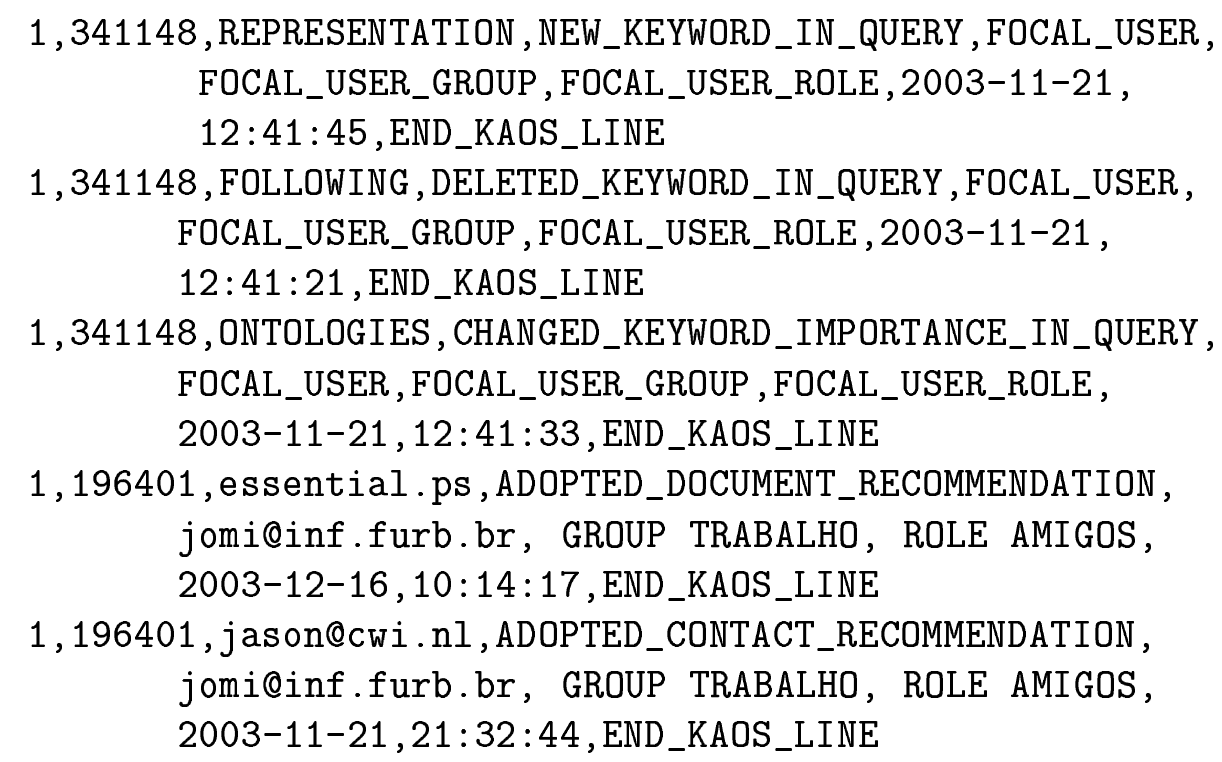

Figura 5.15: Amostras da representação textual de instâncias da anotação KAOS.

- Inserção de um novo atributo;

- Retirada de um atributo;

- Alteração da importância de um atributo;

- Adoção de um novo atributo recebido de outro contato;

- Adoção de documento recomendado por outro contato.

- Adoção de contato recomendado.

O agente COMMUNET dedicado a um usuário, para fins de coleta de dados, foi codificado de forma a produzir uma saída textual, a partir da qual foram obtidos os dados analisados. Na figura 5.15 são apresentadas amostras do conteúdo de arquivos, ilustrando o registro de algumas das ações citadas, através de instâncias da anotação KAOS. Os dois primeros valores de cada anotação, e.g. 1, 341148, são utilizados de modo a auxiliar na identificação do conceito sendo referenciado.

A versão implementada da faceta $K U O S$ no agente COMMUNET, é mostrada na figura 5.16. Como no caso da faceta $K A O S$, a mesma é implementada apenas parcialmente. A figura 5.16 mostra a versão da faceta KUOS implementada. 


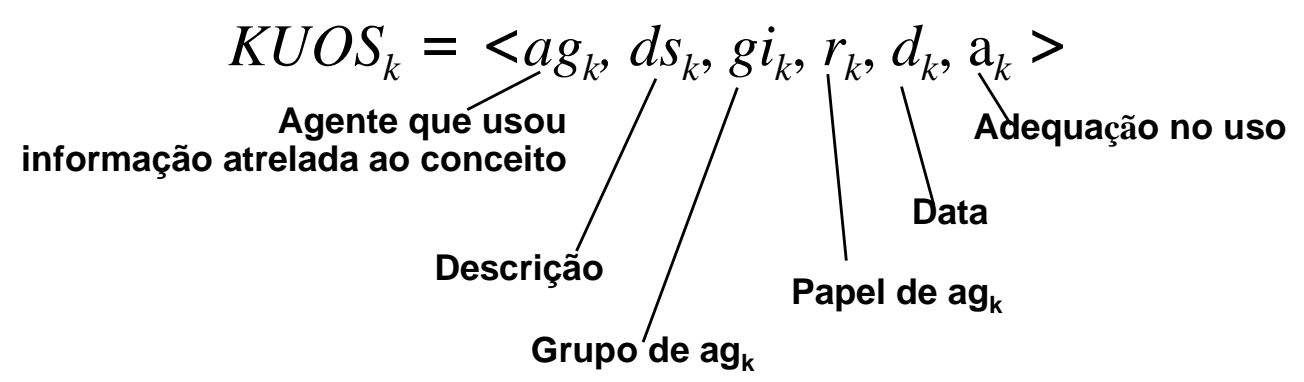

Figura 5.16: Versão implementada da faceta $K U O S$.

1, 341148, KEYWORDS , STARTED_QUERY , FOCAL_USER , FOCAL_USER_GROUP, FOCAL_USER_ROLE , 2003-11-21, $12: 35: 34,1.0$, END_KUOS_LINE

1, 341148, AGENT_RESOURCES , ASWERED_WITH_RECOMMENDATIONS , gracas.marietto@poli.usp.br, GROUP TRABALHO, ROLE AMIGOS , 2003-11-21,12:35:40,0.0,END_KUOS_LINE

1,96417,Barners-Lee-Scientific-American-May-2001.pdf, RECEIVED_AND_READ_ADOPTED_DOCUMENT_RECOMMENDATION, diana.adamatti@poli.usp.br, GROUP TRABALHO, ROLE COLEGAS , 2003-12-17, 13:35:35, 0.8 ,END_KUOS_LINE

1,341148,L_TEAM_learning_search_planning_in_MAS-94-32.psc, READ_SELF_DOCUMENT , FOCAL_USER , FOCAL_USER_GROUP, FOCAL_USER_ROLE , 2003-11-21, $12: 36: 07,0.3$,END_KUOS_LINE

Figura 5.17: Amostras da representação textual de instâncias da anotação KUOS.

Nesta versão da faceta $K U O S$, o campo descrição é utilizado para explicitar o seguinte conjunto de ações associadas ao uso de recursos ligados a um conceito:

- Consulta utilizando atributos;

- Recepção/resposta a requisições de outros agentes;

- Download e leitura de um documento;

- Alteração da importância de um atributo já existente como conseqüência da recomendação de um contato;

- Leitura de documento próprio;

Na figura 5.17, aparece a representação textual de algumas dessas ações através de amostras de instâncias da anotação KUOS. 


\subsection{Condições experimentais}

Após a implementação do agente seguindo o modelo proposto, foi realizada a validação experimental do modelo através da avaliação quantitativa/qualitativa do uso do protótipo por usuários reais. O número de usuários envolvidos foi seis. Além do uso do sistema, cada usuário respondeu a um questionário de avaliação do mesmo.

\subsubsection{Testes com usuários reais}

Para cada usuário foi instalado um agente pessoal COMMUNET. Esta atividade durou aproximadamente uma semana. Uma vez que os usuários envolvidos tinham instalado os seus respectivos agentes, apresentaram aos mesmos as suas mensagens e documentos. Assim, foi iniciado o período em que os agentes pessoais isolados passaram a funcionar como SMA. Ao todo, o período de testes estendeu-se ao longo de quatro semanas. Os testes envolveram dois aspectos complementares: uma visão geral do SMA, monitorando a comunicação entre os agentes pessoais, e as visões particulares dos agentes pessoais enfatizando o impacto do aprendizado através da interação com outros agentes.

Quanto ao primeiro aspecto, o agente que funcionou como "páginas brancas" esteve encarregado de monitorar e armazenar eventos que eram decorrentes de requisições dos agentes pessoais, solicitando a entrada na sociedade, o endereço de outros agentes ou a saída da sociedade. Assim, o agente monitor armazenou apenas os horários em que os agentes pessoais tentaram comunicar-se.

No tocante ao segundo aspecto, cada agente pessoal armazenou as interações com outros agentes, decorrentes de uma consulta do usuário. O foco esteve nas ocorrências das anotações KAOS e KUOS, incluindo o registro das opiniões do usuário quanto à utilidade dos documentos lidos e dos links acessados. A duração desta fase foi de três semanas de uso contínuo pelos usuários envolvidos.

A seguir é detalhado o questionário apresentado aos usuários envolvidos no experimento. 


\subsubsection{Questionário}

Findado o período de uso contínuo cada usuário respondeu a um questionário com as seguintes perguntas ${ }^{11}$ :

\section{Usabilidade}

- Interação gráfica: Você achou os elementos gráficos da interface (telas, listas, árvores etc.) intuitivos para o uso?;

- Comunicação gráfica: Você sentiu-se confortável na interação com o agente (realizando consultas, criando grupos etc.)?;

- Você teve acesso às informações que você precisou sobre o agente?;

- Você desenvolveu um bom entendimento do porquê o agente retornava as informações na forma apresentada (a ordem das recomendações, documentos etc.)?

\section{Agentes}

- Personalização: Você acha que o agente gradualmente foi apresentando melhores recomendações (as recomendações dos contatos mais interessantes apareciam primeiro)?;

- Se você foi mudando o contato que você achava mais adequado, o agente acompanhou tal mudança?;

- Seu agente chegou a surpreendê-lo, trazendo para algum tópico informações que você não esperava, mas que você achou interessantes?;

- Confiança: Você confiaria em agentes deste tipo para preencher a maioria ou parte) das suas necessidades de informação? Por quê?;

- Você sente-se confortável com a perspectiva de usar agentes deste tipo que coletem informação para você?;

\footnotetext{
${ }^{11}$ Este modelo de questionário foi inspirado naquele usado na avaliação da dissertação de mestrado B. Seth, A Learning Approach to Personalized Information Filtering, MIT, 1994. A escolha foi baseada na semelhança do enfoque empírico aplicado nos testes.
} 
- Se você conhece o Gnutella (através de aplicativos como o LimeWire, Mactella ou análogos como o Kazaa, Morpheus etc.), como você compararia o seu uso com relação a um agente como o testado nesta experiência?;

- Quais seriam os ítens relacionados à privacidade que você consideraria importantes/preocupantes dado que o agente tem acesso a informações confidenciais (como e-mail, documentos etc.)?

\subsection{Resultados e Análise}

Os resultados obtidos podem ser melhor analisados considerando quatro etapas sucessivas. Cada uma das etapas fornece consecutivamente dados adicionais às anteriores, i.e. é mostrado, incrementalmente, que o agente possui dados detalhados sobre: os horários do usuário, as diferentes ações relacionadas à busca enquanto atreladas a conceitos particulares, a associação de contatos a conceitos e, finalmente, a relação entre papéis e conceitos.

\subsubsection{Rastreamento temporal}

Este primeiro nível de análise se baseia nos dados disponíveis no arquivo log do agente utilizado como "páginas brancas" pelo sistema. Como a arquitetura do SMA é do tipo P2P, este agente não tem acesso a quaisquer informações sobre os agentes COMMUNET, exceto a sua localização. Estes últimos, por sua vez, só o ativam para determinar quais agentes COMMUNET estão ativos num determinado momento.

No entanto, a partir do $\log$, tal agente (centralizado) pode inferir quais são os horários de acesso de cada um dos outros agentes, baseado nas requisições de cada um. Isto é mostrado na figura 5.18, onde nitidamente os horários de acesso parecem corresponder ao horário comercial.

Este tipo de informação é útil (e monitorada há tempos nos servidores web) para definir, e.g., a carga de tráfego e/ou a possível indicação dos horários de trabalho/lazer dos participantes (o que poderia ser atrelado às páginas visitadas). Tal fato pode ser visto claramente na comparação entre os histogramas individuais da figura 5.19. O comportamento de um usuário ou de um grupo pode ser assim 


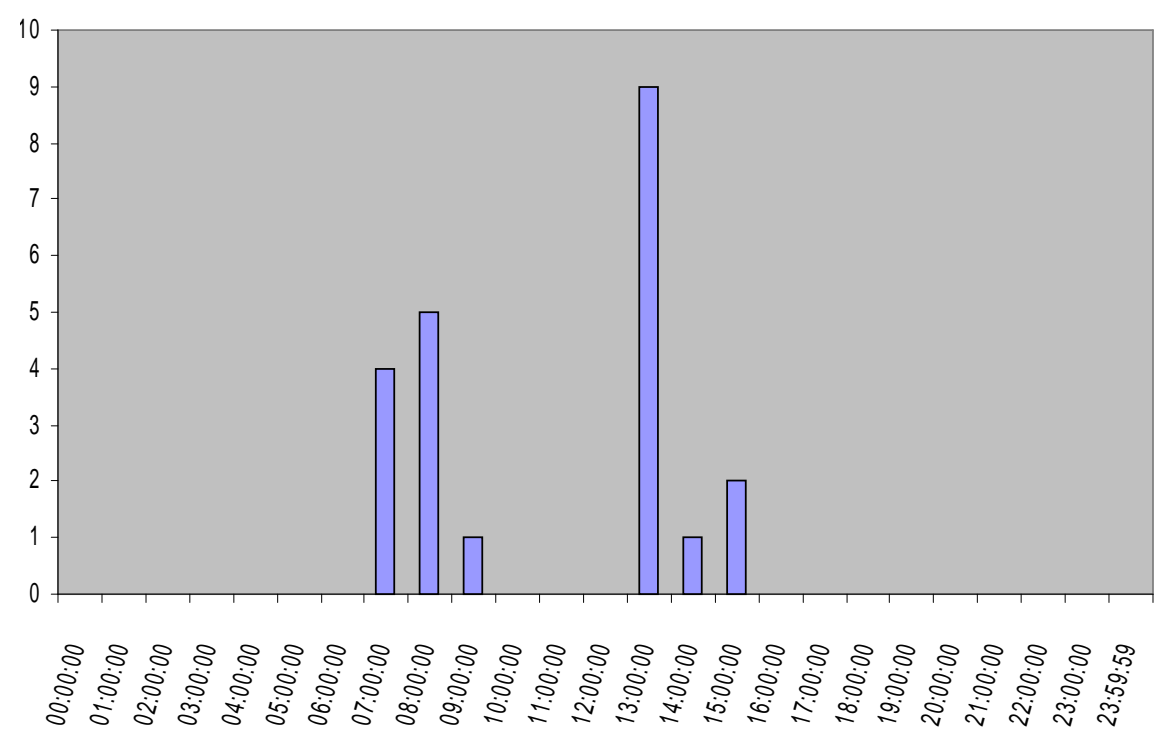

Figura 5.18: Histograma dos horários de acesso do usuário User1 segundo o agente utilizado como páginas brancas.

caracterizado através deste tipo de informação. No caso de um sistema P2P, a privacidade das interações fica a salvo de sistemas invasivos que poderiam fazer parte de um agente como o "páginas brancas".

A monitoração dos horários de uso pode ser utilizada, a partir de uma visão organizacional centralizada, para designar papéis pró-ativamente. Por exemplo, pode ser determinado, para cada agente, um conjunto de horários em que ele desempenhe o papel de consumidor (i.e., os horários de uso normal) e um conjunto de horários em que ele desempenhe preferencialmente o papel de fornecedor (i.e. os horários em que o usuário ao qual está dedicado normalmente não efetua requisições). Certamente, cada um de tais papéis pode ter associadas obrigações e facilidades específicas.

A anuência ou não de um agente quanto a desempenhar papéis poderia ser negociada através do acúmulo ou cessão de créditos, da mesma maneira em que agrupações humanas o fazem nos grupos de trocas, organizados de forma espontânea em redes solidárias emergentes (MANCE, 2003). Tais créditos poderiam ser contabilizados, e.g. através do número de bytes recebidos/transmitidos por período de tempo, baseadas na qualidade das informações transmitidas (avalizadas por outros agentes), etc. 

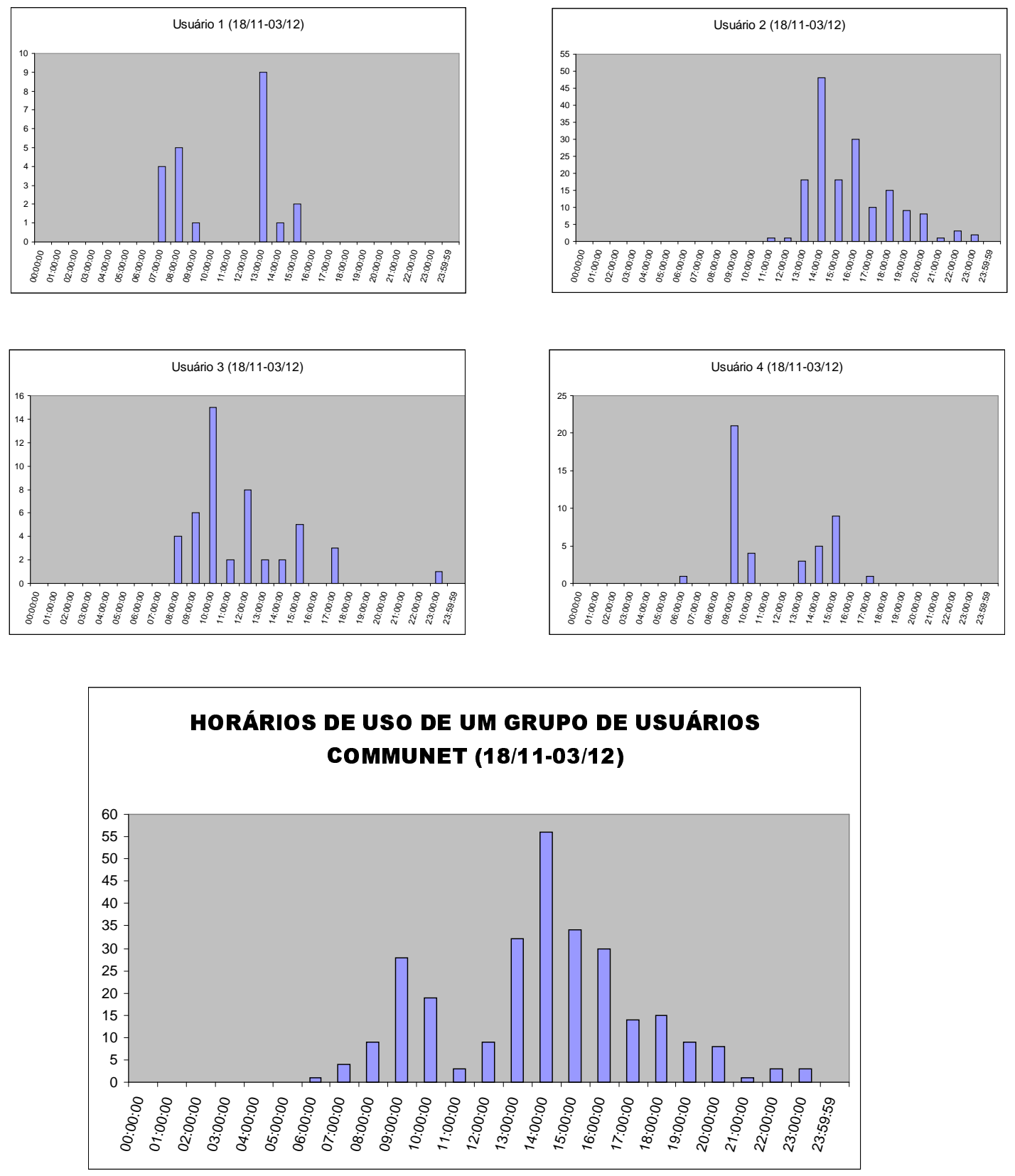

Figura 5.19: Histogramas de horários de acesso individuais e histograma conjunto de um grupo de usuários COMMUNET. 


\subsubsection{Diferenciação de ações e detecção de mudanças nas categorias da busca}

Duas dimensões detectadas por um agente COMMUNET, utilizando as anotações propostas, dizem respeito à associação de tipos diferentes de ações de busca a categorias específicas e ao rastreamento de mudanças de foco nas categorias alvo das seqüências de busca.

Uma primeira dimensão detectada pelo agente COMMUNET, graças às anotações, é a diferenciação dos tipos de ações de busca. Dentre as ações passíveis de serem detectadas pelo agente, citadas na seção 5.1.4, as mais freqüêntes foram:

- Consultas utilizando atributos, i.e. queries;

- Download e leitura de documentos recomendados;

- Leitura de páginas web e documentos próprios.

Além das ações citadas, houve casos em que foram adotadas recomendações de contatos e atributos.

Para facilitar a análise, os dados coletados são mostrados graficamente. As figuras foram elaboradas como visualizações dos dados reais coletados e armazenados pelos respectivos agentes COMMUNET do experimento, através das versões implementadas das anotações propostas. Para diferenciar os tipos de ações detectadas pelo agente, foi adotada uma convenção gráfica para as figuras que representam ações atreladas a seqüências e conceitos.

A convenção utilizada atribui uma coluna para cada ação do usuário detectada por um agente COMMUNET e designa alturas diferentes segundo o tipo de ação. As seqüências mostradas respeitam rigorosamente os dados coletados pelos agentes. Assim, na figura 5.20, são observados três tipos de ações, as colunas mais baixas correspondem à execução de consultas, as colunas de altura mediana representam a leitura de documentos e links próprios e as mais elevadas mostram downloads de documentos recomendados por contatos. Na figura 5.21 aparece uma coluna ainda mais elevada, sinalizando a adoção de um contato. Adicionalmente, a cor de uma coluna indica qual o conceito alvo da busca. 


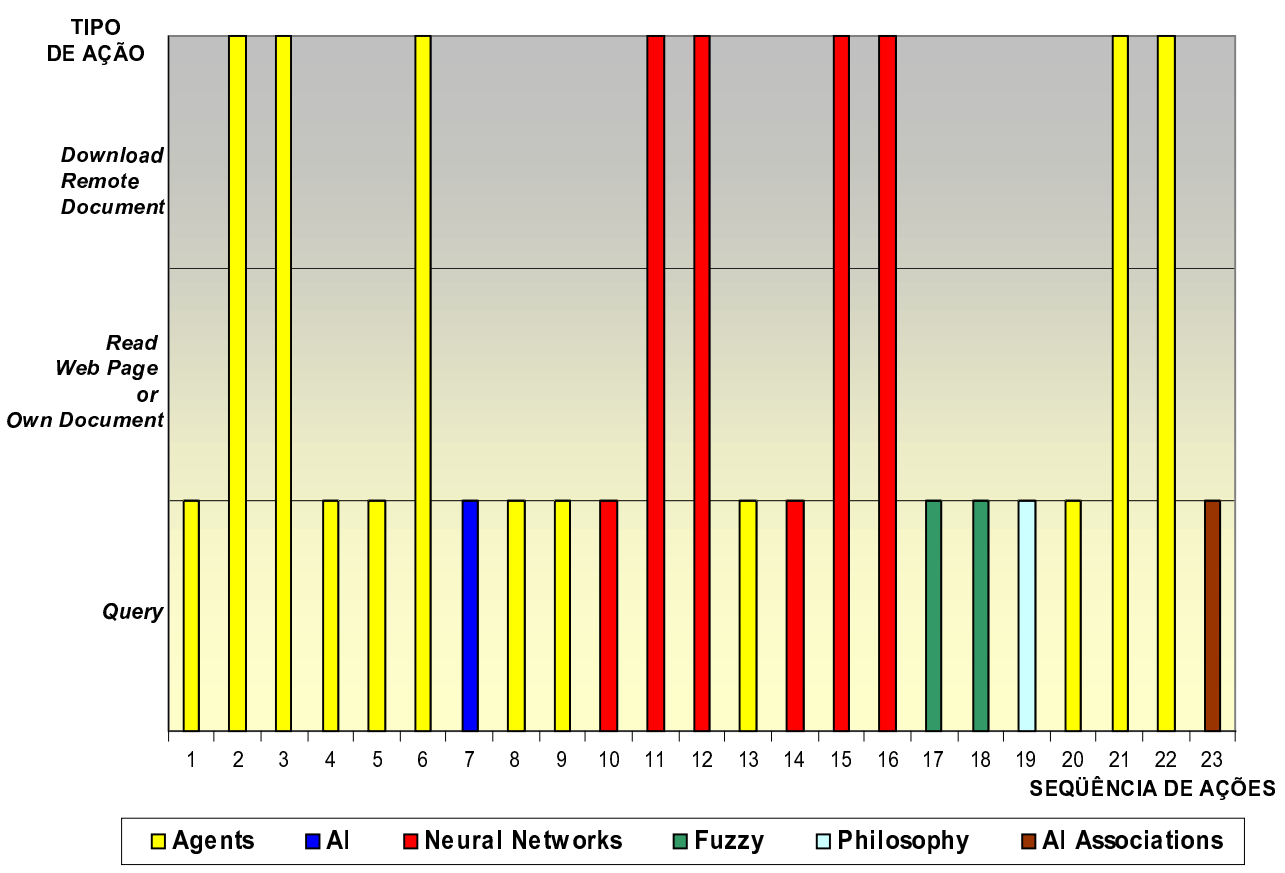

Figura 5.20: Seqüência de ações de busca do usuário User1, diferenciando as ações de consulta, os downloads e as leituras de documentos próprios.

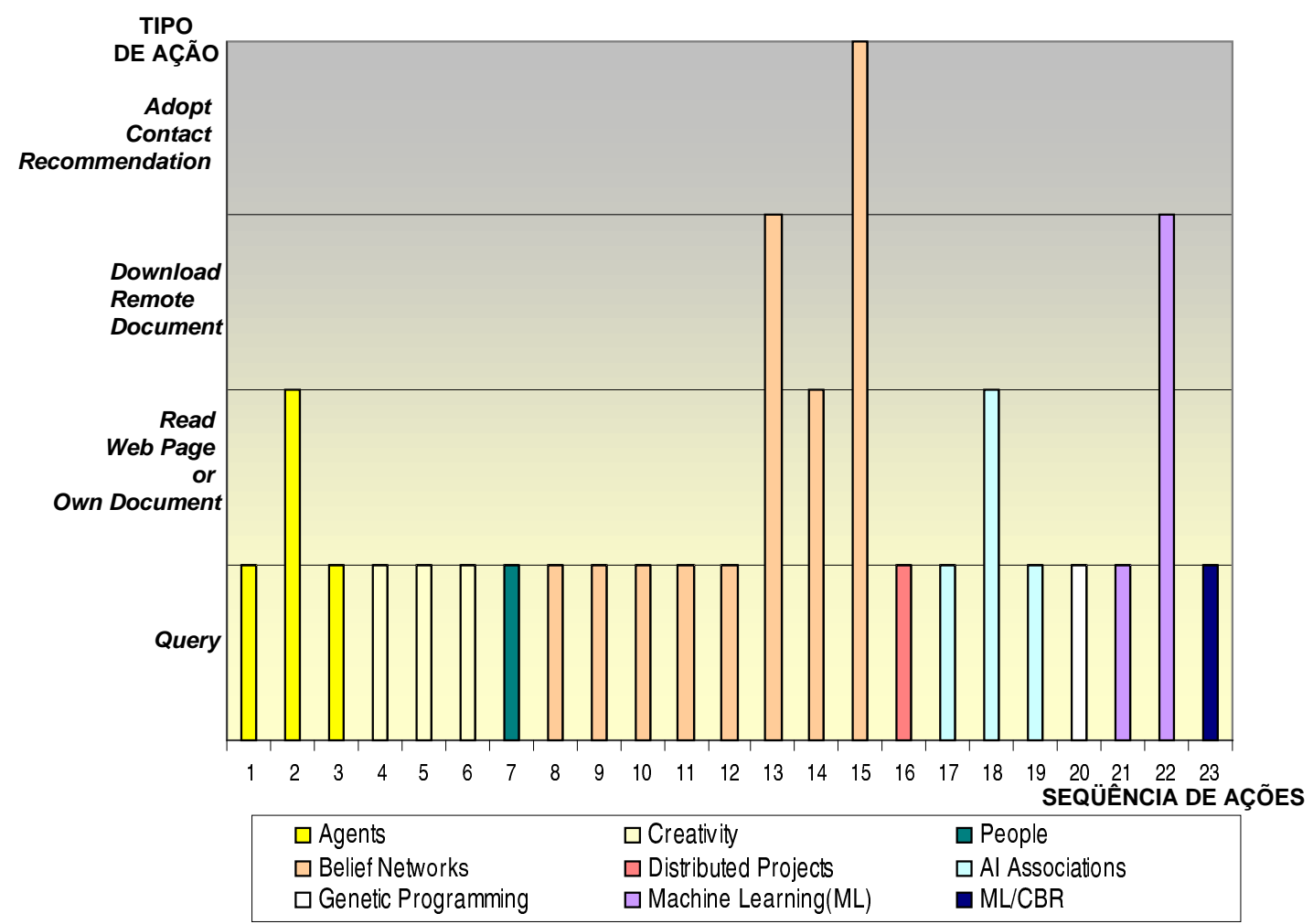

Figura 5.21: Seqüência de ações de busca do usuário User2, diferenciando as consultas, os downloads, as leituras de documentos próprios e a adoção de contatos recomendados. 
A segunda dimensão detectada pelo agente COMMUNET diz respeito à mudança do foco de atenção conceitual do usuário. No decurso de uma sessão, um usuário pode efetuar seqüências contínuas de consultas em relação ao mesmo tema ou não. Nas figuras 5.22, 5.23 e 5.24, elaboradas a partir dos dados armazenados por agentes COMMUNET, podem ser diferenciados tentativamente três tipos de tendências comportamentais em relação aos temas:

- Exploração detalhada de um mesmo tema: em que as diversas ações do usuário (leitura, download etc.) estão concentradas num mesmo conceito;

- Exploração com um eixo (temático) central: quando o usuário explora diversos conceitos correlacionados com o conceito considerado eixo da sua busca, ao qual ele sempre retorna;

- Exploração com mudança de foco: em que o usuário procura informações em relação a conceitos distintos, não retornando ao conceito inicialmente buscado.

Cada uma das seqüências referenciadas nas figuras 5.22, 5.23 e 5.24, pertencem a usuários diferentes. A figura 5.22 exemplifica a primeira tendência descrita. De fato, as ações que vão de 1 até 41 estão centradas no mesmo tema, $A I$.

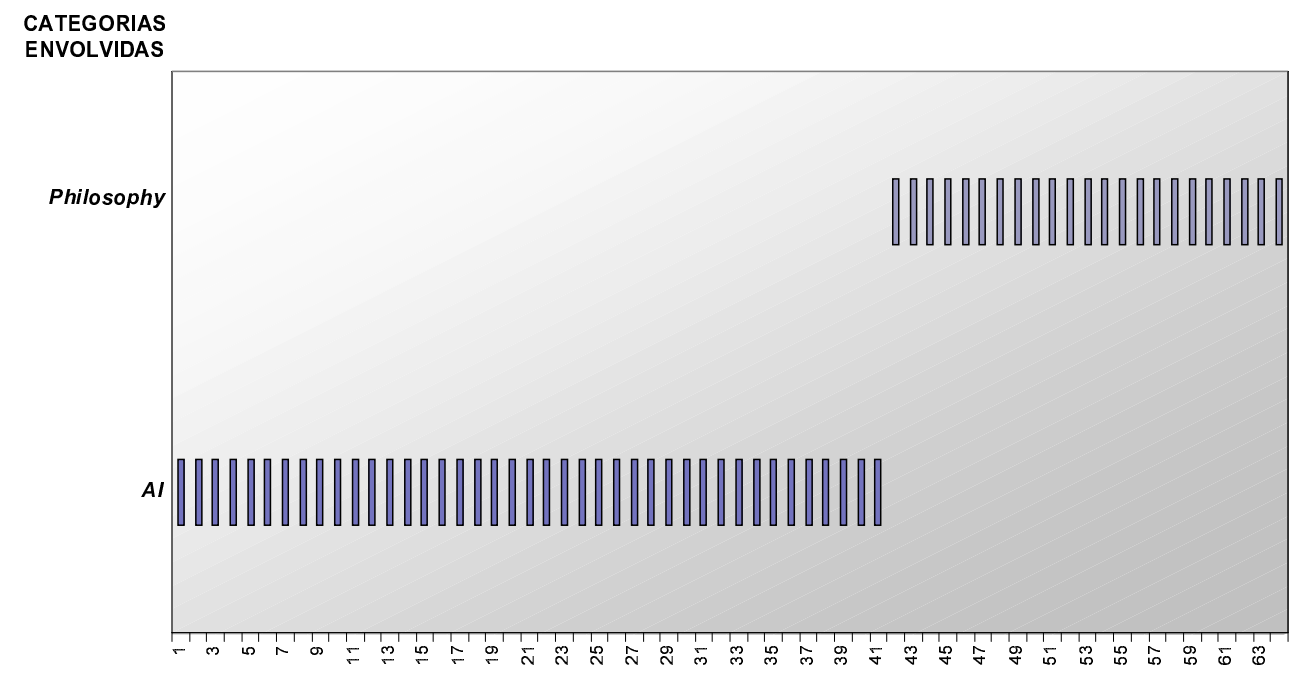

Figura 5.22: Seqüência de ações de busca temática concentrada, detectadas pelo agente COMMUNET dedicado ao usuário Userß.

$\mathrm{Na}$ figura 5.23 aparece o segundo tipo de tendência descrita. Neste caso o eixo central da busca é o tema Agents. 


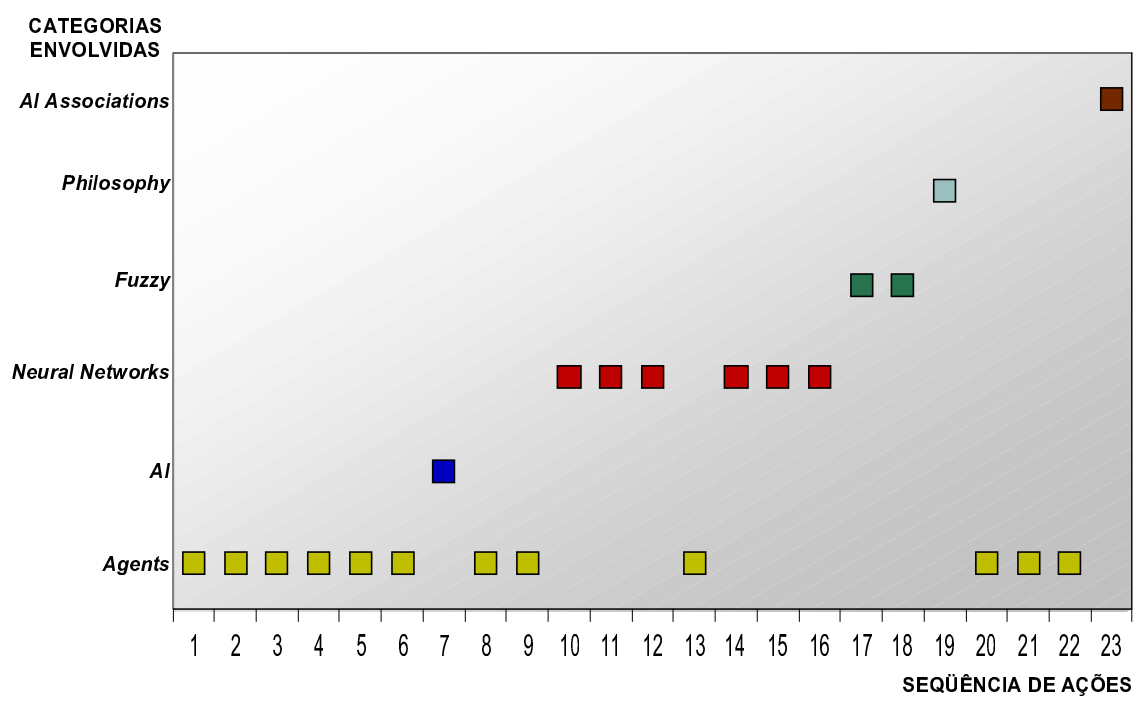

Figura 5.23: Seqüência de ações de busca temática com um eixo central, detectadas pelo agente COMMUNET dedicado ao usuário User1.

Na figura 5.24 pode ser vista uma seqüência de ações de busca onde um usuário exibe a tendência de mudança gradual do conceito alvo, no decorrer de uma mesma sessão.

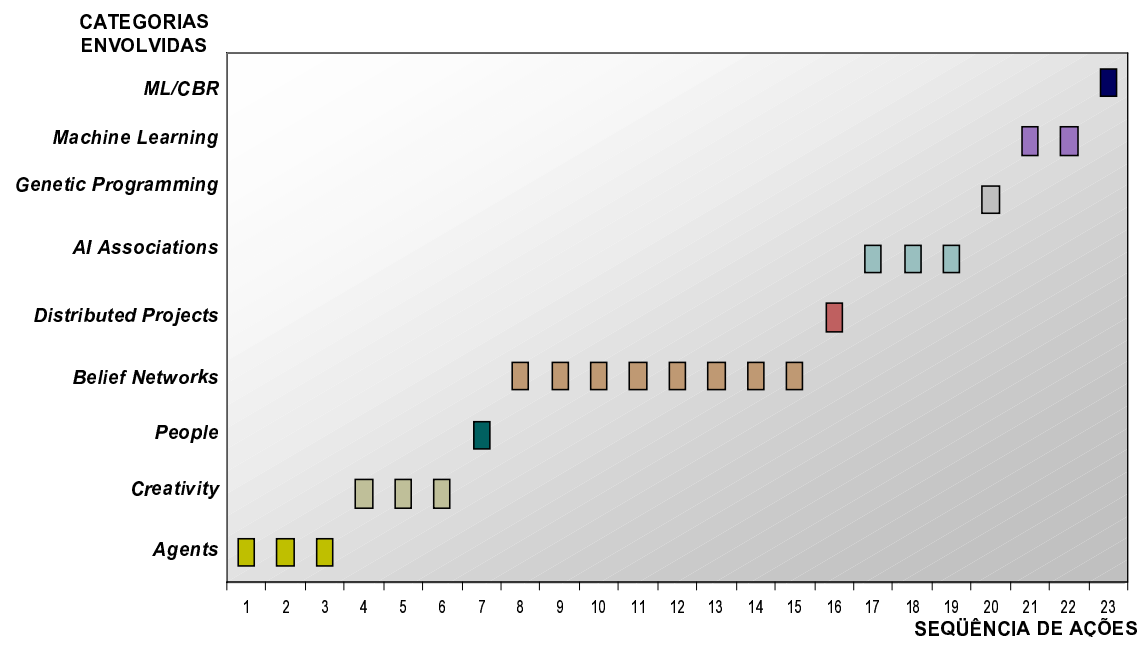

Figura 5.24: Seqüência de ações de busca temática com mudança de foco, detectadas pelo agente COMMUNET dedicado ao usuário User2.

Os dados apresentados podem ser compostos numa visão tridimensional, associando tipos de ações e conceitos às seqüências de busca. A figura 5.25 compõe os dados apresentados nas vistas bidimensionais das figuras 5.20 e 5.23. Na figura 5.26 pode ser apreciada a composição tridimensional dos dados correspondentes às figuras 5.21 e 5.24, referentes ao agente dedicado ao usuário User2. 


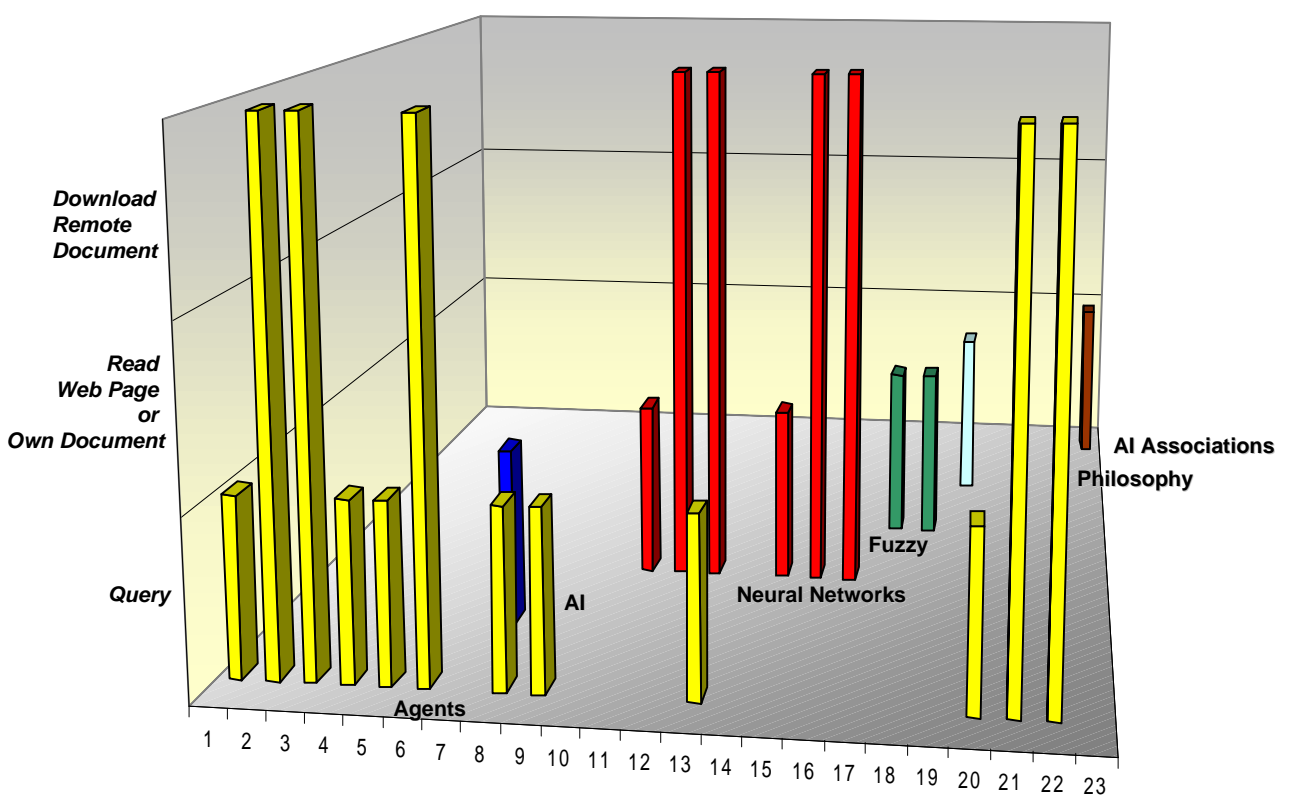

$\square$ Agents $\quad$ Al $\quad \square$ Neural Networks $\quad \square$ Fuzzy $\square$ Philosophy $\quad$ Al Associations

Figura 5.25: Visão tridimensional dos tipos de ações de busca e conceitos na seqüência detectada pelo agente COMMUNET do usuário User1.

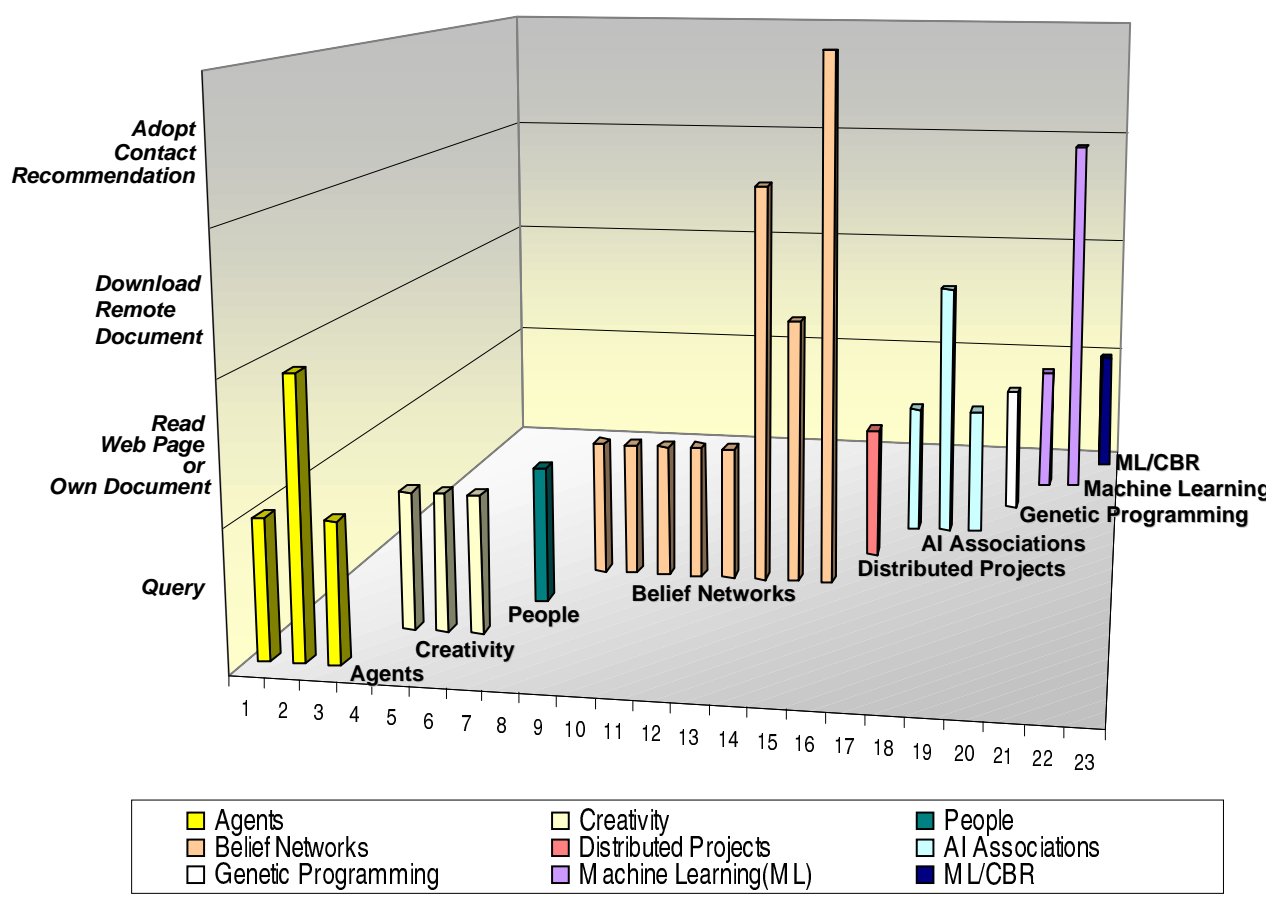

Figura 5.26: Visão tridimensional dos tipos de ações de busca e conceitos na seqüência detectada pelo agente COMMUNET do usuário User2. 
Assim, pode-se observar que um agente COMMUNET, graças às anotações, possui a habilidade de detectar quais os tipos de ações de busca que o usuário executa em relação a um conceito e ainda, descobrir quais as tendências comportamentais de busca em relação a conceitos diferentes. Como citado na seção 4.3 o processamento das informações fornecidas pelas anotações dependem do domínio de aplicação e das habilidades do agente projetado.

\subsubsection{Tratamento de sociogramas conceituais}

Como as anotações fornecem um caminho de mão dupla, que leva de contatos a conceitos e vice-versa, é possível para um agente COMMUNET identificar contatos a partir de conceitos. Ao enveredar por esta senda, o agente COMMUNET é capaz de construir sociogramas conceituais. Um sociograma conceitual é mostrado na figura 5.27 .

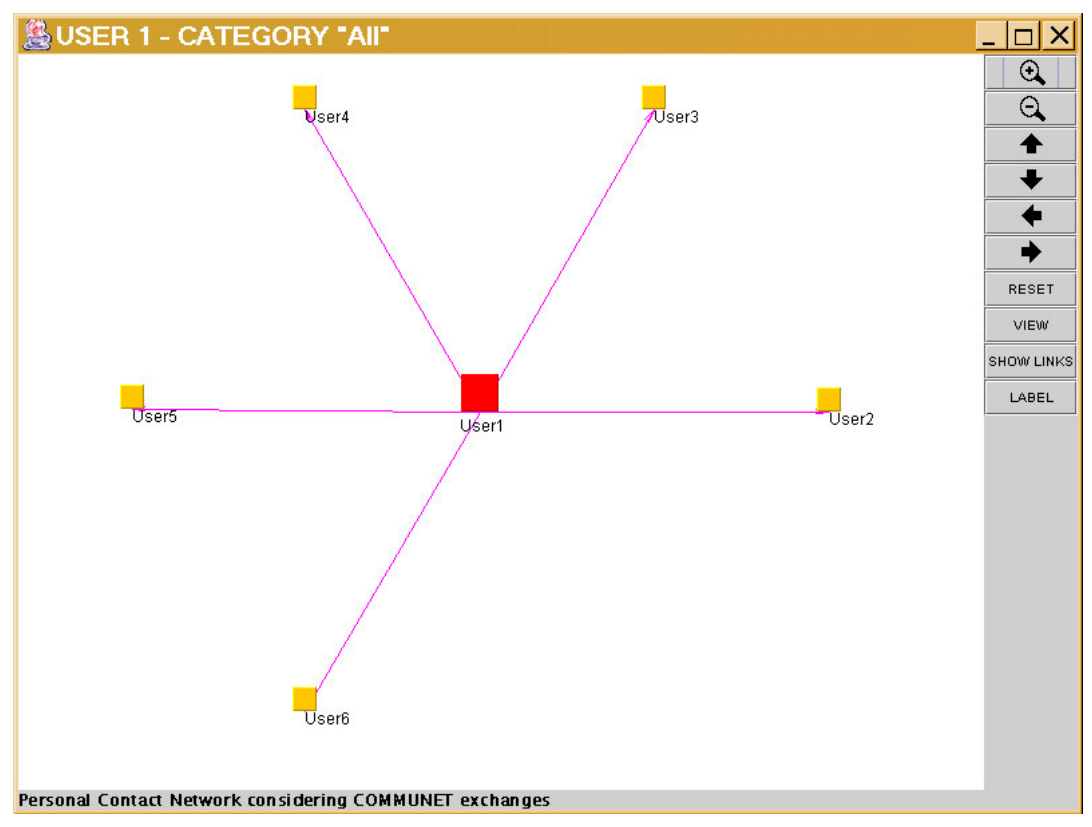

Figura 5.27: Sociograma conceitual inicial, computado pelo agente do usuário User1. Os contatos encontram-se igualmente distantes do usuário.

Um sociograma como o da figura 5.27 exibe a mesma aparência para qualquer agente COMMUNET no momento de ser apresentado aos dados do usuário. Na figura 5.27, o agente do usuário User1 considerou todas as categorias por ele conhecidas, sendo que a distância de cada contato ao usuário é menor quanto maior 
a contribuição do contato em relação às categorias consideradas. Inicialmente, a aparência deste sociograma é a mesma para qualquer categoria considerada. Nesta situação, os contatos não foram ainda acionados para iniciar a partilha.

Na presente versão do agente COMMUNET, apenas por uma questão de escolha, a visualização dos sociogramas conceituais não está ativa ${ }^{12}$. No entanto, o agente de fato computa e utiliza sociogramas temáticos cada vez que executa uma consulta, pois está é a fonte da informação utilizada para ordenar as respostas dos contatos.

Neste ponto cabe citar que logo no início do experimento, um dos usuários teve de interromper a sua participação. Como o agente do mesmo passou a ser não responsivo, esta situação passou a ser considerada análoga ao caso de pares não responsivos em redes $\mathrm{P} 2 \mathrm{P}$. Com isto, a distância de tal usuário, quando visto como contato, nos sociogramas dos agentes dos outros usuários, permanece a mesma da situação inicial. Este usuário, identificado como User6, passa a servir como referência nos sociogramas apresentados, ilustrando a distância máxima entre um usuário e qualquer um dos contatos participantes do experimento.

Após diversas interações com outros pares, o sociograma conceitual pode aparecer como mostrado nas figuras 5.28 e 5.29. Na figura 5.28, o agente COMMUNET do usuário User2 verificou que os contatos User1, User3 e User4 contribuíram positivamente, diferenciando-os dos demais para o conceito Knowledge Representation. Ainda, o contato User3 aparece como sendo o mais próximo, razão pelo qual, quando o usuário User2 requisitar informações sobre o conceito, o agente apresentará primeiro os recursos partilhados pelo contato User3.

O mesmo agente do usuário User2 fornece um sociograma conceitual diferente para o conceito Agents. O mesmo aparece na figura 5.29, o agente COMMUNET verificou que foram os contatos User1, User4 e User5 aqueles que se mostraram mais úteis quando de solicitações anteriores sobre o conceito Agents. Dentre esses contatos, o contato User1 aparece como sendo o mais próximo, o que levará o agente a apresentar primeiramente as recomendações do mesmo, da próxima vez que o usuário User2 requisitar informações sobre Agents.

Assim como são gerados sociogramas conceituais para cada categoria, todos

\footnotetext{
${ }^{12} \mathrm{O}$ sociograma disponibilizado graficamente para o usuário é aquele decorrente do processamento automático das suas mensagens de $e$-mail.
} 


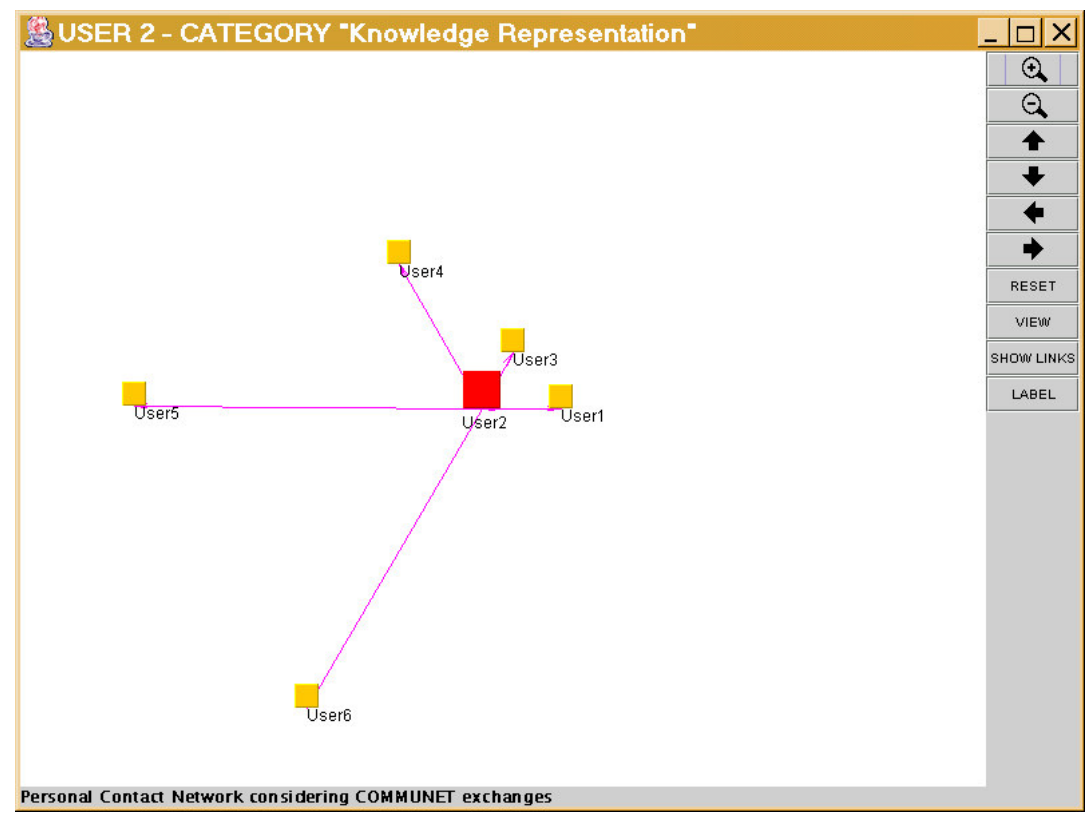

Figura 5.28: Sociograma conceitual, considerando apenas a categoria Knowledge Representation, computado pelo agente do usuário User2.

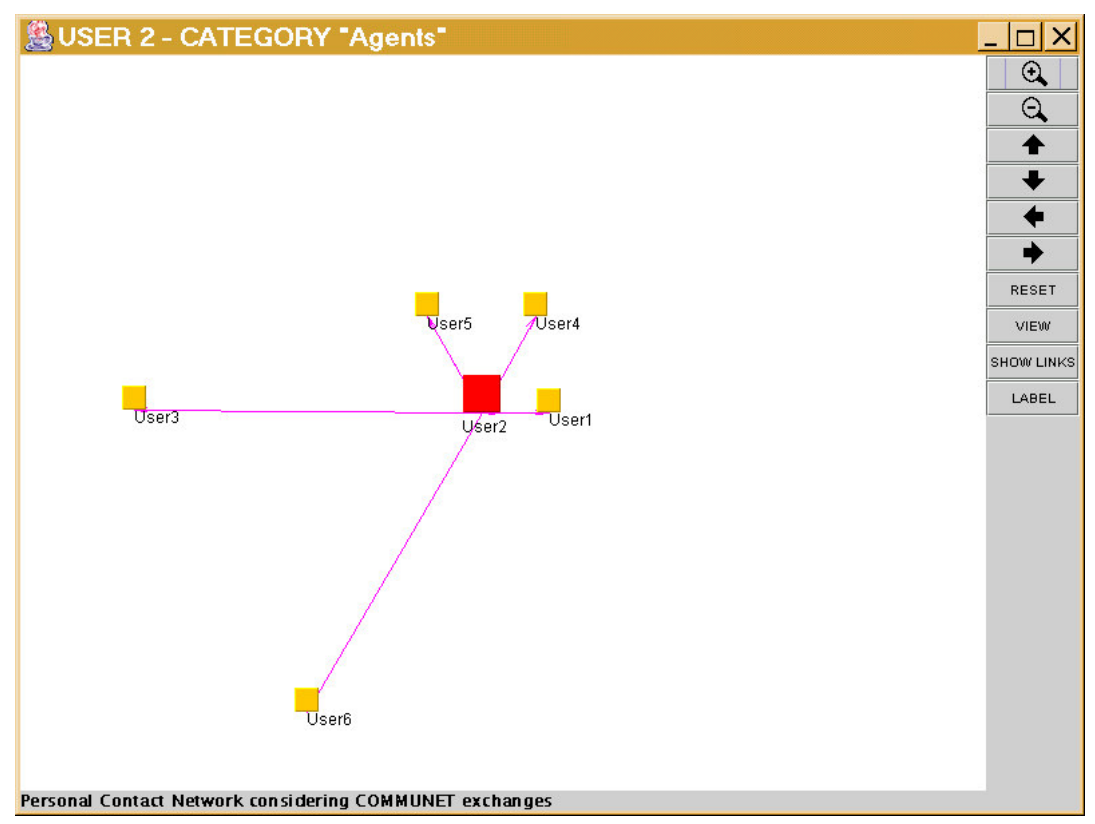

Figura 5.29: Sociograma conceitual, considerando apenas a categoria Agents, computado pelo agente do usuário User2. 
eles podem ser considerados de maneira conjunta. Na figura 5.30, um sociograma deste tipo é exibido, segundo o mesmo agente COMMUNET dedicado ao usuário User2. Pode-se observar que os resultados acumulados para cada contato evidenciam que todos, com exceção do usuário não responsivo User6, contribuíram com o usuário.

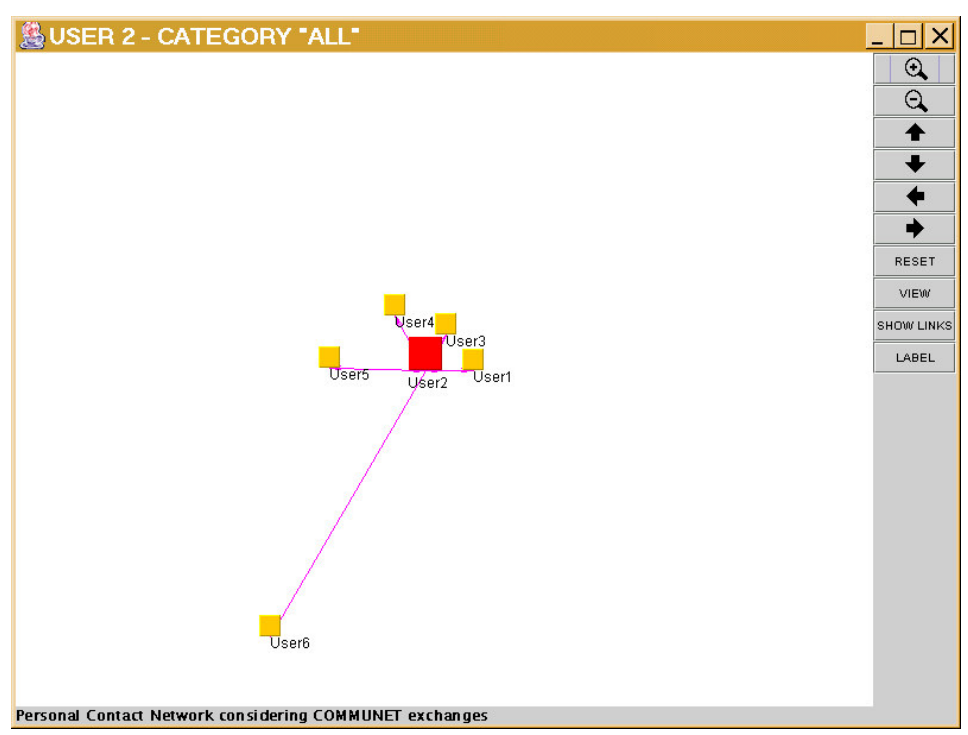

Figura 5.30: Sociograma conceitual, considerando todas as categorias, computado pelo agente do usuário User2 após múltiplas interações.

O experimento permite então supor que um agente pode, através das anotações propostas, diferenciar as contribuições de outros agentes que participam numa comunidade, em relação a conceitos específicos. A seguir, será discutido um outro aspecto, acessível a um agente COMMUNET graças às anotações e à representação organizacional, qual é a associação de contatos a papéis nos diagramas conceituais.

\subsubsection{Papéis em sociogramas conceituais}

Como visto na seção 5.1.3, um agente COMMUNET requisita do usuário ao qual está designado a estruturação dos seus contatos em papéis que possuem permissões particulares de acesso ao conhecimento do usuário. Deste modo, o agente passa a ter acesso explícito à visão organizacional subjetiva do usuário. Esta informação pode então ser utilizada, combinada com as anotações, possibilitando 
uma representação mais rica do sociograma conceitual. Nos sociogramas exibidos a seguir, é adotada a convenção gráfica de circundar os contatos que desempenham um mesmo papel com uma linha, para realçar os papéis, diferenciando-os segundo as cores seguintes:

- O papel Amigos do grupo TRABALHO aparece traçado na cor vermelha;

- O papel Colegas do grupo TRABALHO aparece traçado na cor azul;

- O papel Desafetos do grupo TRABALHO aparece traçado na cor preta;

- O papel Amigos do grupo $C A S A$ é representado por duplo traço vermelho ${ }^{13}$;

- O papel Default do grupo OUTROS aparece traçado na cor verde.

Um sociograma conceitual deste tipo aparece na figura 5.31.

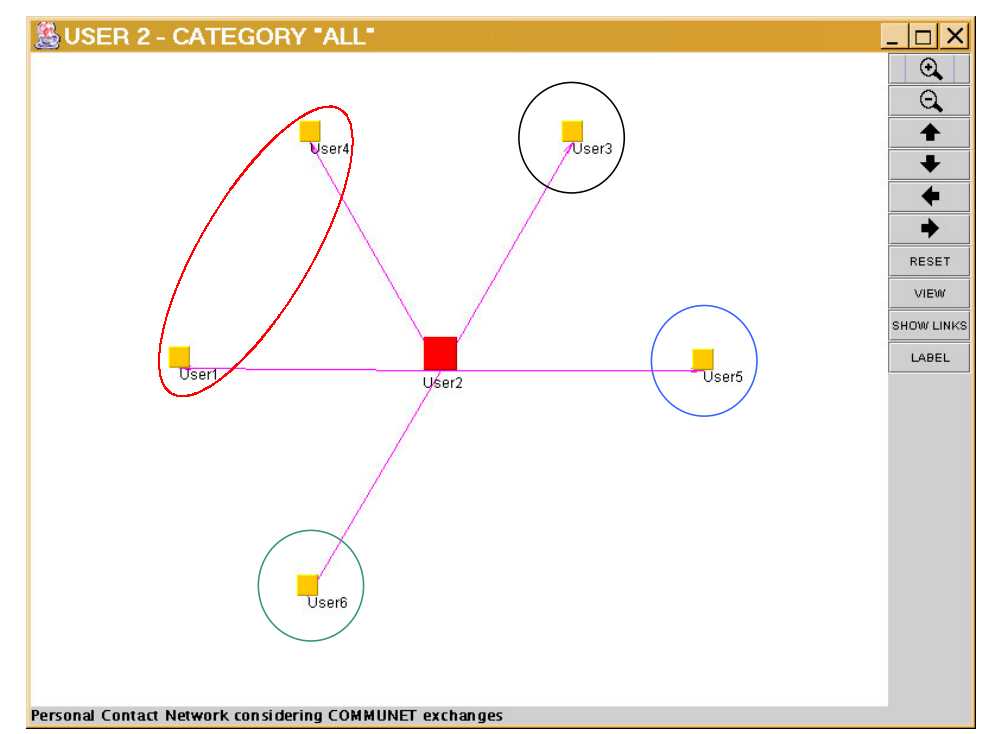

Figura 5.31: Sociograma conceitual inicial, considerando todas as categorias e mostrando quatro papéis, computado pelo agente do usuário User2.

No sociograma da figura 5.31 aparecem quatro papéis. Na verdade, a figura mostra o sociograma inicial do usuário User2. Da mesma maneira, os sociogramas representados nas figuras 5.28 e 5.29, enriquecidos com a representação dos papéis, aparecem novamente nas figuras 5.32 e 5.33 respectivamente.

\footnotetext{
${ }^{13}$ Particularmente, este caso não é retratado nas figuras que aparecem nesta seção.
} 


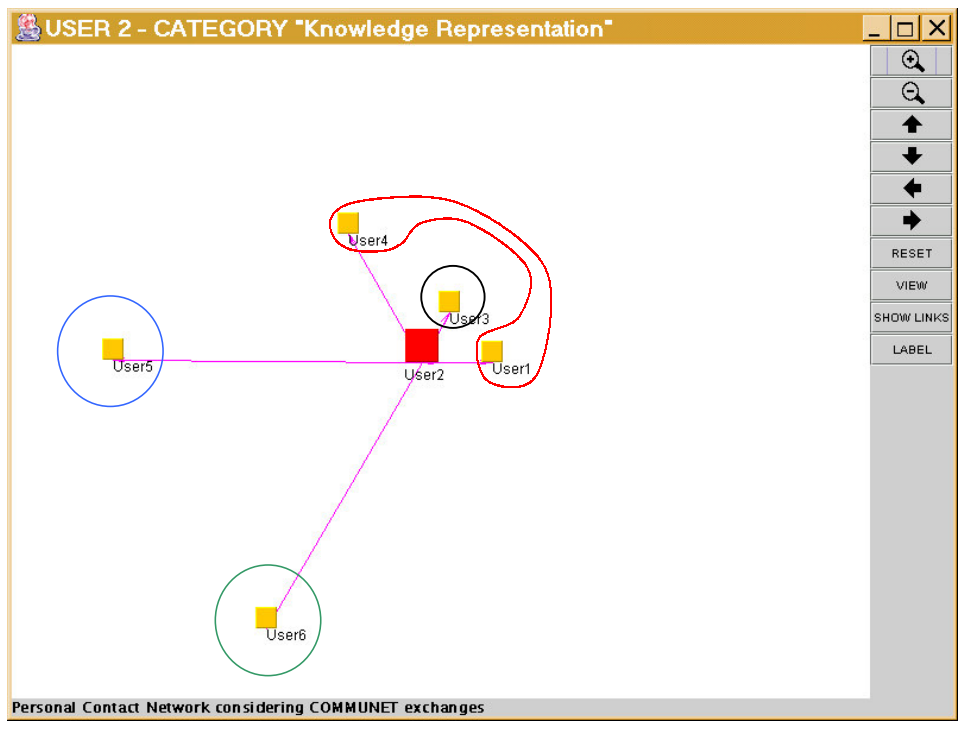

Figura 5.32: Sociograma conceitual para a categoria Knowledge Representation, mostrando papéis, computado pelo agente do usuário User2.

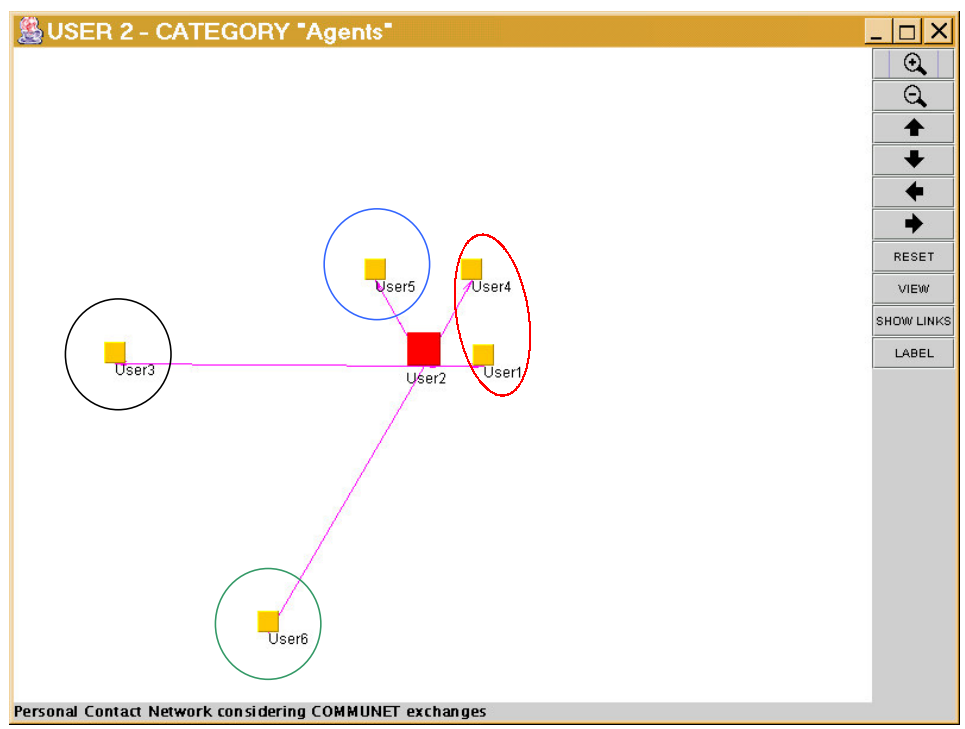

Figura 5.33: Sociograma conceitual para a categoria Agents, mostrando papéis, computado pelo agente do usuário UserQ. 
Um caso particularmente interessante é mostrado na figura 5.32. Nesse sociograma conceitual, um contato que é considerado desafeto (representado dentro do círculo preto) é aquele com a maior contribuição em relação ao conceitos Knowledge Representation. De fato, são diversas as reflexões que podem ser reavivadas com este tipo de constatação (computacional), auxiliando na explicitação de estruturas inerentes aos relacionamentos entre seres humanos e cujos traços podem ser vislumbrados através das interações. De posse das associações explícitas entre ações, contatos, papéis e conceitos, um agente pode analisar diversas estratégias que facilitem a interação com o usuário ao qual estão dedicados.

\subsubsection{Avaliação do questionário}

Para obter um retorno em relação aos aspectos qualitativos do experimento, foram avaliadas as respostas dos usuários ao questionário apresentado na seção 5.2.2.

De forma geral, a implementação foi muito bem recebida pelos membros do grupo de teste. Como pontos positivos mais ressaltantes, foram mencionados de forma recorrente os seguintes aspectos:

- A possibilidade aberta pelo agente COMMUNET de realizar buscas temáticas numa comunidade;

- A proximidade da representação de papéis sociais permitida pelo agente, em relação ao entorno comunitário dos usuários;

- A novidade positiva quanto à associação da memória temática a contatos;

- A possibilidade de diferenciação dos seus próprios documentos quanto à privacidade.

Certamente estes pontos positivos são decorrentes das habilidades projetadas para o agente a partir da proposta desta tese. Como conseqüência do uso, diversas idéias apareceram para extensões e aperfeiçoamentos quanto ao protótipo, dentre elas, as principais foram direcionadas para:

- Permitir a cada usuário incluir e retirar categorias nas suas ontologias particulares; 
- Possibilitar a alteração dinâmica da representação organizacional subjetiva do entorno do usuário;

- Detalhes relacionados à interface como: forma de apresentar os resultados, requisição de telas distintas para a busca P2P e para a busca utilizando uma máquina de busca geral, detalhes de navigação nos conceitos, etc.

Os dois primeiros pontos levantados decorrem de escolhas quanto ao controle do ambiente experimental. Um agente COMMUNET, através dos pacotes desenvolvidos, possibilita a adição e a retirada de novos conceitos, devendo ser alterada a $A P I$ dos mesmos de forma a possibilitar esta manipulação através da interface. No que diz respeito a tratar requisições decorrentes de ontologias modificadas, torna-se necessária a implementação de um algoritmo capaz de rastrear mudanças a partir da ontologia inicial.

Quanto à dinâmica da visão organizacional subjetiva, da mesma maneira que na representação organizacional, as restrições visando controlar o ambiente do experimento vedaram a alteração da visão organizacional com a inclusão e exclusão de papéis e grupos. No entanto, esta características, dentre as citadas, é a de mais fácil alteração.

Em relação aos aspectos de interface, os mesmos requerem, de fato, um estudo mais cuidadoso. Cabe ressaltar que a configuração atual foi desenvolvida apenas como prova de conceito.

\subsection{Comentários}

Este capítulo descreveu a implementação e análise experimental da idéia proposta, permitindo obter respostas a várias das perguntas apresentadas no capítulo introdutório.

Foi demonstrado como um agente pode levar em conta a associação entre os conceitos que ele referencia e a historicidade das ações de um usuário, enquanto imerso numa comunidade de pares. De fato, foi aberto um caminho para novas indagações, seja no contexto das relações cognitivas de agentes autônomos com a sua historicidade social, seja na representação de um componente social do conhecimento. Certamente, um sistema nos moldes idealizados pressupõe a disposição 
das pessoas para partilhar os seus conhecimentos sem, no entanto, permitir a invasão de privacidade através da partilha indiscriminada dos seus recursos.

Os resultados aqui apresentados mostraram, de forma gradativa, as possibilidades abertas na prática. Já o próximo capítulo aborda as conclusões e os possíveis trabalhos futuros. 


\section{Conclusões}

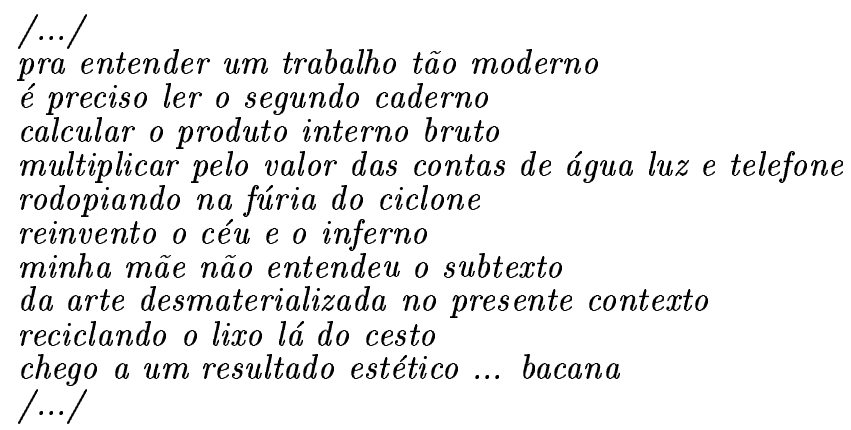

Z. Baleiro - Bienal

Alguns dos problemas associados à partilha de informação em comunidades abertas compostas de usuários, relacionados entre si como pares e mediados por agentes computacionais, foram introduzidos como perguntas no capítulo inicial deste trabalho. Tais problemas foram parcialmente solucionados. As respostas encontradas estão fundadas numa abordagem derivada da adoção de uma visão do conhecimento como sendo socialmente concebido, porém, historicamente dependente da experiência particular de um agente. Não se pretende que tal conhecimento seja estático do ponto de vista dos agentes nem único entre os diversos grupos aos quais ele pode pertencer.

\subsection{Contribuições}

A principal contribuição deste trabalho é a representação do conhecimento de agentes computacionais na forma de ontologias anotadas com informação organizacional. Tal contribuição possibilita a integração e o tratamento explícito de três aspectos distintos do comportamento sócio-cognitivo de um agente:

- Redes sociais, como representação do entorno social de um agente; 
- Papéis sociais, como representação da estruturação orgânica do entorno social de um agente;

- Ontologias, como representação da estruturação do seu conhecimento.

Ao aplicar tal enfoque à partilha de conhecimento, podem ser destacadas as seguintes conseqüências:

- Associação de conceitos a interações sociais (quais contatos usam quais conceitos), o que possibilita rastrear grupos de usuários relacionados a conceitos particulares e quando os utilizam;

- Associação explícita das ações executadas por um agente a conceitos particulares;

- Utilização das associações para qualificar o conhecimento oferecido por contatos quando da interação de partilha em comunidades.

Retomando as perguntas propostas na seção introdutória, foi verificado que muitas delas tinham sido respondidas a partir do estudo experimental desenvolvido com o agente COMMUNET. As respostas que seguem auxiliam a destacar vários aspectos das contribuições desta tese:

- Como construir uma representação da rede social da(s) comunidade(s) à(s) qual(is) pertence um usuário de forma a se aproximar da visão do usuário? Utilizando como base as mensagens de e-mail em conjunção com o modelo organizacional $\mathcal{M}$ oISE $^{+}$pode ser levantada a visão organizacional subjetiva do usuário, i.e. dando ao usuário a possibilidade de estruturar os contatos através de papéis sociais.

- Como podem ser relacionadas a estruturação do conhecimento e a rede social de um usuário?

Utilizando representação do conhecimento na forma de ontologias anotadas com informação organizacional.

- Como utilizar a estruturação do conhecimento e a rede social do usuário para localizar pessoas que possuam conhecimentos num certo domínio? 
Utilizando as ontologias anotadas, pode-se chegar aos agentes associados a um conceito.

- Como pode o usuário ter maior controle sobre diferentes recursos (documentos, contatos, ontologias, etc.), preservando a sua privacidade sem inviabilizar a partilha de informação P2P?

Os recursos, assim como os conceitos, podem ter diferentes níveis de privacidade relacionando permissões a papéis sociais

- Quais são as inovações deste método?

Fornece uma perspectiva de busca P2P não existente previamente (levando em conta papéis sociais, permissões e conhecimento num contexto comunitário aberto) e que pode ser muito útil como um método complementar a alguns já existentes (máquinas de busca geral) e a outros em desenvolvimento (como os métodos que tentam localizar comunidades de usuários a partir de páginas web (FLAKE et al., 2002; PUJOL; SANGUESA; DELGADO, 2002) tomadas como pontos de partida).

- Como construir a ontologia de um usuário com o mínimo de intervenção da sua parte?

Esta pergunta foi respondida parcialmente. O caminho escolhido foi o de iniciar com a mesma ontologia geral única para cada usuário, usando como atributos dos conceitos as palavras-chaves extraídas de páginas classificadas manualmente sob os mesmos.

Adicionalmente, surgiu outra questão:

- Como poderia ser realizada a comparação de ontologias entre usuários diferentes?

Aqui, apenas uma resposta parcial pode ser oferecida. Embora não tenha sido implementado no estudo de caso, o enfoque proposto não impede os usuários de alterar as ontologias dos agentes dedicados. Utilizando as anotações apresentadas, cada agente fica de posse do histórico de mudanças da ontologia de um usuário. O histórico de inserção, modificação, retirada de novos conceitos pode ser utilizado considerando a ontologia inicial 
como âncora em combinação com métodos de comparação de ontologias. Um destes métodos foi explorado durante a elaboração deste trabalho com resultados satisfatórios (GIMÉNEZ-LUGO et al., 2002). Entretanto, são necessários novos estudos para atingir resultados similares com um nível maior de formalismo.

Ainda, diversas publicações foram geradas durante os trabalhos desenvolvidos como parte da elaboração deste tese:

- Lugo, G. Giménez, Andrade, M. T. Carvalho de, Sichman, J. S. Recuperação de Informação usando Computação Nebulosa a partir de documentos com estruturas heterogêneas. In: WORKCOMP,São José dos Campos, 2000.

- Lugo, G. Giménez, Hübner, J., Sichman, J. S. Representação e Evolução de Esquemas Sociais em SMA: um Enfoque Funcional. In: III ENIA Fortaleza, 2001.

- Giménez-Lugo, G. A., Amandi, A., Sichman, J. S. and Godoy, D. Enriching information agents' knowledge by ontology comparison: a case study. In: IBERAMIA - Sevilla, 2002.

- Giménez-Lugo, G. A., Amandi, A., Sichman, J. S. Comparação de Perfís de Usuários coletados através do Agente de Interface PersonalSearcher. In: Boletim Técnico da Escola Politécnica da USP, Departamento de Engenharia de Computação e Sistemas Digitais, 2002.

- Giménez-Lugo, G., Sichman, J.S. e Hübner, J. F. Reconciliando Ontologias através de Conhecimento Organizacional para Agentes de Informação em Comunidade. In: IV ENIA - Campinas, 2003.

- Giménez-Lugo, G., Sichman, J.S. e Hübner, J. F. Integrating Knowledge Centered MAS Through Organizational Links. In: KIMAS 03, IEEE International Conference on Integration of Knowledge Intensive Multi-Agent Systems, Boston, 2003.

- Giménez-Lugo, G. A., Sichman, J.S. e Hübner, J. F. Empowering Knowledge Sharing in Internet-Mediated Communities through Socially-Aware Autonomous Intelligent Agents. In: WBC 04, International Conference on Web Based Communities, Lisboa, 2004. 


\subsection{Trabalhos futuros}

A implementação deste trabalho apresentou resultados interessantes. Porém, as possibilidades abertas estão longe de terem sido esgotadas. Vários caminhos podem ser explorados com maior profundidade. Eles podem estar associados aos seguintes aspectos:

- Estudar como o modelo pode ser utilizado para que agentes possam cooperar de forma pró-ativa, e.g. quando um agente descobre que um outro agente possui um certo conhecimento, pode convidar o mesmo a pertencer/formar um grupo e assumir um papel;

- Na geração e transmissão de conceitos em redes sociais, o modelo pode auxiliar a verificar quais as condições e os mecanismos de geração de conceitos em comunidades virtuais, assim como os mecanismos de transmissão, além das permanências e as rupturas em grupos distintos (e culturas diversas);

- En relação à influência dos papéis sociais na transmissão, deve ser verificado o efeito da explicitação dos papéis sociais desde o ponto de vista dos receptores de informação (quais os mecanismos de síntese e de mimese que aparecem). Adicionalmente, pode ser estudado qual o grau de aderência entre as representações explicitadas e os grupos sociais vivenciados quando da aplicação a comunidades numerosas;

- No que se refere ao impacto da associação entre conceitos e papéis na emergência de organizações, o modelo pode auxiliar a verificar se existe alguma correlação entre a acumulação de conhecimento (específico) e o surgimento de papéis e grupos em organizações;

- Ao examinar sistemas de reputação, o modelo pode ser utilizado para tentar descobrir as condições organizacionais que favorecem a acumulação de (certos tipos de) conhecimento. Ainda, podem ser pesquisadas as variáveis que influenciam a relação entre reputação e conhecimento;

- A proposta fornece uma base para explorar e/ou desenvolver métodos que possam medir a conformidade de agentes a papéis. Seja através da exploração dos parâmetros que podem ser utilizados para associar um compor- 
tamento (através da observação direta ou indireta) a um papel, ou ainda estabelecer a viabilidade computacional dos mesmos.

De um ponto de vista mais pragmático, dado que o modelo apresentado pode ser utilizado tanto para o levantamento dos papéis atribuídos a indivíduos como para a verificação do comportamento entre pares, tal estudo pode ser feito tanto com grupos reais quanto em simulações. 


\section{Anexo A - Associação de ações e categorias a seqüências de busca}

Nesta seção são apresentados, em cada página, grupos de 3 gráficos relativos a amostras de seqüências de busca de usuários do sistema COMMUNET, conforme visto na seção 5.3.2, respectivamente:

- Duas seqüências de ações de busca do usuário User1;

- Duas seqüências de ações de busca do usuário User2;

- Duas seqüências de ações de busca do usuário User3;

Cada grupo de figuras contém duas vistas bidimensionais: uma mostrando a associação entre conceitos e seqüências de busca, outra exibindo os tipos de ações de busca que aparecem numa seqüência de interações do usuário. Ainda, um terceiro gráfico integra ambas as vistas anteriores. 

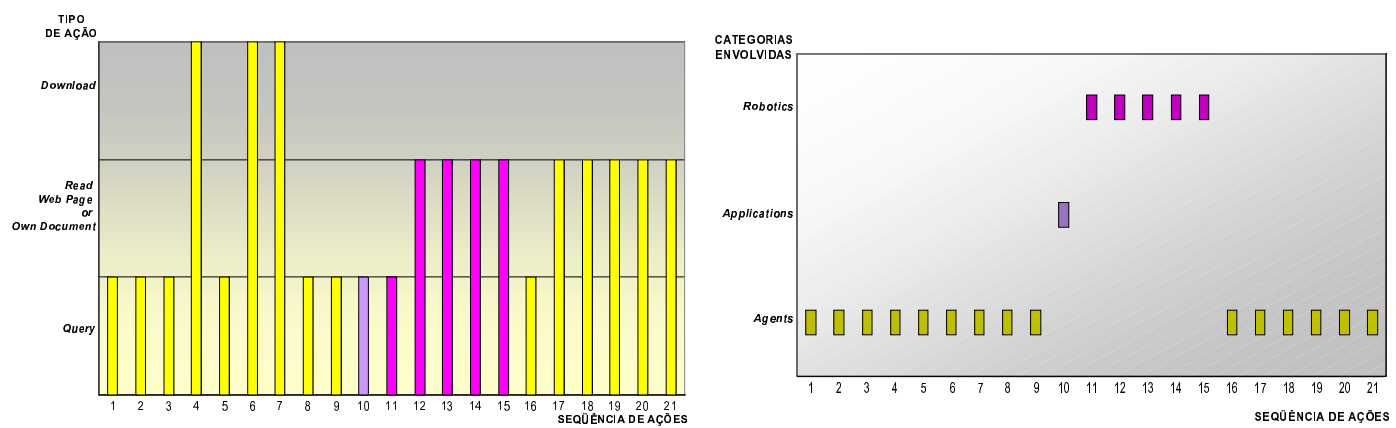

Figura A.1: Amostra de uma seqüência de ações do usuário User1, por tipo de ação (esq.) e considerando os conceitos envolvidos (dir.).

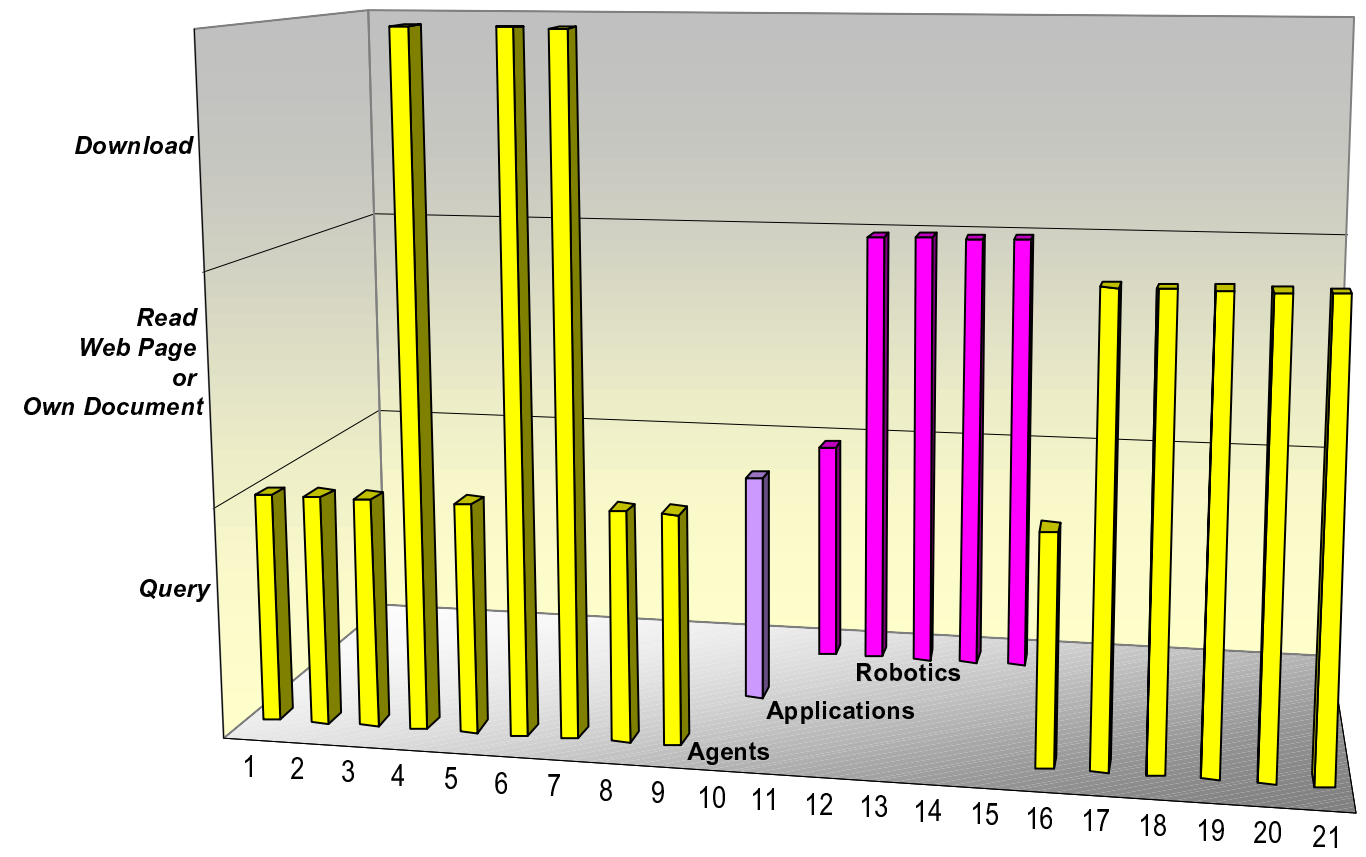

Figura A.2: Agente do usuário User1: visão tridimensional da seqüência tratada na figura A.1. 

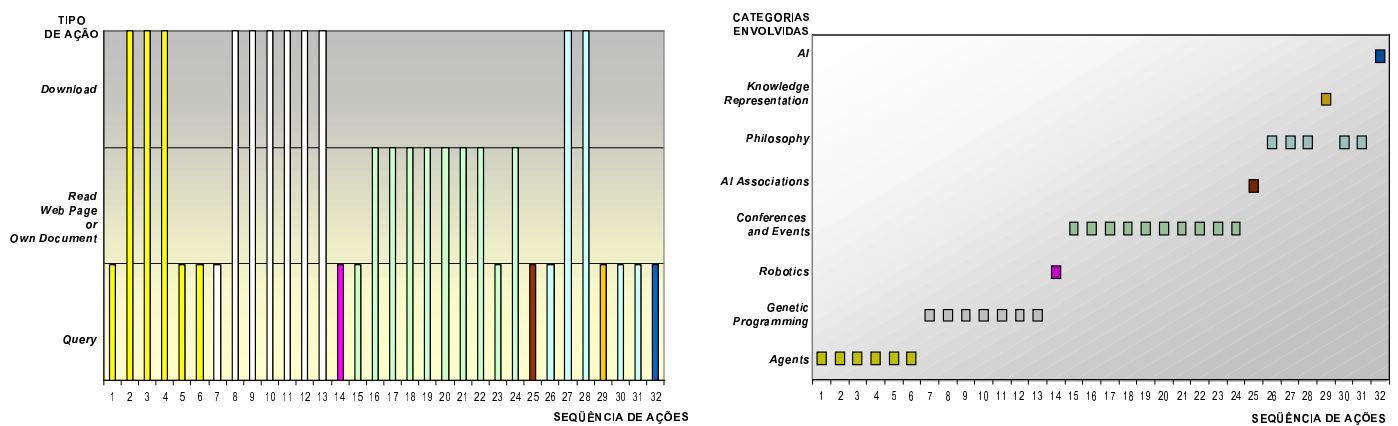

Figura A.3: Segunda amostra de uma seqüência de ações do usuário User1, por tipo de ação (esq.) e mostrando os conceitos envolvidos (dir.).

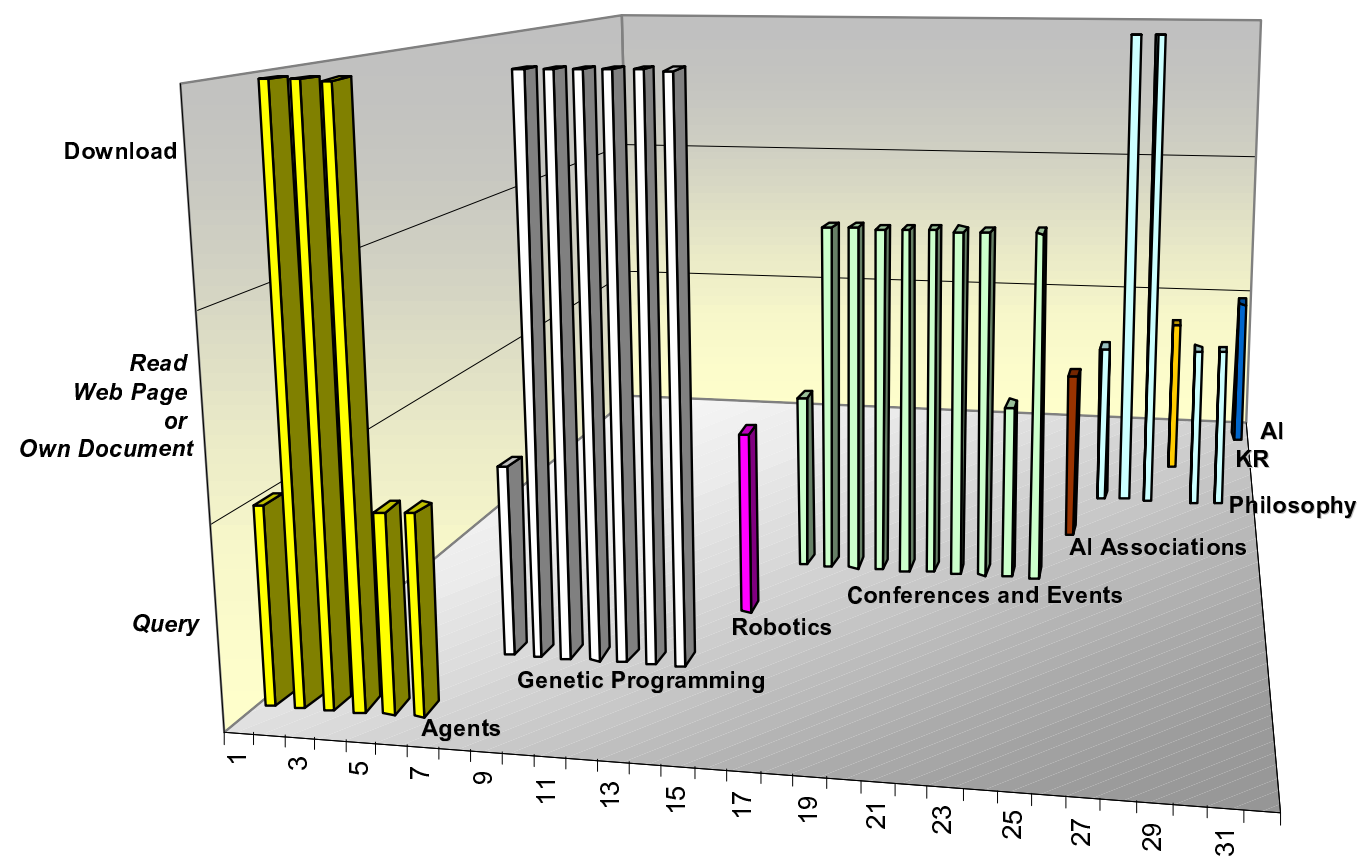

Figura A.4: Agente do usuário User1: visão tridimensional da mesma seqüência da figura A.3. 

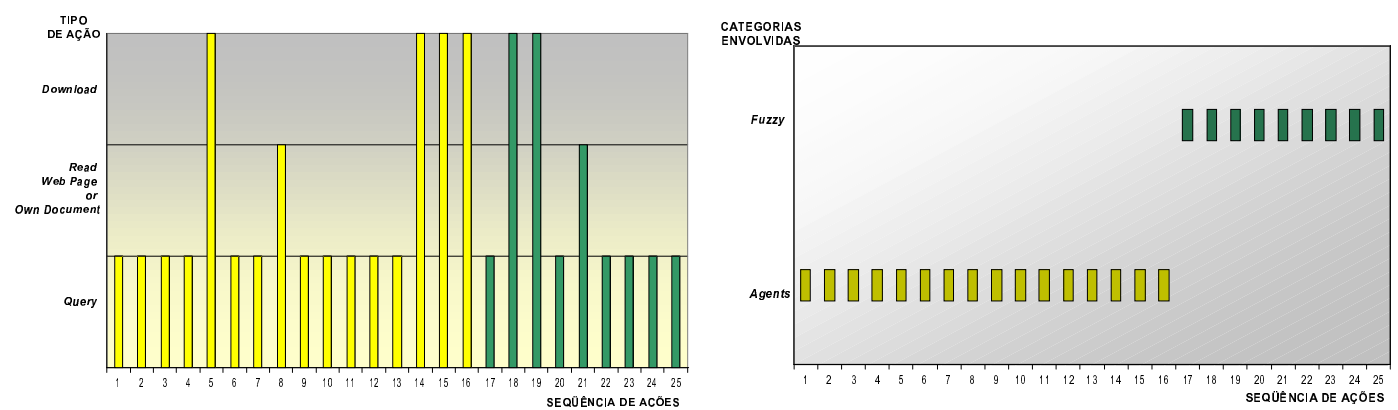

Figura A.5: Amostra de uma seqüência de ações do usuário User民, por tipo de ação (esq.) e considerando os conceitos envolvidos (dir.).

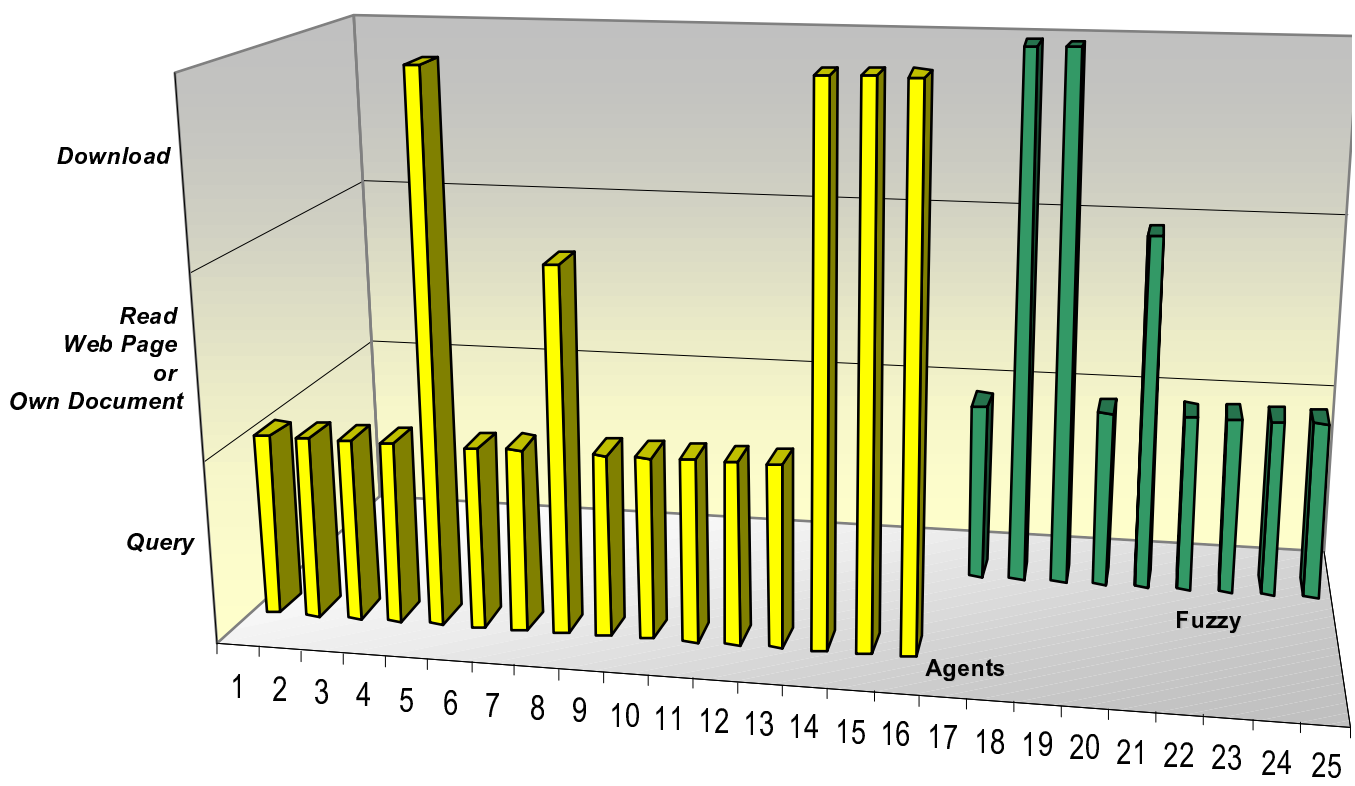

Figura A.6: Agente do usuário User2: visão tridimensional da mesma seqüência referenciada na figura A.5. 

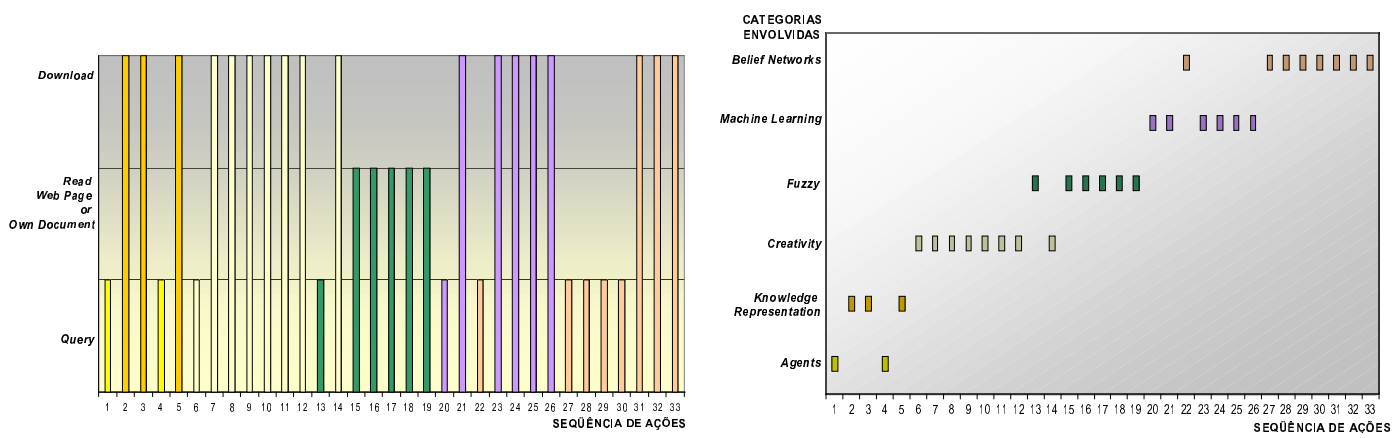

Figura A.7: Segunda amostra de uma seqüência de ações do usuário User2, por tipo de ação (esq.) e considerando os conceitos envolvidos(dir.).

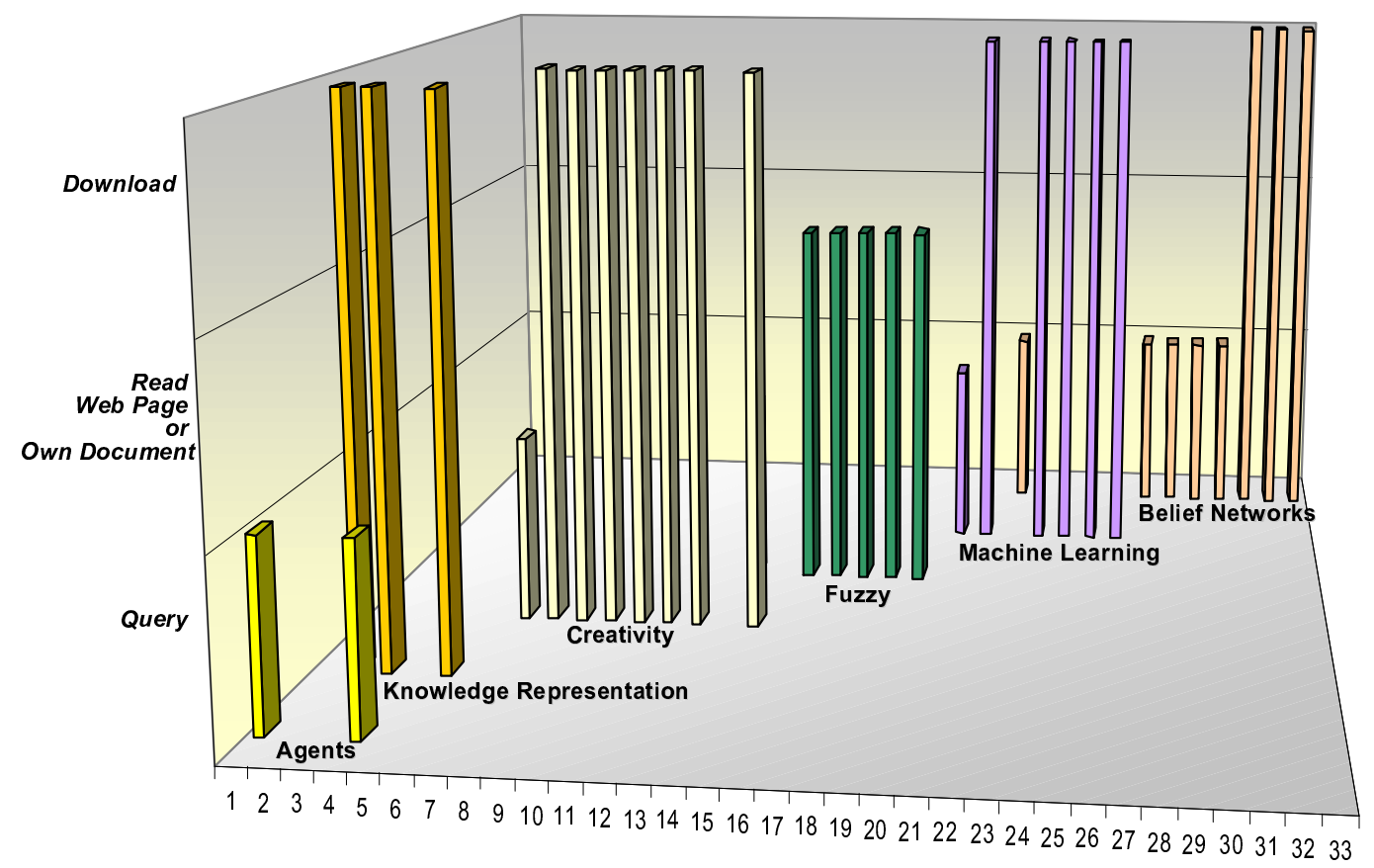

Figura A.8: Vista tridimensional da seqüência de ações do usuário User2, mostrada na figura A.7. 

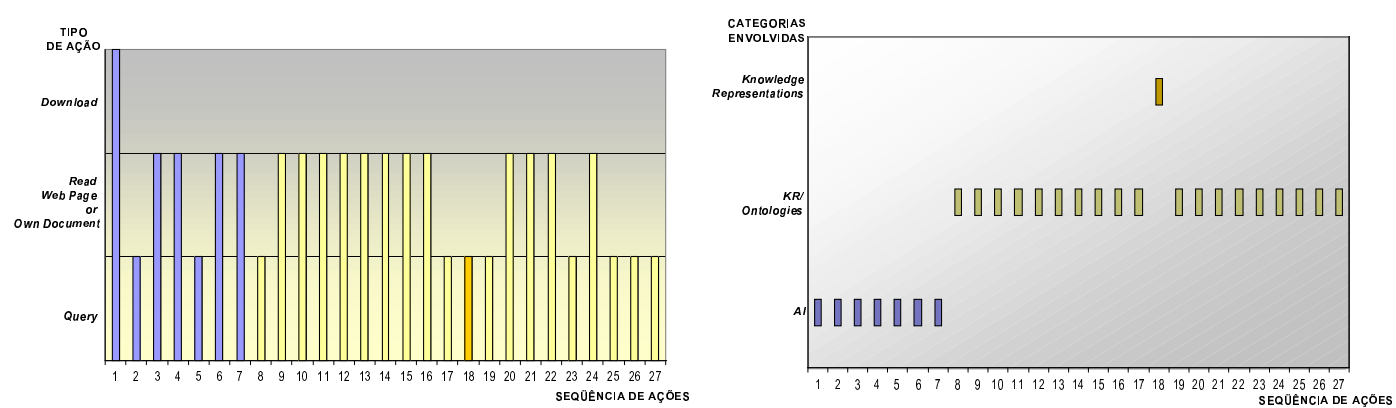

Figura A.9: Amostra de uma seqüência de ações do usuário User3, por tipo de ação (esq.) e segundo os conceitos envolvidos (dir.).

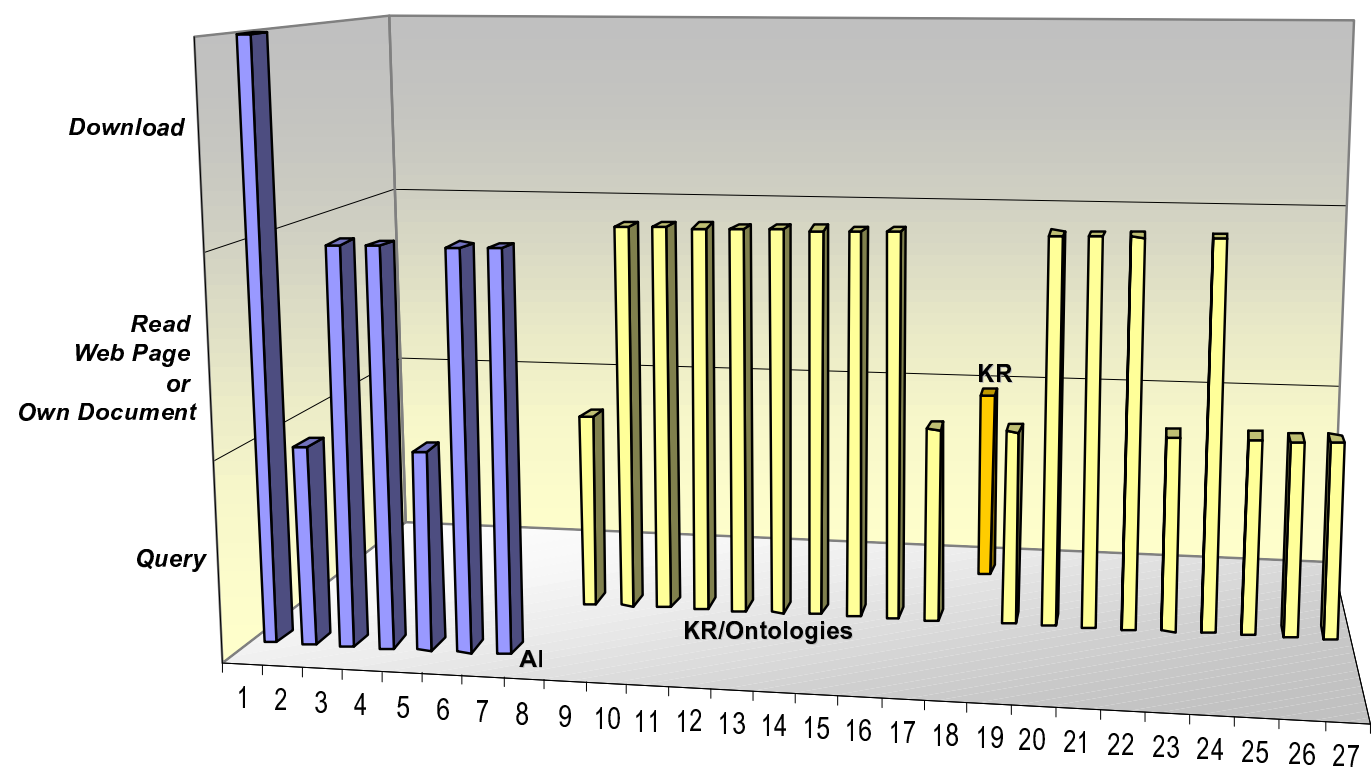

Figura A.10: Visão tridimensional da mesma seqüência referenciada na figura A.9, executada pelo usuário User3. 

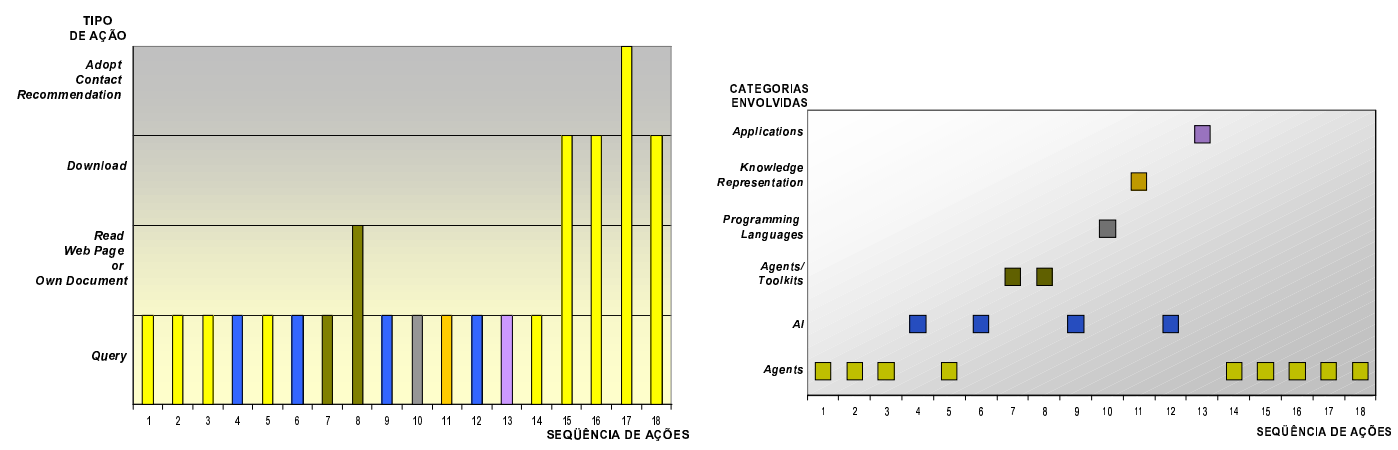

Figura A.11: Segunda amostra de uma seqüência de ações do usuário User3, por tipo de ação (esq.) e considerando os conceitos envolvidos(dir.).

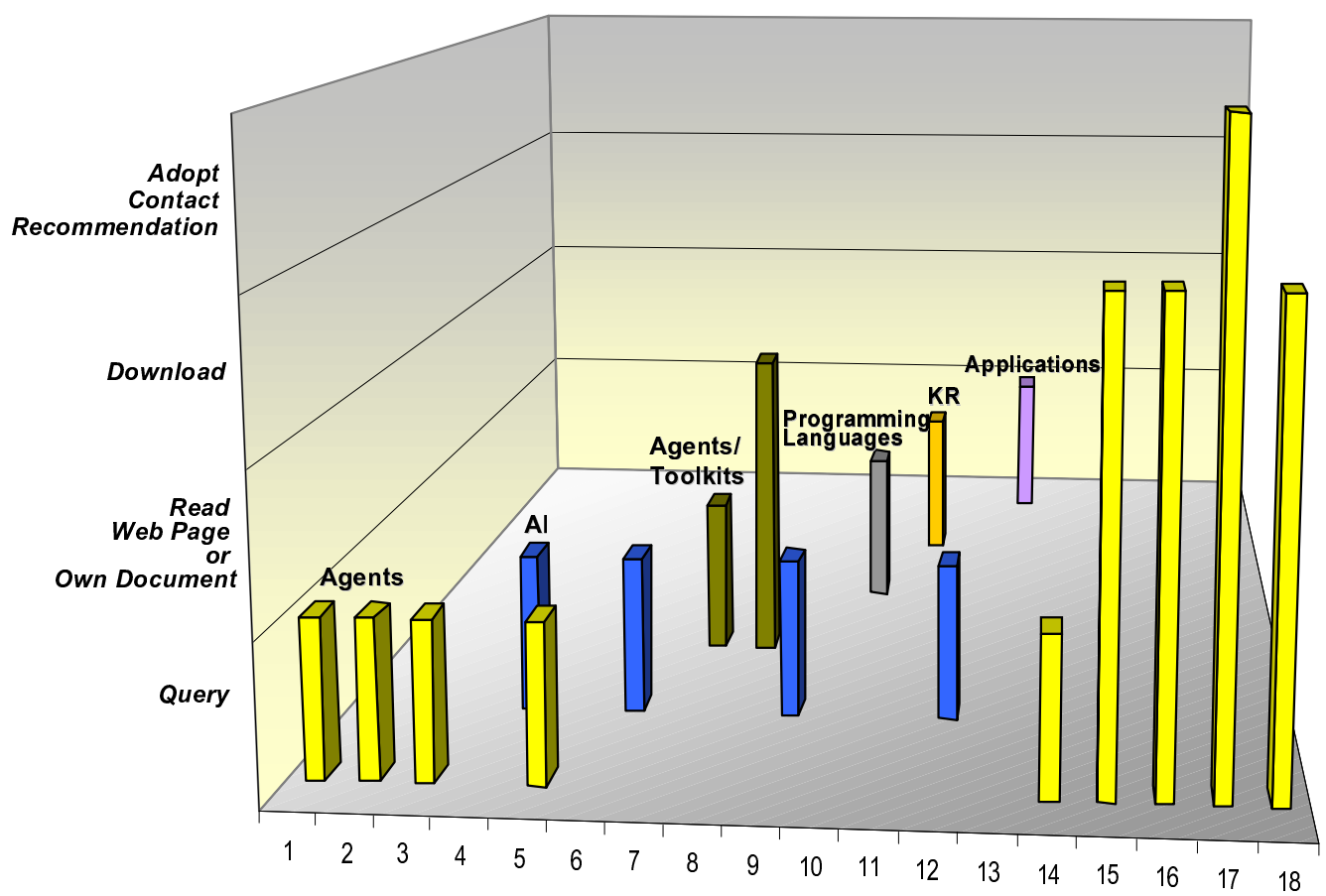

Figura A.12: Vista tridimensional da seqüência de ações do usuário User3, mostrada na figura A.11. 


\section{Anexo B - Sociogramas conceituais}

O presente anexo contém diagramas conceituais computados pelos agentes COMMUNET de usuários que participaram do experimento. Para cada um dos usuários, um subconjunto de categorias foi escolhido para explicitar graficamente a relação do respectivo usuário focal com os seus contatos. São mostrados, lado a lado, duas versões do sociograma de cada categoria. À esquerda é exibido o sociograma apenas mostrando os contatos, já o sociograma à direita mostra os papéis na visão do respectivo usuário. A categoria referenciada por cada sociograma aparece no título da respectiva janela.

O primeiro par de sociogramas de cada usuário mostra o sociograma inicial do mesmo, considerando todas as categorias (com o título "All" na janela). Da mesma maneira, o último par de sociogramas para cada usuário, mostra a situação dos contatos considerando todas as categorias.

As cores escolhidas para cada papel seguem a convenção citada na seção 5.3.4. 

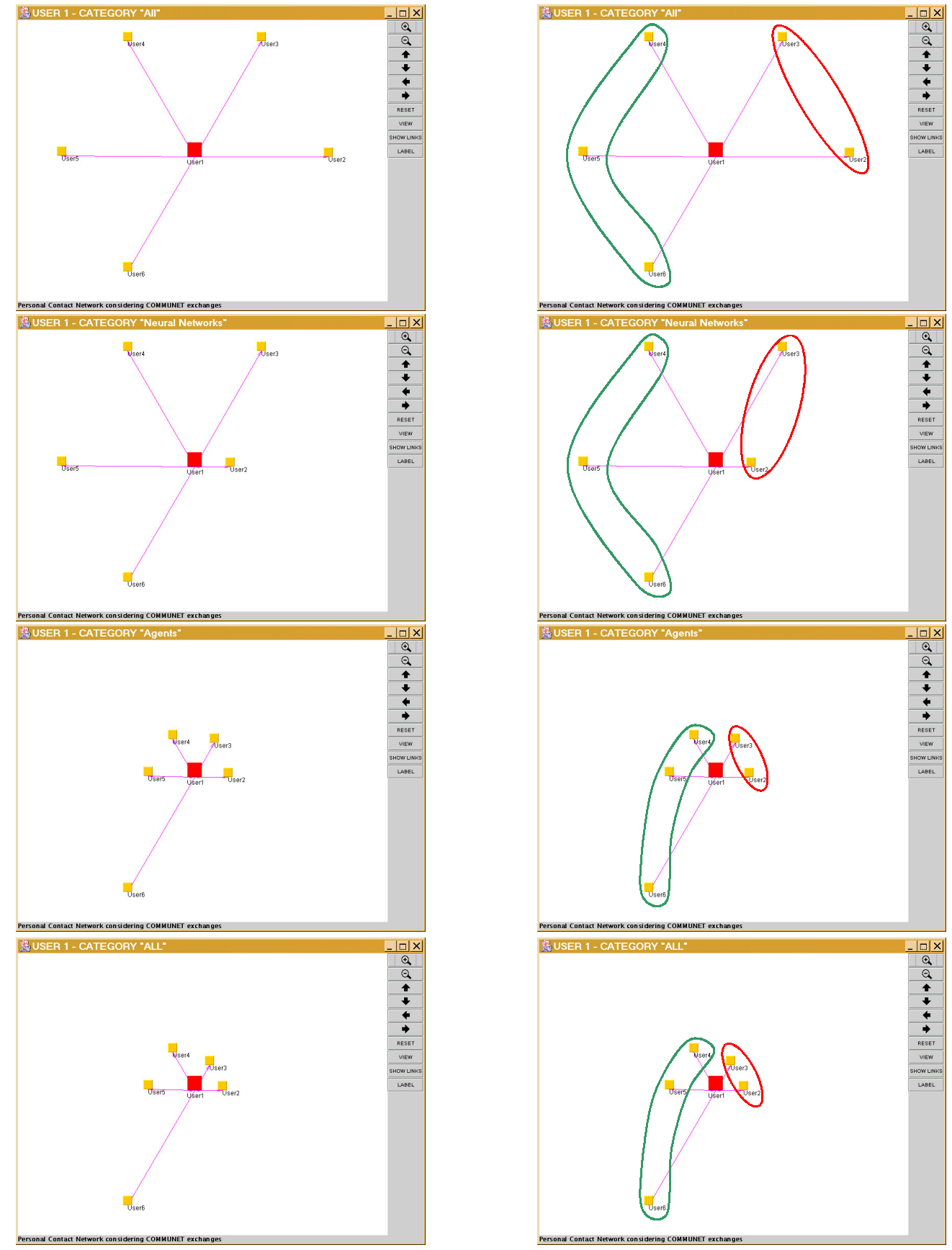

Figura B.1: Sociogramas conceituais simples e incluindo papéis sociais, para o usuário User1. São mostradas as categorias: Neural Networks e Agents. 

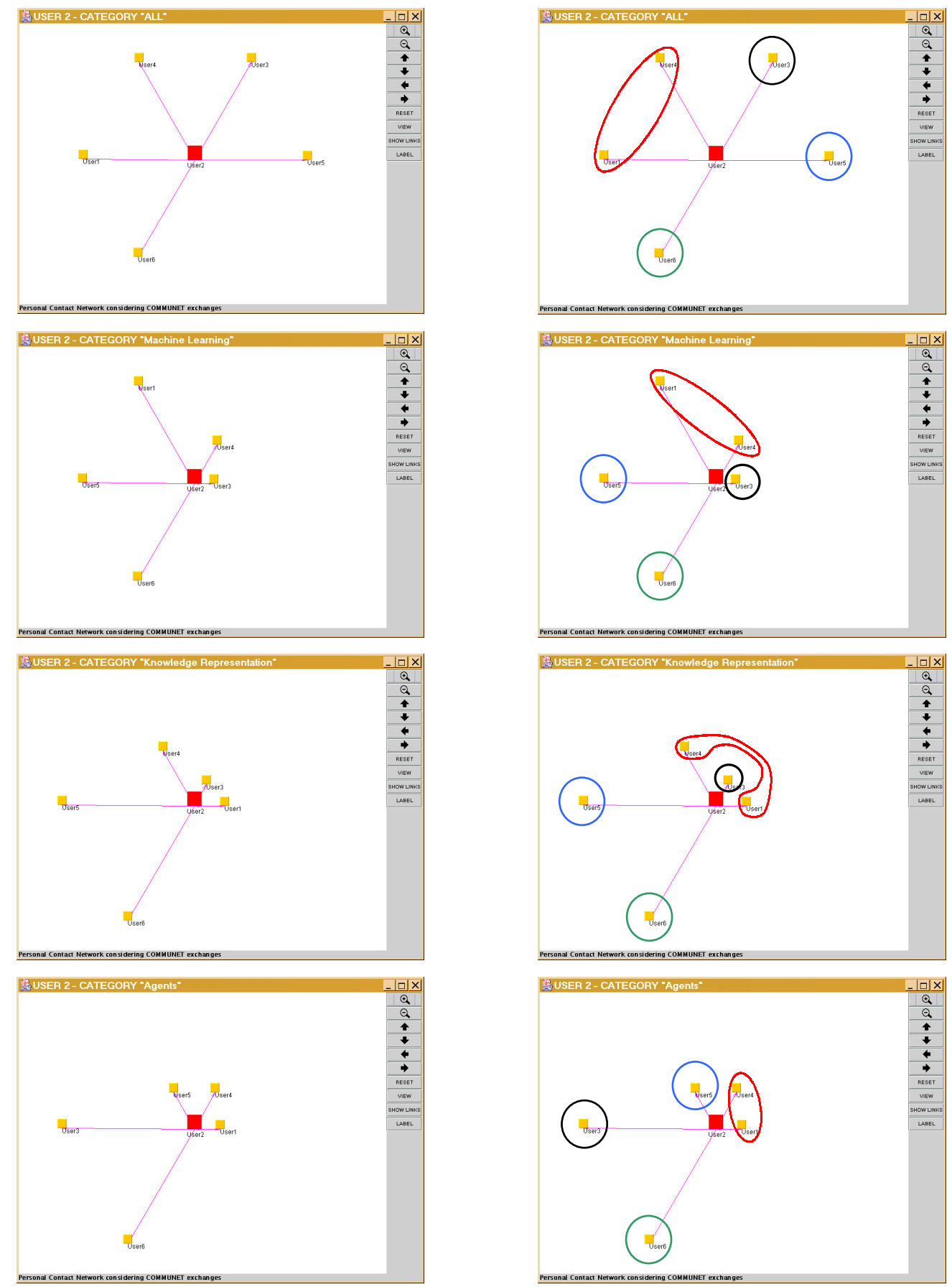

Figura B.2: Sociogramas conceituais do usuário User2. São mostradas as categorias: Machine Learning, Knowledge Representation e Agents. 

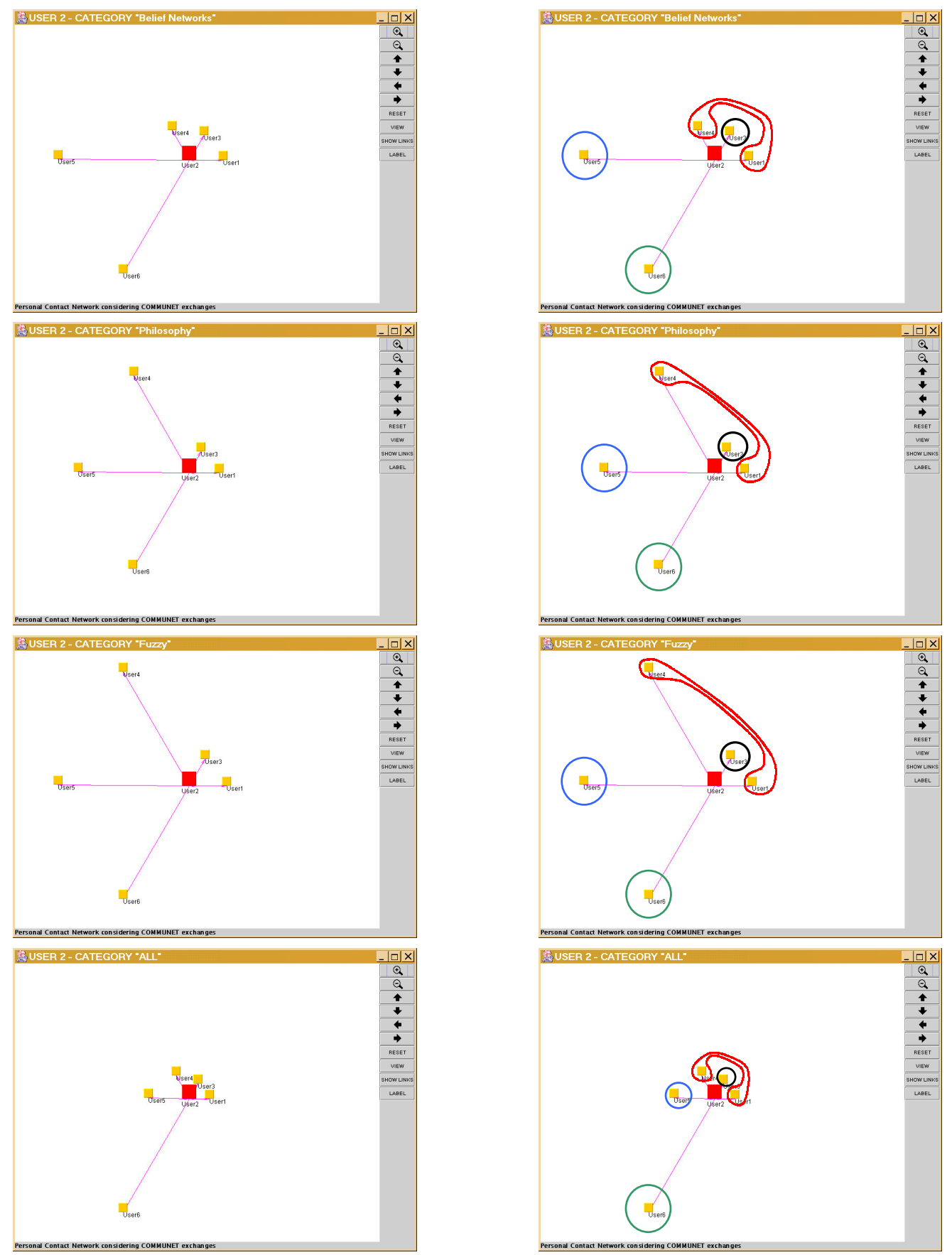

Figura B.3: Sociogramas conceituais do usuário User2. São tratadas isoladamente as categorias: Belief Networks, Philosophy e Fuzzy. 

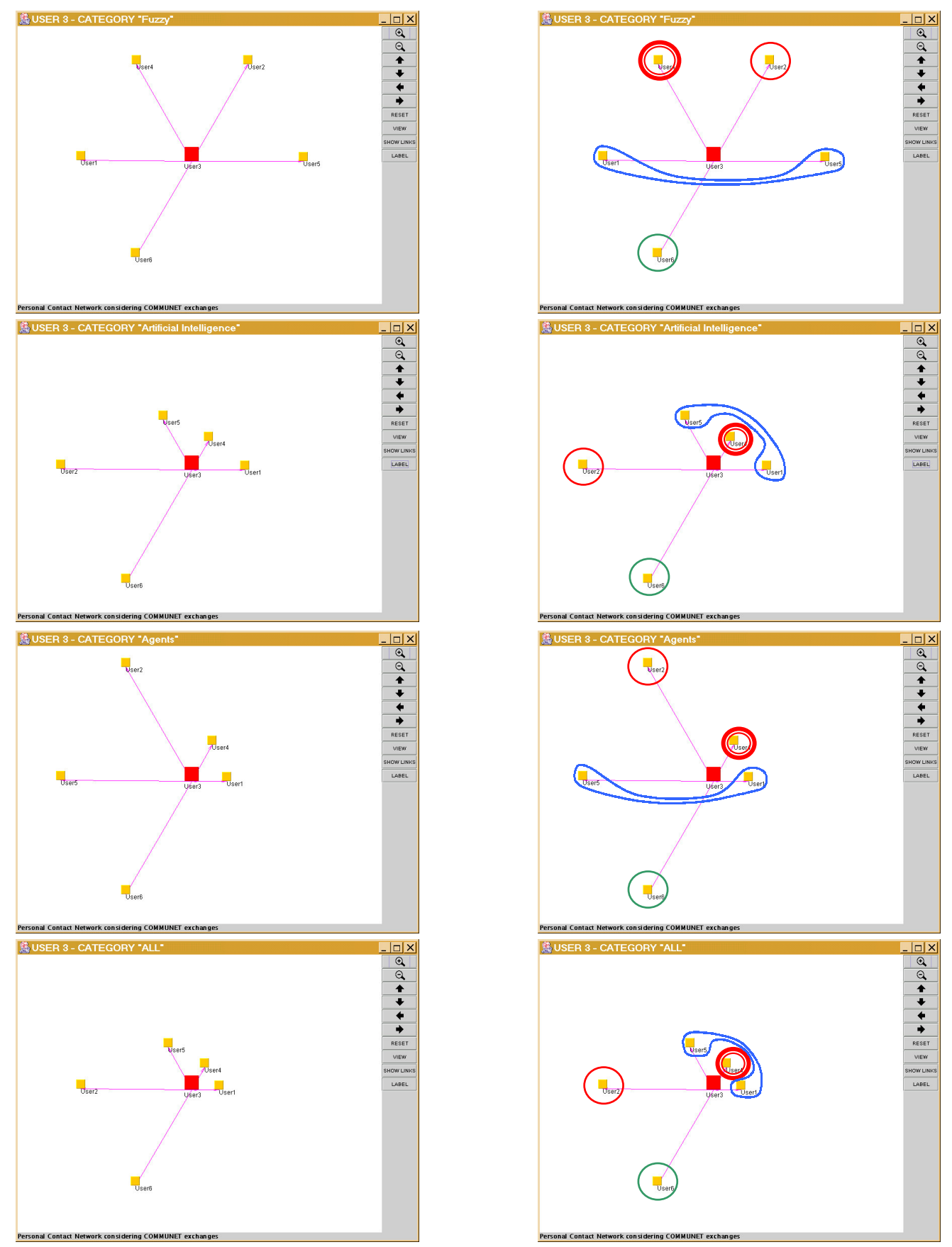

Figura B.4: Sociogramas do usuário User3. Aparecem as categorias: Artificial Intelligence e Agents. 

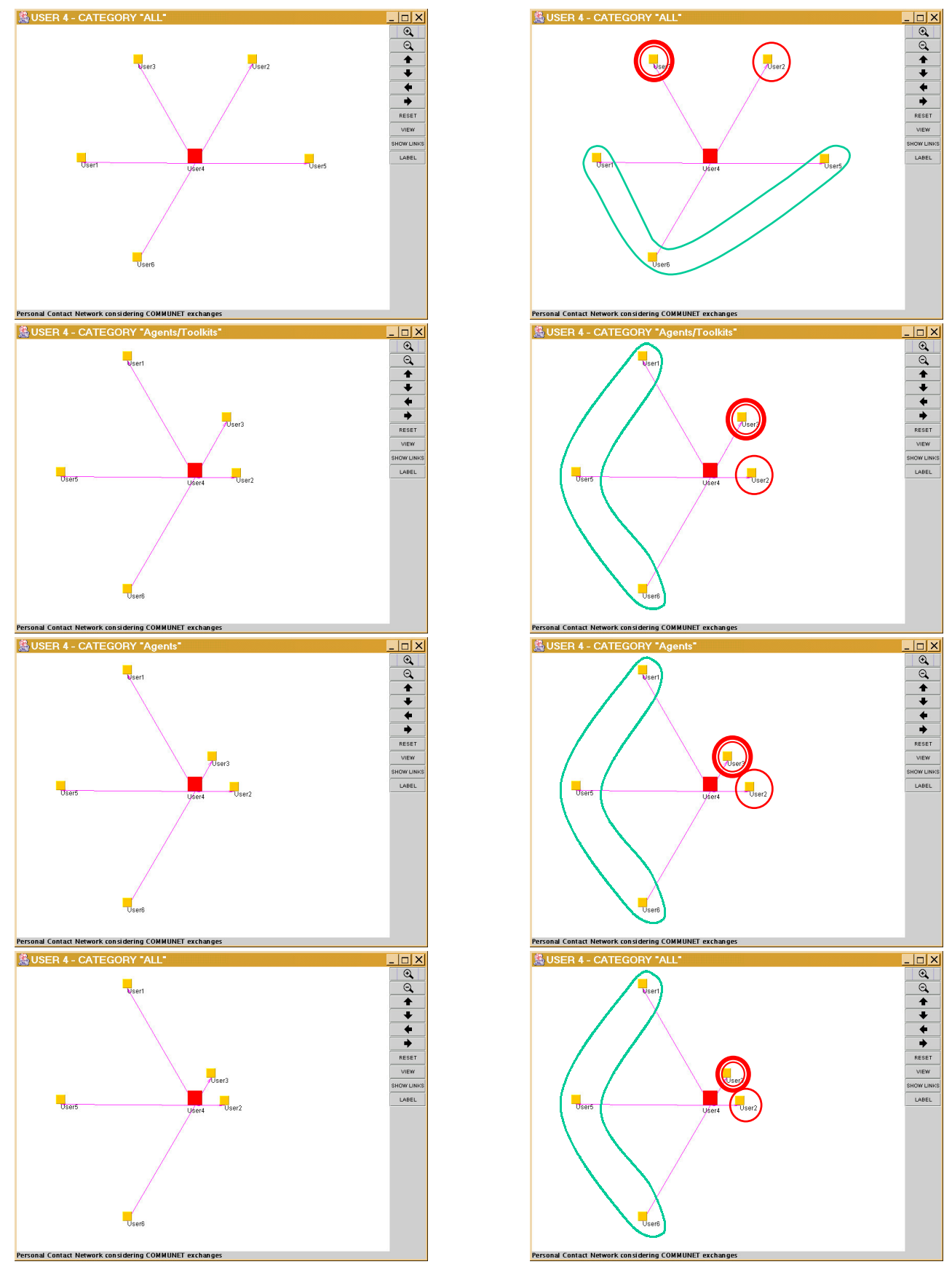

Figura B.5: Sociogramas do usuário User4. São mostradas as categorias: Agents/Toolkits e Agents. 

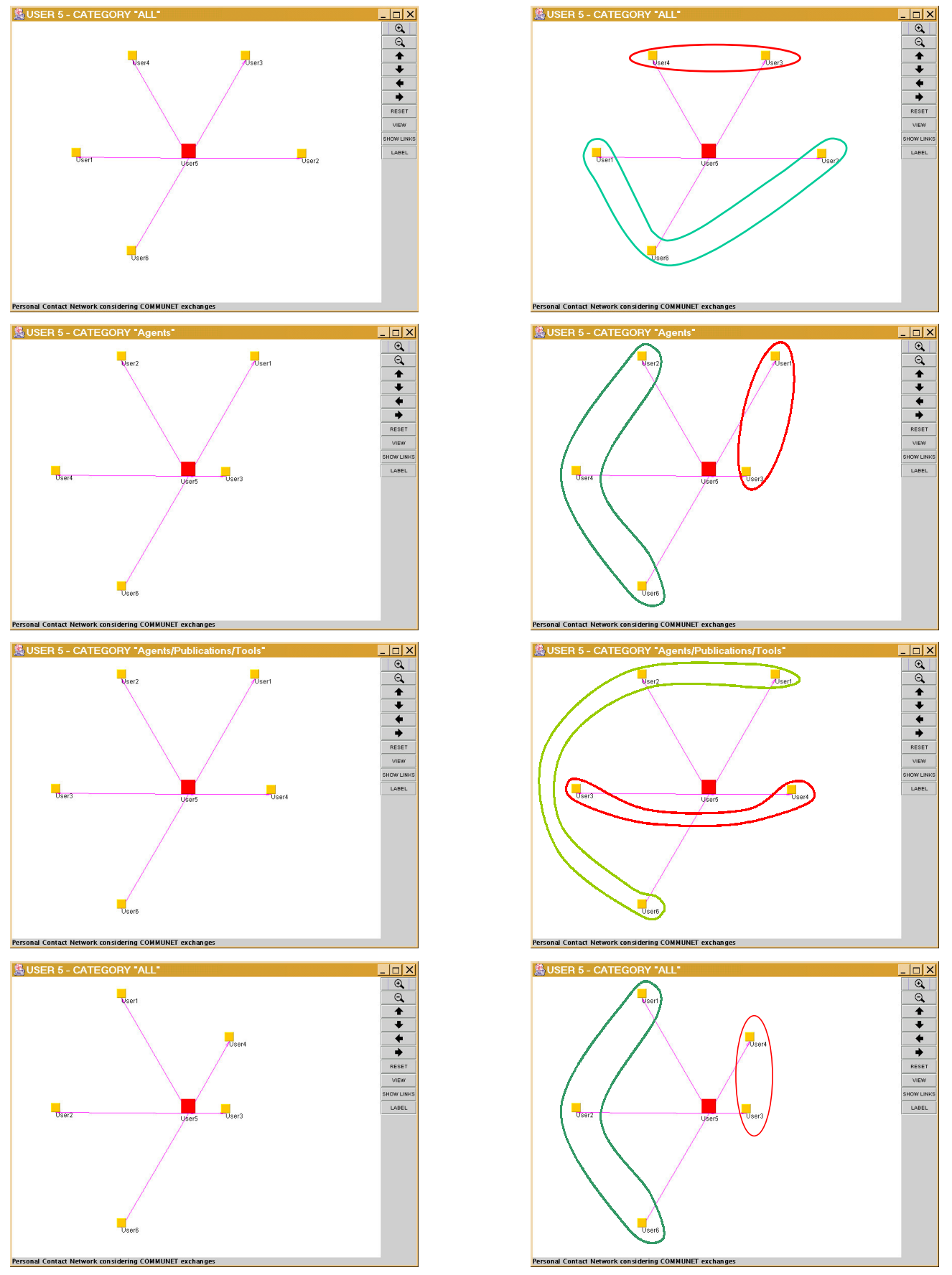

Figura B.6: Sociogramas do usuário User5. Aparecem as categorias: Agents e Agents/Publications/Tools. 


\section{Anexo C - Respostas de um usuário ao questionário}

Dentre os questionários respondidos, foram escolhidas as respostas de um dos participantes, sendo as mesmas transcritas integralmente neste anexo. 


\section{C.1 Usuário X}

Questionário COMMUNET

ニニニニニニニニニニニニニニニニニニニニニ

USABILIDADE

I) Interação gráfica: Você achou os elementos gráficos da interface (telas, listas, árvores etc.) intuitivos para o uso?;

Sim. Achei interessante apresentar com "bolinhas" de cores diferentes, para diferentes funcoes.

II) Comunicação gráfica: Você sentiu-se confortável na interação com o agente (realizando consultas, criando grupos etc.)?; Sim. Acredito que a consulta a agentes deve ser separada da consulta ao "google".

III)Você teve acesso às informações que você precisou sobre o agente?;

Sim.

IV)Você desenvolveu um bom entendimento do porque o agente retornava as informações na forma apresentada (a ordem das recomendações, documentos etc.)?

Sim.

AGENTES

I)Personalização: Você acha que o agente gradualmente foi apresentando melhores recomendações (as recomendações dos contatos mais interessantes apareciam primeiro)?; Sim. 0 que eu considerava mais importante foi mostrado primeiro.

II) Se você foi mudando o contato que você achava mais 
adequado, o agente acompanhou a mudança?;

Nao realizei esta mudanca.

III) Seu agente chegou a surpreendê-10, trazendo para algum tópico informações que você não esperava, mas que você achou interessantes?;

Sim, a apresentacao de paginas html interessantes, que ainda nao havia consultado sobre o tema.

IV)Confiança: Você confiaria em agentes deste tipo para preencher a maioria (parte) das suas necessidades de informação? Por que?; Sim. Acredito que a configuracao inicial do sistema, quando da indexacao, eh muito boa. Com a utilizacao, as informacoes vao se adaptando ao nosso perfil.

V) Você sente-se confortável com a perspectiva de usar agentes deste tipo que coletem informação para você?;

Sim.

VI) Se você conhece o Gnutella (através de aplicativos como o LimeWire, Mac-tella ou análogos como o Kazaa, Morpheus etc.), como você compararia o seu uso com relação a um agente como o testado neste experimento?;

Nao conheco o Gnutella.

VII) Quais seriam os itens relacionados à privacidade que você consideraria importantes/preocupantes dado que o agente tem acesso a informações confidenciais (como e-mail, documentos etc.)?

Acredito que os itens mais preocupantes seriam arquivos. As vezes, existem informacoes que ainda nao poderiam estar disponiveis a todos. Mas para isso, existe a divisao dos tipos de arquivos (privados, etc). Acredito que o sistema eh seguro e confiavel. 


\section{HABILIDADE SOCIAL}

I) Você acha que o mapeamento de seu entorno social, feito pelo agente através de papéis, é uma aproximação satisfatória (ou razoável) da visão pessoal que você possui dos seus contatos ? Acho bem razoavel, com varias subdivisoes, como existe na vida real.

II) Você acha que o uso que o agente faz da representação do seu entorno social é adequada (útil, confortável)?

Sim.

III) Quais seriam os outros grupos e papéis sociais que você gostaria de ver representados?

Acho que incluiria para o grupo familia, o subitem parentes e/ou pais, por exemplo, que na maioria das vezes, tem maior e/ou total liberdade de consulta as nossas informacoes.

IV) Qual a sua sugestão para melhorar as habilidades sociais do agente?

Acredito que a percepcao de um agente sobre as acoes de outro, ou seja, quando um agente esta realizando pesquisa, download, etc, em outro agente, ambos deveriam "perceber" com quem estao interagindo e criar um "perfil" para estas interacoes. Por exemplo, saber quais os assuntos mais comuns nas consultas, facilitando a interacao.

\section{SUGESTÕES PARA VERSÕES POSTERIORES}

I) Quais seriam as habilidades que você gostaria de ver implementadas numa versão melhorada do agente COMMUNET?

II)Quais as habilidades que você achou inconvenientes(lentidão, desconfortável, frustrante, etc.) na versão atual?

Acho que o sistema esta um pouco lento, mas isso eh devido a 
implementacao em Java. Acho que por ser um prototipo, esta excelente!

III)Que habilidades do agente você achou insuficientes (você tentou e não consiguiu)?

OUTROS COMENTÁRIOS :- 


\section{Referências Bibliográficas}

AAS, K.; EIKVIL, L. Technical Report 941, Text Categorisation: A Survey. Norwegian Computing Center, Norway, 1999.

BACZKO, B. Imaginação Social. Enciclopédia Einaud (Anthropos-Homem). Lisboa: Imprensa Nacional/Casa da Moeda, v. 5, p. 309-312, 1985.

BAEZA-YATES, R.; RIBEIRO-NETO, B. Modern information retrieval. USA: ACM Press, 1999.

BALABANOVÍC, M.; SHOHAM, Y. Fab: Content-based collaborative recommendation. Communications of the ACM, v. 40, n. 3, p. 66-72, 1997.

BASU, C.; HIRSH, H.; COHEN, W. W. Recommendation as classification: Using social and content-based information in recommendation. In: AAAI. 1998. USA, 1998. p. 714-720.

BERNERS-LEE, T. Information Management: A Proposal. March 1989.

Disponível em: <http://www.w3.org/History/1989/proposal.html>. Acesso em: Dezembro 2002.

BERNERS-LEE, T. The semantic web, academic discussion. In: Japan Prize. Japan Prize. [s.n.], 2002. Disponível em: <http://www.w3.org/2002/Talks/04sweb>. Acesso em: Outubro 2003.

BILLSUS, D.; PAZZANI, M. J. Learning collaborative information filters. In: 15th International Conf. on Machine Learning, San Francisco, 1998. USA: Morgan Kaufmann, 1998. p. 46-54.

BOBBIO, N.; MATteuCCI, N.; PASQUINO, G. Dicionário de Política. 11a.. ed. Brasília: UNB, 1998.

BOND, A.; GASSER, L. Readings in Distributed Artificial Intelligence. San Mateo, CA, USA: Morgan Kaufmann, 1988.

BOURDIEU, P. A economia das trocas lingüisticas. São Paulo, SP, Brasil: EDUSP, 1998.

BOYD, S. Are you ready for social software? What's New Magazine, May 2003. Disponível em: < http://www.darwinmag.com/read/050103/social.html >. Acesso em: Julho 2003. 
BRAY, T. Divine metadata for the web. XML.com, January 2001. Disponível em: <http://www.xml.com/lpt/a/2001/01/24/rdf.html>. Acesso em: Junho 2003.

BREIMAN, L. Bagging predictors. Machine Learning, v. 24, p. 123-140, 1996.

BREIMAN, L. et al. Classification and Regression Trees. Belmont, CA, USA: Wadsworth, 1984.

BRICKLEY, D.; MILLER, L.; LISTMEMBERS rdfweb-dev. FO-

$A F$ : the 'friend of a friend' vocabulary. June 2003. Disponível em: $<$ http://xmlns.com/foaf/0.1/>. Acesso em: Julho 2003.

BUCKLEY, C. et al. Automatic query expansion using smart: Trec 3. In: TREC. 3rd. Text Retrieval Conference. USA, 1994.

BUSH, V. As we may think. Atlantic Monthly, 1945.

CAMPBELL, K.; LEE, B. Name Generators in Surveys of Personal Networks. Social Networks, v. 13, p. 203-222, 1991.

CARLEY, K. M. Smart Agents and the Organizations of the Future. In: LIEVROUW, L.; LIVINGSTONE, S. (Ed.). The Handbook of New Media. Thousand Oaks, CA, USA: Sage, 2002. cap. 12, p. 206-220.

CARTER, J.; BITTING, E.; GHORBANI, A. Technical Report TR02-153, Reputation formalization for an information sharing multiagent system. 2002. Disponível em: <www.cs.unb.ca/tech-reports>. Acesso em: Julho 2002.

CASTELFRANCHI, C. Modeling social action for AI agents. Artificial Intelligence, n. 103, p. 157-182, 1998.

CASTELFRANCHI, C. The theory of social functions: challenges for computational social science and multi-agent learning. Journal of Cognitive Systems Research, 2001.

CASTORIADIS, C. A instituição e o imaginário: primeira abordagem. In: $A$ instituição imaginária da sociedade. RJ, Brasil: Editora Paz e Terra, 1991.

CHAFFEE, J.; GAUCH, S. Personal ontologies for web navigation. In: ACM. CIKM. McLean, VA, USA, 2000. p. 227-234.

CHAUDHRI, V. et al. OKBC: A programmatic foundation for knowledge base interoperability. In: AAAI. Proc. of the AAAI-98 Conference. USA: AAAI Press/MIT Press, 1998. p. 600-607.

CLARK, K. G. The social meaning of rdf. XML.com, Março 2003. Disponível em: <http://www.xml.com/pub/a/2003/03/05/social.html>. Acesso em: Junho 2003 . 
CLARKE, I. et al. Freenet: A distributed anonymous information storage and retrieval system. In: ICSI Workshop on Design Issues in Anonimity and Unobservability. USA: Springer, 2001.

COOPER, W. S. The formalism of probability theory in ir: A foundation or and encumbrance? In: ACM-SIGIR. Proc. of the 17th Annual International SIGIR Conference. Ireland: Springer-Verlag, 1994.

COSTA, N. C. A. da. Sistemas Formais Inconsistentes. Tese de Cátedra, Faculdade de Filosofia, Ciências e Letras — Universidade do Paraná, Curitiba, Paraná, 1964.

COSTELLO, R. L. Creating OWL-Enhanced Applications. The MITRE Corporation, 2003. Disponível em: <http://www.xfront.com>. Acesso em: Dezembro de 2003.

COSTELLO, R. L.; JACOBS, D. B. Owl web ontology language. In: EUROLAN. Bucharest, Romania, 2003. Disponível em: < http://www.racai.ro/EUROLAN2003/html/lectures.html>. Acesso em: Dezembro de 2003.

CROW, L. Software Agents for Internet-Based Knowledge Engineering. Ph. D. Thesis - University of Nothingham, UK, 2000.

DEERWESTER, S. et al. Indexing by latent semantic indexing. Journal of the American Society for Information Science, v. 41, n. 6, p. 391-407, 1990.

DELGADO, J. Research Report Dept. LSI-01-37-R, Emergence of Social Conventions in Complex Networks. Universitat Politècnica de Catalunya, Spain, 2001.

DENNETT, D. C. The Intentional Stance. Cambridge, MA: MIT Press, 1987.

DUDA, R. O.; HART, P. E. Pattern Classification and Scene analysis. New York, USA: John Wiley and Sons, 1973.

DUMAIS, S. et al. Inductive Learning Algorithms and Representations for Text Categorization. Microsoft Research, USA, 1998.

DUMAIS, S. T. Improving the retrieval information from external sources. Behaviour Research Methods, Instruments and Computers, v. 23, n. 2, p. 229-236, 1991.

FALASCONI, S.; LANZOLA, G.; STEFANELLI, M. Using Ontologies in MultiAgent Systems. In: KAW. 10th Knowledge Acquisition for Knowledge-Based Systems Workshop KAW96. Canada, 1996.

FALOUTSOS, C.; OARD, D. W. Technical Report CS-TR-3514, A Survey of Information Retrieval and Filtering Methods. 1995. Disponível em: $<$ http://citeseer.nj.nec.com/faloutsos96survey.html>. Acesso em: Junho de 2002 . 
FININ, T.; NICHOLAS, C.; MAYFIELD, J. Agent-based information retrieval. In: IEEE. IEEE ADL'98, Advances in Digital Libraries Conference '98. USA, 1998.

FLAKE, G. W. et al. Self-organization and identification of web communities. IEEE Computer, v. 35, n. 3, p. 66-71, 2002.

FONER, L. N. Political artifacts and Personal Privacy: The Yenta Multi-Agent Distributed Matchmaking System. Ph. D. Thesis — MIT, 1999.

FRAKES, W. B.; BAEZA-YATES, R. Introduction to information storage and retrieval systems. In: Information Retrieval - Data Structures and Algorithms. USA: Prentice-Hall, 1992.

FREITAS, F. L.; BITTENCOURT, G.; CALMET, J. Master-web: An ontology-based internet data mining multi-agent system. In: SSGRR. Proc. of the Second International Conference on Advances in Infrastructure for E-Business, E-Science and E-Education. L'Aquilla, Itália, 2001.

FREITAS, F. L. G. de. Ontologias e a web semântica. In: SBC. III MCIA XXIII Congresso da SBC. III MCIA - Anais do XXIII Congresso da SBC. Campinas, SP, Brasil, 2003.

FREUND, Y.; SHAPIRE, R. E. Experiments with a new boosting algorithm. In: SAITTA, L. (Ed.). 13th Intl. Conf. on Machine Learning. Bari, Italy: Morgan Kaufmann, 1996.

FRIDMAN, N.; MUSEN, M. A. An algorithm for merging and aligning ontologies: Automation and tool support. In: Proc. of the Workshop on Ontology Management at the AAAI-99 Conf. USA: AAAI Press, 1999.

FRIDMAN-NOY, N.; HAFFNER, C. The state of the art in ontology design: A survey and comparative review. AI Magazine, p. 53-74, Fall 1997.

GANDON, F. Engineering an Ontology for a Multi-Agent Corporate Memory System. In: Université de Technologie de Compiègne, France. Proc. of the 8th Conf. on the Management of Industrial and Corporate Knowledge, ISMICK 2001. [S.1.], 2001. p. 209-228.

GARTON, L.; HAYTHORNTHWAITE, C.; WELLMAN, B. Studying Online Social Networks. Journal of Computer Mediated Communication, v. 3, n. 1, June 1997.

GIBSON, D.; KLEINBERG, J. M.; RAGHAVAN, P. Inferring web communities from link topology. In: ACM. Conference on Hypertext and Hypermedia, 1998. Proceedings of the ninth ACM conference on Hypertext and hypermedia. Pittsburgh, Pennsylvania, United States: ACM Press, 1998. p. 225-234.

GILES, C. L.; BOLLACKER, K.; LAWRENCE, L. Citeseer: An automatic citation indexing system. In: WITTEN, I.; AKSCYN, R.; III, F. M. S. (Ed.). 
Digital Libraries 98 - The Third ACM Conference on Digital Libraries. [S.l.: s.n.], 1998. p. 89-98.

GIMÉNEZ-LUGO, G. A. et al. Enriching information agents' knowledge by ontology comparison: a case study. In: GARIJO, F.; RIQUELME, J.; TORO, M. (Ed.). IBERAMIA 2002, Seville, Spain. LNAI 2527, Proc. of the 8th IBERAMIA Conference. Germany: Springer Verlag, 2002. p. 546-555.

GÓMEZ-PÉREZ, A. Knowledge sharing and reuse. In: LIEBOWITZ, J. (Ed.). The Handbook of Applied Expert Systems. Florida, USA: CRC Press, 1998.

GRANOVETTER, M. S. The strength of weak ties. American Journal of Sociology, v. 78, p. 1360-1380, 1973.

GRUBER, T. Towards principles for the design of ontologies used for knowledge sharing. International Journal of Human and Computer Studies, v. 43, n. 5/6, p. 907-928, 1995.

GUARINO, N. Formal ontological distinctions for information organization. In: MARIA TEREZA PAZIENZA(ED). SPRINGER-VERLAG. Information Extraction: A Multidisciplinary Approach to an Emerging Information Technology. LNAI 1299. [S.1.], 1997. p. 139-170.

GUARINO, N.; GIARETTA, P. Ontologies and knowledge bases- towards a terminological clarification. In: MARS, N. (Ed.). Towards Very Large Knowledge Bases - Knowledge Building and Knowledge Sharing. Amsterdam, NL: IOS PRESS, 1995. p. 25-32.

HALBWACHS, M. A Memória Coletiva. São Paulo, SP, Brasil: Vértice, 1990.

HAYES-ROTH, B.; BROWNSTON, L.; GENT, R. van. Technical Report KSL-94-69, Multi-agent Collaboration in Directed Improvisation. Stanford University, USA: Knowledge Systems Laboratory, Stanford University, 1995.

HAYTHORNTHWAITE, C. Online Personal Networks: Size, Composition and Media Use among Distance Learners (draft version). New Media and Society, v. 2, n. 3, p. 195-226, 2000.

HÜBNER, J. F. Um Modelo de Reorganização de Sistemas Multiagentes. Tese de Doutoramento - Universidade de São Paulo, Escola Politécnica, São Paulo, 2003.

HÜBNER, J. F.; SICHMAN, J. S. SACI: uma ferramenta para a implementação e monitoração da comunicação entre agentes. In: MONARD, M. C.; SICHMAN, J. S. (Ed.). Proc. of the IBERAMIA-SBIA 2000 Open Discussion Track. Brasil: ICMC-USP, 2000. p. 47-56.

HÜBNER, J. F.; SICHMAN, J. S.; BOISSIER, O. A Model for the Structural, Functional and Normative Specification of a MAS Organization. In: SBIA 2002. Proceedings of the 16th Brazilian Symposium on Artificial Intelligence (SBIA'02). Heidelberg: Springer Verlag, 2002. p. 118-128. 
HEARST, M. A. Text Data Mining: Issues, Techniques and the Relation to Information Access. 1997. Disponível em: $<\mathrm{http}: / /$ www.sims.berkeley.edu/ ${ }^{\sim}$ hearst/talks/dm-talk/textfile.html $>$. Acesso em: Janeiro de 2001.

HUSSERL, E. A Idéia da Fenomenologia. Lisboa: Edições 70, 1986.

INTRONA, L.; NISSENBAUM, H. Defining the web: The politics of search engines. IEEE Computer, January 2000.

JENNINGS, N.; WOOLDRIGDE, M. (Ed.). Applications of Intelligent Agents. Germany: Springer Verlag, 1998.

JOACHIMS, T. Technical Report, Text Categorization with Support Vector Machines: Learning with many relevant features. 1997.

KANFER, A.; SWEET, J.; SCHLOSSER, A. Humanizing the Net: Social Navigation with a Know-who Email Agent. In: Proc. of the 3rd Conference on Human Factors and the Web. Denver, CO, USA: [s.n.], 1997.

KAUTZ, H.; SELMAN, B. Creating Models of Real-World Communities with ReferralWeb. In: AAAI. Working notes of the AAAI-98 Workshop on Recommender Systems. Madison, WI, USA, 1998.

KAUTZ, H.; SELMAN, B.; MILEWSKI, A. Agent Amplified Communication. In: AAAI. Proceedings of AAAI-96. MIT Press. USA, 1996.

KAUTZ, H.; SELMAN, B.; SHAH, M. Referral Web: Combining social networks and collaborative filtering. Communications of the $A C M$, v. 40, n. 3, p. 63-65, 1997.

KENT, A. et al. Machine Literature Learning VIII. Operational criteria for designing information retrieval systems. American Documentation, 1955.

KLUSCH, M. Intelligent information agents. In: THIRD EUROPEAN AGENT SYSTEMS SUMMER SCHOOL, ECCAI, AGENT LINK. Third European Agent Systems Summer School. Advanced Course on Artificial Intelligence ACAI-01. Prague, Czech Republic, 2001.

KOBAYASHI, M.; TAKEDA, K. Information retrieval on the web. ACM Computing Surveys, v. 32, n. 2, p. 144-173, 2000.

KOIVUNEN, M.-R. W3c semantic web activity. In: W3C. Semantic Web Kick-off. Semantic Web Kick-off Meeting. Finland, 2001. Disponível em: $<$ http://www.w3.org/Talks/2001/1102-semweb-fin>. Acesso em: Fevereiro 2003.

KONSTAN, J. et al. Grouplense: Applying filtering to usenet news. Comm. of the $A C M$, v. 40, n. 3, p. 77-87, 1997.

KRULWICH, B. Lifestyle finder. AI magazine, v. 18, n. 2, p. 37-46, 1997. 
LABOVITZ, C.; AHUJA, A.; BAILEY, M. Shining light on dark address space. Arbor Networks, Technical Report, n. December, 2001.

LACHER, M. S.; GROH, G. Facilitating the exchange of explicit knowledge through ontology mappings. In: AAAI Press. Proc. of the 14th FLAIRS Conference. Key West, Florida, USA, 2001.

LANSING, J. S. "Artificial Societies" and the Social Sciences. Artificial Life, v. 8 , n. $3,2002$.

LASSILA, O.; MCGUINNESS, D. The Role of Frame-Based Representation on the Semantic Web. Linköping Electronic Articles in Computer and Information Science, v. 6, n. 5, 2001. ISSN 1401-9841.

LAVABRE, M. C. For a sociology of collective memory. 2000. Disponível em: $<$ http://www.cnrs.fr/cw/en/pres/compress/memoire/lavabre.htm>. Acesso em: Outubro 2001.

LAWRENCE, S.; GILLES, C. Accessibility of information on the Web. Nature, n. 400, p. 107-109, 1999.

LAWRIE, D.; CROFT, W.; ROSENBERG, A. Finding Topic Words for Hierarchical Summarization (draft version). In: ACM SIGIR. SIGIR'01. New Orleans, Louisiana, USA, 2001.

LEVY, A. Y.; WELD, D. S. Intelligent internet systems. Artificial Intelligence, v. 118, n. 1-2, p. 1-14, 2000.

LEWIS, D. D.; GALE, W. A. A sequential algorithm for training text classifiers. In: ACM SIGIR. 17th Annual International SIGIR Conference on Research and Development in Information Retrieval SIGIR'94. Dublin, Ireland, 1994.

LIEBERMAN, H. Letizia: an agent that assists web browsing. In: IJCAI. Montreal, Canada, 1995.

LINDBERG, D. et al. Use of medline by physicians for clinical problem solving. JAMA, The Journal of the American Medical Association, USA, 1993.

LIVINGSTON, B. Did Google give Yahoo a boost? November 2000. Disponível em: <http://news.cnet.com/news/0-1278-210-3605424-1.html>. Acesso em: Junho de 2001.

LOVELOCK, J. A numerical model for biodiversity. Phil. Trans. R. Soc. of London, B, n. 338, 1992.

LUGO, G. G.; HÜBNER, J. F.; SICHMAN, J. S. Representação e Evolução de Esquemas Sociais em SMA: um enfoque funcional. In: SBC. Encontro Nacional de Inteligência Artificial, Fortaleza, Ceará, Brasil, 2001. Proc. ENIA. Brasil, 2001. p. 1237-1246.

LÉVINAS, E. Entre Nós: ensaios sobre a alteridade. Brasil: Vozes, 1997. 
LYMAN, P.; VARIAN, H. R. How Much Information? School of Information Management, Univ. of California at Berkeley, 2000. Disponível em: <www.sims.berkeley.edu/how-much-info>. Acesso em: Fevereiro de 2002.

MAES, P. Agents that Reduce Work and Information Overload. Communications of the $A C M$, v. 37, n. 7, p. 30-40, 1994.

MAGLIO, P. P. et al. SUITOR: An attentive information system. In: ACM. Proceedings of the 5th International Conference on Intelligent User Interfaces. New Orleans, Louisiana, USA, 2000. p. 714-720.

MAMDANI, E. H. On the classification of uncertainty in relation to the application needs. In: MOTRO, A.; SMETS, P. (Ed.). Uncertainty Management in Information Systems. USA: Kluwer Academic Publishers, 1997.

MANCE, E. Como Organizar Redes Solidárias. Rio de Janeiro: DP\&A Editora, 2003.

MCCALLUM, A. et al. Automating the construction of internet portals with machine learning. Information Retrieval Journal, Kluwer Academic Publishers, p. $127-163,2000$.

MINSKY, M. A framework for representing knowledge. [S.l.]: Memo 306, MIT AI Lab, 1974.

MINSKY, M. The Society of the Mind. New York: Simon and Schuster, 1986.

MINSKY, M.; RIECKEN, D. A Conversation with Marvin Minsky about Agents. Communications of the ACM, v. 37, n. 7, p. 22-29, 1994.

MLADENIC, D. Text-learning and related intelligent agents: a survey. IEEE Intelligent Systems, v. 14, n. 4, p. 44-54, 1999.

MÜLLER, C.; WELLMAN, B.; MARIN, A. How to use spss to study ego-centered networks. Bulletin de méthodologies sociologiques, 1999.

MOOERS, C. N. Zatocoding applied to mechanical organization of knowledge. American Documentation, v. 2, p. 20-32, 1951.

NEWELL, A. The Knowledge Level. Artificial Intelligence, v. 18, 1982.

NODINE, M.; PERRY, B.; UNRUH, A. Experience with the InfoSleuth agent architecture. In: AAAI PRESS. Proc. of the AAAI-98 Workshop on Software Tools for Developing Agents. Madison, Wisconsin, USA, 1998.

OARD, D. W. Natural Language Processing for Information Retrieval. 2000. Disponível em: <http://www.umiacs.umd.edu/ bonnie/cmsc723-00>. Acesso em: Janeiro de 2002.

OGATA, H.; FUKUI, T.; YANO, Y. SocialPathFinder: Computer Supported Exploration of Social Networks on WWW. In: IOS PRESS. Proc. of the ICCE 99. Amsterdam, NL, 1999. p. 768-771. 
ORTIZ, R. Coleção Grandes Cientistas Sociais: Pierre Bourdieu. São Paulo, Brasil: Ática, 1983.

OYAMA, S.; HIRAMATSU, K.; ISHIDA, T. Cooperative Information Agents for Digital Cities. International Journal of Cooperative Information Systems, v. 10, n. $1 \& 2$, p. 197-216, 2001.

PIKRAKIS, A. et al. MEMOIR: Software Agents for Finding Similar Users by Trails. In: PAAM. Proc. of the 3rd Intnl. Conf.on the Practical Applications of Agents and Multi-Agent Systems, PAAM-98. London, UK, 1998. p. 453-466.

POIBEAU, T. Deriving a multi-domain information extraction system from a rough ontology. In: NEBEL, B. (Ed.). 2001. USA: Morgan Kaufmann, 2001.

PRETSCHNER, A. Ontology Based Personalized Search. MSc. Thesis. USA: University of Kansas, 1999.

PUJOL, J.; SANGUESA, R.; DELGADO, J. Extracting Reputation in Multi Agent Systems by Means of Social Network Topology. In: ACM. AAMAS. Bologna, Italy, 2002.

QUEIROZ, S. et al. Making recommendations for groups using collaborative filtering and fuzzy majority. In: SBC. Proc. of the XVI Brazilian Symposium on Artificial Intelligence - SBIA'02. Recife, PE, Brasil, 2002.

QUINLAN, J. R. C4.5: Programming for machine learning. San Mateo, CA, USA: Morgan Kauffman, 1993.

RAVIA, F. Web-search Session talk. In: HAL. HAL 2001. HAL 2001 Workshop. Netherlands, 2001. Disponível em: <www.searchlores.org>. Acesso em: Junho de 2002 .

RODHES, J.; MAES, P. Just-in-time information retrieval agents. IBM Systems Journal, v. 39, n. 3\&4, p. 685-703, 2000.

RUCKER, J.; POLANCO, M. J. Siteseer: Personalized navigation for the Web. Communications of the ACM, v. 40, n. 3, p. 73-76, 1997.

RUSSELL, S. J.; NORVIG, P. Artificial Intelligence. New Jersey, USA:

Prentice-Hall, 1995.

SALTON, G.; BUCKLEY, C. Term weighting approaches in automatic text retrieval. Information Processing and Management, v. 24, n. 5, p. 513-523, 1988.

SALTON, G.; MCGILL, M. J. Introduction to Modern Information Retrieval. NY, USA: McGraw-Hill, 1983.

SARACEVIC, T. Evaluation of evaluation in information retrieval. In: ACM. SIGIR. Proceedings of the 18th SIGIR Conference. Seattle, Washington, USA, 1995. p. $138-146$. 
SAROIU, S.; GUMMADI, P. K.; GRIBBLE, S. D. A measurement study of peer-to-peer file sharing systems. In: MMCN. MMCN'02. Proceedings of Multimedia Computing and Networking 2002 (MMCN'02). San Jose, CA, USA, 2002.

SCARUFFI, P. Machine Intelligence. 1998. Disponível em: <http://www.thymos.org >. Acesso em: Fevereiro 2000.

SCHLICHTER, J. H.; KOCH, M.; XU, C. Awareness - the common link between groupware and community support systems. In: KYOTO MEETING ON SOCIAL INTERACTION AND COMMUNITYWARE. Community Computing and Support Systems. Springer, 1998. p. 77-93.

SCHLOSSER, M. T.; CONDIE, T. E.; KAMVAR, S. D. Simulating a P2P file-sharing network. In: Twelfth International World Wide Web Conference. Budapest, Hungary: [s.n.], 2003.

SCHUTZ, A. Fenomenología del mundo social. Buenos Aires: Paidós, 1972.

SCHWARTZ, M. F.; WOOD, D. C. M. Discovering shared interests using graph analysis. Communications of the ACM, v. 36, n. 8, p. 78-89, 1993.

SCOTT, J. Social Network Analysis. Second edition. London and Beverley Hills: Sage Publications, 1992.

SEARLE, J. Intentionality. Cambridge: Cambridge University Press, 1983.

SEBASTIANI, F. Machine learning in automated text categorization. $A C M$ Computing Surveys, v. 34, n. 1, p. 1-47, 2002.

SHAPIRE, R. E.; SINGER, Y. Draft, BoosTexter: A System for Multi-Label Text Categorization. 1998.

SHIN-YUAN, H. Course Reading Notes, Statistical Methods

for Information System Research. 2001. Disponível em:

$<$ http://www.mis.ccu.edu.tw/ syhung/2001stat/ch3.htm>. Acesso em: Janeiro de 2002.

SICHMAN, J. DEPINT: Dependence-based coalition formation in an open multi-agent scenario. Journal of Artificial Societies and Social Simulation, v. 1, n. 2,1998 .

SICHMAN, J.; CONTE, R. On personal and role mental attitudes: A preliminary dependence-based analysis. In: SBC. SBIA. Advances in Artificial Intelligence. Berlin: Springer, 1998. p. 1-10.

SICHMAN, J. et al. A social reasoning mechanism based on dependence networks. In: COHN, T. (Ed.). Proc. of the 11th ECAI. Amsterdam, The Netherlands: John Wiley and Sons, 1994. p. 188-192. 
SICHMAN, J. S. A Dependence-Based Model for Social Reasoning in Multi-agent Systems. Technical Report BT/PCS/0108. São Paulo, SP, Brasil: Departamento de Engenharia de Computação e Sistemas Digitais, EPUSP, 2001.

SILVA Álvaro Ferreira da. Introdução às Ciências Sociais - apontamentos de aula. 2003. Disponível em: <www.fe.unl.pt/FE/cadeiras/intcienciassociais>. Acesso em: Julho 2003.

SINGH, M.; YU, B.; VENKATRAMAN, M. Community-based service location. Communications of the ACM, v. 44, n. 4, p. 49-54, 2001.

STEELS, L. The origin of ontologies and communication conventions in multi-agent systems. Autonomous Agents and Multi-Agent Systems, v. 1, n. 2, p. 169-194, October 1998.

STEELS, L.; KAPLAN, F. Situated grounded word semantics. In: IJCAI. IJCAI 99. Stockholm, Sweden, 1999.

STEELS, L.; KAPLAN, F. Aibo's first words. the social learning of language and meaning. Evolution of Communication, John Benjamins Pub. Company, v. 4, n. 1, 2001.

SYCARA, K. In-context information management through adaptive collaboration of intelligent agents. In: KLUSCH, M. (Ed.). Intelligent Information Agents: Cooperative, Rational and Adaptive Information Gathering on the Internet. Germany: Springer, 1999.

TAGUE-SUTCLIFFE. The pragmatics of information retrieval experimentation. Information Processing and Management, v. 28, n. 2, p. 467-490, 1992.

TAMMA, V.; BENCH-CAPON, T. A conceptual model to facilitate knowledge sharing in multi-agent systems. In: OAS. Ontologies in Agent System, OAS Workshop. Montreal, Canada, 2001.

TAMMA, V. A. M. An Ontology Model supporting Multiple Ontologies for Knowledge sharing. Ph. D. Thesis - University of Liverpool, U.K., 2002.

TERVEEN, L. et al. PHOAKS: A system for sharing recommendations. Communications of the ACM, v. 40, n. 3, p. 59-62, 1997.

TRAVERS, J.; MILGRAM, S. An Experimental Study of the Small World Problem. Sociometry, v. 32, n. 4, p. 425-443, December 1969.

TURTLE, H. W.; CROFT, W. B. Uncertainty in information retrieval systems. In: MOTRO, A.; SMETS, P. (Ed.). Uncertainty Management in Information System. USA: Kluwer Academic Publishers, 1997.

USCHOLD, M.; GRUNINGER, M. Ontologies: principles, methods, and applications. Knowledge Engineering Review, v. 11, n. 2, p. 93-155, 1996. 
VAN-RIJSBERGEN, C. Information Retrieval. London, UK: Butterworths, 1979 .

VEL, O. de; NESBITT, S. A collaborative filtering agent system for dynamic virtual communities on the web. In: CONALD. Working notes of the Conf. on Automated Learning and Discovery, CONALD-98. Pittsburgh, PA, USA, 1998.

WACHE, H. et al. Ontology-based integration of information - a survey of existing approaches. In: IJCAI. Proc. of the IJCAI 2001 Workshop on Ontologies and Information Sharing. Seattle, USA, 2001.

WASSERMAN, S.; FAUST, K. Social network analysis: Methods and applications. New York, USA: Cambridge University Press, 1994.

WASSERMAN, S.; GALASKIEWICZ, J. Advances in Social Network Analysis. Thousand Oks, Calf.: S. Wasserman and J. Galaskiewicz (eds.), Sage Publications, 1994.

WEBER, M. A Ética Protestante e o Espírito do Capitalismo. Brasil: Martin Claret, 2001. (A obra-prima de cada autor).

WEISS, S. M.; APTE, C.; DAMERAU, F. J. Maximizing text-mining performance. IEEE Intelligent Systems, 1999.

WELTY, C.; GUARINO, N. Supporting ontological analysis of taxonomical relationships. Data and knowledge engineering, v. 39, n. 1, p. 51-74, 2001.

WIEDERHOLD, G. Mediators in the Architecture of Future Information Systems. Computer, v. 25, n. 3, p. 38-49, 1992.

WILLIAMS, A. B.; REN, Z. Agents teaching agents to share meaning. In: ACM. Proc. of the 5th Intl. Conf. on Autonomous Agents. Montreal, Canada, 2001.

YANG, Y. An Evaluation of Statistical Approaches to Text Categorization. Computer Science Department, 1997.

YANG, Y.; PEDERSEN, J. P. Feature selection in statistical learning of text categorization. In: ICML. . Proc. of the 14th Intl. Conf. on Machine Learning. Nashville, Tennessee, USA, 1997.

YU, B.; SINGH, M. A multiagent referral system for expertise location. In: AAAI. Working Notes of the AAAI Workshop on Intelligent Information Systems. Orlando, Florida, USA, 1999. p. 66-69. 